\title{
Design of Radiation-Tolerant Structural Alloys for Generation IV Nuclear Energy Systems
}

\author{
Professor Todd R Allen \\ June 30, 2009 \\ University of Wisconsin-Madison
}

Prepared for the Department of Energy under award number DE-FC07-06ID14740 
Project Title: Radiation-Stability of Candidate materials For Advanced Fuel Cycles

Covering Period: $\quad$ March 13, 2006 through March 12, 2009

Date of Report: June 23, 2009

Recipient: $\quad$ University of Wisconsin

1500 Engineering Drive

Madison, WI 53706

Award Number: $\quad$ DE-FC07-06ID14740

Project Number: $\quad$ 06-007

Principal Investigator： Todd Allen, 608-265-4083, allen@engr.wisc.edu

Project Objective: This project will use proton irradiation to further understand the microstructural stability of ceramics being considered as matrix material for advanced nuclear fuels. The following objectives were pursued:

- Determine the radiation stability of candidate materials in response to proton irradiation at temperatures between $600-900^{\circ} \mathrm{C}$. Following radiation, samples were examined using transmission electron microscopy to understand the effect of radiation on lattice stability, phase change, void growth, and other microstructural features.

- Determine the effect of radiation on hardness and fracture toughness in response to proton irradiation at temperatures between $600-900^{\circ} \mathrm{C}$. Estimates of the relative changes in fracture toughness as a function of radiation were made using crack length propagation following Vicker's indentation, and using testing on nanobeams created with a focused ion beam.

The following materials were included in the test plan.

- TiC, $\mathrm{ZrC}$, TiN, and $\mathrm{ZrN}$. These materials are currently being considered as matrix materials for gas-cooled fast reactor (GFR) systems and additionally could be used as higher temperature replacements for $\mathrm{SiC}$ in a TRISO fuel.

- $\mathrm{MgO}, \mathrm{MgO}-\mathrm{ZrO}_{2}$, and $\mathrm{MgO}-\mathrm{ZrO}_{2}-\mathrm{Er}_{2} \mathrm{O}_{3}$. These magnesium-zirconium oxide-base materials are leading candidates in the U.S. for inert matrix fuel use due to the combination of the high thermal conductivity of $\mathrm{MgO}$ and the corrosion resistance in PWR water of $\mathrm{ZrO}_{2}$. The addition of $\mathrm{MgO}$ to the $\mathrm{ZrO}_{2}$ is also expected to enhance the ability to recycle, as $\mathrm{MgO}$ is dissolvable in nitric acid. 


\section{Table of Contents}

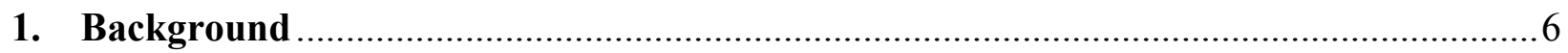

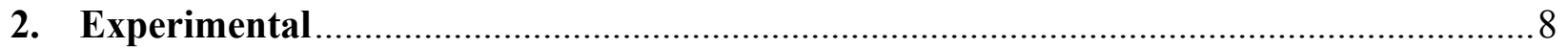

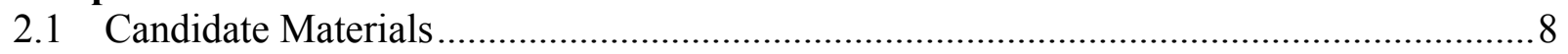

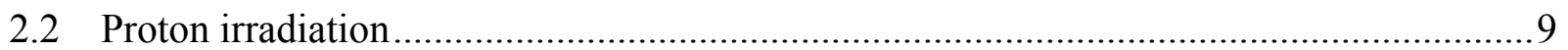

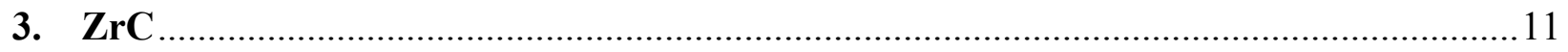

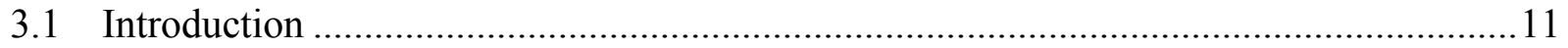

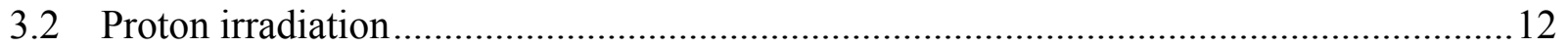

3.3 SEM and EDS characterization on annealed and irradiated specimens ..........................14

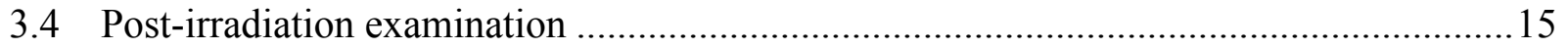

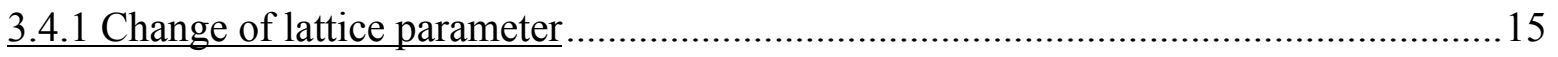

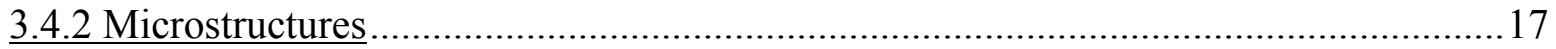

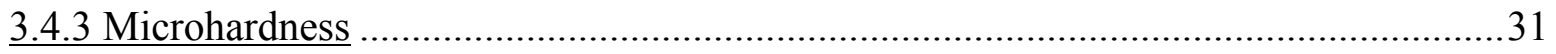

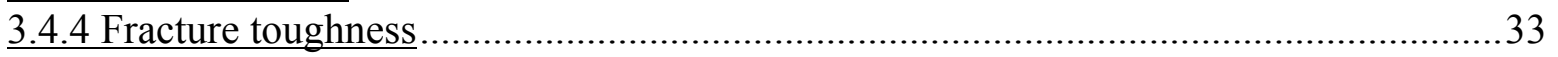

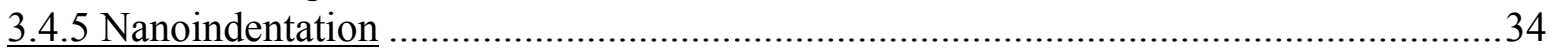

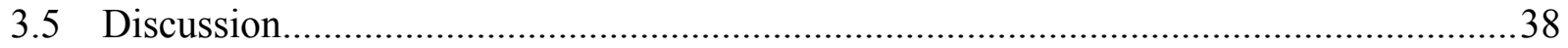

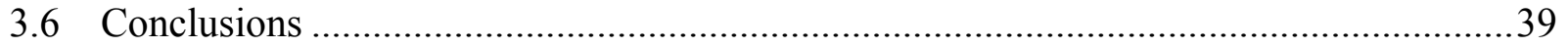

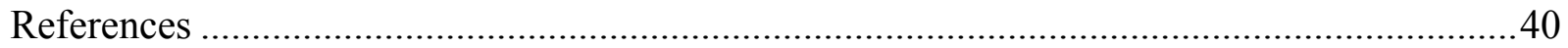

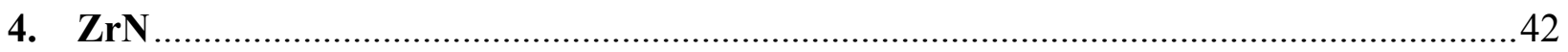

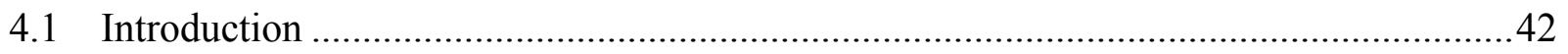

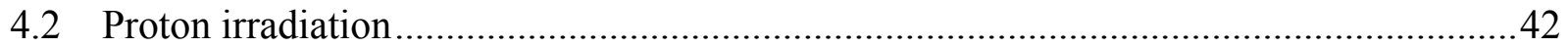

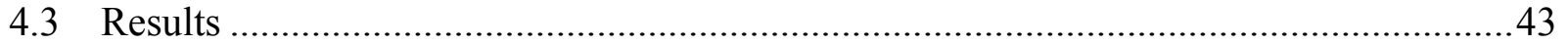

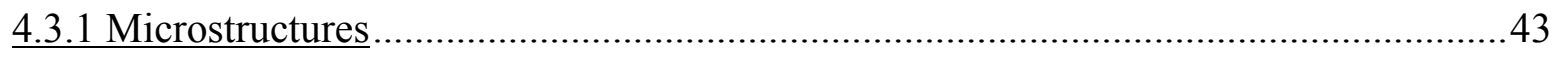

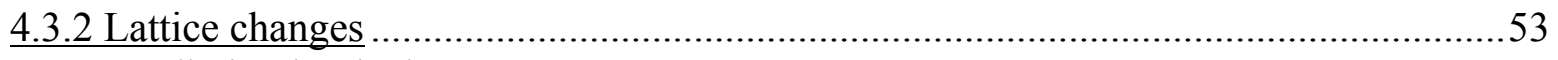

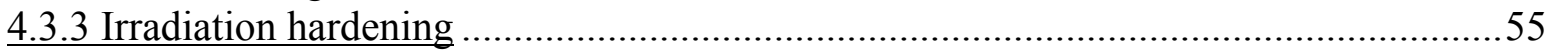

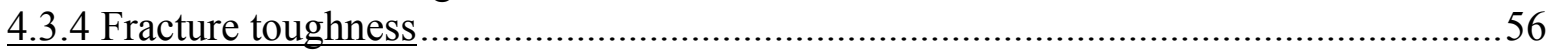

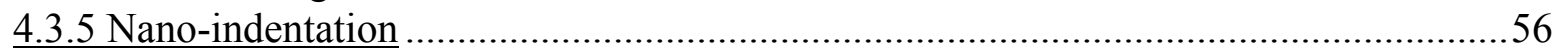

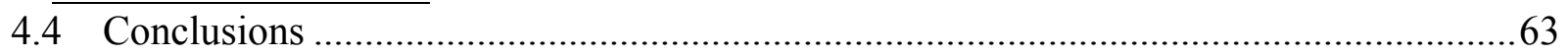

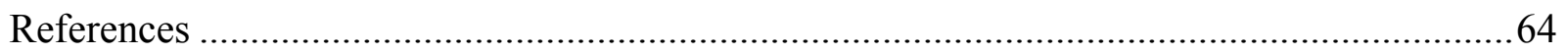

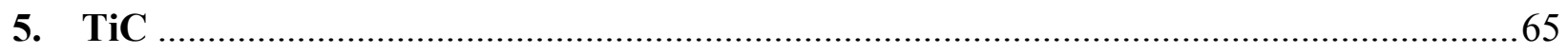

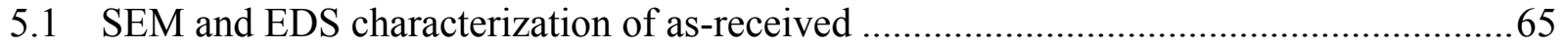

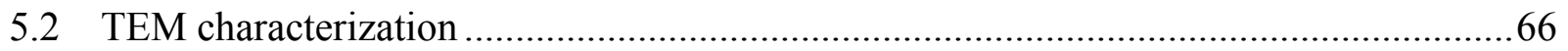

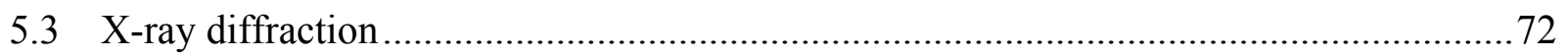

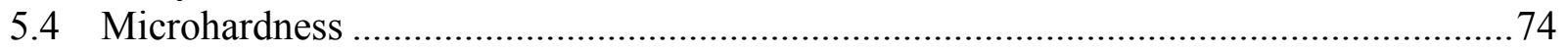

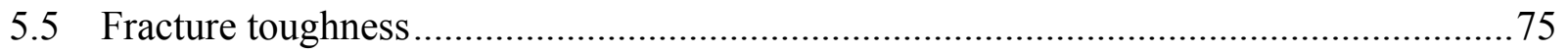

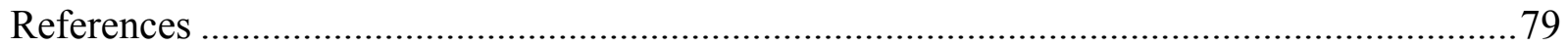

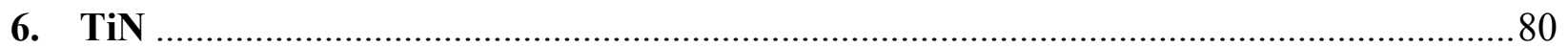

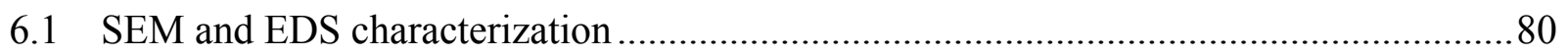

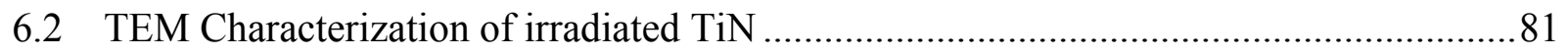

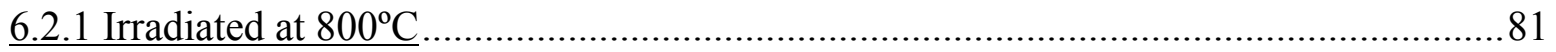

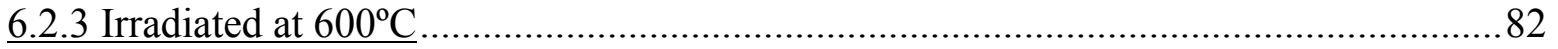

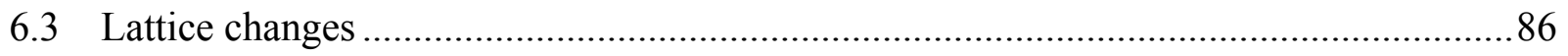

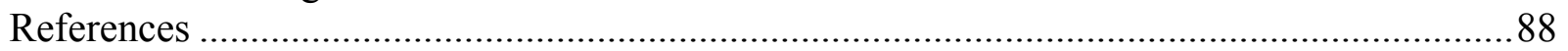

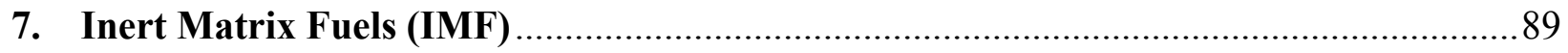

7.1 Characteristics of Dual-Phase MgO-ZrO2 Samples........................................................8 


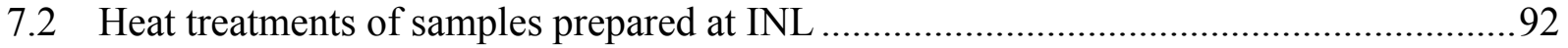

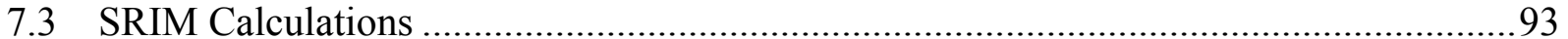

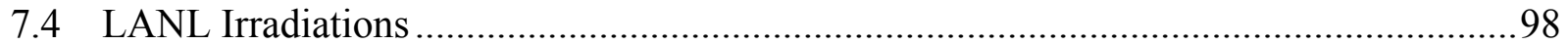

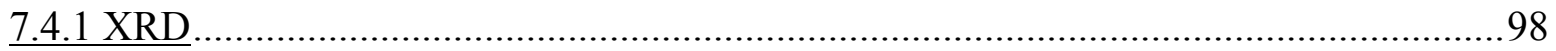

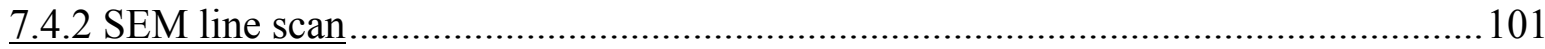

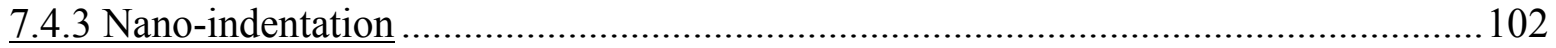

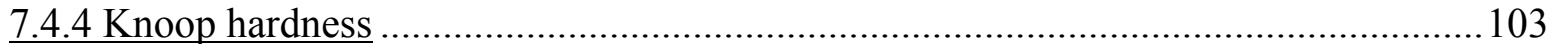

7.5 Synthesis of Materials ....................................................................................... 104

7.6 Failed Irradiation and Explanation of Thermal Cycling ............................................ 105

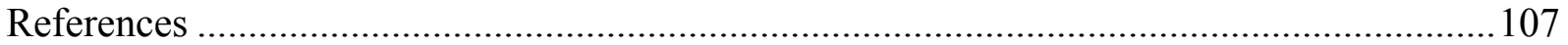

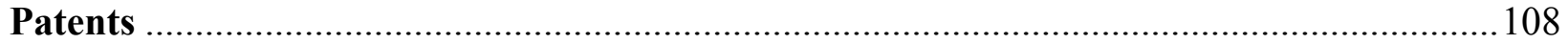

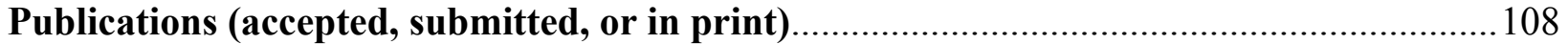

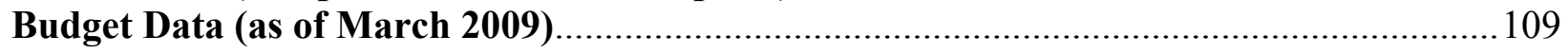




\section{Radiation-Stability of Candidate Materials For Advanced Fuel Cycles}

Project No. 06-007

Final Report

Task Research Significance and Benefits

Understanding the microstructural development of candidate fuel forms under controlled temperature irradiation is a critical data need for the Advanced Fuel Cycle Initiative (AFCI). This worked combined cutting edge ion beam irradiation technology with advanced electron microscopy characterization techniques to understand the microstructural changes that could lead to swelling, loss of thermal conductivity, and changes in mechanical properties. The estimation of fracture toughness changes using crack propagation and nanobeam testing provides a critical semi-quantitative picture of the fracture toughness response under irradiation.

This work provides some of the first irradiation effects data ever for multiple candidate fuel matrix materials being considered under the AFCI. TiC, $\mathrm{TiN}, \mathrm{ZrN}, \mathrm{ZrC}$, and $\mathrm{MgO}-\mathrm{ZrO}_{2}$-base materials all have properties desired as an advanced fuel form. The nitrides and carbides are being considered as matrix materials for a gas-cooled fast reactor or as a high-temperature alternative to $\mathrm{SiC}$ in TRISO fuels for thermal spectrum gas-cooled reactors. The $\mathrm{MgO}-\mathrm{ZrO}_{2}-$ base materials are being considered as an inert matrix fuel for the transmutation of actinides in light water reactors. In each case, the fundamental radiation response is either unknown or supported by a limited database. Although these materials are being irradiated in the Advanced Test Reactor and in PHENIX, the irradiation campaigns in these test reactors can only supply a limited range of test data. This ion irradiation program provides supporting data and a broader understanding of the microstructural response to radiation. 


\section{Background}

The development of advanced fuel is a key need in developing technologies that support the goals of the AFCI [1.1]. Three fuel types play important roles within AFCI, specifically inert matrix fuels (IMF) for reducing actinide inventories using light water reactors, coated particle fuels such as the TRISO fuel design being pursued for the very high temperature gas-cooled reactor (VHTR), and ceramic-ceramic (CERCER) composites being pursued for the gas-cooled fast reactor (GFR). While the candidate matrix materials for these fuel types are currently being irradiated in the Advanced Test Reactor and are slated for irradiation in the PHENIX fast test reactor, the limited neutron exposure and limited available irradiation temperatures that will come available will be insufficient to fully understand the microstructural stability under radiation. This project uses proton irradiation to further understand microstructural stability of ceramics being considered as matrix or coating material for the advanced fuels. The primary irradiation effects occurring in ceramics under radiation are swelling, decrease in thermal conductivity, and changes in mechanical properties.

Dimensional changes in ceramics under radiation can be caused by several mechanisms, such as amorphization, lattice strain, void swelling, and other mechanisms. Swelling at low temperature is due to amorphization and lattice strain. As temperature is increased in the lattice strain regime, the number of surviving defects is reduced due to temperature-enhanced diffusion and recombination of point defects that reduces the driving force for lattice strain. At very high temperature, swelling can occur due to the formation and growth of voids. In the intermediate temperature range between lattice strain and void swelling, the dimensional changes due to swelling may be acceptable. The exact temperature at which the lattice strain and void swelling are the dominant mechanism is dependent on the specific ceramic. For ceramics with a hexagonal crystal structure, such as $\mathrm{SiC}$, anisotropic swelling may occur. Swelling due to lattice strain typically saturates after a few displacements per atom (dpa), where void swelling may increase with increasing dose. For this project, the effect of radiation on swelling was estimated from measured changes in lattice constant, loss of crystalline structure, and void size distributions measured using transmission electron microcopy (TEM) following irradiation.

The thermal conductivity of all ceramics degrades with neutron irradiation and tends to saturate at a very low dose (a few dpa). The cause of this degradation in thermal conductivity is phononscattering by irradiation-induced defects (primarily vacancies and small vacancy clusters). Although the unirradiated thermal conductivity is dependent on the sample material and processing route, the thermal conductivity following radiation is a function of the radiation parameters that drive the final microstructures. The unirradiated thermal conductivity is not a good metric for selecting materials with the highest irradiated thermal conductivity. Thermal conductivity typically saturates after less than $1 \mathrm{dpa}$. Although this project will not measure thermal conductivities, it will characterize irradiated microstructures, providing qualitative information on possible shifts in conductivity.

With the exception of graphite and very limited information on alumina, magnesium aluminate spinel, and silicon carbide, there is very little information on the effect of irradiation on the strength, elastic modulus, or fracture toughness of ceramics, especially at higher temperature. The change in fracture toughness as a function of radiation is a critical data need for advanced fuel forms. While this project measured fracture toughness of irradiated materials indirectly, the 
changes in fracture toughness as a function of radiation were estimated from crack growth measurements following hardness indents and from bending of nanobeams.

Proton irradiation is the primary tool for carrying out irradiation studies. Although, like any ion irradiation technique, proton irradiation cannot provide an irradiated volume sufficient to perform bulk mechanical testing, it is a fast and economical technique for studying the effect of radiation on microstructures. Since all bulk property changes are linked to microstructural changes, analysis of samples following proton radiation provides key information on radiation stability. However, since only a few MeV are required to surmount the Coulomb barrier for light ions, there is a minor amount of sample activation that increases with proton energy. The final energy chosen for irradiation is based on the balance between irradiation depth and sample activation. Additionally, depending on the particular ceramic, the basic radiation-induced primary damage may be influenced by radiolysis (electronic excitations generated by interaction with ionizing radiation).

Due to the relatively low neutron fluxes present in fast test reactors as compared to proton beams from ion accelerators, the displacement rates from neutron irradiations are considerably lower. It is important here to point out this fundamental difference and discuss how proton irradiation experiments can be modified to adequately compare to neutron experiments. Based on Mansur's development [1.2], a rough estimate of radiation induced-changes in microstructures can be made by defining a variable, $N_{s}$, as the number of point defects absorbed at sinks and holding this value constant. For a given total dose, the proton and neutron irradiation temperatures must have the following relation:

$$
T_{2}-T_{1}=\frac{\left(k T_{1}^{2} / E_{v}^{m}\right) \ln \left(K_{2} / K_{1}\right)}{1-\left(k T_{1} / E_{v}^{m}\right) \ln \left(K_{2} / K_{1}\right)}
$$

for the difference in neutron to proton dose rates to have no effect on $N_{s}$, where $T$ is temperature, $k$ is Boltzmann's constant, $E_{v}{ }^{m}$ is the vacancy migration energy, and $K$ is the displacement rate [1.2]. With values for the migration energy, proton irradiations can be conducted such that the resulting microstructure will be significantly similar to those experiments using neutrons to similar doses.

\section{References}

1.1. http://www.ne.doe.gov/AFCI/neAFCI.html

1.2. Mansur, L.K., Journal of Nuclear Materials, 1994. 216: p. 97-123. 


\section{Experimental}

\subsection{Candidate Materials}

The ceramics, $\mathrm{ZrC}, \mathrm{ZrN}$, TiC, TiN currently studied are commercial grade, made by CERCOM, and fabricated using vacuum hot pressing. The chemical compositions are listed in Table 2.1. The $3 \mathrm{~mm}$ diameter disks with a thickness of $\sim 300 \mu \mathrm{m}$ were cut using a low speed diamond saw, and polished to less than a $1 \mu \mathrm{m}$ surface finish for proton irradiation. In addition, TiN ceramic from CEA, possibly with lower porosity, was also irradiated and studied.

Table 2.1. Elemental composition of ceramics from CERCOM

\begin{tabular}{|c|c|c|c|c|c|c|c|}
\hline \multicolumn{2}{|c|}{ ZrC } & \multicolumn{2}{c|}{ TiC } & \multicolumn{2}{c|}{ ZrN } & \multicolumn{2}{c|}{ TiN } \\
\hline Element & $\mathbf{w t} \%$ & Element & $\mathbf{w t \%}$ & Element & $\mathbf{w t} \%$ & Element & $\mathbf{w t} \%$ \\
\hline $\mathrm{Zr}$ & 84.8 & $\mathrm{Ti}$ & 80.2 & $\mathrm{Zr}$ & 87.6 & $\mathrm{Ti}$ & 78.9 \\
\hline $\mathrm{C}$ & 13.1 & $\mathrm{C}$ & 19.4 & $\mathrm{~N}$ & 11.4 & $\mathrm{Al}$ & 0.022 \\
\hline $\mathrm{Hf}$ & 1.91 & $\mathrm{~N}$ & 0.057 & $\mathrm{C}$ & 0.76 & $\mathrm{~B}$ & 0.001 \\
\hline $\mathrm{Ti}$ & 0.19 & $\mathrm{Al}$ & 0.027 & $\mathrm{Al}$ & 0.09 & $\mathrm{Ca}$ & 0.008 \\
\hline & & $\mathrm{Ca}$ & 0.005 & $\mathrm{Ca}$ & 0.011 & $\mathrm{Cr}$ & 0.004 \\
\hline & & $\mathrm{Fe}$ & 0.012 & $\mathrm{Cr}$ & 0.034 & $\mathrm{Na}$ & 0.003 \\
\hline & & $\mathrm{Si}$ & 0.007 & $\mathrm{Fe}$ & 0.069 & $\mathrm{Si}$ & 0.001 \\
\hline & & $\mathrm{V}$ & 0.005 & $\mathrm{Hf}$ & 0.015 & $\mathrm{Zr}$ & 0.011 \\
\hline & & $\mathrm{Zn}$ & 0.17 & $\mathrm{Mn}$ & 0.001 & $\mathrm{Ti}$ & 78.9 \\
\hline & & $\mathrm{Zr}$ & 0.018 & $\mathrm{Mo}$ & 0.021 & $\mathrm{Al}$ & 0.022 \\
\hline & & & $\mathrm{Ni}$ & 0.003 & $\mathrm{~B}$ & 0.001 \\
\hline & & & & $\mathrm{Si}$ & 0.007 & $\mathrm{Ca}$ & 0.008 \\
\hline & & & & $\mathrm{Sn}$ & 0.011 & $\mathrm{C}$ & 0.58 \\
\hline & & & & $\mathrm{Te}$ & 0.003 & $\mathrm{~N}$ & 14.0 \\
\hline & & & & $\mathrm{Ti}$ & 0.095 & $\mathrm{O}$ & 0.46 \\
\hline & & & & $\mathrm{V}$ & 0.02 & & \\
\hline & & & & $\mathrm{W}$ & 0.19 & & \\
\hline
\end{tabular}

Initial examination of IMF materials began with $\mathrm{MgO}$; the samples were prepared from the bulk material provided by Idaho National Laboratory (INL). Material was received as a cylinder approximately $10 \mathrm{~mm}$ in diameter. Thin discs, approximately $500 \mu \mathrm{m}$ thick, were cut from the bulk cylinder. An ultrasonic cutter was used to fashion $3 \mathrm{~mm}$ disks for testing. The $\mathrm{MgO}$ samples were polished to a $1 \mu \mathrm{m}$ finish for the following tests and irradiation. Dual-phase $\mathrm{MgO}-$ $\mathrm{ZrO}_{2}$ (DPMZ) was also studied. Much of the work on DPMZ was carried out at Los Alamos National Laboratory (LANL), collaborating with Kurt Sickafus. The composition used was 60\% $\mathrm{MgO}$ and $40 \% \mathrm{ZrO}_{2}(60 / 40 \mathrm{DPMZ})$. In addition, the synthesis of dual DPMZ was also performed at the University of Wisconsin (UW), and the heavy-ion-irradiated specimens were systematically analyzed. 


\subsection{Proton irradiation}

Proton irradiations were performed using the UW Tandem Accelerator Facility and High Temperature Radiation Stage. This accelerator is a $1.7 \mathrm{MV}$ machine capable of accelerating protons up to $3.4 \mathrm{MeV}$. Samples are irradiated in the form of $3 \mathrm{~mm}$ diameter disks coupled to a metallic stage through a graphite foil, which can provide enough compliance to ensure samples of slightly varying thickness are coupled to the stage for adequate temperature control. Fifteen different samples can be irradiated simultaneously and temperature is monitored and controlled through beam heating and a stage temperature controller. The rastered irradiation beam is centered on the target via an aperture system with total beam current measured to provide a measure of radiation dose.

The stage consists of a flange welded to a steel cylinder, a sample holding plate, and a face plate, as shown in Figure 2.1. The samples, $\varnothing 3 \mathrm{~mm} \times 10.30 \mathrm{~mm}$ disks, are placed in wells milled into the sample plate, which is then attached to the stage and precisely positioned using dowel pins. By making the sample holding mechanism independent of the flange, modifications to the system are easily implemented. A facing plate is then placed over the sample holding plate to secure the samples. Slots in the facing plate eliminate interfering reflection to the camera and expose a great amount of the sample to the beam. The sample holding plate and facing plate also work to secure three thermocouples.

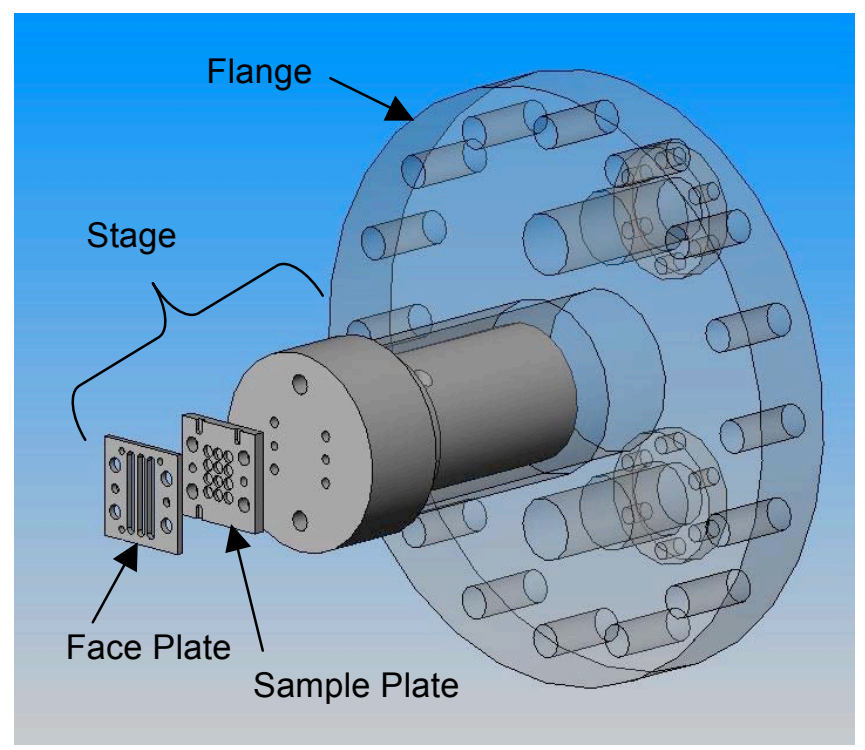

(a)

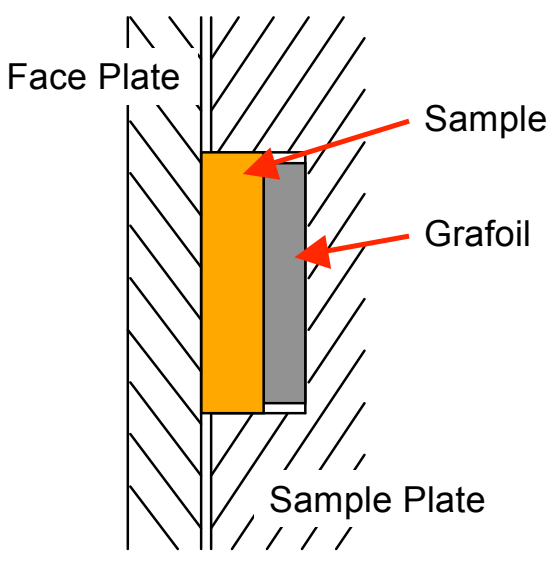

(b)

Figure 2.1. a) Stage design, b) Schematic of sample securing components

The experimental temperature is achieved by heating the chamber via a Gaumer GB301X-500CB cartridge heater to a temperature below that which will be reached when the beam is introduced. Three K-type thermocouples and a Mikron 7302 infrared camera are used to monitor the sample temperatures. The thermocouples are fastened to the sample plate, and their readings are used to calibrate the local sample emissivities via the camera, prior to beam exposure. To better facilitate the acquisition of the infrared signals, the stock sapphire viewport window was replaced with a custom-built zinc selenide window. The ZnSe allows $90 \%$ transmission between 
8 and $14 \mu \mathrm{m}$ wavelengths, which corresponds to the temperatures at which the experiment is conducted. During an irradiation the camera can be used to monitor differences in sample temperatures caused by beam irregularities.

The beam is rastered as it approaches the stage, to achieve an even distribution of current over the sample area. To ensure the beam maintains a centered position throughout the length of an irradiation, the current from four electrically isolated aperture plates is monitored. To achieve this isolation, tantalum plates are fastened to an alumina base, which is then aligned and secured with the chamber via a collar and set screws, as shown in Figure 2.2. The beam is considered centered on the stage when opposing plates (top-bottom and right-left) read similar currents. The aperture also defines the area of the irradiation, which is used in calculating the flux and irradiated doses of the samples. Current readings from the individual aperture plates, as well as from the stage, are lead out of the chamber and terminated at separate picoammeters, each of which gives a proportional output that is recorded and monitored via a National Instruments data acquisition system.

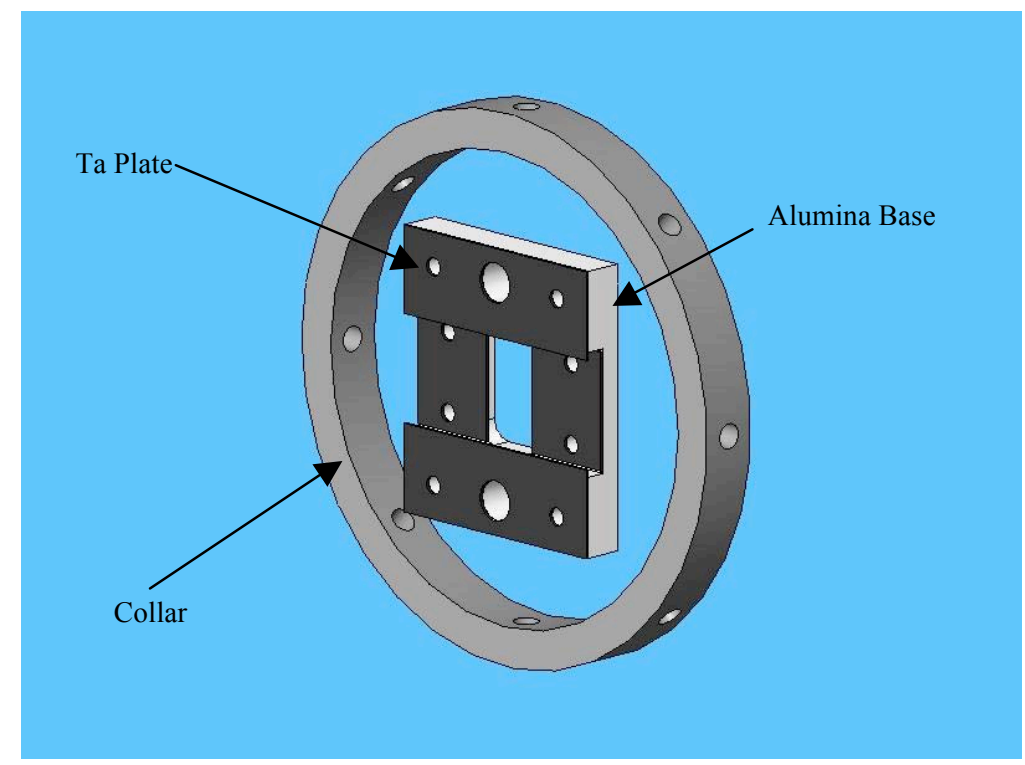

Figure 2.2. Aperture (set screws are not shown)

During the course of an irradiation, the current from the ion source is rarely constant over a long period of time, which has implications throughout the system. The most apparent effect of current instability is the ultimate temperature at the stage, while another, more obscure effect is the energy of the beam as it travels through the accelerator. As charged particles travel through the accelerator due to the terminal potential, the ions load the corresponding electronics. The bottom line is that as more current travels through the accelerator more power is needed to maintain a constant terminal potential, otherwise the terminal potential and thus the beam energy will decrease. Changes in beam energy affect the positioning of the beam at the stage, due to magnetic and electrostatic steering components between the accelerator and the experimental chamber. To cope with these variations in beam current and energy, the operator must make frequent, minor adjustments to the ion source power and electrostatic steering components to make sure the intended stage temperature is maintained and the beam is centered. In general, the 
irradiation temperatures were maintained constantly with minor variation, as shown in Figure 2.3 .

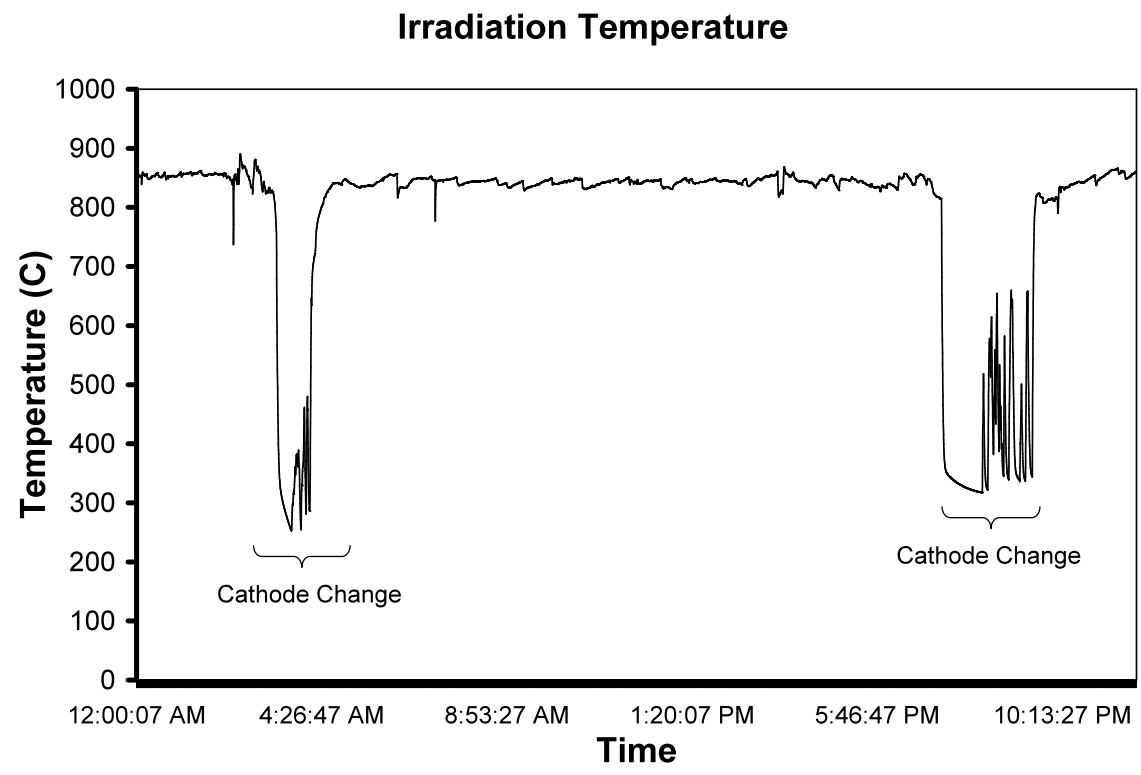

Figure 2.3. Example of irradiation temperature histories

Based on the shielding of the facility, the proton beam with an energy of $2.6 \mathrm{MeV}$ and current of $40 \mathrm{uA}$ was used to irradiate the selected ceramics. The damage profiles were calculated from SRIM-2008 (the Stopping and Range of Ions in Matter) [2.1]. The depth of greatest interest is the "flat" region before the peak; more details on the SRIM calculation will be discussed for each material in the following sessions.

\section{References}

J. F. Ziegler, J. P. Biersack, U. Littmark, The Stopping and Range of Ions in Solids, Pergamon Press, New York, 1996.

\section{3. $\mathrm{ZrC}$}

\subsection{Introduction}

For the deep-burn (DB) concept and higher temperature gas-cooled reactor systems, zirconium carbide $(\mathrm{ZrC})$ is a good candidate material to replace $\mathrm{SiC}$ as a TRISO fuel coating layer because of its higher decomposition temperature, better corrosion resistance to fission products and good retention capability of cesium [3.1]. The use of $\mathrm{ZrC}$ is also considered for either the kernel itself or on the buffer layer for the TRISO fuel particles [3.2]. Determining and predicting stability in response to radiation will be a key part in developing a practical $\mathrm{ZrC}$-based fuel, however, there is very limited information concerning the radiation tolerance of $\mathrm{ZrC}$. The primary irradiation effects of technological importance occurring in ceramics under radiation are dimensional instability, changes in transport properties, and changes in mechanical properties [3.3]. 
$\mathrm{ZrC}$ has been irradiated in nuclear reactors as a component of TRISO-type fuel particles to low burnup, but detailed post-irradiation microstructural analysis of the $\mathrm{ZrC}$ layer has not been published [3.4-3.6]. Some $\mathrm{ZrC}$ data have been generated under a limited range of irradiation conditions [3.7-3.10]. These studies show a $\mathrm{ZrC}$ lattice parameter increase at a neutron fluence of $\sim 1.5 \times 10^{20} \mathrm{n} / \mathrm{cm}^{2}(0.2 \mathrm{dpa})$ at 50,150 and $1100^{\circ} \mathrm{C}$, with a lattice parameter increase of $0.32 \%$, $0.47 \%$ and $0.12 \%$, respectively. The work by Patriarca, et al. on $\mathrm{ZrC}$ and $\mathrm{TiC}$ irradiated in the Engineering Test Reactor (ETR) at temperatures of $130-355^{\circ} \mathrm{C}$ to a dose of $\sim 7.5$ dpa showed a volume increase of $\sim 3 \%$ and 2 to $3 \%$ for $\mathrm{ZrC}$ and $\mathrm{TiC}$, respectively [3.9]. Keilholtz et al. reported the volumetric expansion of $\mathrm{ZrC}$ irradiated with fast neutrons at $300-700^{\circ} \mathrm{C}$ in the ETR. An $\sim 3 \%$ volume increase at a dose of $\sim 3$ dpa was measured. The major cause of damage to carbides is postulated to be the accumulated point defects, and less than $50 \%$ of the crystal expansion was accounted for by increases in lattice parameter [3.10]. Recently, Gan et al. used 1 $\mathrm{MeV} \mathrm{Kr}$ irradiation at $800{ }^{\circ} \mathrm{C}$ to study the microstructural stability of $\mathrm{ZrC}$, and observed a lattice expansion of approximately $7 \%$ for $\mathrm{ZrC}$ irradiated to $70 \mathrm{dpa}$, while no radiation-induced amorphization was observed [3.11]. After $4 \mathrm{MeV}$ Au ion irradiation at room temperature, Gosset has also shown a moderate swelling and high internal stress, which both saturated at an $\mathrm{Au}$ fluence around $10^{14} \mathrm{~cm}^{-2}$ corresponding to a few dpa, and there is a high density of small faulted dislocations revealed by TEM [3.12].

$\mathrm{ZrC}$ is a typical transition metal carbide that takes the $\mathrm{NaCl}$ ground-state crystal structure, and the properties of $\mathrm{ZrC}$ are dominated by strong covalent bonds, assisted by weaker and slightly metallic bonds. In addition, the properties of $\mathrm{ZrC}$ are often sensitive to the stoichiometry [3.133.14] and the irradiation behavior is likely related to the $\mathrm{C} / \mathrm{Zr}$ ratio. As reported by Andrievskii, the sub-stoichiometric materials were damaged less than the nearly-stoichiometric ones under neutron irradiation over a large stoichiometric range [3.15]. This chapter presents the microstructure and mechanical property changes of nearly-stoichiometric $\mathrm{ZrC}$ bombarded with protons to different dose levels at 600,800 and $900^{\circ} \mathrm{C}$.

\subsection{Proton irradiation}

Accelerated particles can induce damage in ceramics over a large range of incident particle fluxes and temperatures without activation of the materials, and they are efficient tools to test different physical models able to describe the behavior of materials in nuclear plants [3.16]. However, to produce radiation damage similar to that in nuclear reactors, it is important to estimate the primary recoil spectrum of ion irradiation compared with those in reactor. Figure 3.1(a) shows the primary recoil spectrum in $\mathrm{ZrC}$ irradiated with $2.6 \mathrm{MeV}$ protons. Compared with the recoil spectra of neutron irradiation in fast-neutron breeder reactors (FBRs) and $4 \mathrm{MeV}$ $\mathrm{Au}$ irradiation as reported by Gosset and shown in Figure 3.1(b) [3.12], the peak of the spectra from $2.6 \mathrm{MeV}$ protons is very close, which means a high probability of cascades initiated by primary recoil atoms with similar energy. 

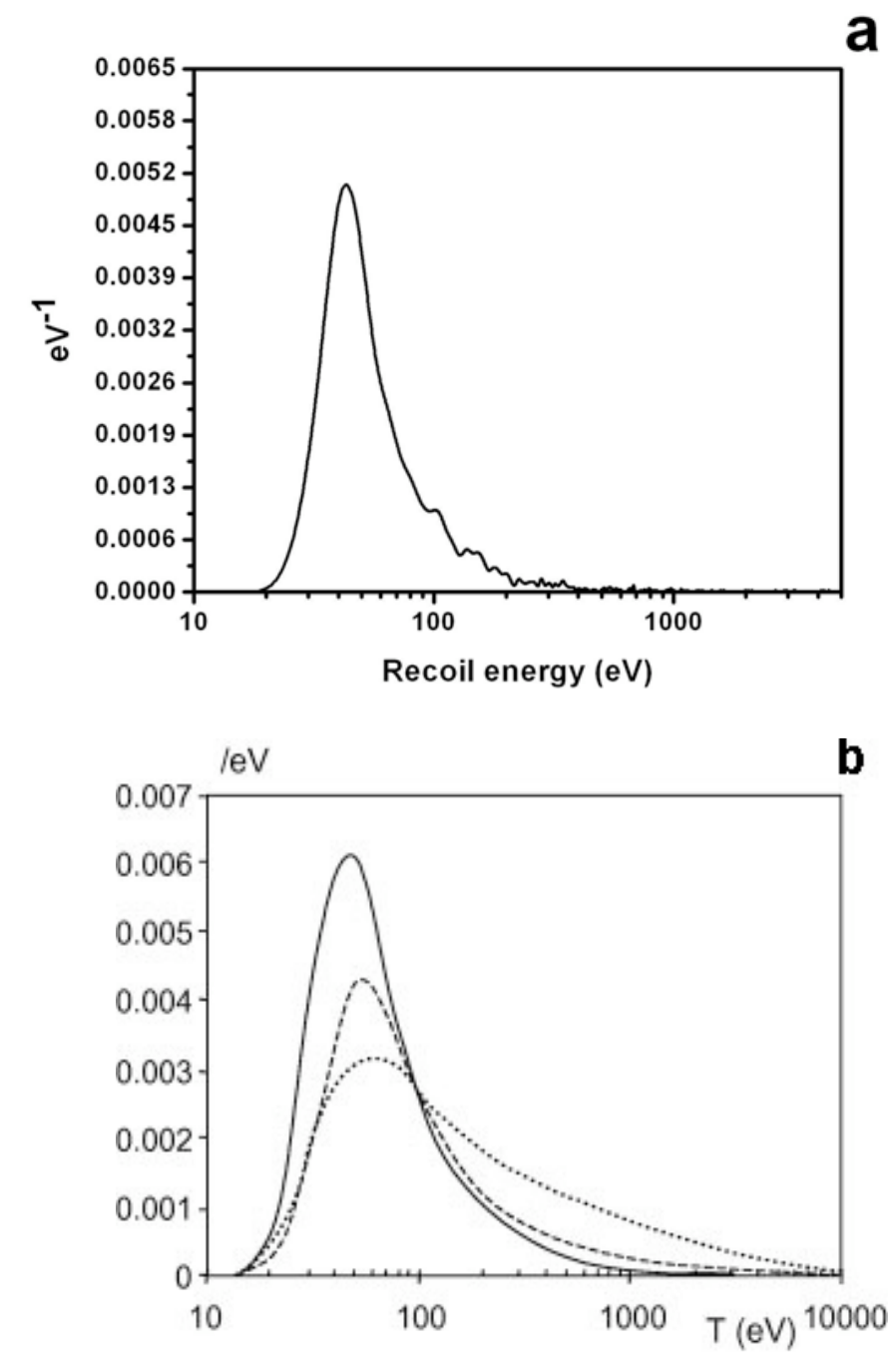

Figure 3.1. a) The primary recoil spectrum in $\mathrm{ZrC}$ irradiated with $2.6 \mathrm{MeV}$ protons, as estimated from SRIM-2008 [3.17]; b) Probability density of primary knock-on atoms (PKAs) in $\mathrm{ZrC}$ irradiated in different conditions: full line, $4 \mathrm{MeV} \mathrm{Au} \mathrm{ions;} \mathrm{broken} \mathrm{line:}$ HTR neutron spectrum; and dotted line: FBR neutron spectrum [3.12].

The damage profile was calculated using SRIM-2008, with a threshold displacement energy $\left(E_{d}\right)$ of $35 \mathrm{eV}$ for zirconium and $25 \mathrm{eV}$ for $\mathrm{C}$ based on the estimation from Gosset [3.12]. The damage profile is shown in Figure 3.2. The depth of greatest interest is the "flat" region, 10-25 $\mu \mathrm{m}$ before the damage peak, and this region is where the damage, as measured in dpa, was calculated. The $\mathrm{H}+$ ion concentration is nearly negligible in this region. Damage rates were taken from the "Full Damage Cascade" calculation condition in the SRIM-2008 program, and the calculated dose rate is approximate $1 \times 10^{-5} \mathrm{dpa} / \mathrm{s}$. Two irradiation doses of 0.35 and $0.75 \mathrm{dpa}$ were performed on the samples at temperatures of 800 and $900^{\circ} \mathrm{C}$, while three doses of $0.35,0.75$ and 1.75 dpa were achieved for $600{ }^{\circ} \mathrm{C}$. The radiation temperature was measured in-situ by three stage-embedded thermal couples, and the uniformity of the experimental temperature across the samples was monitored using an infrared camera. 


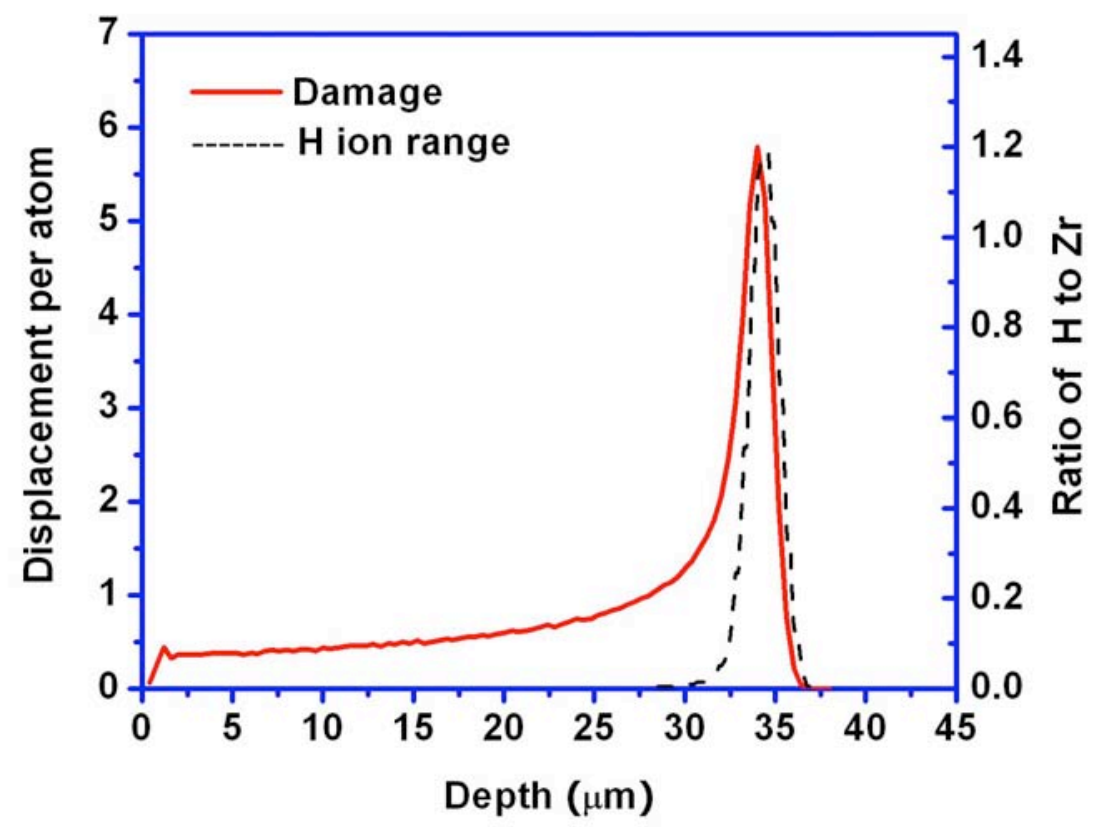

Figure 3.2. Damage profile estimated with SRIM-2008 in $\mathrm{ZrC}$ and concentration of implanted $\mathrm{H}$ (broken line), irradiated with $1 \times 10^{19} / \mathrm{cm}^{2} 2.6 \mathrm{MeV}$ protons.

\subsection{SEM and EDS characterization on annealed and irradiated specimens}

The scanning electron microscropy (SEM) image in Figure 3.3 clearly displays the grain structure of the annealed $\mathrm{ZrC}$. The material has relative low porosity, no apparent inclusion phases were identified, and the average grain size is $\sim 24 \mu \mathrm{m}$. The spectrum of energy dispersive spectroscopy (EDS) matches well with the chemical composition in Table 2.1.
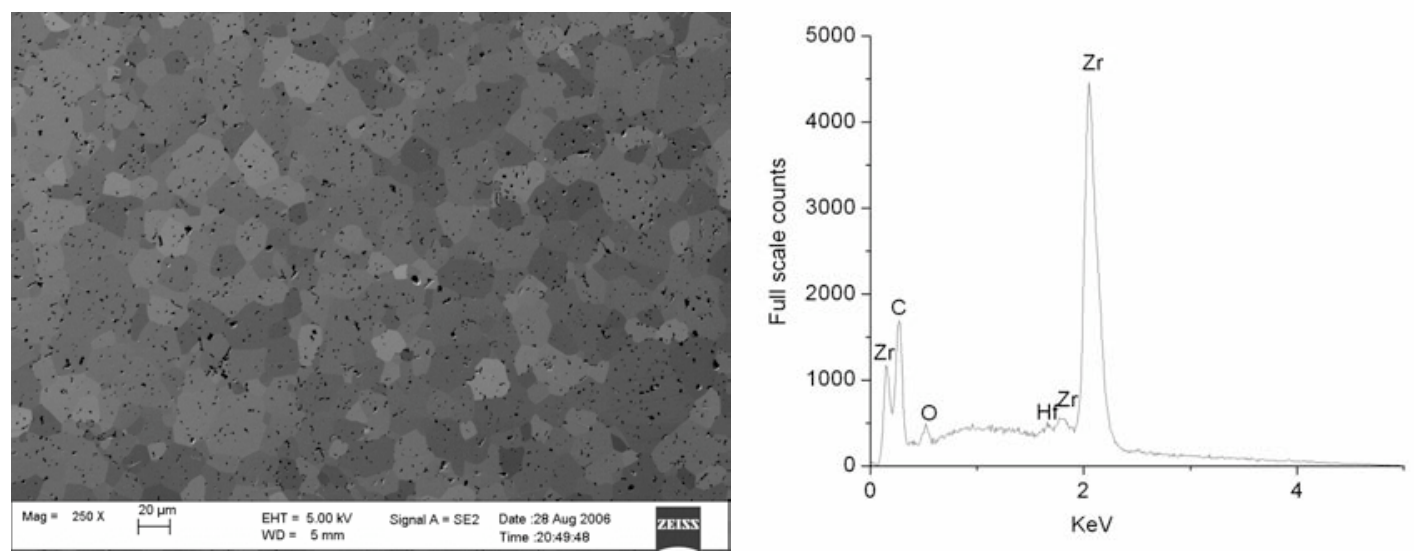

Figure 3.3. SEM and EDS of unirradiated $\mathrm{ZrC}$

After irradiation, a thin oxidation layer was found on the irradiated surface, but no indication of grain boundary separation was observed in any case, as shown in Figure 3.4(a). Figure 3.4(b) 
shows a continuous oxidation layer formed on the surface of the irradiated $\mathrm{ZrC}$. To measure the thickness of the oxidation, a $10 \mu \mathrm{m}$ deep trench was cut using ion milling with a focused ion beam (FIB) to reveal the cross section of the oxidation layer, which was measured as $\sim 350 \mathrm{~nm}$ thick. Some sputtering on the sample surface during irradiation was also identified with EDS.
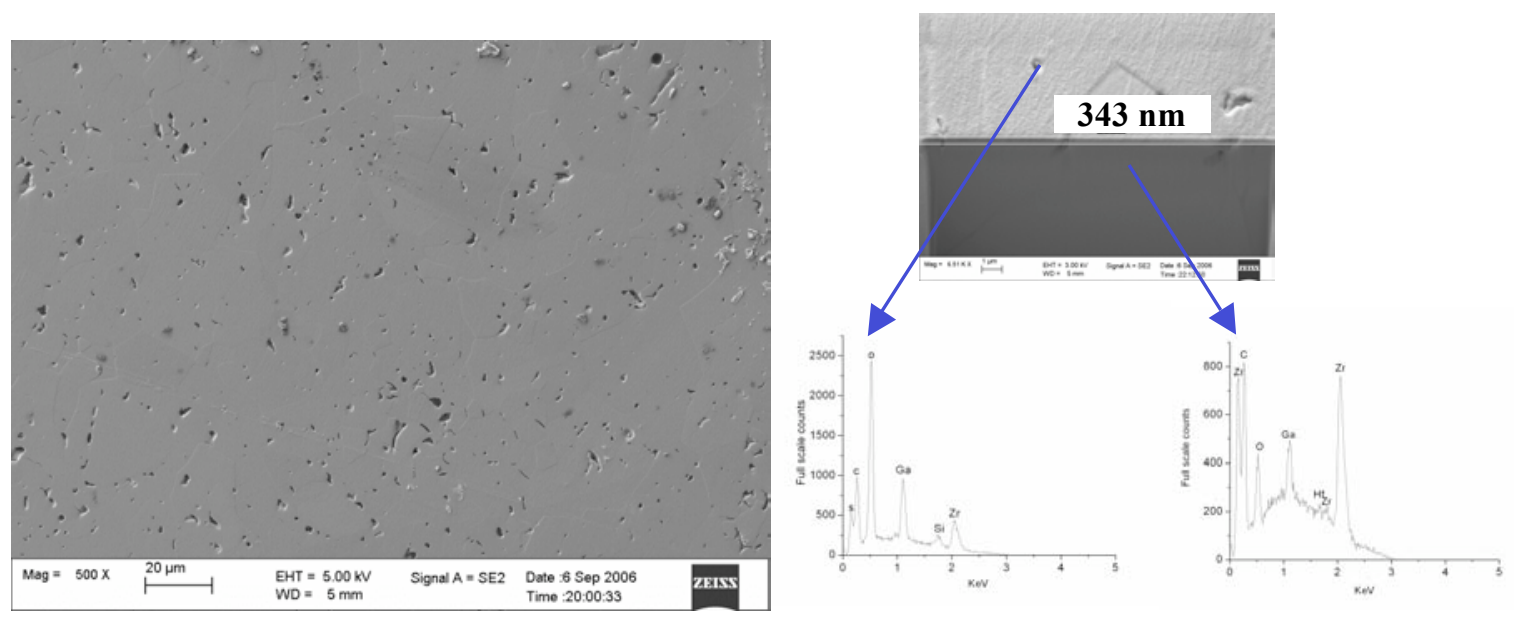

(a) SEM plan view of the irradiated surface (b) SEM/EDS of the cross-sectional cut by FIB Figure 3.4. SEM/EDS on the irradiated $\mathrm{ZrC}$

\subsection{Post-irradiation examination}

After irradiation, a thin layer of $\sim 10 \mu \mathrm{m}$ was removed from the irradiated side to eliminate the free surface defects sink effect from subsequent microstructural and mechanical property studies. The TEM samples were prepared using wedge polishing, followed by low angle ion milling. For the irradiated sample, the electron transparent area was controlled to be at the middle of the radiation damage range, which is about $20 \mu \mathrm{m}$ deep from the irradiated surface. The TEM characterization was conducted using a JEOL 200CX-II and a Philips CM200UT TEM, and the possible radiation-induced segregation (RIS) across the grain boundaries or dislocation loops was examined using EDS with a spot size diameter of $6 \mathrm{~nm}$. To study the lattice expansion caused by proton irradiation, X-ray diffraction (XRD) was conducted using a STOE X-ray powder diffractometer. Microhardness changes were measured using a Micromet 2003 micro indenter, and the sample surfaces were lapped up to $1 \mu \mathrm{m}$ diamond and finished with $\sim 0.04 \mu \mathrm{m}$ silica polishing.

\subsubsection{Change of lattice parameter}

XRD scans of $\mathrm{ZrC}$ have shown very small peak shifts to lower or higher $2 \theta$ values, and one example is displayed in Figure 3.5 for the specimen irradiated at $800^{\circ} \mathrm{C}$. Guided by Bragg's law, $\lambda=2 d \sin \theta$, smaller values of $2 \theta$, the observed peak position, would have to be accompanied by an increase in $d$, the plane spacing corresponding to a specific set of planes, in order for $\lambda$, the wavelength of the x-rays, to remain constant. Preliminary analysis of these data has shown lattice parameter, $a$, differences of less than $0.2 \%$. Because of the very small changes and possible 
incorporation of alignment and positioning errors, measures were taken to eliminate the error in the data to obtain more accurate lattice parameters by using alumina as a reference marker. The $2 \theta$ of each scan was corrected with the standard peaks of alumina, and the lattice parameters were calculated using the Werner's function in Winxpow ${ }^{\circledR}$.

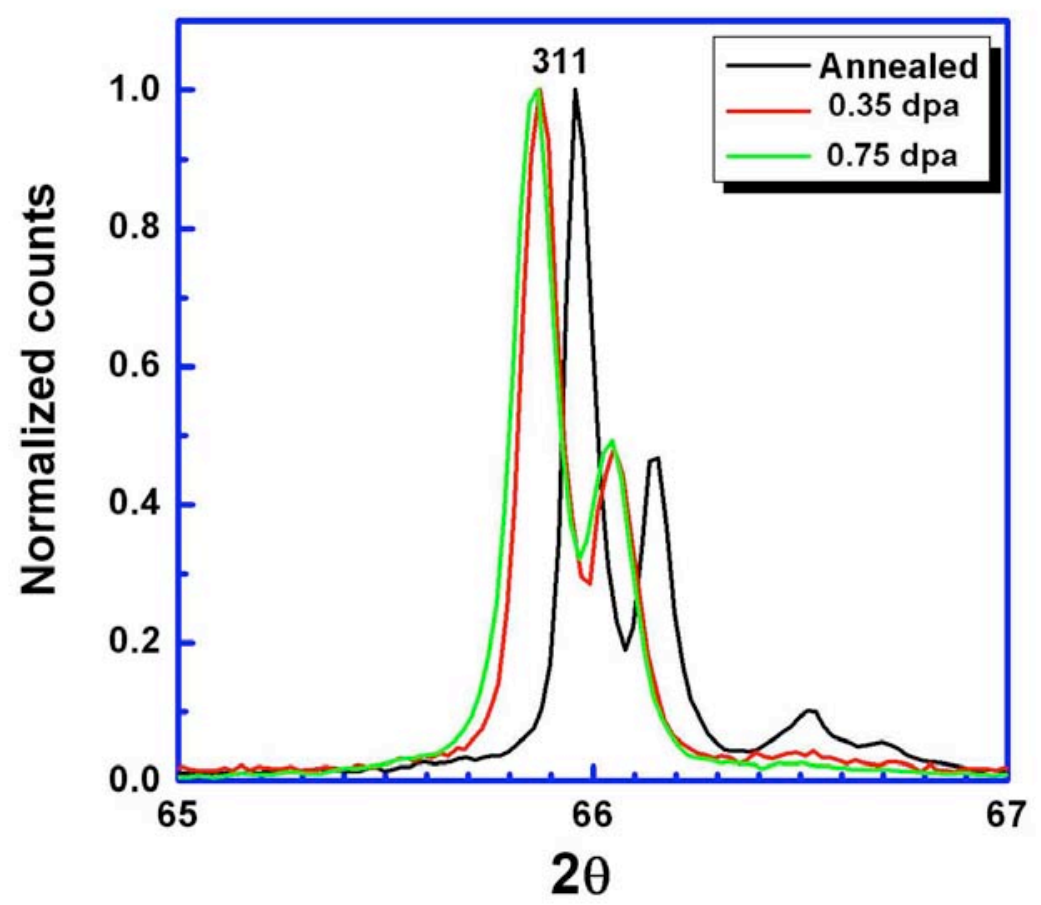

Figure 3.5. XRD of $\mathrm{ZrC}$ with different irradiation doses $\left(800^{\circ} \mathrm{C}\right)$

The changes in the lattice parameter of $\mathrm{ZrC}$ with different irradiation doses and temperatures are summarized in Figure 3.6. For temperatures of 600 and $800^{\circ} \mathrm{C}$, the lattice parameter increases with dose, while the $800^{\circ} \mathrm{C}$ irradiation induces less lattice expansion because the temperature increases the mobility of point defects, most notably interstitials, such that either the annihilation of the point defects with defects of opposite nature or the accumulation of point defects at sinks occurs more rapidly. The increase in lattice parameter is about $0.09 \%$ for the dose of $0.35 \mathrm{dpa}$ and $0.11 \%$ for the dose of $0.75 \mathrm{dpa}$ at $800^{\circ} \mathrm{C}$, and $0.14 \%, 0.21 \%$ and $0.33 \%$ for the doses of 0.35 , 0.75 and $1.75 \mathrm{dpa}$ at $600^{\circ} \mathrm{C}$, respectively. The corresponding volume increase due to lattice constant increase for irradiation of $1.75 \mathrm{dpa}$ at $600^{\circ} \mathrm{C}$ is around $0.99 \mathrm{vol} . \%$. However, for the irradiation at $900^{\circ} \mathrm{C}$, the lattice parameter-dose relation deviates from those of the other two temperatures, and as the dose increases, the lattice shows slight contraction; the underlying mechanism is being studied. 


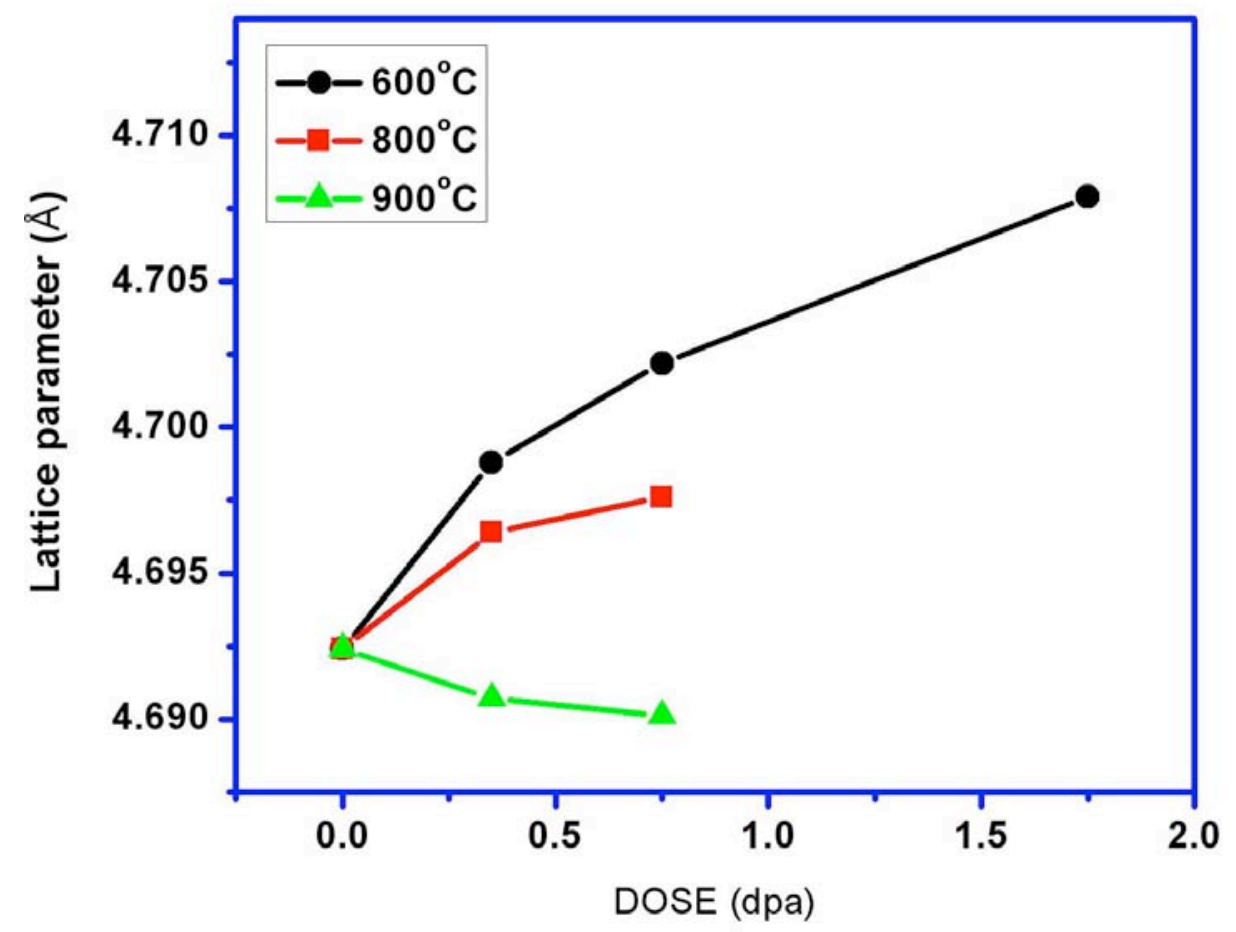

Figure 3.6. Lattice parameter changes for $\mathrm{ZrC}$ with different irradiation doses and temperatures

\subsubsection{Microstructures}

The irradiated microstructures were thoroughly characterized using TEM at bright field (BF), weak beam dark field (WBDF) and high-resolution conditions. For comparison, the microstructure of the annealed material was also examined. Information about the expected damage microstructure of irradiated $\mathrm{ZrC}$ can be inferred from the collision cascades, as simulated by Brutzel et al. using molecular dynamics simulation at 300 Kelvin [3.18]. In those calculations, no amorphization was observed, and all $\mathrm{Zr}$ interstitials form a dumbbell structure oriented in the $<111>$ direction and $\mathrm{C}$ interstitials are either isolated or form a $<111>$ dumbbell structure. Calculations show that clusters of interstitials of two different species have a tendency to form interstitial dislocation loops in the $\{111\}$ plane. Some isolated vacancies or small vacancy clusters, involving either $\mathrm{C}$ or $\mathrm{Zr}$ vacancies, were found in the core of the cascade.

\subsubsection{Annealed sample}

Figure 3.7 shows images taken close to a near $<011>$ zone axis under a $g=200,2$-beam $\mathrm{BF}$ condition. The microstructure of the annealed $\mathrm{ZrC}$ mainly consists of scattered nanometer-size black spots, which were induced by the ion milling during sample preparation. No dislocation lines or precipitates were identified. Figure 3.8 shows the high-resolution transmission electron microscopy (HRTEM) of the annealed $\mathrm{ZrC}$; apparently the microstructure is nearly free from defects, except some thickness contrasts induced from ion milling. 


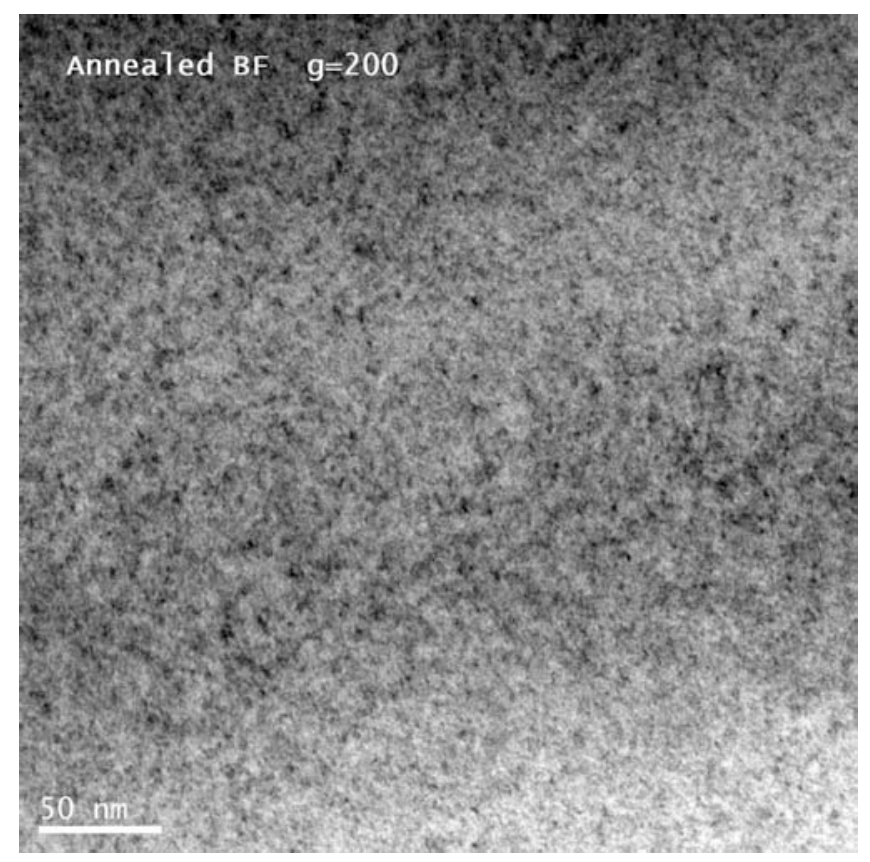

Figure 3.7. BF image of annealed $\mathrm{ZrC}$

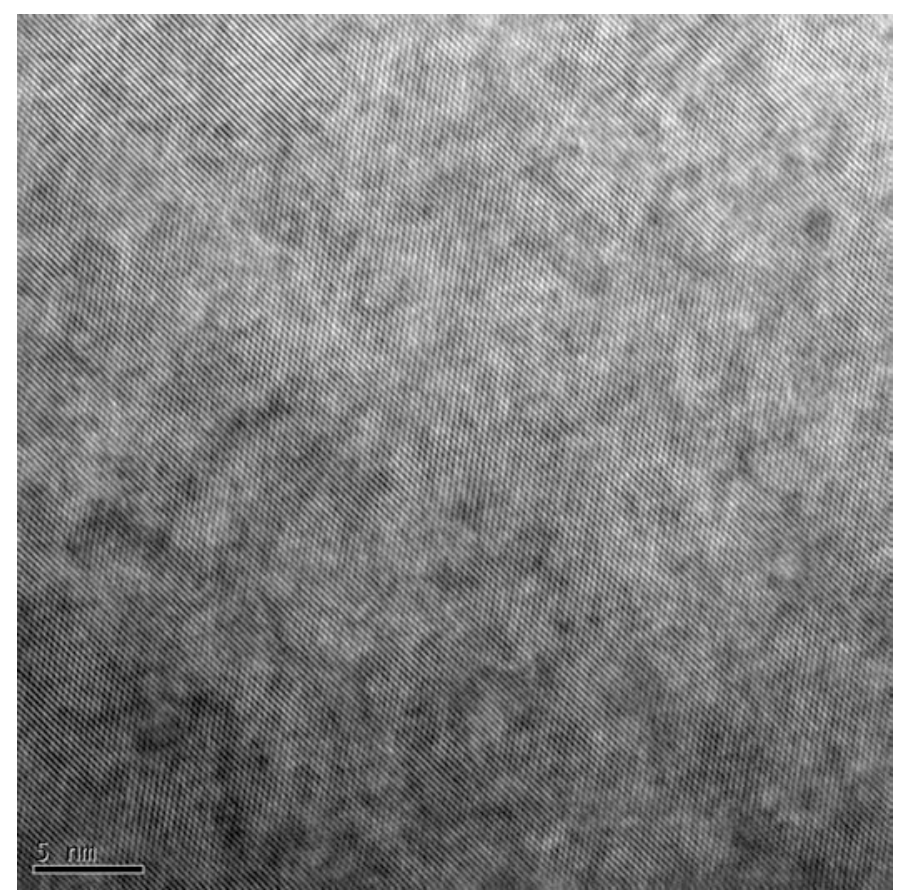

Figure 3.8. HRTEM of annealed ZrC

\subsubsection{Microstructures in samples irradiated at $800^{\circ} \mathrm{C}$}

No voids or bubbles were observed in the irradiated samples with the image resolution up to less than $1 \mathrm{~nm}$. However, Gan found some nanometer-sized bubbles in the unirradiated $\mathrm{ZrC}$ sample (Gan analyzed the same $\mathrm{ZrC}$ from CERCOM) prepared by ion milling [3.11]; this discrepancy may be due to different ion milling conditions for our sample preparation, which included low 
angle $\leq 9^{\circ}$ degree, low voltage $\leq 4 \mathrm{kV}$ and very short milling time. Figure 3.9 shows the images taken close to a near [011] zone axis under a $\mathrm{g}=200,2$-beam $\mathrm{BF}$ condition, and images with high resolution taken at the [011] zone axis. The microstructure of the annealed $\mathrm{ZrC}$ mainly consists of scattered nanometer-size black spots, which were induced by the ion milling during sample preparation. No dislocation lines or precipitates were identified, and the diffraction pattern obtained by titling the sample away from the [011] zone axis along $g=31 \overline{1}$ doesn't show any Rel-rod streaks in the unirradiated $\mathrm{ZrC}$. 

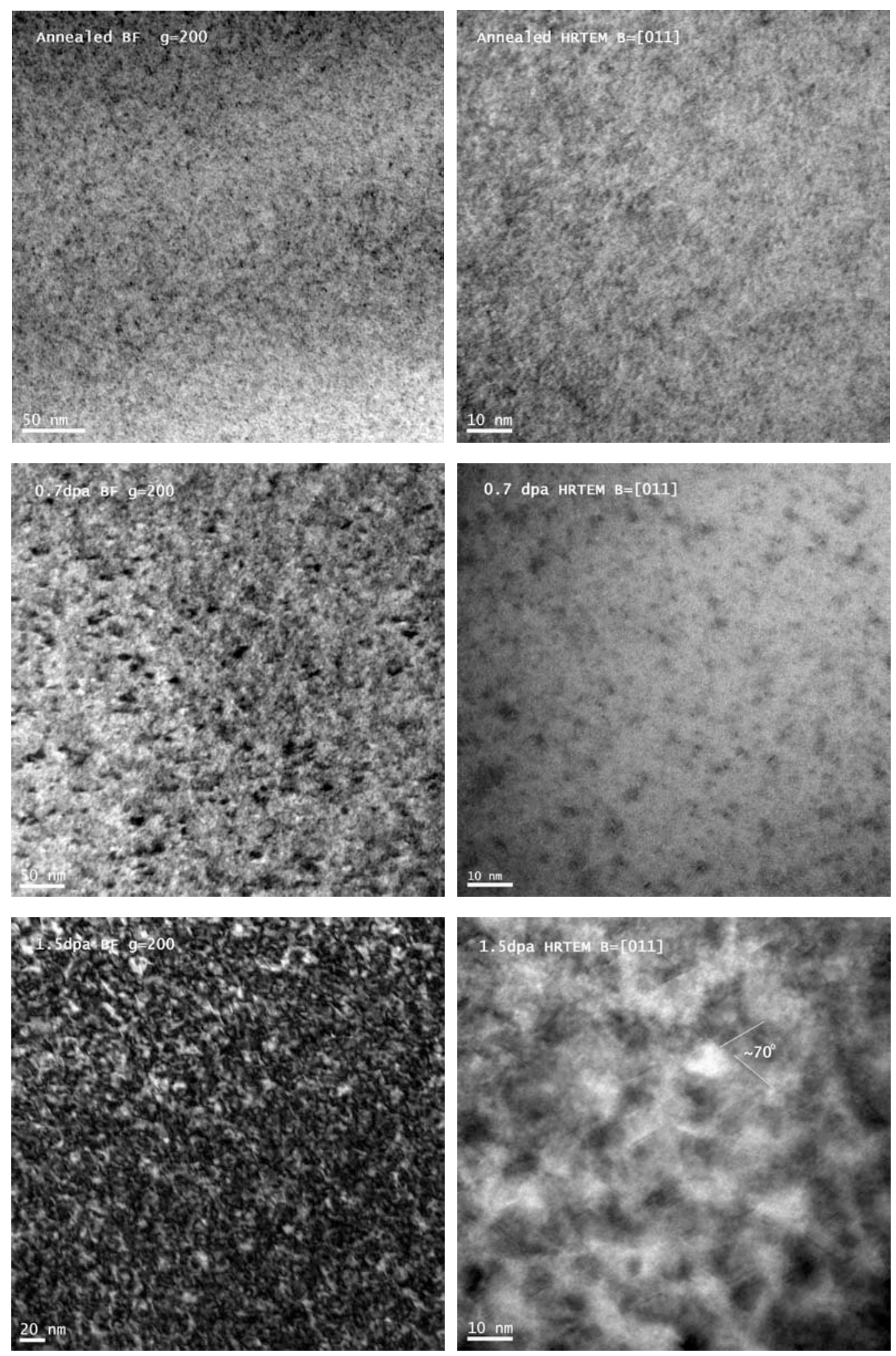

Figure 3.9. BF and HRTEM images for annealed and irradiated $\mathrm{ZrC}$ 
For the $800^{\circ} \mathrm{C}$ irradiated $\mathrm{ZrC}$, Frank loops (FLs) in the plane $\{111\}$ were observed in thesamples at both dose levels 0.35 and $0.75 \mathrm{dpa}$. Based on the HRTEM and DF images, FLs are the only identified defects with observable density in the proton-irradiated $\mathrm{ZrC}$. The size and density of loops increases as the dose level increases, as displayed in the HRTEM images. From the BF images at the $\mathrm{g}=200$ 2-beam condition, it can be seen that the microstructure of irradiated $\mathrm{ZrC}$ matrix becomes highly strained locally as the dose increases. Due to the local lattice distortion, no Kikuchi bands can be observed in the convergent beam diffraction for the sample with dose of $0.75 \mathrm{dpa}$, as shown in Figure 3.10. Additional details of the defect structures are shown in the lattice plane resolution image, Figure 3.11. The near edge-on FLs can be identified clearly, while no obvious stacking fault tetrahedron (SFT) was observed.
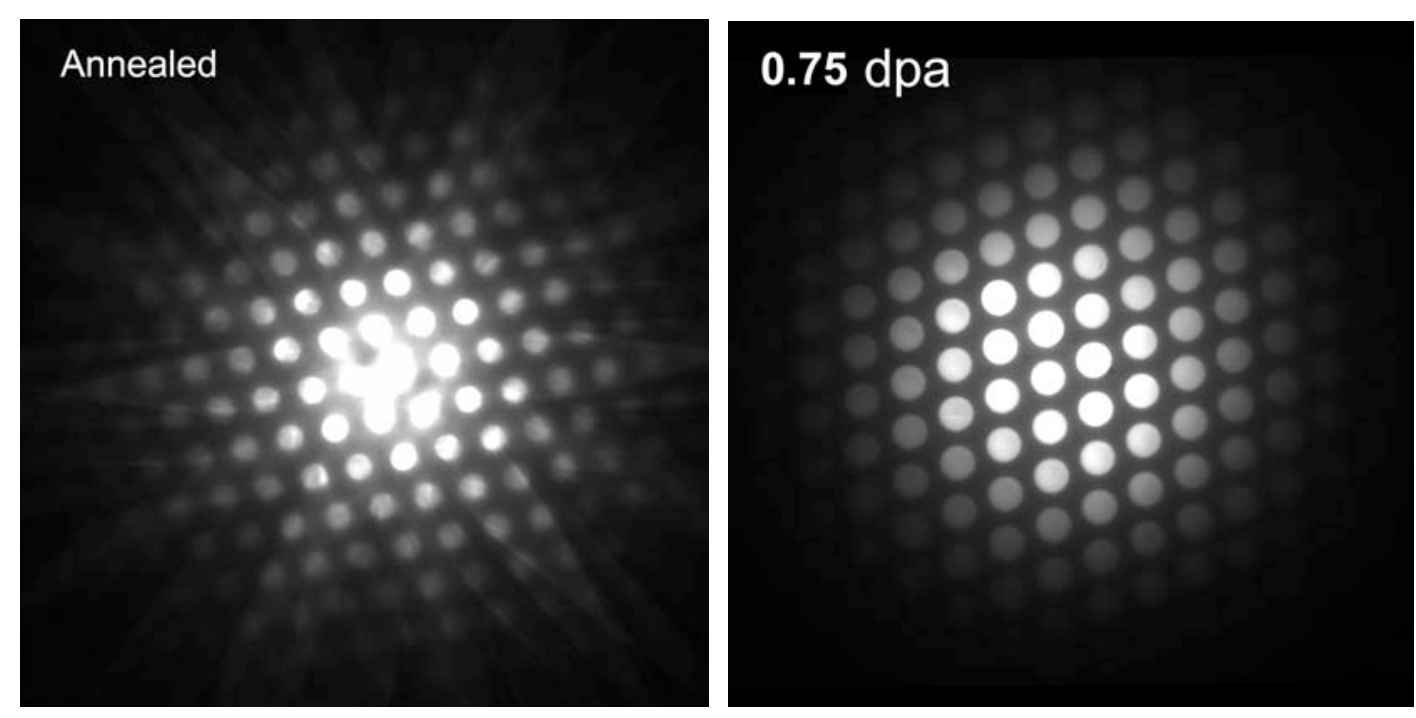

Figure 3.10. Convergent beam diffraction patterns on unirradiated and 0.75 dpa irradiated $\mathrm{ZrC}$ 


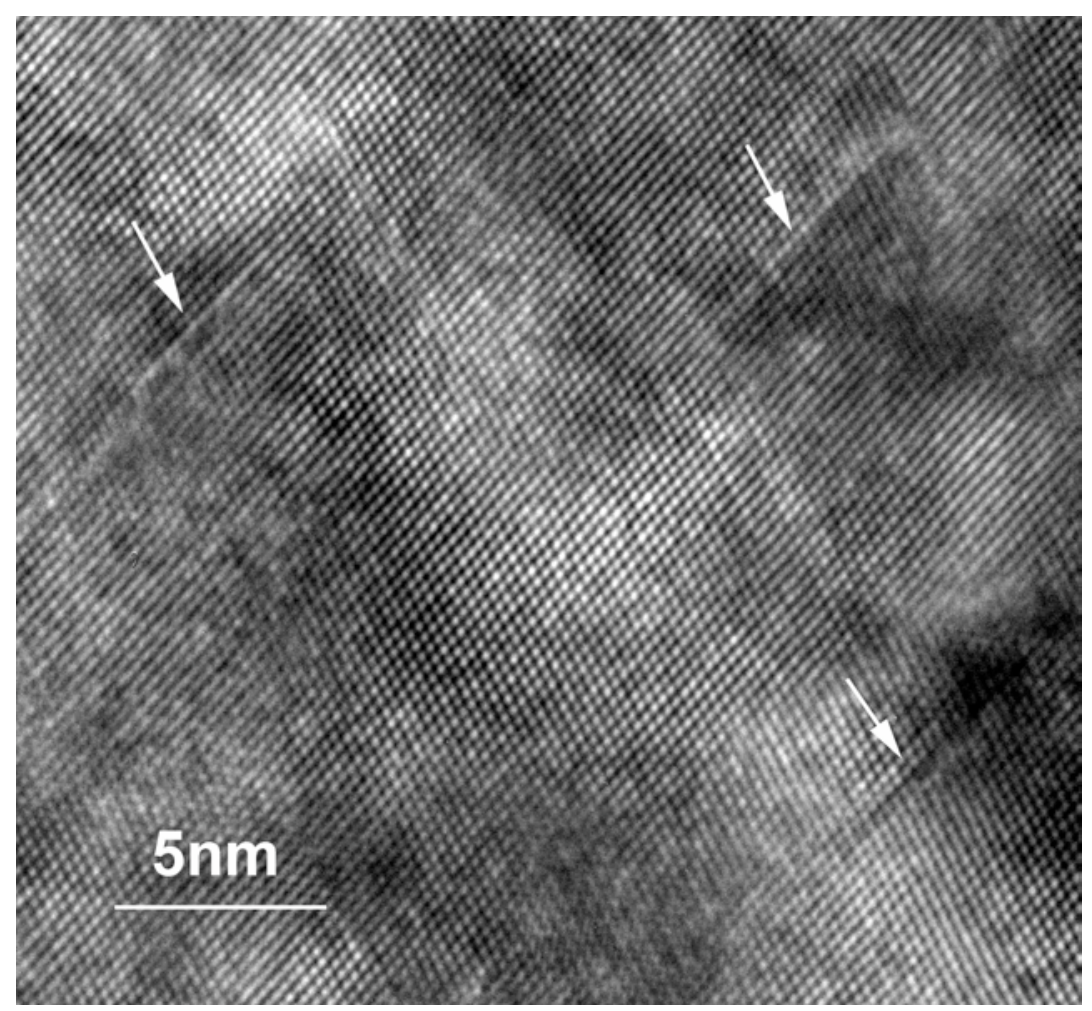

Figure 3.11. Lattice resolution image of FLs, indicated with arrows

As one of the major microstructural defects in irradiated samples with a face-centered cubic (fcc) structure, faulted dislocation loops lie on the four $\{111\}$ planes with a Burgers vector $a / 3<111>$ and can be clearly delineated in materials using the Rel-rod technique. The relevant diffraction condition was conducted by tilting the sample close to the $g=31 \overline{1}$ 2-beam condition near the $<011>$ zone axis, and the Rel-rod dark field (DF) image is formed from the Rel-rod streak selected by the objective aperture. The diffraction conditions are schematically shown in Figure 3.12 (a). The density of the FLs can be determined from this orientation by multiplying by four to account for the three variants not being imaged, assuming an isotropic distribution. The measurements were performed near the edge of the wedge samples to minimize overlap of the defects and improve accuracy of the results. For the $\mathrm{Kr}$-irradiated $\mathrm{ZrC}$ from Gan et al., no clear FLs structures or irradiation-induced line dislocations were observed in sample irradiation up to 70 dpa at $800^{\circ} \mathrm{C}[3.11]$. 

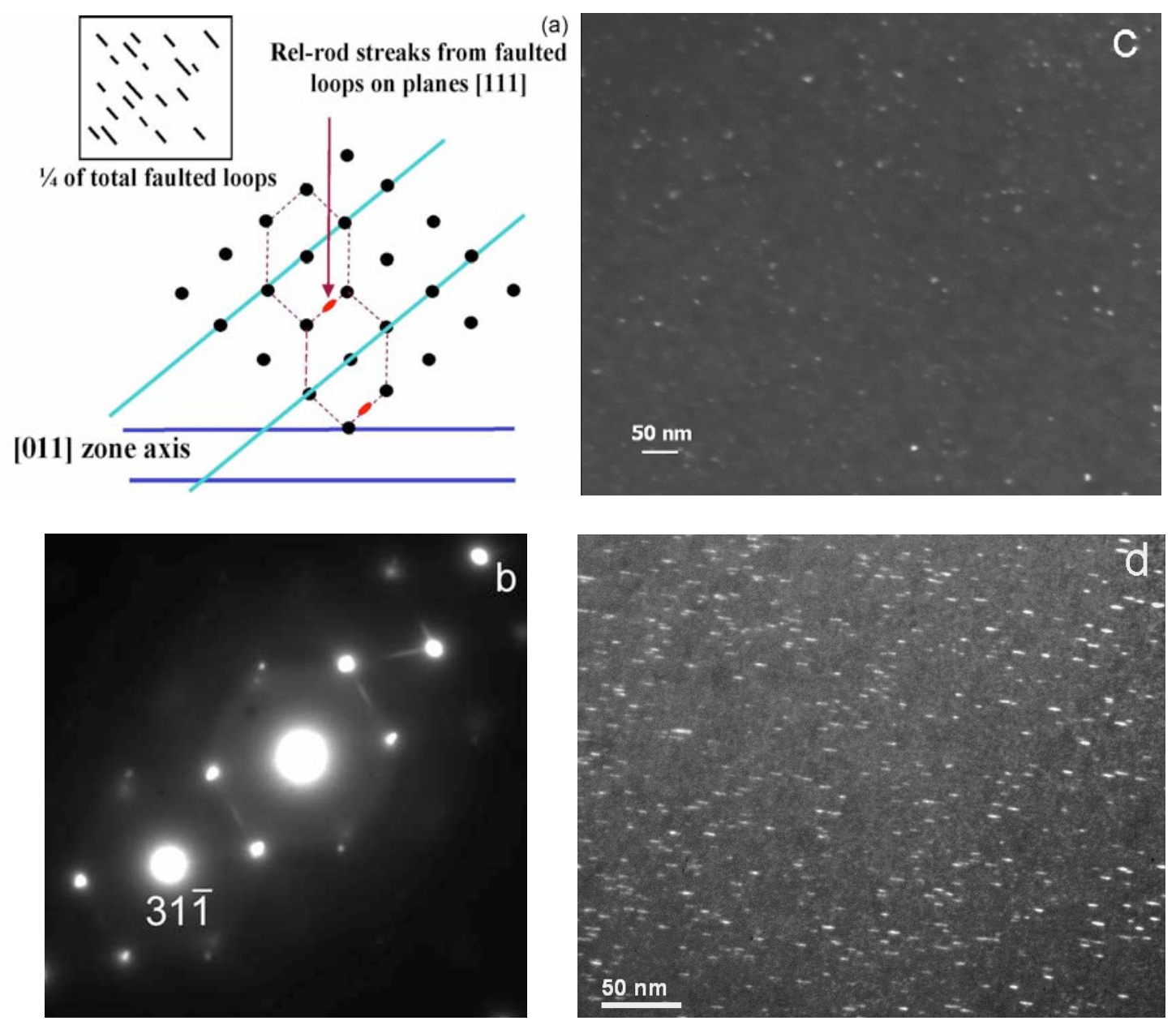

Figure 3.12. Rel-rod DF image of FLs (a) schematic of the diffraction condition (b) diffraction pattern at $g=31 \overline{1}$ near [011] zone axis (c) sample with dose of $0.35 \mathrm{dpa}(\mathrm{d}$ ) sample with dose of $0.75 \mathrm{dpa}$

Table 3.1 the denuded zones width in irradiated $\mathrm{ZrC}$ at GB

\begin{tabular}{ll}
\hline Dose (dpa) & $\begin{array}{l}\text { Denuded Zone } \\
\text { Width (nm) }\end{array}$ \\
\hline 0.7 & $38 \pm 0.9$ \\
\hline 1.5 & $30 \pm 1.4$ \\
\hline
\end{tabular}

Irradiation also led to changes in the near-boundary regions in the form of defect-denuded zones, as illustrated in Figure 3.13. For each dose level, more than six grain boundaries were measured, and for each measurement, the grain boundary plane was tilted to parallel with the electron beam. The measured widths of these zones are summarized in Table 3.1. As the dose increases, the average width of the denuded zone tends to be narrower. However, the large variation in width may be related to different boundary characters with associated grain boundary energies. 
According to equation (6) in the paper by Zinkle, the measured denuded zone widths at several different irradiation temperatures or damage rates can be used to evaluate the interstitial diffusivity, provided that the bulk interstitial concentration over the difference between the bulk interstitial concentration and critical interstitial concentration is relatively independent of the irradiation temperature or dpa rate [3.17]. This evaluation will be conducted in future studies.

The samples were also examined for possible RIS using EDS. No detectable elemental depletion or enrichment was found at the grain boundaries in the irradiated $\mathrm{ZrC}$, but due to the limitations of the resolution in the TEM used, segregation cannot be ruled out until measurements are attempted using an appropriate TEM. Similarly, no profiles were successfully obtained across the FLs oriented edge-on. RIS will be further studied using electron energy loss spectroscopy (EELS) in our future research.
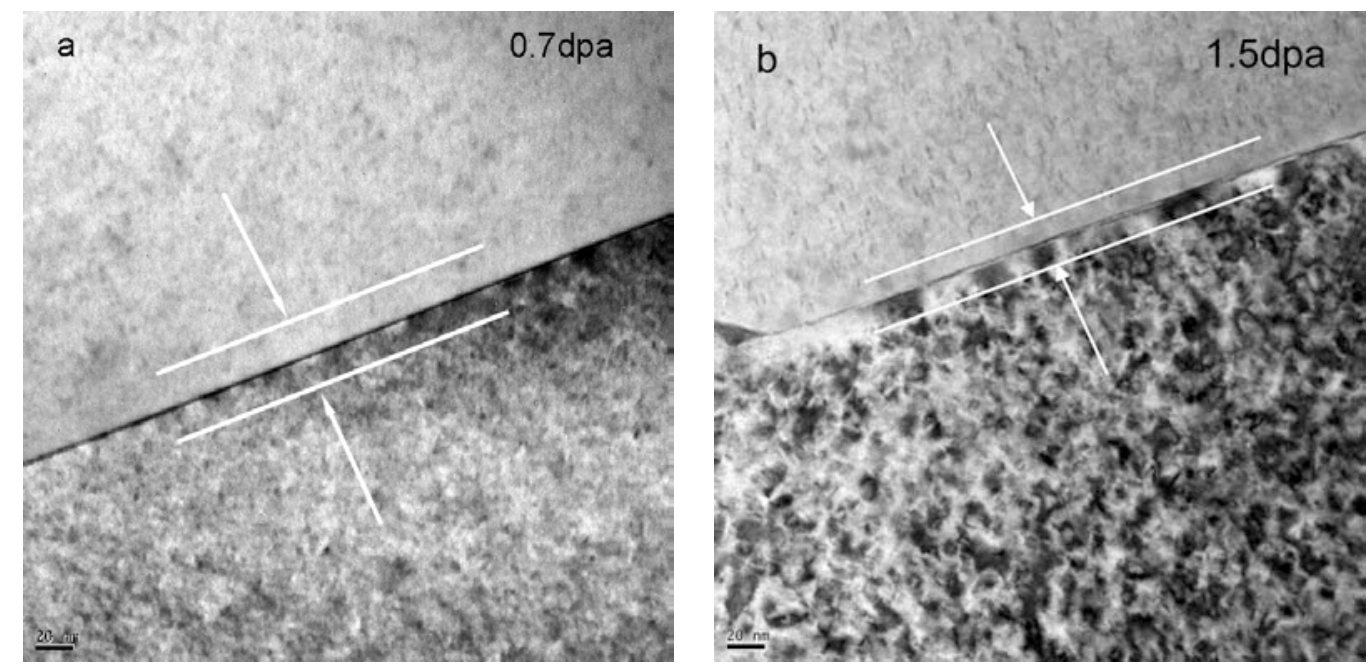

Figure 3.13. Denuded zones were found in the irradiated $\mathrm{ZrC}$ at a 2-beam $\mathrm{g}=200$ condition

Convergent beam electron diffraction (CBED) methods analyze slight changes in position of higher-order Laue zone (HOLZ) lines that are sensitive to small changes in lattice constants, allowing resolution of strains as small as $0.02 \%$ from spatial regions as small as $1 \mathrm{~nm}$ [3.18]. Additionally, commercial software is available to automate the determination of strain by leastsquares refinement fitting of experimental and simulated data (www.soft-imaging.net). Although it may be possible to measure strain with $1 \mathrm{~nm}$ spatial resolution using CBED, the probe interaction volume is a function of the probe size and convergent angle, as well as probe spreading due to elastic scattering through the thickness of the TEM sample. Usually, the sample is tilted to higher-order zones to reduce dynamical contrast; however tilting can cause the probe to sample neighboring regions, effectively reducing spatial resolution.

For $\mathrm{ZrC}$, the HOLZ lines patterns were obtained for both unirradiated and irradiated samples. Diffractions were performed on a LEO 912 with Zeiss Omega energy filter and nitrogen-cooled stage. As shown in Figure 3.14 for the unirradiated sample, the HOLZ lines are clearly presented on the 000 disc with sharp lines, while for the irradiated sample with $0.75 \mathrm{dpa}$, the HOLZ lines are nearly invisible. For HOLZ lines, any stacking disorder in the beam direction will reduce the contrast lines, and high defect concentration can also degrade the pattern greatly. Although the 
results demonstrate that quantitatively measuring the lattice strain or expansion of the irradiated $\mathrm{ZrC}$ is not feasible using the HOLZ lines method for this irradiated material, the difference between these two patterns strongly reflect that the lattice in irradiated $\mathrm{ZrC}$ is locally highly strained, which is consistent with the high concentration of dislocation loops shown in Figure 3.9.

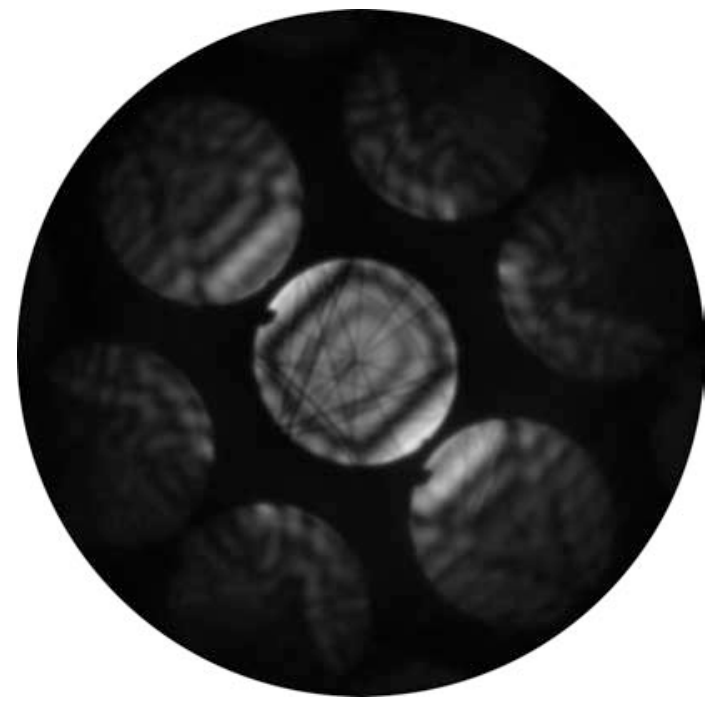

(a)

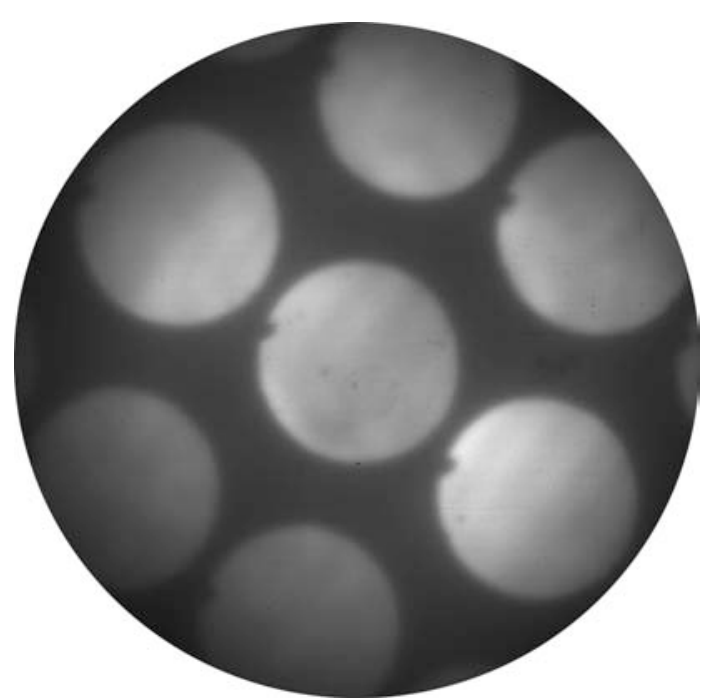

(b)

Figure 3.14. (a) HOLZ lines of unirradiated $\mathrm{ZrC}$ with $\mathrm{Z}=[114]$, (b) CBED pattern of irradiated $\mathrm{ZrC} @ 0.75$ dpa with $\mathrm{Z}=[114]$

\subsubsection{Microstructures in samples irradiated at $600^{\circ} \mathrm{C}$}

Figure 3.15 shows the $\mathrm{BF}$ images at the $\mathrm{g}=200$ 2-beam condition of $\mathrm{ZrC}$ irradiated at $600^{\circ} \mathrm{C}$. The microstructure of irradiated $\mathrm{ZrC}$ becomes highly strained locally as the dose increases, due to the local lattice distortion, and Kikuchi bands become diffused and invisible in the convergent beam diffraction patterns as the dose increases. 

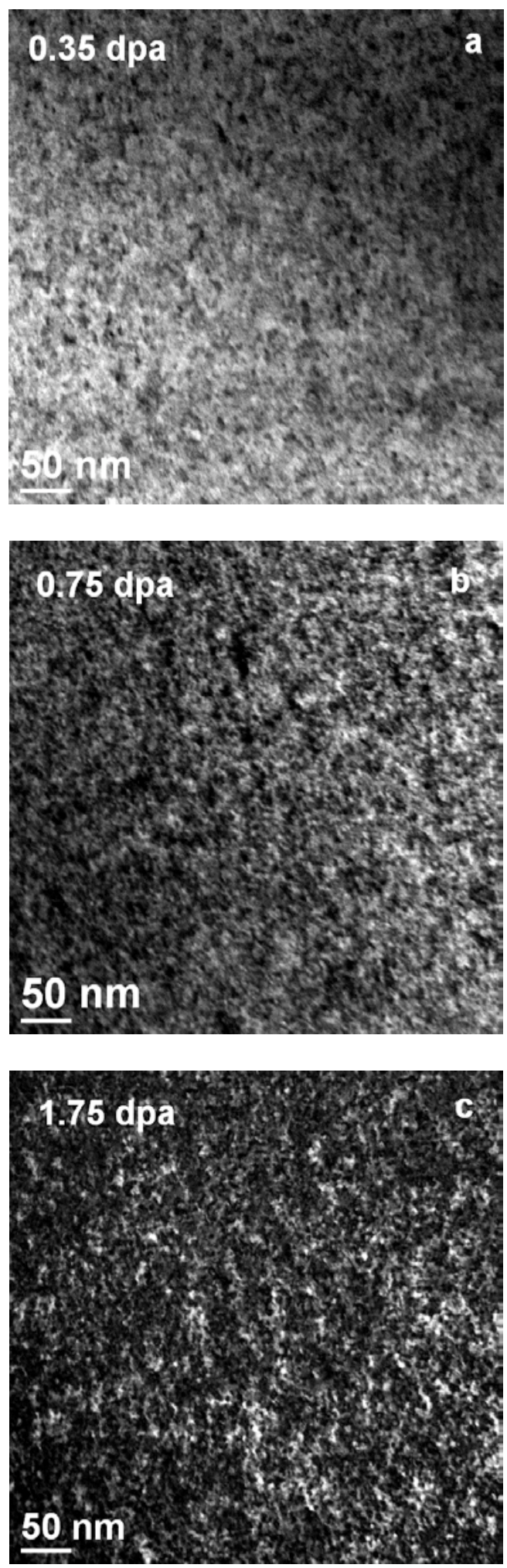

Figure 3.15. BF images at $\mathrm{g}=200$ 2-beam condition near the $<011>$ zone axis of $\mathrm{ZrC}$ irradiated at $600^{\circ} \mathrm{C}$ : a) $0.35 \mathrm{dpa}$, b) $0.7 \mathrm{dpa}$ and c) $1.75 \mathrm{dpa}$ 
As shown by the HRTEM in Figure 3.16, the dislocation loops lying in the plane $\{111\}$ are clearly observed in the irradiated sample at a dose of $1.75 \mathrm{dpa}$. For the TEM image at the zone axis $<011>$, half of the dislocation loops appear as edge-on, while another half are inclined. For $0.7 \mathrm{dpa}$ irradiation, the average size of the dislocation loops is close to that of $1.75 \mathrm{dpa}$ irradiation, while the density of loops is lower. For the 0.35 dpa irradiation, the size of the dislocation loops is much smaller and average close to $1 \mathrm{~nm}$ or less based on estimation from the HRTEM images, and the density of dislocation is also lower as compared with the other two doses.

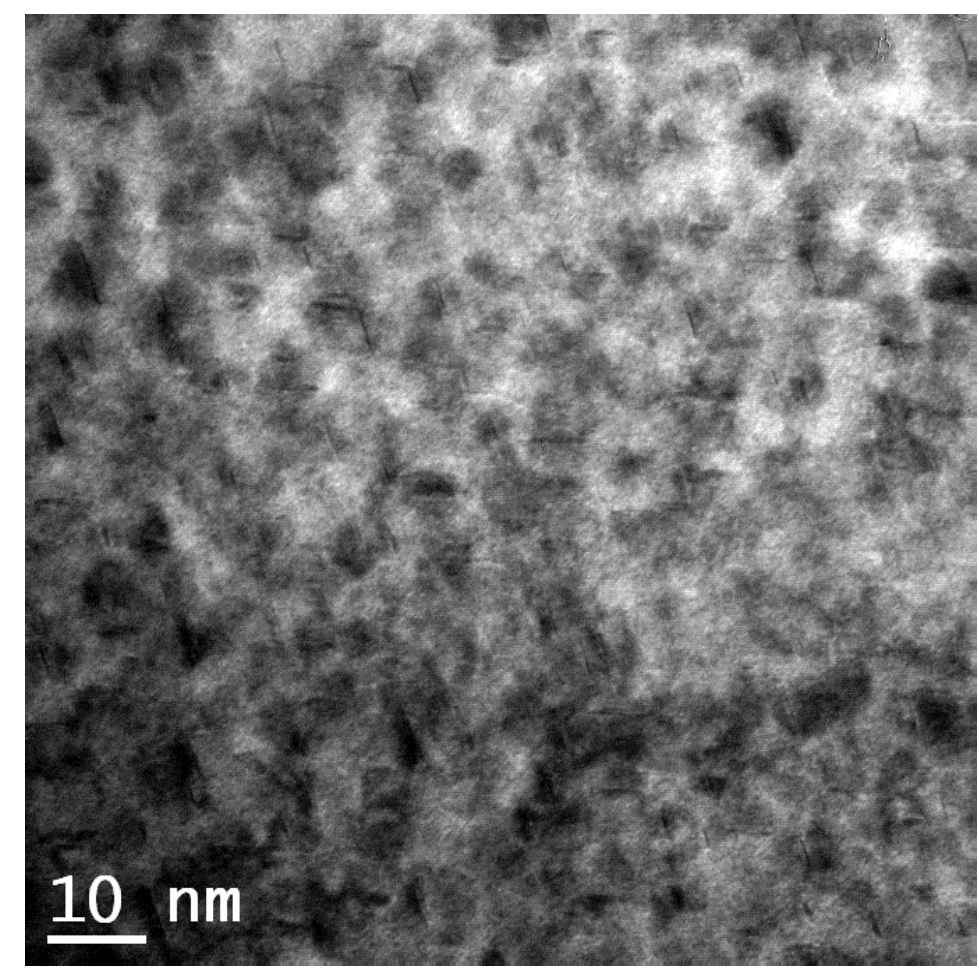

Figure 3.16. High resolution TEM image at zone axis $<011>$ of $\mathrm{ZrC}$ irradiated at $600^{\circ} \mathrm{C}$ with a dose of $1.75 \mathrm{dpa}$

As one of the major microstructural defects in irradiated samples with a fcc structure, faulted dislocation loops lie on the four $\{111\}$ planes with a Burgers vector $\mathrm{a} / 3<111>$ and can be clearly delineated in materials using the Rel-rod technique. The relevant diffraction condition was explained previously. Clear Rel-rod streaks were observed in the diffraction of the sample irradiated to $1.75 \mathrm{dpa}$, which corresponds to a large population of FLs. Figure 3.17 shows the Rel-rod DF image of the $\mathrm{ZrC}$ irradiated at $600^{\circ} \mathrm{C}$ and $1.75 \mathrm{dpa}$, and the irradiated microstructure consists of a high density of small FLs that uniformly distribute in the grains. 


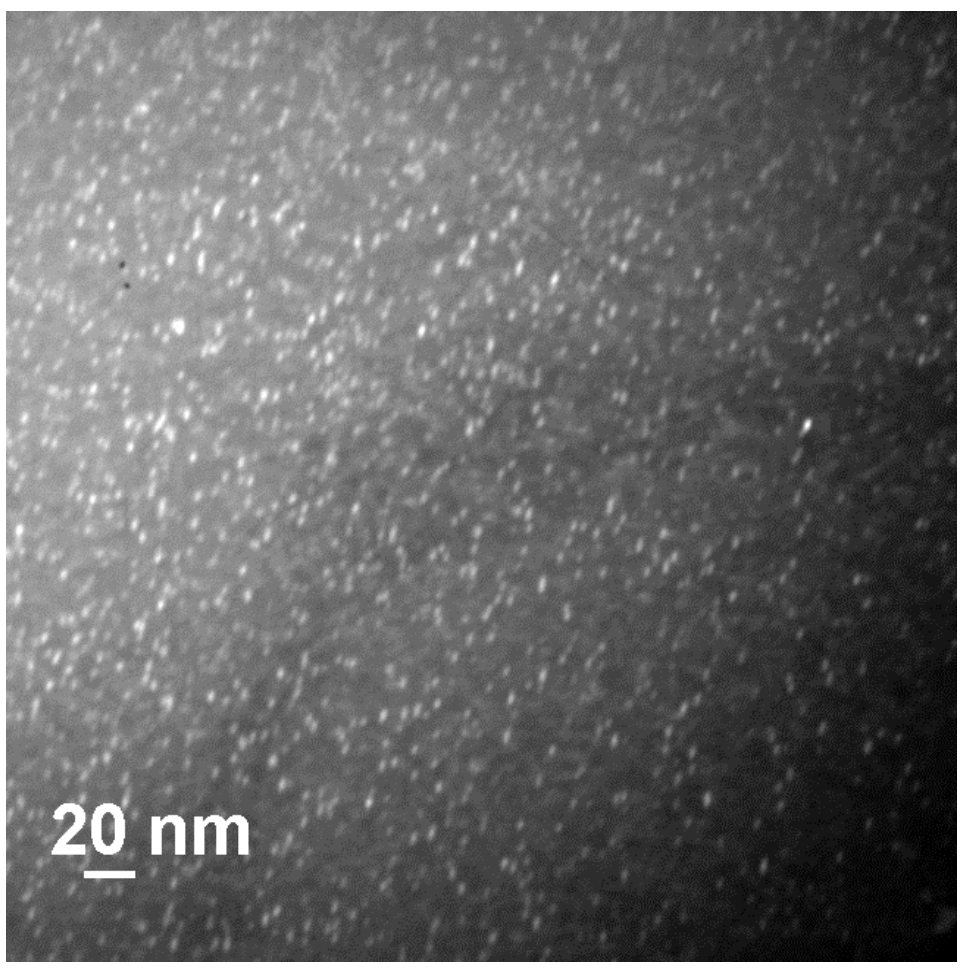

Figure 3.17. Rel-rod DF image of FLs in $\mathrm{ZrC}$ irradiated at $600^{\circ} \mathrm{C}$ to $1.75 \mathrm{dpa}$

\subsubsection{Microstructures in samples irradiated at $900^{\circ} \mathrm{C}$}

The irradiated samples were examined at close to the zone axis $<011>$. The microstructures appear nearly featureless for the dose of 0.35 dpa and are only decorated with a few dislocation loops, but the large dislocation loops with a moderate density were observed in the samples with a dose of $0.75 \mathrm{dpa}$, as shown in Figure 3.18. Additional TEM studies show that the irradiation defects are not uniformly distributed; some denuded areas were observed even within a grain, as shown in Figure 3.19. However, the underlying mechanism is unclear and needs further investigation. 


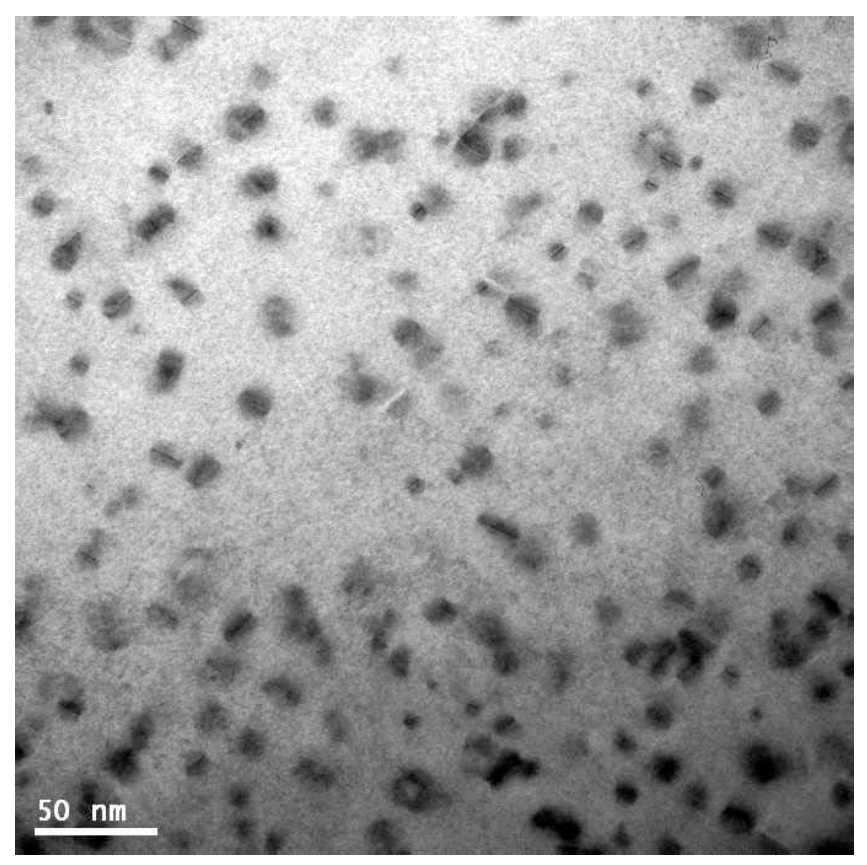

Figure 3.18. BF image showing defects in the $\mathrm{ZrC}$ irradiated to 0.75 at $900^{\circ} \mathrm{C}$

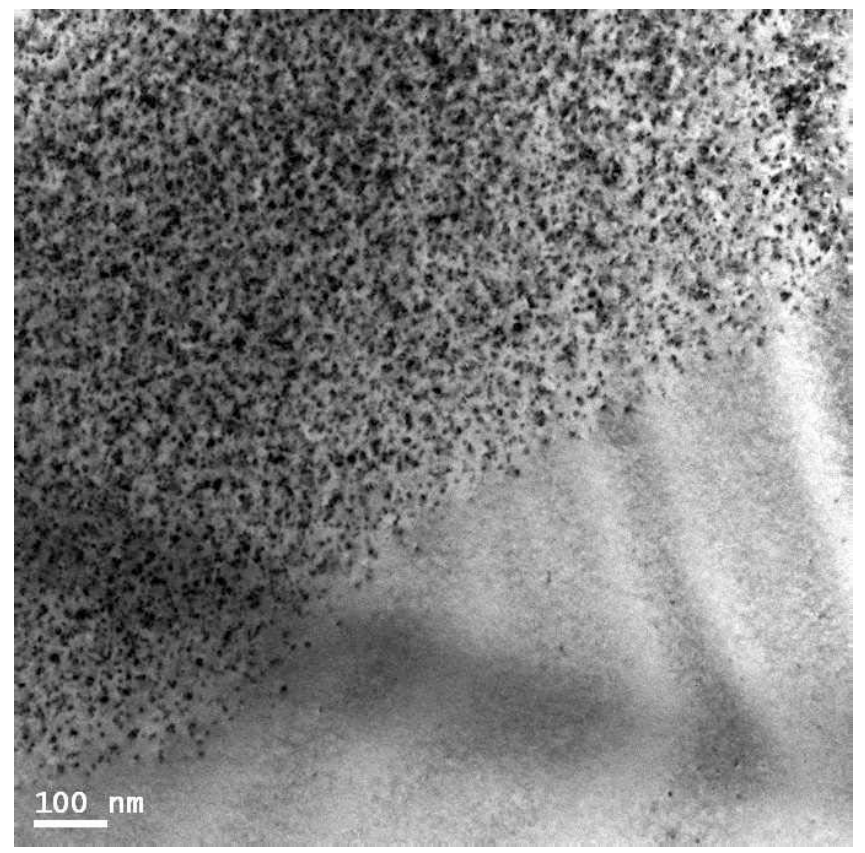

Figure 3.19. Defects in denuded area in $\mathrm{ZrC}$ irradiated at $900^{\circ} \mathrm{C}$ to $0.75 \mathrm{dpa}, \mathrm{g}=311$ near $<011>$

Rel-rod diffraction patterns were recorded for both different dose levels; however no clear Relrod streaks can be identified, which means a low density of faulted dislocation loops. Lattice imaging, combined with Fourier-filtering, was used to study the nature of the defect. Figure 3.20 shows an image of a typical planar-like defect projected as streaks along the [200] direction. 
After masking the $11 \overline{1}$ diffraction spots and applying an inverse Fourier transformation, an interstitial type dislocation loop with habit plane $\{111\}$ is clearly displayed, and the dislocation loop is identified as an interstitial type prismatic loop. Since no Rel-rod streaks were observed at the 2-beam condition of $\mathrm{g}=311$ near zone axis $<011>$, it can be concluded that there are a significantly low density of faulted dislocation loops present in the $900^{\circ} \mathrm{C}$ irradiated $\mathrm{ZrC}$.

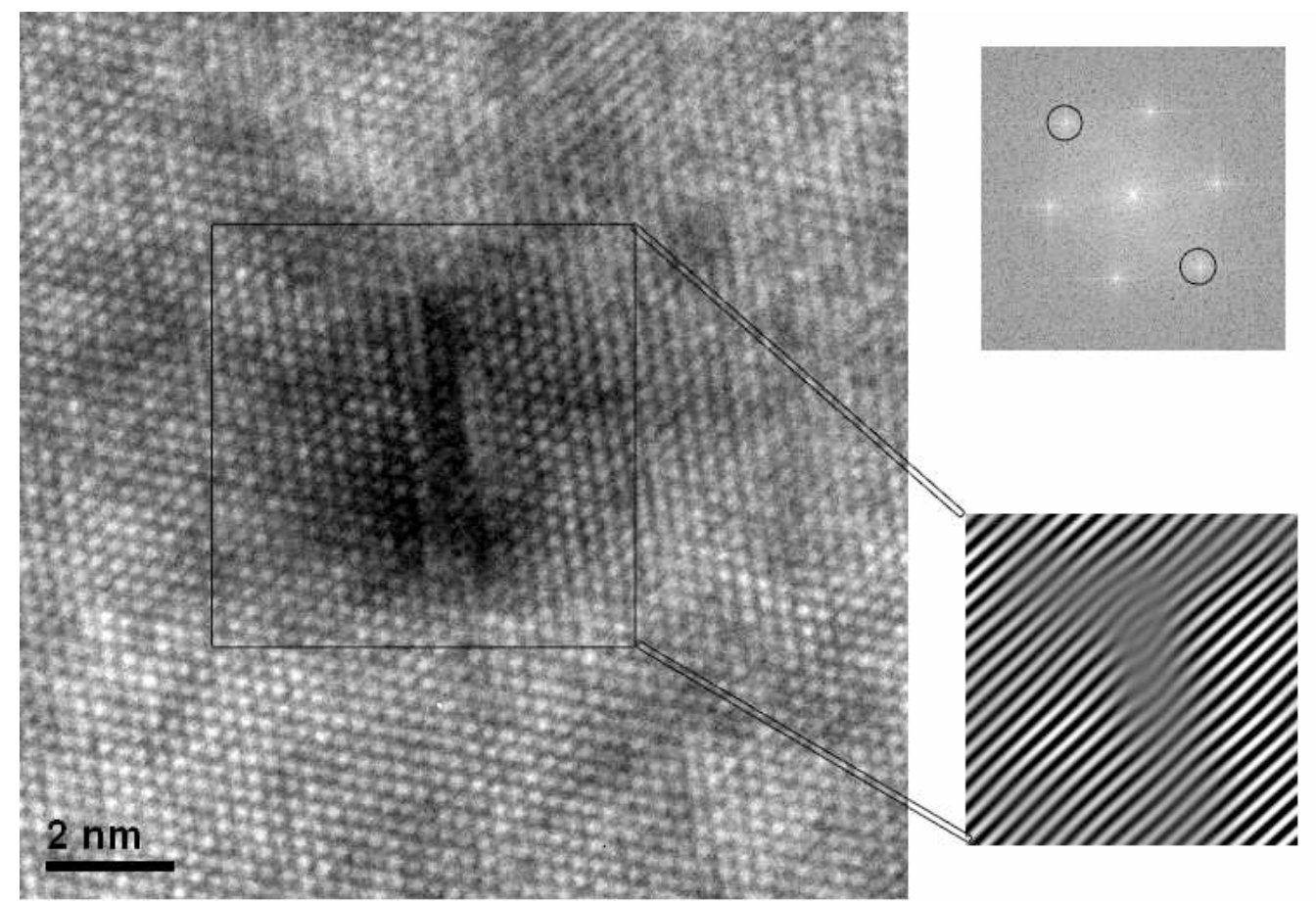

Figure 3.20. $<011>$ lattice image of planar-like defect, and revealed as an interstitial type prismatic loop

The grain boundaries were carefully examined for samples with dose of $0.75 \mathrm{dpa}$, and possible precipitates at grain boundaries were observed, however, the EDS spectra did not reveal any composition difference from the matrix, which might be due to the limited resolution of the detector on the light elements. Another clear feature shown in Figure 3.21 is the clusters of nanometer-size bubbles along a high population of grain boundaries. 


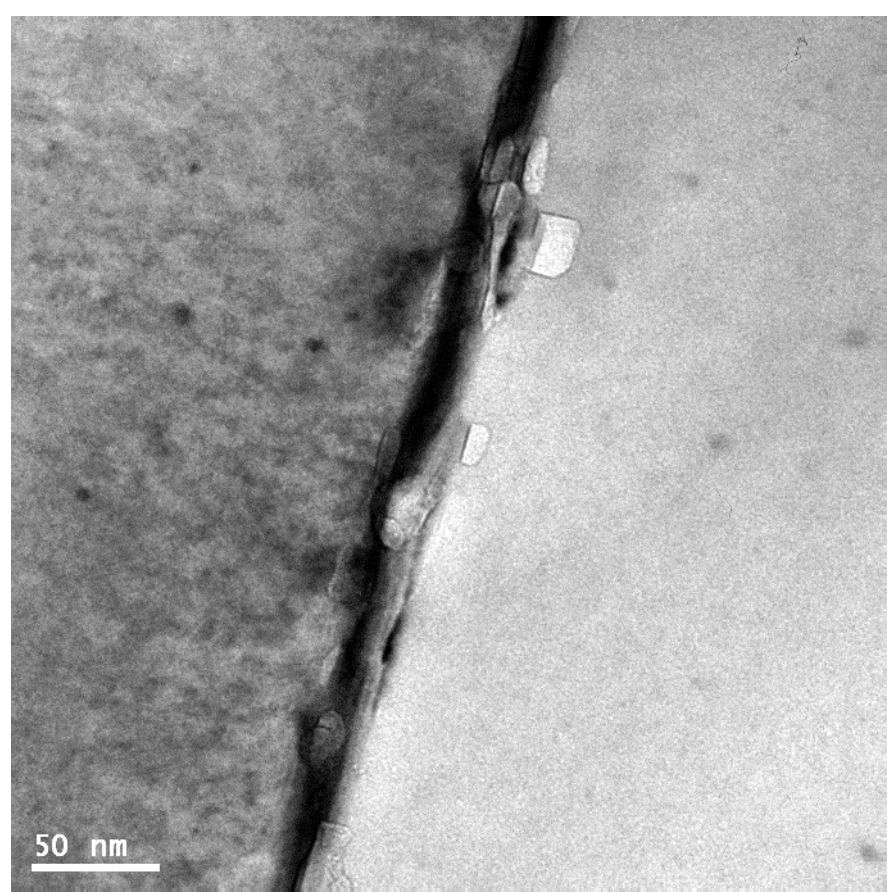

Figure 3.21. Bubbles clustered at the grain boundaries of $\mathrm{ZrC}$ irradiated at $900^{\circ} \mathrm{C}$ to $0.75 \mathrm{dpa}$

\subsubsection{Microhardness}

Since a high density of dislocation loops was observed in irradiated $\mathrm{ZrC}$, it is reasonable to study the irradiation hardening. The test, which was evaluated using Vicker's micro-indentation with a $1000 \mathrm{gf}$ load and 15 seconds load time according to the ASTM standard [3.19], is schematically shown in Figure 3.22. Many empirical rules and formulae have been proposed to precisely and reliably measure the mechanical properties of hard thin films. Recalling Figure 3.2, the protonirradiated $\mathrm{ZrC}$ is roughly the equivalent of a thin film of different hardness on top of the unirradiated material unaffected by the proton beam. To eliminate the influence of substrate deformation, the upper limit of indentation depth is proposed to be below about $1 / 5$ of the film thickness [3.20]. The indention depth with $1000 \mathrm{gf}$ load on $\mathrm{ZrC}$ in our study is $\sim 4.5 \mu \mathrm{m}$, which is less than $1 / 5$ of the irradiated zone. 


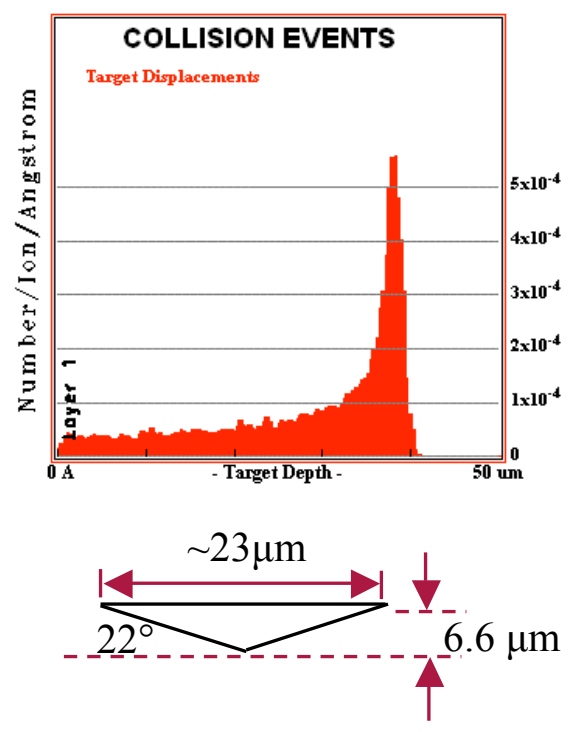

Figure 3.22. (a) schematic of micro-indentation (b) microhardness increment of $\mathrm{ZrC}$

Microhardness test results are summarized in Figure 3.23. For the 600 and $800^{\circ} \mathrm{C}$ irradiation, the microhardess increases with dose, showing the radiation hardening is more pronounced for $600^{\circ} \mathrm{C}$ than $800^{\circ} \mathrm{C}$. For the $900^{\circ} \mathrm{C}$ irradiation, hardening was first observed at $0.35 \mathrm{dpa}$, while for the $0.7 \mathrm{dpa}$ the material became softer, possibly due to the high population of bubble clusters at the grain boundary. The increases in microhardness are $5.8 \%$ for $0.35 \mathrm{dpa}$ and $4.9 \%$ for $0.75 \mathrm{dpa}$ at $900^{\circ} \mathrm{C}$, which are lower than $12.5 \%$ for $0.35 \mathrm{dpa}$ and $14 \%$ for $0.75 \mathrm{dpa}$ at $800^{\circ} \mathrm{C}$. For the $600^{\circ} \mathrm{C}$ irradiation, the increases in hardess are $15.3 \%, 19.4 \%$ and $24.8 \%$ for the doses of 0.35 , 0.75 and $1.75 \mathrm{dpa}$, respectively. Microhardness changes caused by neutron irradiation in $\mathrm{ZrC}$ were measured by Andrievskii et al., for the irradiation dose of $1.5 \times 10^{20} \mathrm{~cm}^{-2}$ at $150^{\circ} \mathrm{C}$ and $1100^{\circ}$ C. In that work, the increments of hardness in $\mathrm{ZrC}$ were $12 \%$ and $7 \%$, respectively [3.8].

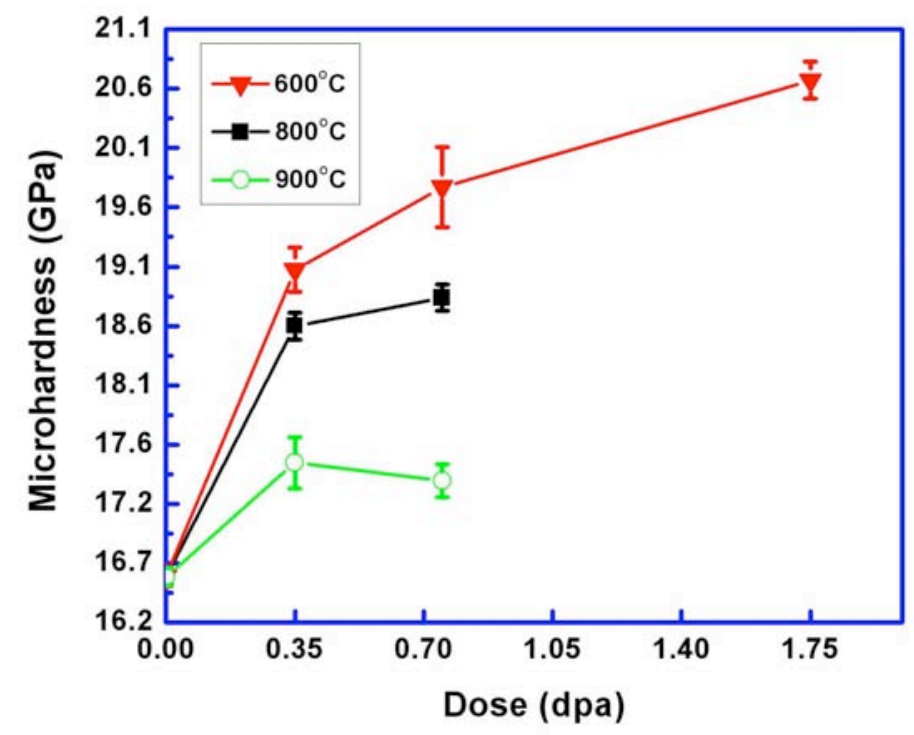

Figure 3.23. Microhardness changes in irradiated $\mathrm{ZrC}$ 


\subsubsection{Fracture toughness}

The change in fracture toughness as a function of irradiation is a critical data need for advanced fuel forms, but with the exception of graphite and very limited information on alumina, magnesium aluminate spinel and silicon carbide, there is little information on the effect of irradiation on the fracture toughness of ceramics. Due to the irradiation volume limits of proton irradiation, the fracture toughness of $\mathrm{ZrC}$ can not be measured using a conventional pre-cracked beam method; instead, it is estimated by measuring the length of cracks produced by hardness indents. For this measurement, Vickers micro-indentation is specifically considered because it uses a sharp indenter that produces well-defined cracks.

The cracks produced by micro-indentation can be divided into two classes, classic median/radial "half-penny" cracks and "Palmqvist" cracks, as schematically shown in Figure 3.24. The primary difference between half-penny and Palmqvist crack systems exists in the sub-surface cracking of the material. In the half-penny system, cracks emanate from the indentation tips laterally and radially; lateral cracks travel along the surface, while the radial cracks protrude from the indention in a starburst within a radius below the surface of the material. In the Palmqvist crack system, cracks only travel laterally. Notice the variables $c, l$, and $a$ in Figure 3.24; the variable $a$ indicates half the length of the diagonal of the indent, $l$ indicates the length of a crack from the tip of the indent to its termination in the material, and the variable $c$ is the sum of $a$ and $l$. Based on the criterion established in our previous study [3.21], a $c / a$ value greater than or equal to 2 indicates a half-penny crack system. For lower $c / a$ values, a Palmqvist crack system is assumed. Based on the $\mathrm{c} / \mathrm{a}$ value emanating from indents for $\mathrm{ZrC}$, a half-penny crack system was assumed and corresponding estimates of the change of fracture toughness were performed, as shown in Figure 3.25.

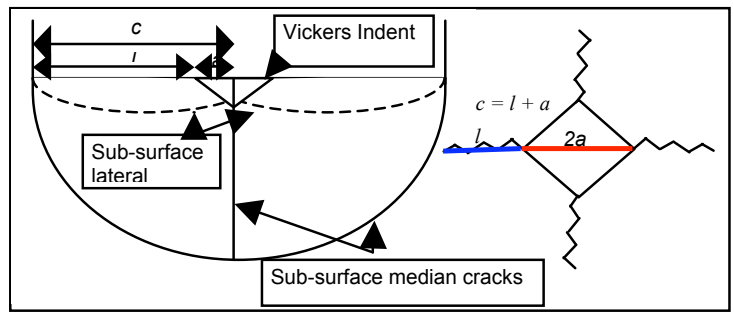

(a)

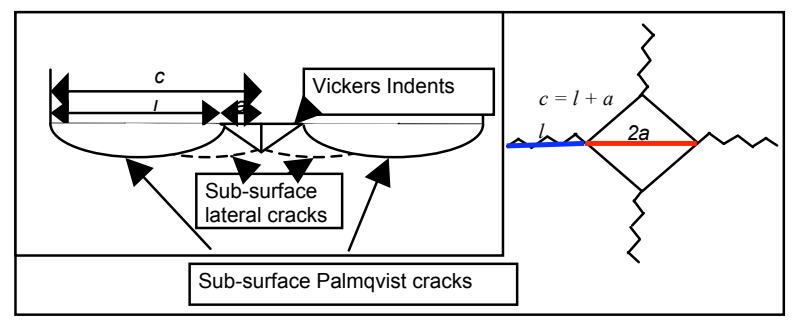

(b)

Figure 3.24. (a) half-penny cracking system and (b) Palmqvist cracking system

After determining $a, l, c$ and the crack system, the relative fracture toughness was calculated according to Equation 3-1, which is valid for a half-penny crack system.

$$
\frac{K_{I C}}{K_{I C o}}=\frac{c_{o}^{\frac{3}{2}}}{c^{\frac{3}{2}}}=\frac{\left(a_{o}+l_{a}\right)^{\frac{3}{2}}}{(a+l)^{\frac{3}{2}}}
$$

where the subscript " $o$ " denotes the annealed samples.

Values of the relative fracture toughness are plotted in Figure 3.26, based on more than 20 measurements for each condition. The greatest change in fracture toughness, an increase of about $79 \%$, was observed in $\mathrm{ZrC}$ irradiated to a dose of $1.5 \mathrm{dpa}$, however there is a large degree of inherent uncertainty in the measurement of indentation fracture toughness, which can result in 
large measurement errors. [3.22]. As explained by Clinard [3.23], the most appropriate irradiation toughening mechanism for ceramics is that involving the coherency strain field generated from a high density of FLs. A propagating crack would likely be deflected by the strain fields, resulting in crack impedance and consequent toughening.

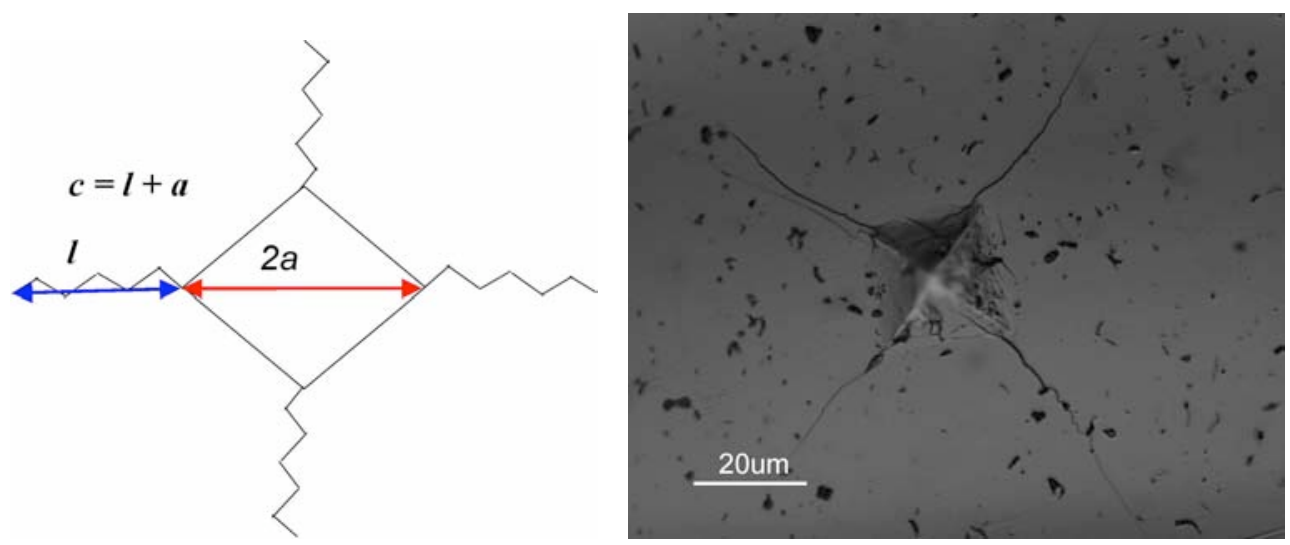

Figure 3.25. Crack system developed in $\mathrm{ZrC}$, with Vicker indentation

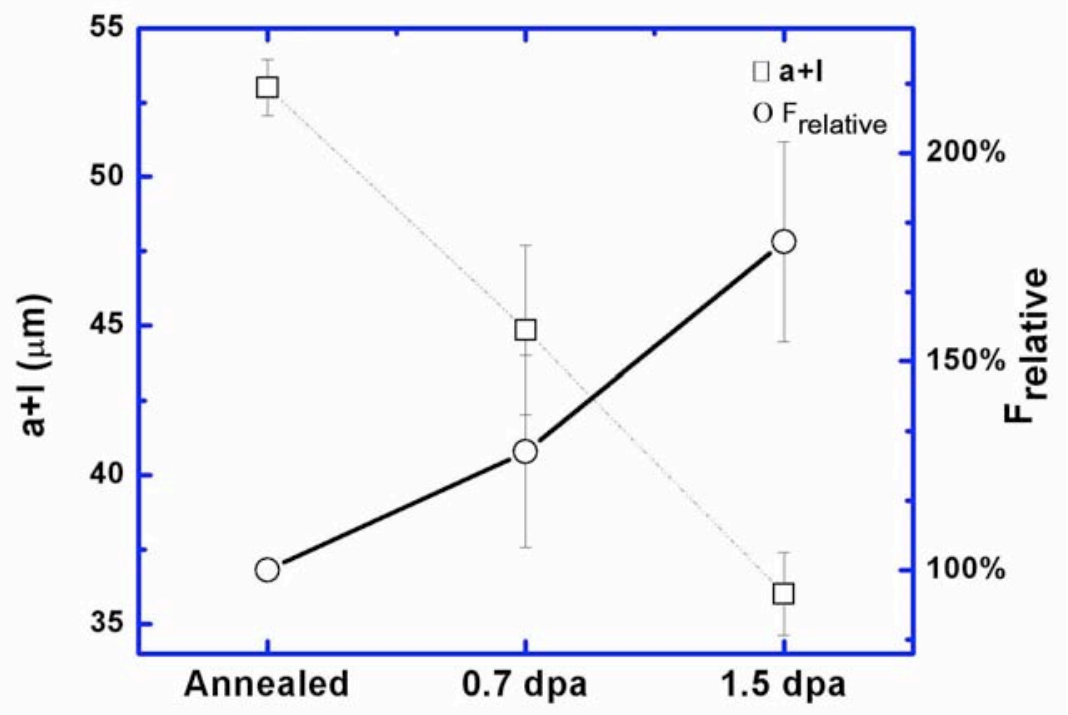

Figure 3.26. Fracture toughness changes for $\mathrm{ZrC}$ with different irradiation doses

\subsubsection{Nanoindentation}

Nanoindentation, also known as instrumented indentation or depth sensing indentation, is a method for testing the mechanical behavior of a material. In this technique, an indenter of welldefined geometry is used to make a small impression on the material's surface. After the indenter is brought into contact with a material's surface, a known load is applied to the indenter. The applied load and depth of penetration into the material are recorded throughout the experiment. 
The test method can provide information on mechanical properties such as hardness, Young's modulus, creep behavior, viscoelasticity, fracture toughness, and work hardening. Because the indenter can be made very sharp, with some indenters having a radius of curvature less than 100 $\mathrm{nm}$ at their tip, nanoindentation can be used to test the mechanical properties of a small volume of material [3.24]. The Hysitron Triboscope nanoindenter instrument used in this study was designed to be interfaced with a Digital Instruments atomic force microscope(AFM). The nanoindenter tip was substituted for the standard cantilever tip. This allows not only the mapping of topographical features, but also the precise location of nanoscale features of interest for testing.

Instead of calculating the area of indentation from the depth, $h$, each indentation was imaged directly using SEM and the area measured using software. According to Stone's work, a continuous indentation technique was used to measure hardness and the Young's modulus simultaneously [3.25]. The loading curve and load-depth are shown in Figure 3.27, where it can be seen that for each indentation four values of unload stiffness with different loads can be obtained. Joslin and Oliver noted that the maximum load, $L$, divided by the square of unloading stiffness, $S$, is a quantity related to the hardness and elastic modulus [3.25], and is introduced as:

$$
J_{0}=\frac{L}{S^{2}}=L C^{2}=\frac{H}{E_{e f f}^{2}}
$$

where $H$ is the hardness, $C$ is the compliance and $E_{\text {eff }}$ is the effective Young's modulus incorporating the modulus of indenter.
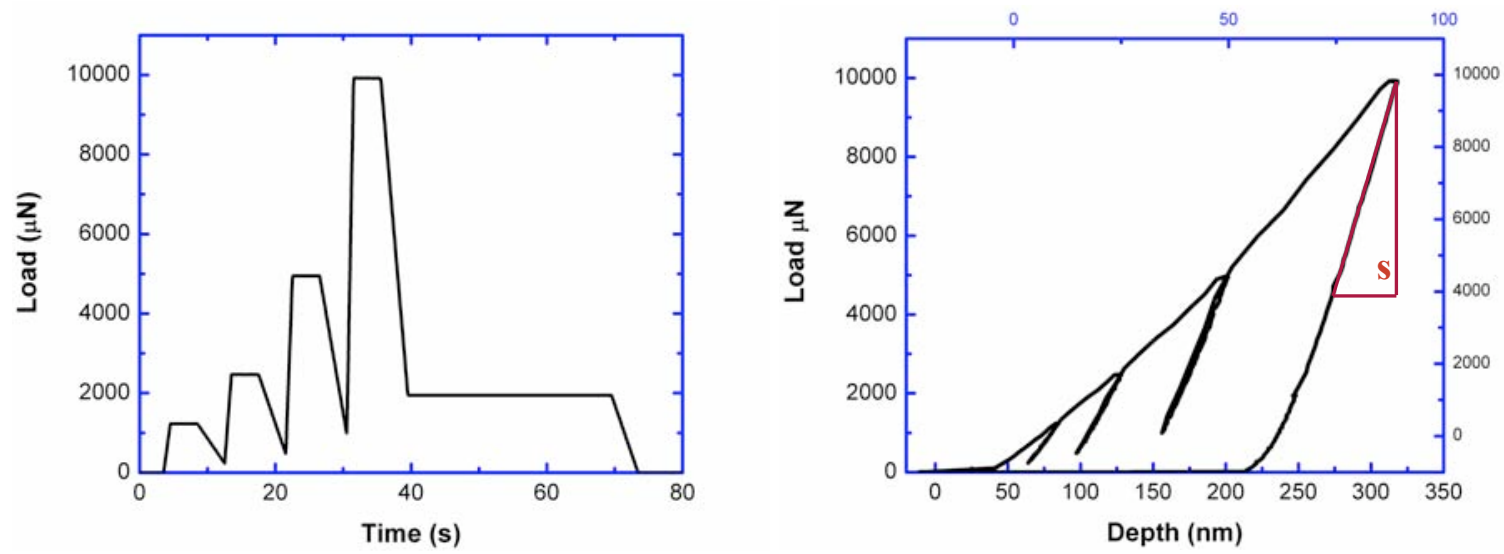

Figure 3.27. Loading cures and the illustration of indentation load-depth

Compliance $\mathrm{C}$ can be express as:

$$
C=C_{o}+C_{m}
$$

Where $C_{0}$ denotes the material's compliance and $C_{m}$ denotes the equipment's compliance.

Multiply Equation (3-3) with $L^{1 / 2}$ :

$$
L^{1 / 2} C=L^{1 / 2}\left(C_{o}+C_{m}\right)
$$

With the definition of $J_{0}$ in Equation (3-2), this becomes 


$$
L^{1 / 2} C=J_{0}+L^{1 / 2} C_{m}
$$

Provided that $H$ and $E_{\text {eff }}$ are independent of $L$, Equation 3-5 can be used to evaluate the equipment compliance $C_{m}$, and the value of $J_{0}$ can be obtained from the intercept of the linear regression between $L^{1 / 2} C$ and $L^{1 / 2}$. As shown in Figure 3.27, for each indentation there are four loads, $L$, and associated unload compliance, $C$.

In order to profile the hardness along the irradiation depth, a cross-section sample was prepared. First, a thin layer of $\sim 10-15 \mu \mathrm{m}$ was removed from the irradiated surface to eliminate the surface effect, and the sample was sandwiched with two pieces of silicon using G-bond glue. After curing, a cross-sectioned sample was sliced from the sandwiched sample using a low speed diamond saw, and the two sides were polished to $1 / 4 \mu \mathrm{m}$ surface finish. The cube corner indenter was used for the nanoindentation, since it has a smaller included half angle compared with the Berkovich indenter, and it is easier to generate cracks at the corner of indentation for fracture toughness evaluation. However, it was found that with this indenter, the maximum load 10,000 $\mu \mathrm{N}$ is not enough to produce cracks during indentation. In total, 29 indentations were conducted from the edge of the irradiated side into the bulk, as shown in Figure 3.28. According to the SRIM-2008 calculation, these indentations were positioned in both the irradiated and unirradiated zone.

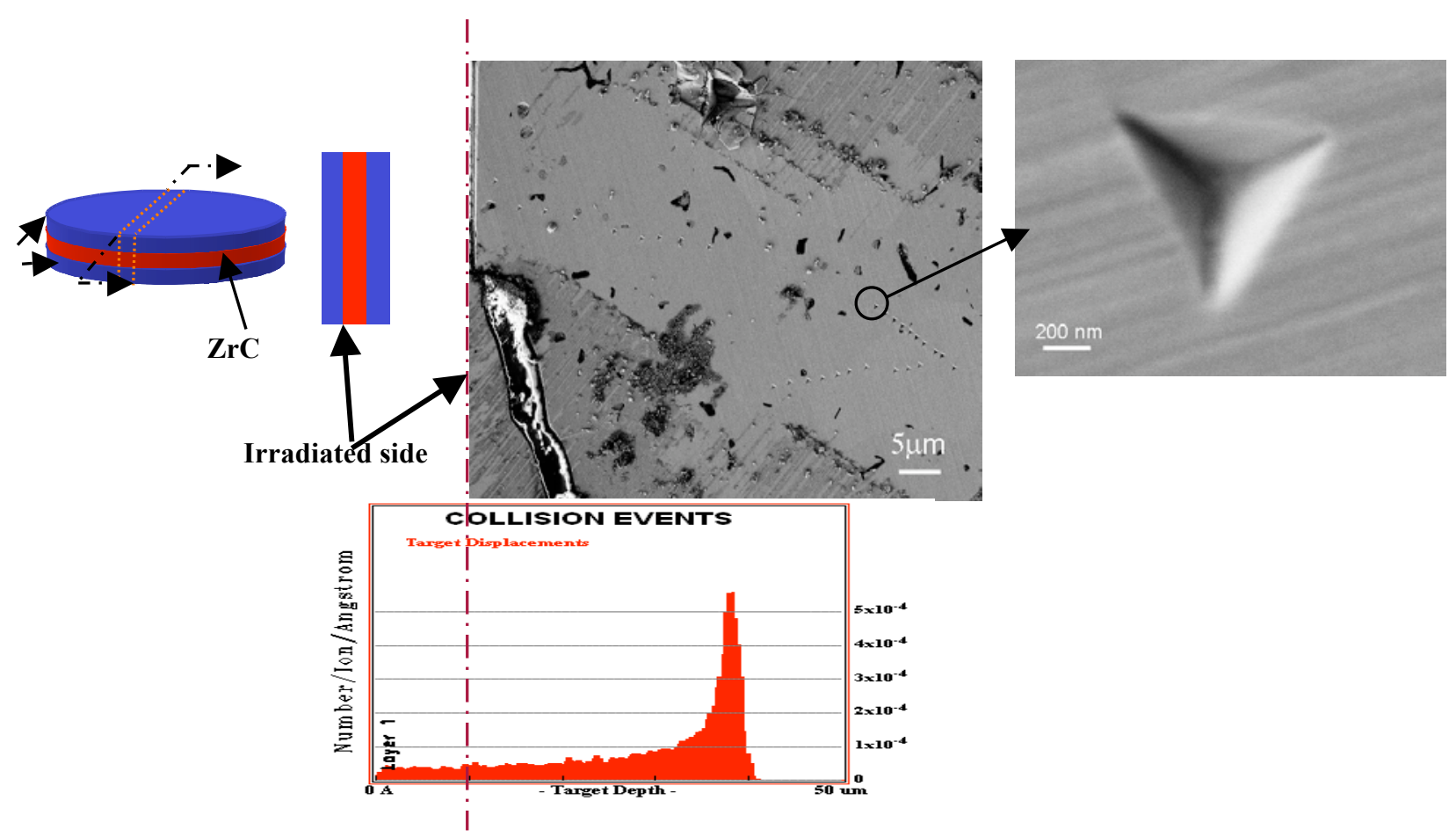

Figure 3.28. Sample preparation and indentations on the cross-sectioned $\mathrm{ZrC}$ sample

One script was programmed using Matlab ${ }^{\circledR}$ for data processing. For each indentation, one linear regression was performed, and the intercept $\left(J_{0}\right)$, and slope (equipment compliance, $C_{m}$ ) were obtained. From the regression lines plotted in Figure 3.29, it can be seen that only one indentation is exceptional and was discarded during later calculation. 


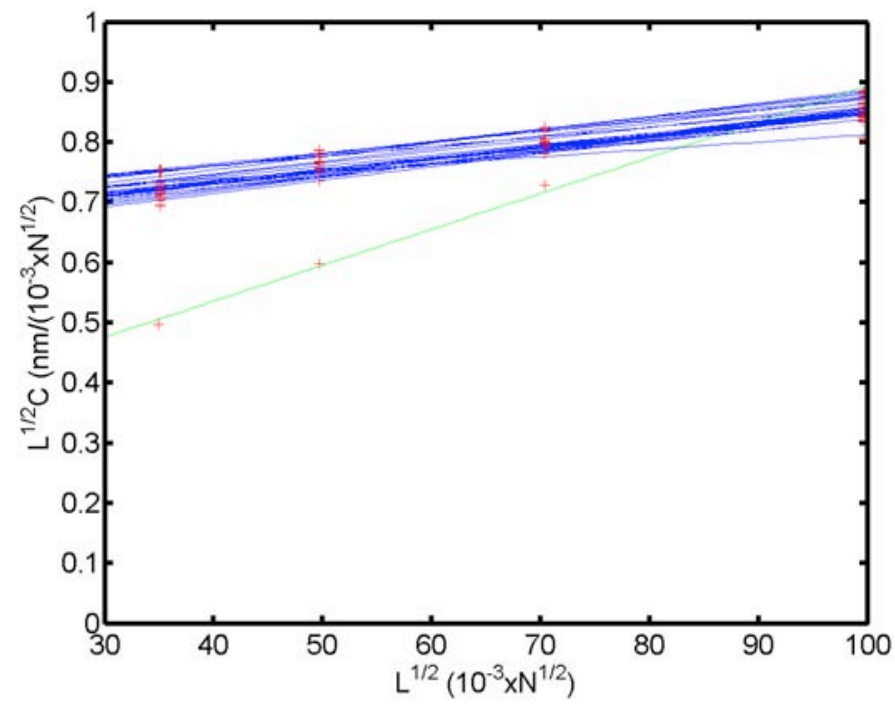

Figure 3.29. Linear regressions of $L^{1 / 2} C$ and $L^{1 / 2}$

The hardness for each indentation was calculated with associated load, $L$, and measured indentation area, $A$, and the effective Young's modulus was determined from Equation 3-2. As shown in Figure 3.30, these values are plotted versus distance from the edge of the irradiation surface side. The increment of hardness is clearly demonstrated, corresponding well with the irradiation damage profile calculated from SRIM-2008, however, the same trend was not observed for the effective Young's modulus. 


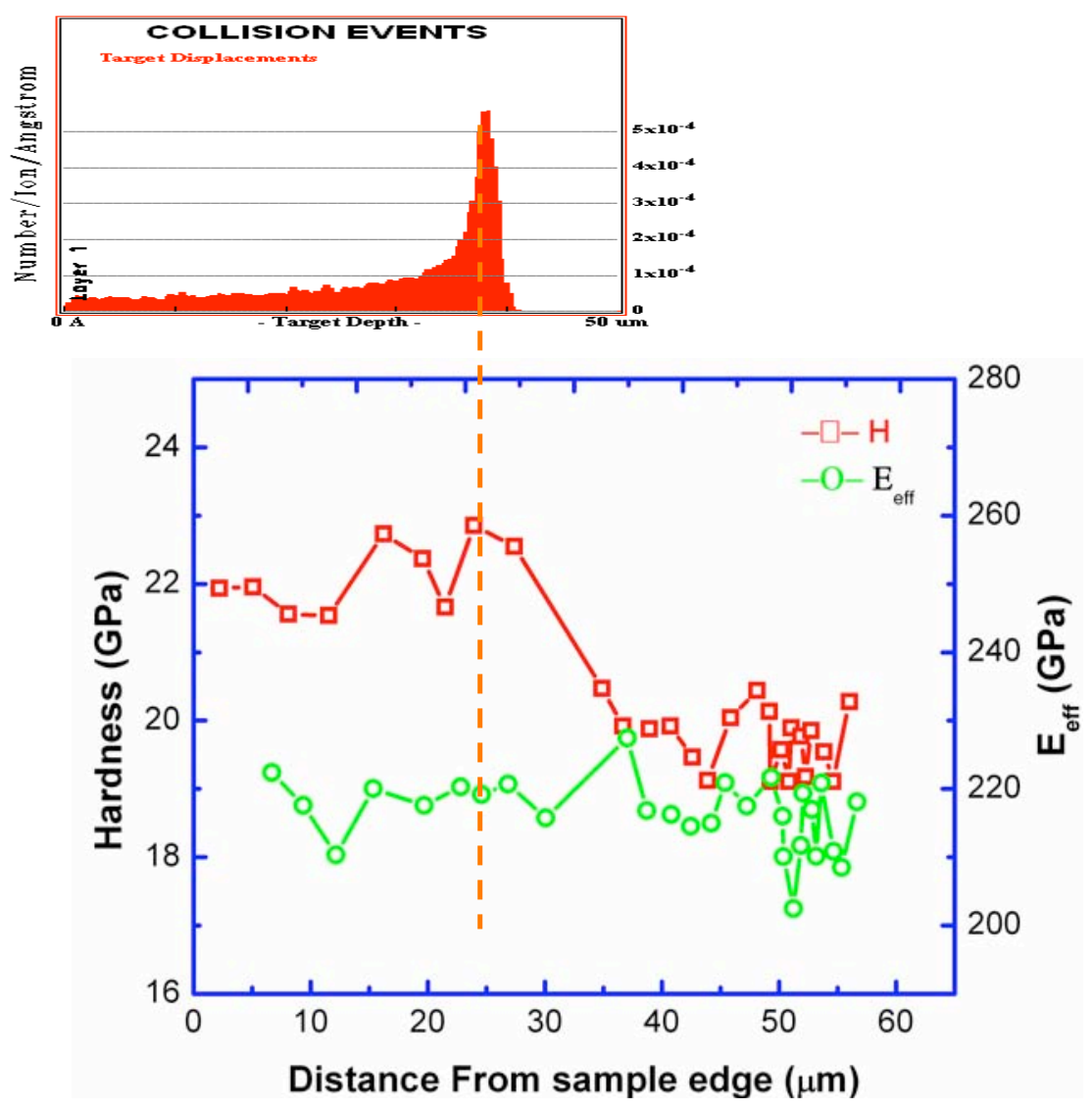

Figure 3.30. Hardness and effective Young's modulus along the irradiation depth

\subsection{Discussion}

For the $\mathrm{Kr}$-ion-irradiated (70 dpa) $\mathrm{ZrC}$, about 7\% lattice expansion was reported [3.11]. For the fast-neutron-irradiated samples examined by Keilholtz et al., the X-ray patterns were obscured and the data scattered too much to draw conclusions concerning whether there was an increase or decrease in lattice spacing with increasing neutron dose, even though a 2 to $3 \%$ volume change was observed for $\mathrm{ZrC}$ samples irradiated at 3 to $8 \mathrm{dpa}$ at temperatures of 300 to $700^{\circ} \mathrm{C}$. Less than $50 \%$ of the crystal expansion was postulated to be from lattice parameter change [3.10]. For the $\mathrm{ZrC}$ irradiated with thermal neutrons at $50^{\circ} \mathrm{C}$, the increase in lattice parameter reached $0.32 \%$ at a dose of $1.5 \times 10^{20} \mathrm{~cm}^{-2}$ [3.9], while for samples irradiated at $150{ }^{\circ} \mathrm{C}$ and $1100^{\circ} \mathrm{C}$ with a neutron dose of $1.5 \times 10^{20} \mathrm{~cm}^{-2}(\mathrm{E} \geq 1 \mathrm{MeV})$, the lattice expansions were $0.46 \%$ and $0.12 \%$, respectively [3.8]. Generally, the lattice expansions in our study are in good agreement with results from other neutron irradiation.

The average size and density of dislocation loops in $\mathrm{ZrC}$ irradiated at various conditions are summarized in Table 3-2. It can be seen that for the same dose level, the lower temperature irradiation induces a higher density of dislocation loops, while the mean size of dislocation loops is smaller. Therefore, for our future work on irradiations at $1100^{\circ} \mathrm{C}$ and higher, a higher dose may be required to observe the dislocation loops or networks of dislocation lines. 
Table 3.2. Average size and density of dislocation loops in the irradiated $\mathrm{ZrC}$

\begin{tabular}{cccc}
\hline Temp $\left({ }^{\circ} \mathrm{C}\right)$ & $\begin{array}{c}\text { Dose } \\
(\mathrm{dpa})\end{array}$ & $\begin{array}{c}\text { Density } \\
\left(\mathrm{x} 10^{23} \mathrm{~m}^{-3}\right)\end{array}$ & $\begin{array}{c}\text { Mean } \\
\text { size }(\mathrm{nm})\end{array}$ \\
\hline 600 & 0.35 & $2.7 \pm 0.05$ & $<1$ \\
\hline & 0.7 & $3.5 \pm 0.06$ & $3.5 \pm 0.6$ \\
\hline & 1.5 & $5.7 \pm 0.04$ & $3.97 \pm 0.3$ \\
\hline 800 & 0.35 & $0.22 \pm 0.04$ & $4.3 \pm 0.5$ \\
\hline & 0.7 & $3.37 \pm 0.12$ & $5.8 \pm 0.56$ \\
\hline 900 & 0.35 & $\mathrm{na}$ & $\mathrm{Na}$ \\
\hline & 0.7 & $0.24 \pm 0.03$ & $10.6 \pm 0.4$ \\
\hline
\end{tabular}

The irradiation hardening in ceramics is mainly attributed to the formation of point defects. Strain fields around point defects can interact with dislocations during deformation and act as a pinning center, and point defects can play an important role in dynamic processes such as crack propagation. Hardening due to irradiation has been studied in $\mathrm{Al}_{2} \mathrm{O}_{3}, \mathrm{MgO} \cdot 3 \mathrm{Al}_{2} \mathrm{O}_{3}, \mathrm{MgAl}_{2} \mathrm{O}_{4}$, AlN and $\mathrm{SiC}$ using the indentation method, and the mechanism of hardening has been clarified, particularly in spinel. As an example, when AlN was neutron irradiated by Iseki at $470^{\circ} \mathrm{C}$ to a fluence of $2.4 \times 10^{24} \mathrm{~m}^{-2}$, a large number of small dislocation loops were observed and the microhardness increased by $\sim 51 \%$. After annealing at a temperature of $1400^{\circ} \mathrm{C}$, the microstructure still contained a large number of small dislocation loops, but the hardness recovery was almost complete, as was the swelling recovery caused by point defects. Therefore, it was concluded that point defects and small defect clusters cause the hardening, while relatively large dislocation loops may play little role in the hardening [3.23]. Further annealing experiments with irradiated $\mathrm{ZrC}$ are planned for microstructure and hardening studies.

\subsection{Conclusions}

The radiation stability of $\mathrm{ZrC}$ was studied using $2.6 \mathrm{MeV}$ protons at 600,800 and $900^{\circ} \mathrm{C}$. The radiation response of $\mathrm{ZrC}$ exhibits metallic-like behavior consistent with its metallically electrical, magnetic, and optical properties. The microstructure of proton-irradiated $\mathrm{ZrC}$ is primarily comprised of a high density of nanometer-sized dislocation loops while no irradiationinduced amorphization or voids are observed in the grains. The average loop size increases with dose, while the density of dislocation loops decreases with irradiation temperature. Lattice expansions were observed for 600 and $800^{\circ} \mathrm{C}$ irradiation and the value of measured lattice expansion is in good agreement with the reported results from neutron irradiation studies. An $\sim 0.99 \%$ volume increase was identified for the irradiation of $1.75 \mathrm{dpa}$ at $600^{\circ} \mathrm{C}$. For $900^{\circ} \mathrm{C}$ irradiation, the microstrutural evolution deviates from those of irradiations at lower temperatures; slight lattice contractions were observed and a high population of grain boundaries were found to be decorated with nano-sized bubble clusters. Regarding the mechanical property changes, increases were found for all three irradiation temperatures, but as temperature increases, the hardening effect becomes less pronounced, and the hardening behavior is likely related to a high concentration of point defects. Nanoindentation measurements on $800^{\circ} \mathrm{C}$ irradiated samples show similar radiation hardening effects, while the Young's modulus is not changed by these nanosized defects. 


\section{References}

3.1. F. Charollais, S. Fonquernie, C. Perrais, M. Perez, O. Dugne, F. Cellier, G. Harbonnier, and M. Vitali, "CEA and Areva R\&D on HTR fuel fabrication and presentation of the CAPRI experimental manufacturing line”, Nuclear Engineering and Design, 236, 534542 (2006)

3.2. R. M. Versluis, F. Venneri, D. Petti, L. Snead and D. McEachern, "Project deep-burn: development of Transuranic fuel for high-temperature helium-cooled reactors", Proc. of the $4^{\text {th }}$ International Topic Meeting on High Temperature Reactor Technology, ASME, Washington, USA (2008)

3.3. L. W.Hobbs, F. W. Clinard, Jr., S. J. Zinkle and R. C.Ewing, "Radiation effects in ceramics", J. Nucl. Mater., 216, 291-321 (1994)

3.4. K. Minato, T. Ogawa, K. Fukuda, H. Sekino, I. Kitagawa and N. Mita, "Fission product release from $\mathrm{ZrC}$-coated fuel particles during post-irradiation heating at 1800 and 2000 ${ }^{\circ}$ C ", J. Nucl. Mater. 249, 142-149 (1997)

3.5. T. Ogawa, K. Fukuda, S. Kashimura, T. Tobita, F. Kobayashi, S. Kaod, H. Miyanishi, I. Takahashi and T. Kikuchi, " Performance of ZrC-Coated particle fuel in irradiation and postirradiation heating tests", J. Am. Ceram. Soc. 75, 2985-2990 (1992)

3.6. K. Minato and T. Ogawa, "Research development of ZrC-Coated particle fuel", Global 2003, 1068-1074, ANS, New Orleans, USA (2003)

3.7. M. S. Kovalchenko and Yu. I. Rogovoi, "Effects of neutron irradiation on the structure and properties of zirconium carbide", Neorg. Mater., 9, 321-322 (1973)

3.8. R. A. Andrievskii, K. P. Vlasov, A. S. Shevchenko, A. G. Lantin, S. A. Pritchin, V. V. Klyushin, S. P. Krushin, and A. S. Maskaev, "Infuence of reactor irradiation on the physicomechanical properties”, Neorg. Mater. 14, 680-683 (1978)

3.9. P. Patriarca, D. J. Rucker, Fuel and Materials Development Program Quarterly Progress Report for Period Ending September 30, 1969, ORNL-4480 (1970)

3.10. G. W. Keilholtz, R. E. Moore and M. F. Osborne, "Fast-neutron effects on the carbides of titanium, zirconium, tantalum, niobium and tungsten”, Nucl. Application, 4, 330-336 (1968)

3.11. J. Gan, M. K. Meyer, R. C. Birtcher and T. R. Allen, " Microstructure evolution in ZrC irradiated with $\mathrm{Kr}$ ions", J. ASTM Intl., 3, 1-7 (2006)

3.12. D. Gosset, M. Dollé, D. Simeone, G. Baldinozzi and L. Thomé, " Structural evolution of zirconium carbide under ion irradiation”, J. Nucl. Mater., 373, 123-129 (2008)

3.13. L. I. Gomozov, I. Sh. Akhmedzyanov, "Thermoelectric properties of ZrC, UC-ZrC, and UC-UN at 285-450K", Soviet Atomic Energy, 48, 413-415 (1980)

3.14. Loo F. J. J. Van, W. Wakelkamp, G. F. Bastin and R. Metselaar, "Diffusion of carbon in $\mathrm{TiC}_{1-\mathrm{y}}$ and $\mathrm{ZrC}_{1-\mathrm{y}}$ ", Pro. of the $11^{\text {th }}$ International Symp. of reactivity of solids, Solid State Ionics, Diffusion \& Reactions, 32-33, 824-832, Princeton, USA (1989)

3.15. R. A. Andrievskii, V. I. Savin, V. Ya Markin, V. T. Spravtsev and V. S. Shevshenko," Effect of reactor irradiation on the electrical and magnetic properties of interstitial phases", Inorg. Mater., 14, 526-529 (1978)

3.16. L. Lunéville, D. Simeone, and C. Jouanne, “ Calculation of radiation damage induced by neutrons in compoundd materials", J. Nucl. Mater., 353, 89-100 (2006)

3.17. S. J. Zinkle, 15th Intl. Symp. on effects of radiation on mater., ASTM STP, n 1125 (1992) 749-763

3.18. Spence, J.C.H. and Zuo, J.M., Electron Microdiffraction, Plenum Press, New York and 
London, 1992

3.19. ASTM standard: C 1327-03, Standard Test Method for Vickers Indentation Hardness of Advanced Ceramics

3.20. J. E. Sundgren and H. T. G. Hentzell, "A review of the present state of art in hard coatings grown from the vapor phase", J. Vac. Sci. Technol. A, 4, 2259-2279 (1986)

3.21. INL/EXT-06-11749, "Evaluation of Alternate Materials for Coated Particle Fuels for the Gas-cooled Faster Reactor", Report, September, 2006

3.22. G. D. Quinn, J. Am. Ceram. Soc. 90 (2007) 673-680

3.23. F. W. Clinard, F.W., Jr., G. F. Hurley, R. A. Youngman, and L. W. Hobbs, L.W., J. Nucl. Mater. 133\&134 (1985) 701-704

3.24. Gordon, A. Shaw , PhD thesis, University of Wisconsin-Madison, 2004

3.25. Stone, D.S., Yoder, K.B., Sproul, W.D., J.Vac.Sci. Technol. A, 1981, v 9 (4), pp.25432547 


\section{4. $\mathrm{ZrN}$}

\subsection{Introduction}

Interest in nitride-based fuels has arisen within the AFCI of the U.S. Department of Energy (DOE) [4.1], and several authors proposed zirconium nitride as one of the most promising inert matrix materials based on superior thermal and neutronic characteristics [4.2-4.5]. In addition, the compatibility of $\mathrm{ZrN}$ with sodium and its solubility in nitric acid have also been tested and confirmed [4.4]. ZrN-based inert matrix fuels could potentially enhance proliferation resistance of next generation reactors and reduce the environmental impact of nuclear energy production via transmutation of transuranic fission products. $\mathrm{ZrN}$ has also been proposed as a surrogate material for development, testing and characterization of transuranic fuel, since it has an isostructure with many actinide mononitrides [4.6].

However, very little information concerning radiation tolerance of $\mathrm{ZrN}$ is available. Most of the reported research has used ion irradiations, such as $\mathrm{He}, \mathrm{Xe}$, and $\mathrm{Kr}$ ion bombardment at various temperatures $[4.7,4.8]$. Neutron irradiation was performed at moderate neutron fluence, but only the electrical resistivity was evaluated [4.9]. Like many transition-metal carbides and nitrides, stoichiometric $\mathrm{ZrN}$ has a $\mathrm{B} 1(\mathrm{NaCl})$ structure, consisting of two intercalated face-centered subnetworks. A strong covalent $\mathrm{Zr}-\mathrm{N}$ bonding confers the refractory properties, while the variability in physical properties is reportedly due to the various stoichiometries, which can affect the electronic structure, intrinsic vacancy concentrations, and potentially the radiation damage structures $[4.10,4.11]$. The chapter will provide some fundamental insight into the radiation response of $\mathrm{ZrN}$ under a proton beam. The microstructural evolutions at different fluences and temperatures were analyzed and the microhardness changes were also evaluated.

\subsection{Proton irradiation}

The damage profile, calculated using SRIM-2008 with a threshold displacement energy $\left(E_{d}\right)$ of $35 \mathrm{eV}$ for zirconium and $25 \mathrm{eV}$ for nitrogen, is shown in Figure 4.1. The values of $E_{d}$ are based on the estimation of $\mathrm{ZrC}$; though the true values of $E_{d}$ for $\mathrm{Zr}$ and $\mathrm{N}$ are not available, it is reasonable to assume that the value of $E_{d}$ for $\mathrm{N}$ is nearly the same as that of $\mathrm{C}$, and to assume that $E_{d}$ for $\mathrm{Zr}$ atoms is $20-40 \mathrm{eV}$, which is typical for many metal atoms. The depth of greatest interest is the "flat" region, 10-25 $\mu \mathrm{m}$ before the peak, where the damage, as measured in dpa, was calculated. Two irradiation doses of 0.35 and $0.75 \mathrm{dpa}$ were performed on the samples at temperatures of 800 and $900^{\circ} \mathrm{C}$, while three doses of $0.35,0.75$ and 1.75 dpa were achieved for $600{ }^{\circ} \mathrm{C}$. 


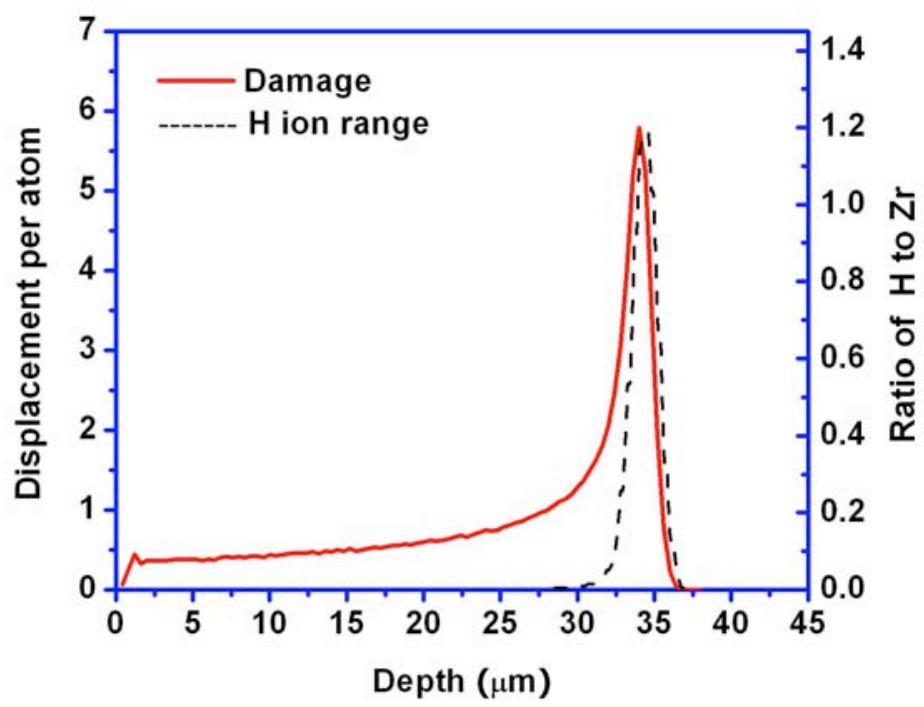

Figure 4.1. Damage profile estimated with SRIM-2008 in $\mathrm{ZrN}$ and concentration of implanted $\mathrm{H}$ (broken line), irradiated with $1 \times 10^{19} / \mathrm{cm}^{2} 2.6 \mathrm{MeV}$ protons

For comparison, the as-received $\mathrm{ZrN}$ samples were also vacuum annealed at $800^{\circ} \mathrm{C}$ for 20 hours, which corresponds to the time needed to accumulate $0.75 \mathrm{dpa}$ at our irradiation conditions, and the related microstructure was fully characterized using SEM, TEM, and XRD. For the irradiated samples, a thin layer of $\sim 10 \mu \mathrm{m}$ was removed from the irradiated surface to eliminate the free surface effects from subsequent microstructural and mechanical property studies. Plan-view and cross-section TEM samples were prepared using wedge polishing followed by low angle ion milling, and for the plan-view specimen, the electron transparent area was controlled to be at around $20 \mu \mathrm{m}$ below the irradiated surface. TEM characterization was conducted using a Philips CM200UT TEM, and the possible radiation-induced segregation along grain boundaries or dislocation loops was examined using EDS with a spot size diameter of $6 \mathrm{~nm}$. To study the lattice expansion caused by proton irradiation, XRD was conducted using a STOE X-ray powder diffractometer. The hardening from proton irradiation was evaluated using a Knoop microindenter with a load of $50 \mathrm{gf}$ and $15 \mathrm{~s}$ load time. Sample surfaces were diamond lapped to $1 \mu \mathrm{m}$ and finished with an $\sim 0.04 \mu \mathrm{m}$ silica final polish. The indentation penetration is $\sim 2.5 \mu \mathrm{m}$, which is nearly one tenth of the irradiated depth; the shallow impression effectively eliminates the influence of underlying damage peaks and unirradiated matrix materials and complies with the ASTM standard [4.12].

\subsection{Results}

\subsubsection{Microstructures}

\subsubsection{Annealed}

The SEM image in Figure 4.2 shows the grain structure of the annealed $\mathrm{ZrN}$. The material has a relative high porosity, especially at triple grain boundary junctions. A second phase was identified, indicated with arrows in Figure 4.2. It contains $\sim 57$ atomic percent of oxygen with the balance of zirconium, and is identified as $\mathrm{Zr}_{\mathrm{x}} \mathrm{O}_{\mathrm{y}}$ using EDS. 
The TEM microstructure of annealed $\mathrm{ZrN}$ is shown in Figure 4.3. In general, the material is nearly free of dislocation lines or networks, but some dislocation lines can be found in the vicinity of submicron-sized precipitates, as shown in Figure 4.3 (c). Significant numbers of heavily-twinned oxides were observed at the triple grain boundary junctions, as shown in Figure 4.3 (b), which was consistent with the mix of monoclinic, tetragonal and cubic phases found in $\mathrm{ZrN}$ by Egeland using glancing angle XRD [4.7]. Additionally, clusters of faceted voids were observed in some grains, and HRTEM revealed a thin layer of an amorphous $\mathrm{Si}_{\mathrm{x}} \mathrm{O}_{\mathrm{y}}$ at the edge of the voids. The diamond-shaped voids were also found by Wheeler et al. in $\mathrm{ZrN}$ annealed at $1400^{\circ} \mathrm{C}$ in a $\mathrm{N}_{2}-6 \% \mathrm{H}_{2}$ environment. Although the formation mechanism of these voids hasn't been positively determined, the sintering and annealing conditions definitely can affect the microstructure and mechanical properties [4.6].

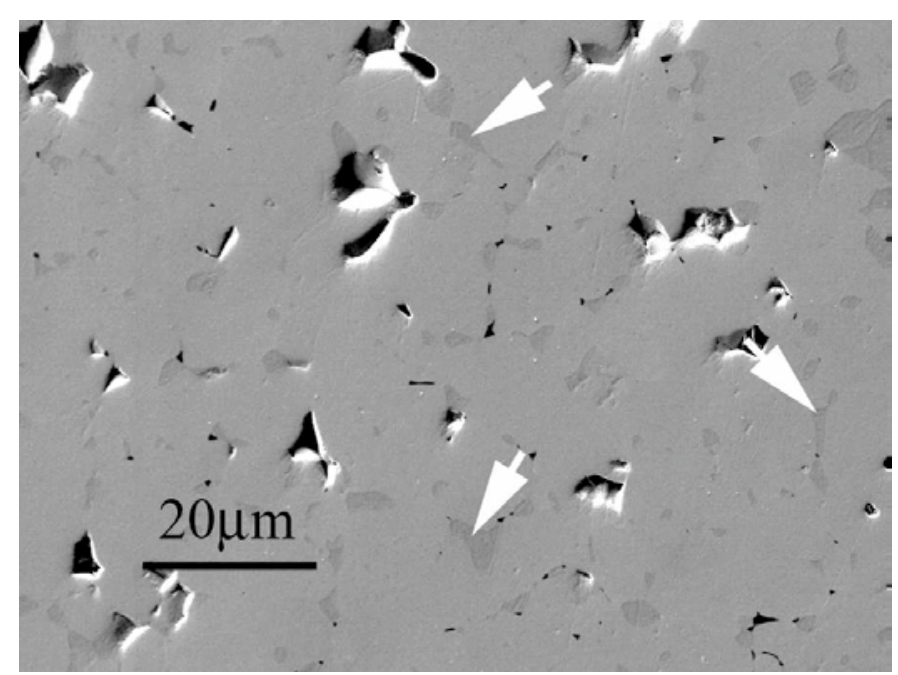

Figure 4.2. SEM image of annealed $\mathrm{ZrN}$, the second phase is identified as $\mathrm{Zr}_{\mathrm{x}} \mathrm{O}_{\mathrm{y}}$ 

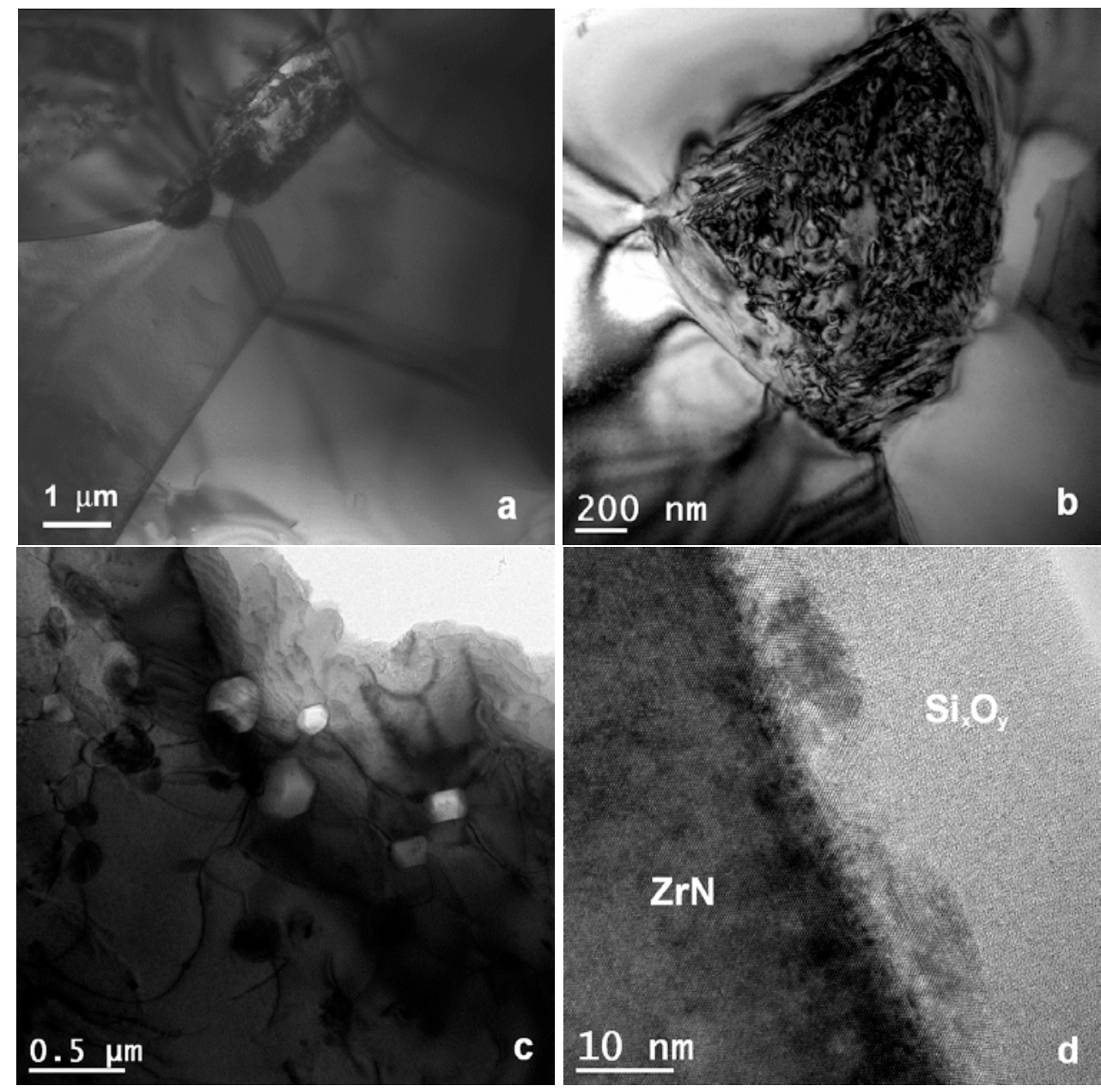

Figure 4.3. a) General view of the microstructure of $\mathrm{ZrN}$; b) Heavily-twinned $\mathrm{Zr}_{\mathrm{x}} \mathrm{O}_{\mathrm{y}}$ phase at triple boundary junction; c) Faceted voids and submicron-sized precipitates of $\mathrm{Zr}_{\mathrm{x}} \mathrm{O}_{\mathrm{y}}$ observed in some grains; d) HRTEM shows amorphous $\mathrm{Si}_{\mathrm{x}} \mathrm{O}_{\mathrm{y}}$ at the edge of voids

\subsubsection{Irradiated at $800^{\circ} \mathrm{C}$}

The irradiated microstructures were characterized using BF, WBDF, and high resolution TEM at or near the zone axis [011]. For comparison, the microstructure of the annealed material is also shown in Figure 4.4. No radiation-induced nano-sized voids or bubbles were observed for dose levels of 0.35 or $0.75 \mathrm{dpa}$ using the through-focus technique, and no amorphization was observed.

From Figure 4.4 (b, c, d and e), it can be noted that the irradiated microstructures are dominated by nano-sized black spots and streaks. Compared with the 0.35 dpa irradiation, a dose of 0.75 dpa produced a higher density of defects, but the sizes of defects are still in a similar range. Although the Moire fringes associated with the defects can already be observed in the $0.35 \mathrm{dpa}$ irradiated sample, they became more pronounced in the microstructures irradiated with 0.75 dpa. The same feature was also observed in Kr-irradiated samples and it was postulated they resulted 
from the overlap of $\mathrm{ZrO}_{2}$ films formed during irradiation [4.8]. However, EDS could not detect oxygen concentrations in the Moire fringes spot regions, and the final conclusion needs to be further investigated with $\mathrm{Z}$ contrast imaging and EELS technologies.

Figure 4.5 shows the irradiated microstructure is very different from that previously studied in proton-irradiated $\mathrm{ZrC}$. The diffraction pattern of the irradiated $\mathrm{ZrN}$ at a 2-beam condition with $g=31 \overline{1}$ near the [011] zone axis doesn't reveal any Rel-rod streaks, which are often used to image the faulted dislocation loops lying on the four $\{111\}$ planes in the materials with a fcc structure $[4.13,4.14]$. Therefore, for the irradiated $\mathrm{ZrN}$, there are much lower densities of faulted dislocation loops than in $\mathrm{ZrC}$. The differences may be caused by the different ionic-covalent bonding. There is a lower tendency for localization of electrons near the $\mathrm{Zr}$ core in the nitride than in the carbide [4.15]. The much higher initial vacancy concentration of $\mathrm{N}$ in the sublattice may also favor different defect structures.

To explicitly identify the nature of the defects observed in irradiated $\mathrm{ZrN}$, the lattice image was analyzed using Fourier-filtering. Figure 4.6 shows an image of a typical planar-like defect projected as streaks along the $\mathrm{B}=[011]$ direction. After masking the 200 diffraction spots and applying inverse Fourier transformation, a pyramidal dislocation loop is clearly displayed. As shown in Fig. 4.6(c), the dislocation loops appear as two opposite-sign dislocations (dipole) between which there exists a region of lattice distortion. Note that these two dislocations are spaced only at a distance of approximately four (200) planes and the defect appears as a vacancy type. However, it should be noted that lattice images are obtained from very localized and thin regions of the sample ( $<20 \mathrm{~nm}$ thick) and the images are very sensitive to sample thickness and microscope settings. Individual images may therefore not represent the real feature and certainly not the entire sample's characteristics. Further experimental work is needed to study the vacancy pyramidal plane condensation mechanism in irradiated $\mathrm{ZrN}$. 

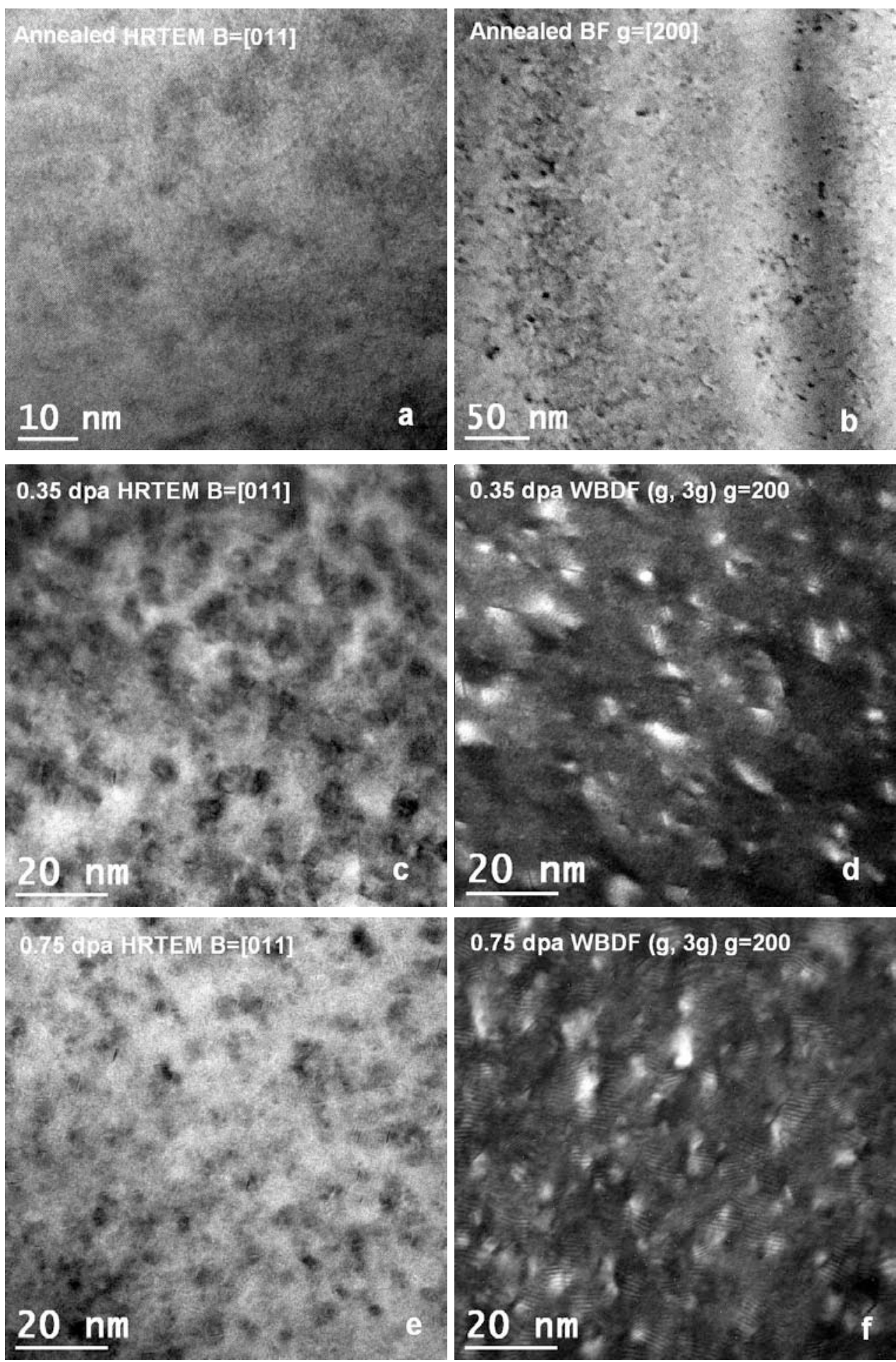

Figure 4.4. BF, WBDF and HRTEM images of as-annealed and irradiated ZrN: a) and b) annealed $\mathrm{ZrN}$; c) and d) sample irradiated with 0.35 dpa with average loop size of $2.23 \mathrm{~nm}$ and density of $8.36 \diamond 10^{15} \mathrm{~m}^{-2}$; e) and f) sample irradiated with 0.75 dpa with average loop size of $2.35 \mathrm{~nm}$ and density of $1.12 \diamond 10^{16} \mathrm{~m}^{-2}$ 


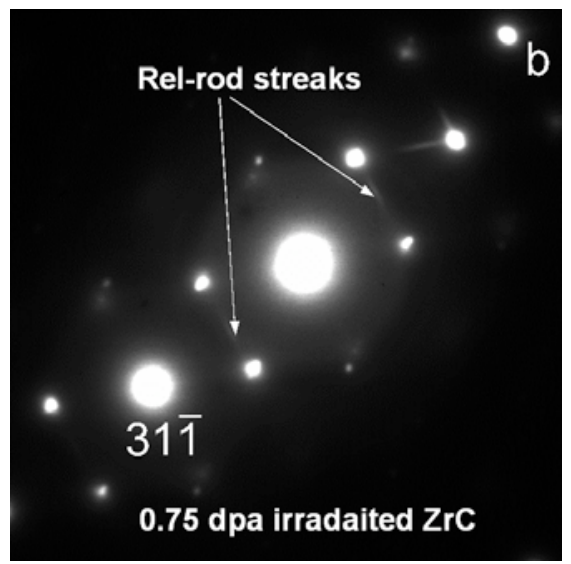

Figure 4.5. 2-beam condition diffraction pattern with $g=31 \overline{1}$ near zone axis [011]: a) 0.75 dpa irradiated $\mathrm{ZrN}$ and b) 0.75 dpa irradiated $\mathrm{ZrC}$ [4.14]
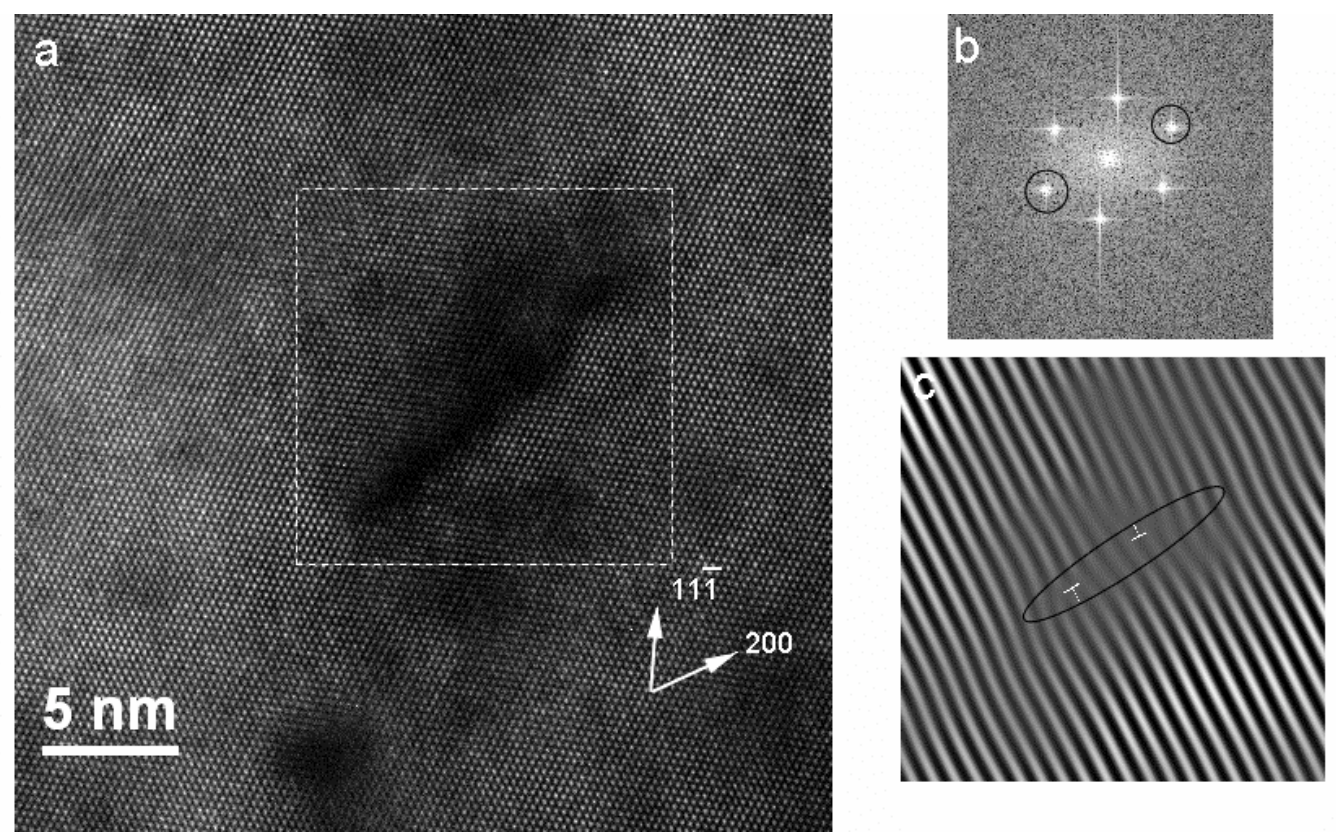

Figure 4.6. a) [011] lattice image of planar-like defect; b) Fourier transformation of selected area; c) Fourier-filtered (200) diffraction lattice images revealing the pyramidal dislocation loops.

To examine the irradiation damage along the proton penetration depth, TEM images were taken on cross-sectional samples. To illustrate more clearly, an optical image of the cross-sectioned, irradiated $\mathrm{ZrN}$ sample is shown in Figure 4.7, where a very sharp crack line is located near the position of the radiation damage peak calculated using SRIM-2008. The detail of the crack line is shown clearly in Figure4.8, where it can be seen that the crack may have formed from the coalescence of aligned voids, and three more lines of small voids can be seen parallel to the crack and perpendicular to the proton beam direction. It seems that the voids were aligned by the proton beam front, moved forward along the irradiation direction, and stop at the peak of damage profile. Additionally, based on the crystal orientations at both sides of the crack, it was found 
that the crack is transgranular instead of intergranular. The void surfaces and the material interconnecting the voids on the crack line were revealed as silicon-rich oxides by the EDS spectrum in Figure 4.8 (b). However the mechanism of Si segregation to the aligned voids caused by the proton irradiation is unclear. Additionally, any hydride formation, especially near the damage peaks, needs further study.

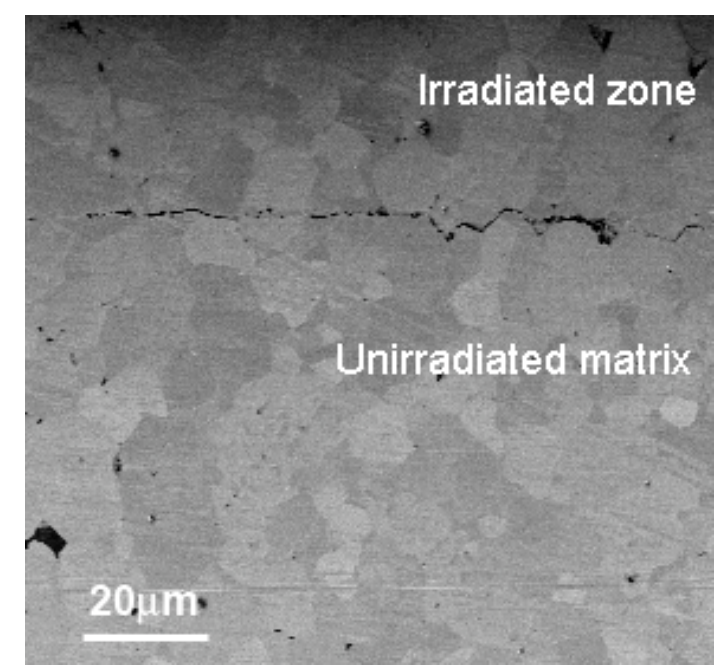

Figure 4.7. Optical image of the cross-section of irradiated $\mathrm{ZrN}$
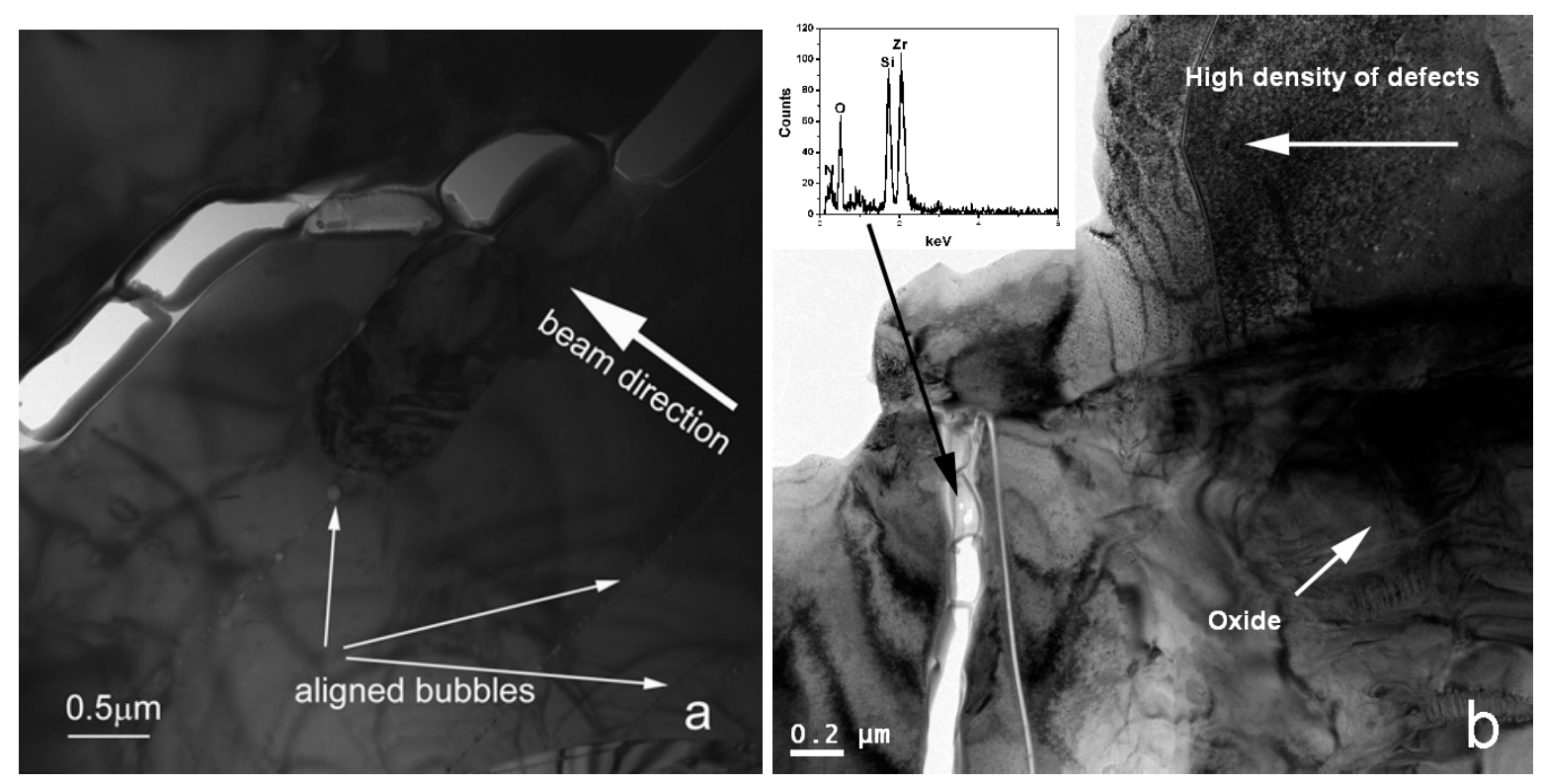

Figure 4.8. TEM image of cross-section sample of irradiated $\mathrm{ZrN}$ with dose of $0.75 \mathrm{dpa}$ : a) aligned bubbles perpendicular to the proton beam direction; b) crack lines formed from the coalescence of aligned voids, and silicon-rich oxides on the void's surface were identified using EDS

As discussed in Section 3.4.2.2, CBED methods analyze slight changes in position of HOLZ lines that are sensitive to small changes in lattice constants [4.16]. The CBED patterns on 
annealed, 0.35 dpa and 0.75 dpa samples are shown in Figure 4.9, with a beam spot size of 100 $\mathrm{nm}$; the simulated pattern was generated using software JEMS ${ }^{\circledR}$ with calibrated voltage. Samples were tilted to a $<114>$ zone axis as a higher index, lower-symmetry pole; the lattice constant of unirradiated $\mathrm{ZrN}$ measured with HOLZ line patterns agrees very well with our XRD result $(\mathrm{a}=0.4584 \mathrm{~nm})$, while there are no noticeable changes in the HOLZ patterns of irradiated samples compared with the unirradiated one.

a

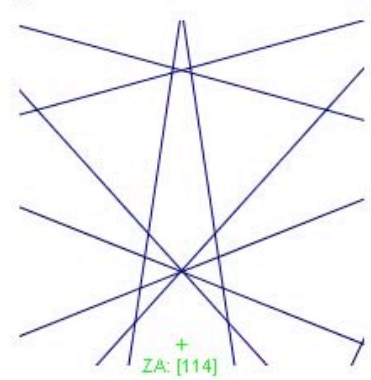

(simulated)

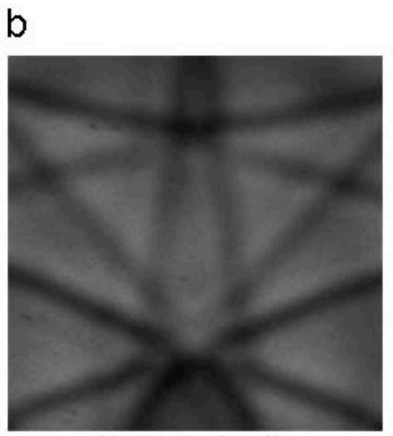

(annealed)
C

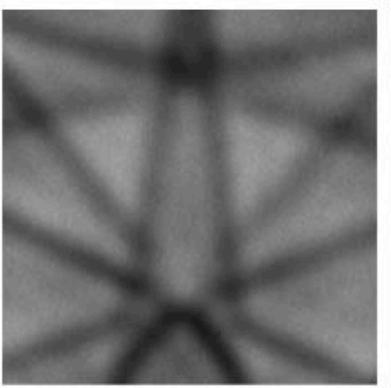

(0.7dpa)

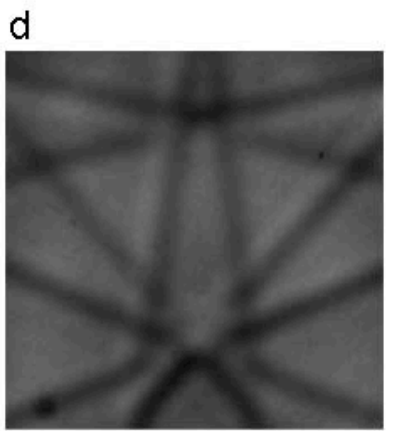

$(1.5 \mathrm{dpa})$

Figure 4.9. Comparison of HOLZ patterns in the transmitted disc on the zone of [114]

\subsubsection{Irradiated at $600^{\circ} \mathrm{C}$}

The $\mathrm{ZrN}$ sample irradiated to $1.75 \mathrm{dpa}$ at $600^{\circ} \mathrm{C}$ was examined using TEM for microstuctural evolution. As shown in Figure 4.10, the irradiated microstructure is decorated with a high density of nano-sized spots. Compared with the microstructures of $\mathrm{ZrN}$ irradiation at $800^{\circ} \mathrm{C}$, the irradiation at $600^{\circ} \mathrm{C}$ doesn't induce a distinguishable dislocation loop structure, but the Moiré fringes become much more pronounced, as shown in Figures 4.11 and 4.12. Generally, the Moiré fringes are caused by an overlapping second phase, and it is postulated that during the irradiation the oxygen from the $\mathrm{Zr}_{\mathrm{x}} \mathrm{O}_{\mathrm{y}}$ inclusions may be mixed into the matrix and then precipitated as a nano-sized phase. However, EDS could not detect oxygen concentrations in the black-spot regions, and a final conclusion needs to be further investigated with $\mathrm{Z}$ contrast imaging and EELS technologies. The diffraction pattern at the 2-beam condition at $g=311$ near $Z=011$ doesn't reveal any Rel-rod streaks, as shown in Figure 4.13, which also confirms the low population of faulted dislocation loops. 


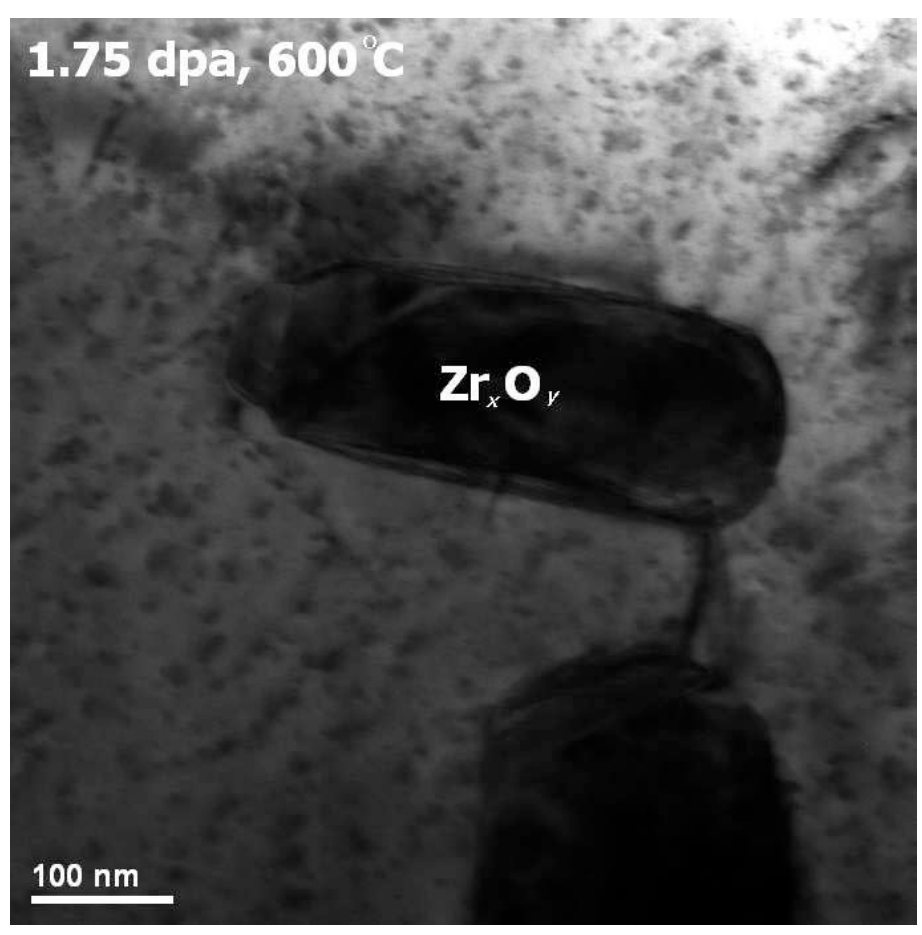

Figure 4.10. Irradiated microstructure of $\mathrm{ZrN}$ at a dose of $1.75 \mathrm{dpa}$ at $600{ }^{\circ} \mathrm{C}$

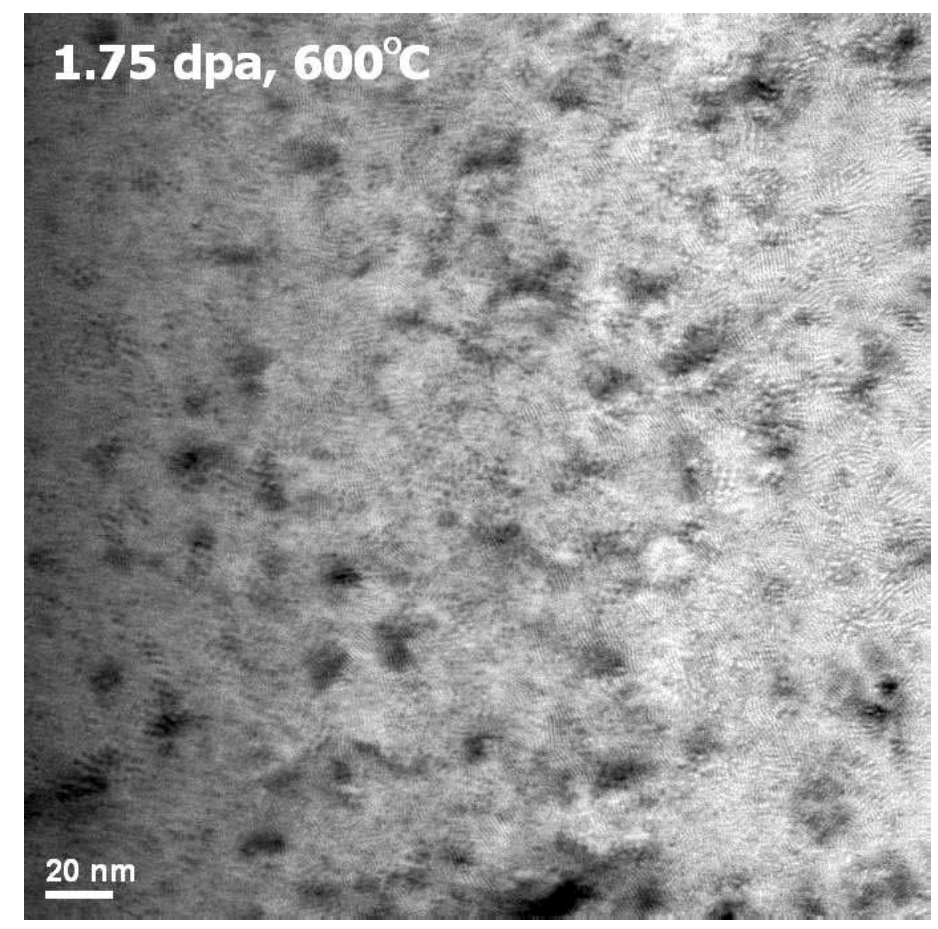

Figure 4.11. TEM image at $\mathrm{z}=011$ of $\mathrm{ZrN}$ irradiated to $1.75 \mathrm{dpa}$ at $600^{\circ} \mathrm{C}$ 


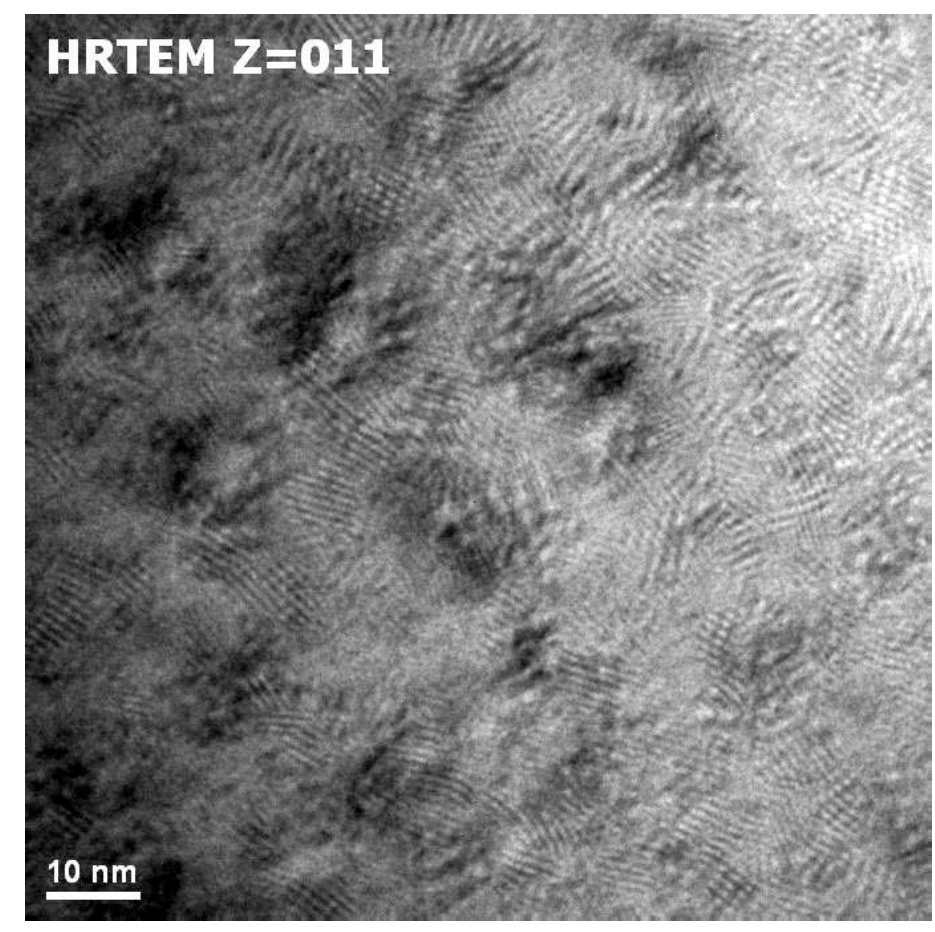

Figure 4.12. HRTEM of Moiré fringes in $\mathrm{ZrN}$ irradiated to $1.75 \mathrm{dpa}$ at $600^{\circ} \mathrm{C}$

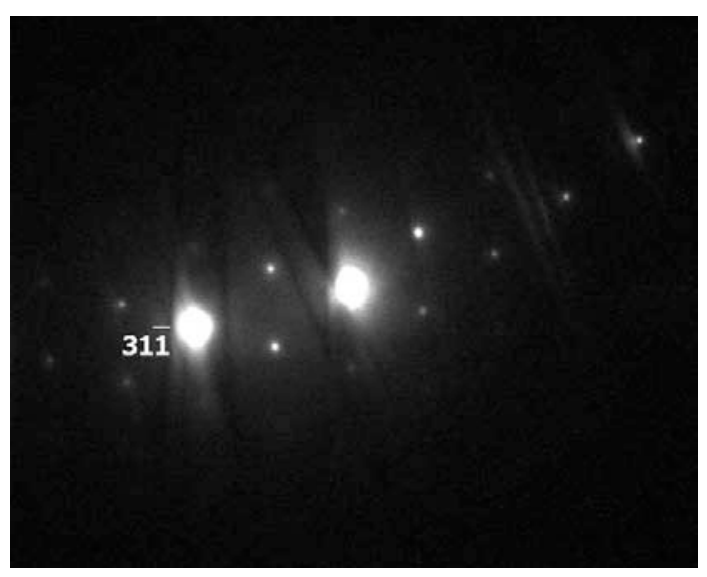

Figure 4.13. 2-beam condition diffraction pattern with $g=31 \overline{1}$ near zone axis [011]

\subsubsection{Irradiated at $900^{\circ} \mathrm{C}$}

The plan-view TEM samples of the $\mathrm{ZrN}$ irradiated at $900^{\circ} \mathrm{C}$ with a dose of 1.5 dpa were prepared using wedge polishing followed by low angle ion milling, and the electron transparent area was controlled to be around $20 \mu \mathrm{m}$ deep from the irradiated surface. Voids were observed in many grains, but were also observed in the annealed sample, therefore the voids should not be induced by proton irradiation. In contrast with the $900^{\circ} \mathrm{C}$ irradiated $\mathrm{ZrC}$, no bubbles were found along the grain boundaries, as shown in Figure 4.14(b). The defects were observed mainly as black spots 
instead of orientated streaks, as shown in Figure 4.14(c). Moiré fringes associated with the defects were not observed in these samples.

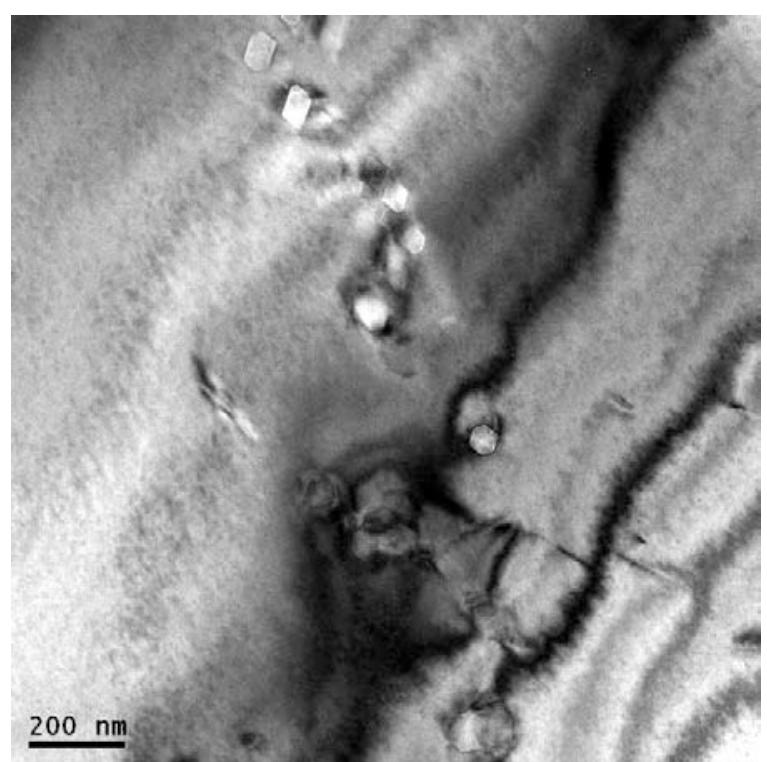

(a) Voids in grains

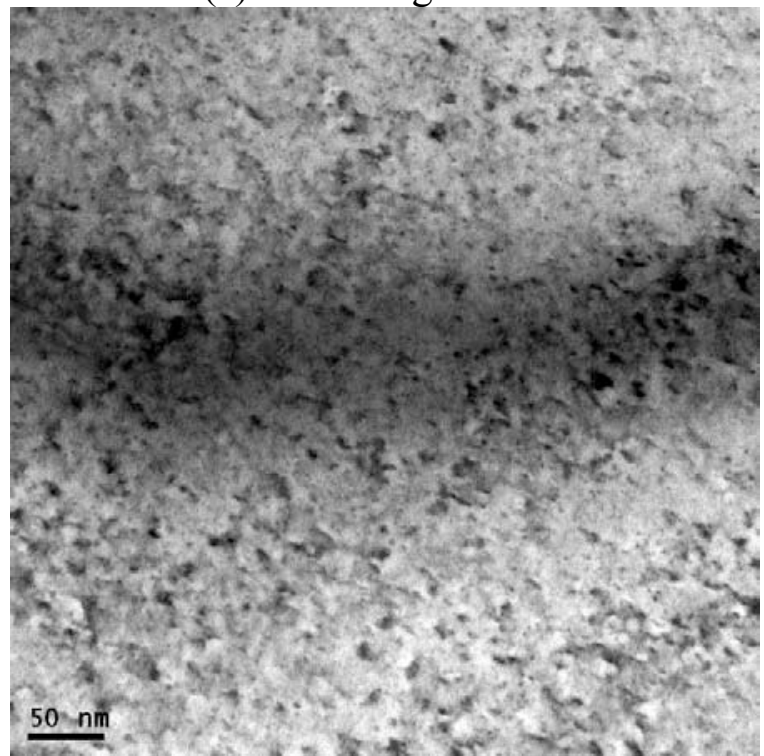

(c) Image of defects

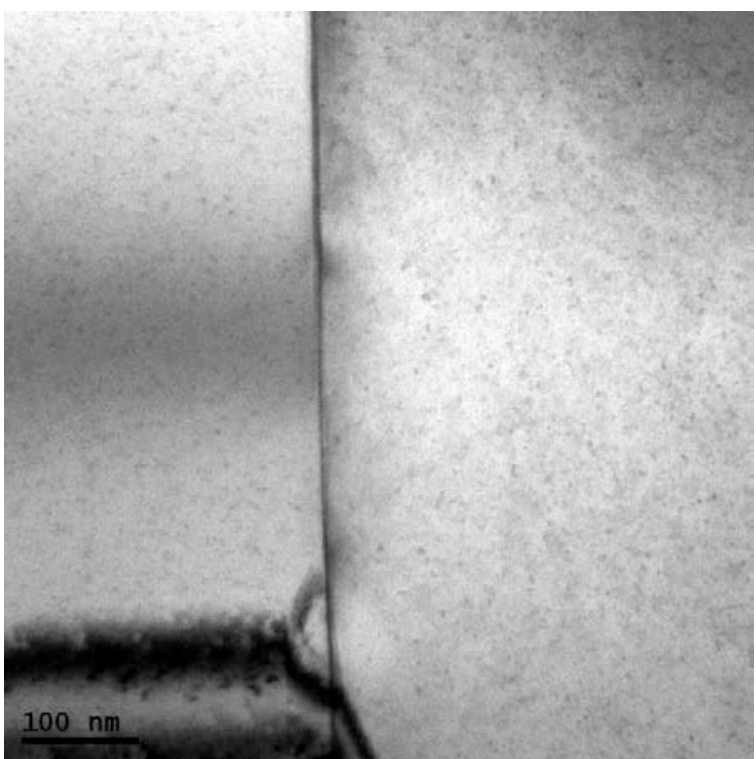

(b) Grain boundary

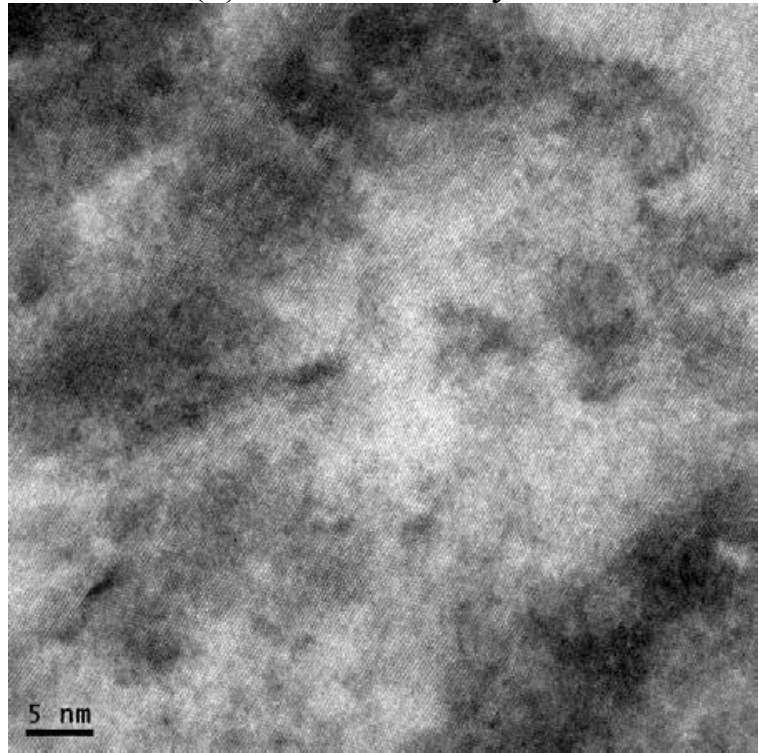

(d) HRTEM image

Figure 4.14. TEM images of $\mathrm{ZrN}$ irradiated at $900^{\circ} \mathrm{C}$ with a dose of $0.75 \mathrm{dpa}$

\subsubsection{Lattice changes}

The lattice constant changes of $\mathrm{ZrN}$ irradiated at different conditions were systematically evaluated using XRD. No phase transformation was induced by irradiation. For irradiation at $600^{\circ} \mathrm{C}$, as shown in Figure 4.15, an obvious broadening of the diffraction peaks, increasing with the proton fluence, is observed. The broadening is due to radiation-induced defects that lead to 
the formation of lattice distortions, and a peak shift toward the low diffraction angles appears and becomes more pronounced when the dose increases. This shift can be associated with an increase of the lattice constant, which is presented in Figure 4.16 . For $600^{\circ} \mathrm{C}$ irradiation, swelling of the irradiated $\mathrm{ZrN}$ is $\sim 0.87$ vol.\% at the dose of $1.75 \mathrm{dpa}$ according to the measured increase of the lattice constant.

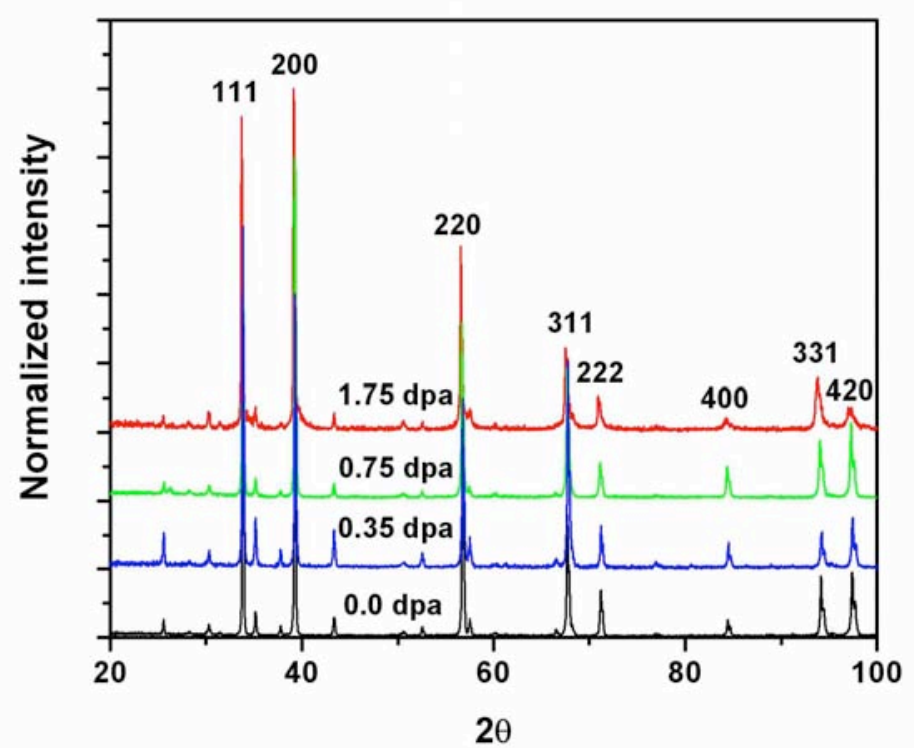

Figure 4.15. XRD patterns recorded for $\mathrm{ZrN}$ irradiated at $600^{\circ} \mathrm{C}$ with doses of $0,0.35,0.75$ and $1.75 \mathrm{dpa}$, where the labeled peaks correspond to the alumina

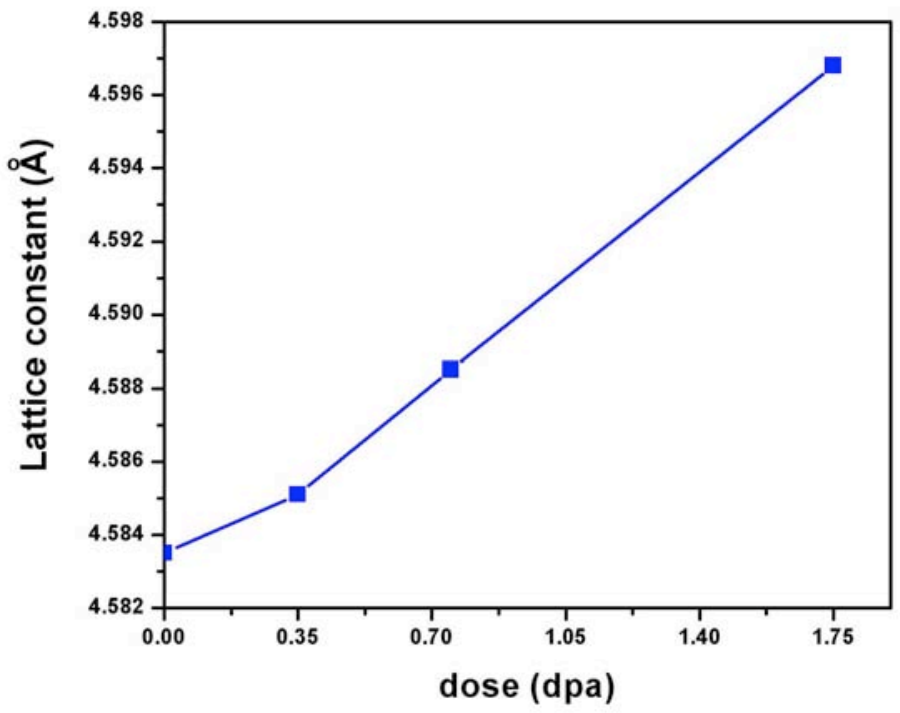

Figure 4.16. Variations of lattice constant vs. dose in $\mathrm{ZrN}$ irradiated at $600^{\circ} \mathrm{C}$

As listed in Table 4.1, for the sample irradiated at $800^{\circ} \mathrm{C}$ and $0.35 \mathrm{dpa}$, there is no noticeable lattice variation from the unirradiated value, since the difference falls within the range of measurement error. For the 0.75 dpa sample a slight lattice expansion was observed. This 
measurement is consistent with our HOLZ evaluation, which shows no noticeable changes in the HOLZ patterns of irradiated and unirradiated samples.

Table 4.1. Lattice variation of $\mathrm{ZrN}$ with different irradiation conditions

\begin{tabular}{llll}
\hline Condition & $\mathrm{a}(\AA)$ & $\nabla \mathrm{a}(\AA)$ & $\Delta(\mathrm{Er})(\AA)$ \\
\hline Annealed & 4.58353 & - & $6.01251 \mathrm{E}-4$ \\
\hline $0.35 \mathrm{dpa}\left(600^{\circ} \mathrm{C}\right)$ & 4.58511 & +0.00158 & 0.00037 \\
\hline $0.75 \mathrm{dpa}\left(600^{\circ} \mathrm{C}\right)$ & 4.58853 & +0.00500 & 0.00069 \\
\hline $1.75 \mathrm{dpa}\left(600^{\circ} \mathrm{C}\right)$ & 4.59684 & +0.01331 & 0.00074 \\
\hline $0.35 \mathrm{dpa}\left(800^{\circ} \mathrm{C}\right)$ & 4.58237 & -0.0016 & 0.00237 \\
\hline $0.75 \mathrm{dpa}\left(800^{\circ} \mathrm{C}\right)$ & 4.58696 & +0.00343 & 0.00147 \\
\hline $0.35 \mathrm{dpa}\left(900^{\circ} \mathrm{C}\right)$ & 4.58415 & +0.00062 & $1.10954 \mathrm{E}-4$ \\
\hline $0.75 \mathrm{dpa}\left(900^{\circ} \mathrm{C}\right)$ & 4.58492 & +0.00139 & 0.00106 \\
\hline
\end{tabular}

\subsubsection{Irradiation hardening}

Irradiation hardening was evaluated using Knoop micro-indentation, in a similar manner as previously described in section 3.5. The Knoop hardness is listed in Figure 4.17. The increase in microhardness due to $900^{\circ} \mathrm{C}$ proton-irradiation is $0.71 \%$ for $0.35 \mathrm{dpa}$ and $5.33 \%$ for $0.75 \mathrm{dpa}$; while for the $800^{\circ} \mathrm{C}$ irradiation, the increase in microhardness is $9.5 \%$ for $0.35 \mathrm{dpa}$ and $14.6 \%$ for $0.75 \mathrm{dpa}$. It can be seen that as irradiation temperature increases, hardening effects become less pronounced.

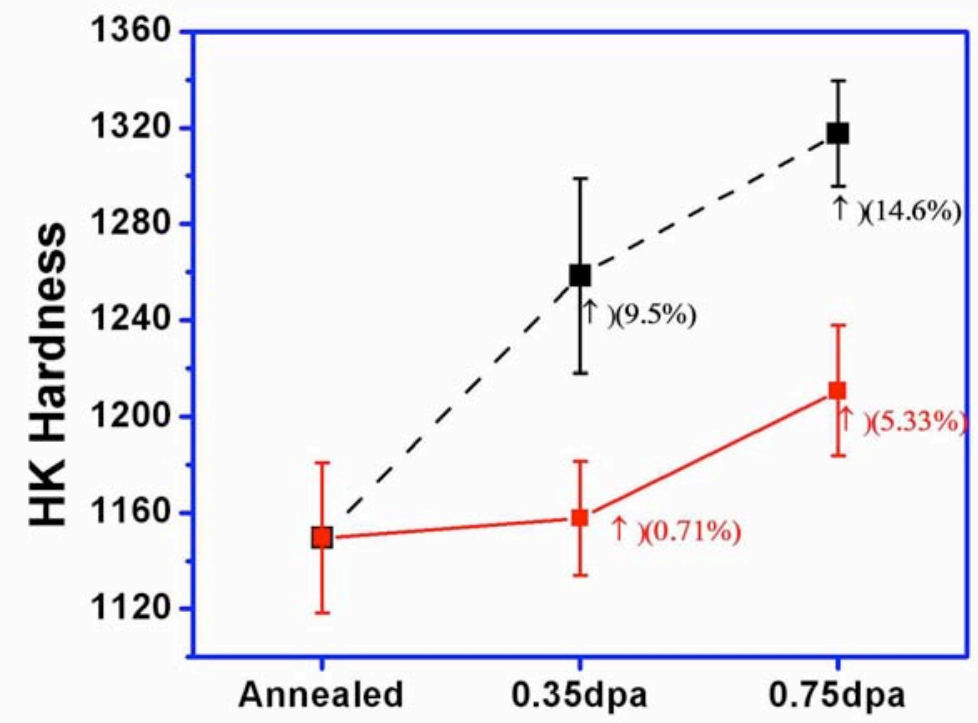

Figure 4.17. Knoop hardness of $\mathrm{ZrN}$ with different irradiation conditions (15 indents were measured for each condition, and error bars denote the standard error of mean) 


\subsubsection{Fracture toughness}

Although the crack system for $\mathrm{ZrN}$ was determined as Palmqvist crack in a previous study [4.17], the typical cracks developed around the indentations are shown in Figure 4.18 and it is difficult to clearly define the crack system. The reasons may be that $\mathrm{ZrN}$ has relatively high porosity and large pore sizes, which can interact with initiation and propagation of cracks. Nanoindentation was used to study the material's mechanical properties, eliminating the effects from grain boundary and other intergranular defects.

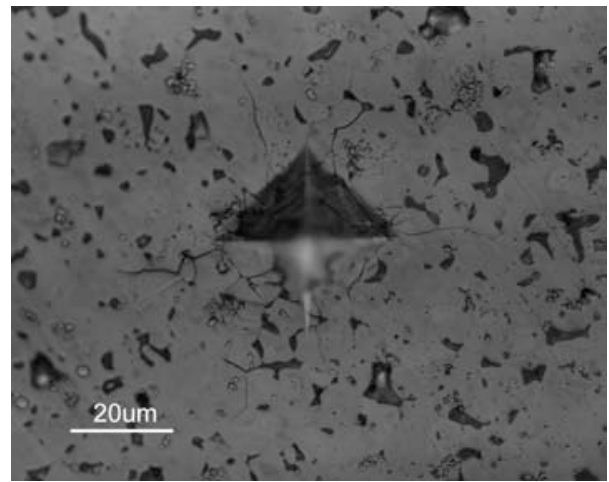

(a)

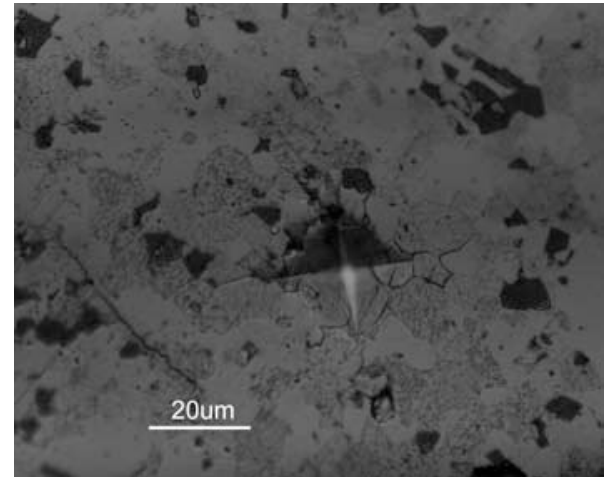

(b)

Figure 4.18. (a) Indentation of samples irradiated with $1000 \mathrm{gf}$ (b) Indentation of unirradiated samples with $500 \mathrm{gf}$

\subsubsection{Nano-indentation}

As pointed out in Section 4.3.4, due to the relative high concentration of porosity and dispersed $\mathrm{ZrO}_{2}$ phase at grain boundaries, the values of measured microhardness or fracture toughness were greatly distorted, and no clearly defined crack system was achieved for $\mathrm{ZrN}$ after many trials. Nano-indentation is an alternative method for evaluating irradiation effects on mechanical properties, similarly to the loading curved applied on $\mathrm{ZrC}$, multi-step loads were also used, as shown in Figure 4.19, and the hardness and Young's modulus were calculated as explained previously 3.4.5. 


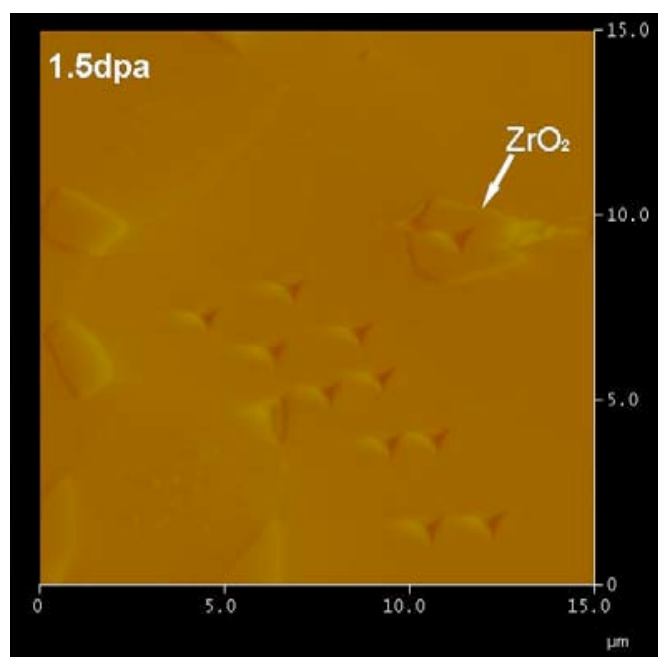

(a)

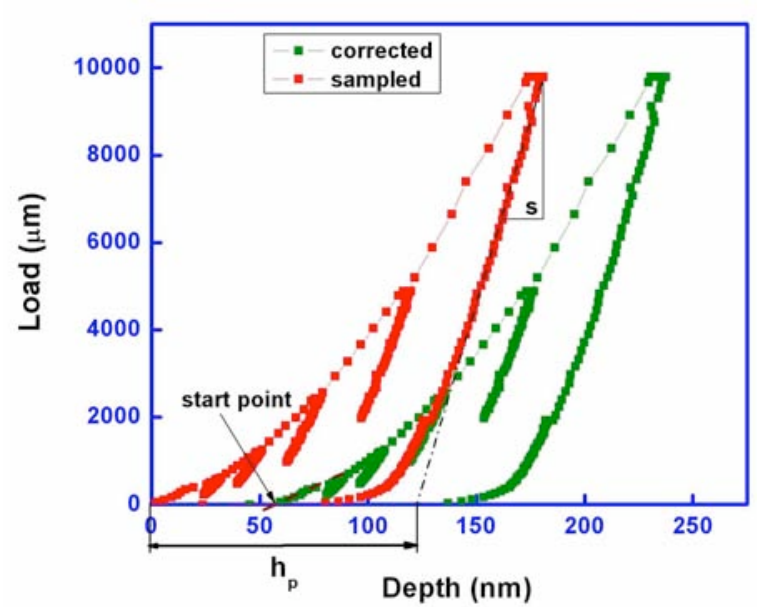

(b)

Figure 4.19. (a) indentation on irradiated $\mathrm{ZrN}$ and (b) the load-depth curve

For this study, a total of nine indentations were made on the unirradiated $\mathrm{ZrN}$ (including two on the $\mathrm{ZrO} 2$ phase) and 11 indentations (including one on the $\mathrm{ZrO} 2$ phase) on the irradiated $\mathrm{ZrN}$ with dose of $0.75 \mathrm{dpa}$. For each indentation, one linear regression was performed, and the intercept $\left(J_{0}\right)$, and the slope (equipment compliance, $C_{m}$ ) were obtained; the regression lines are plotted in Figure 4.20. 

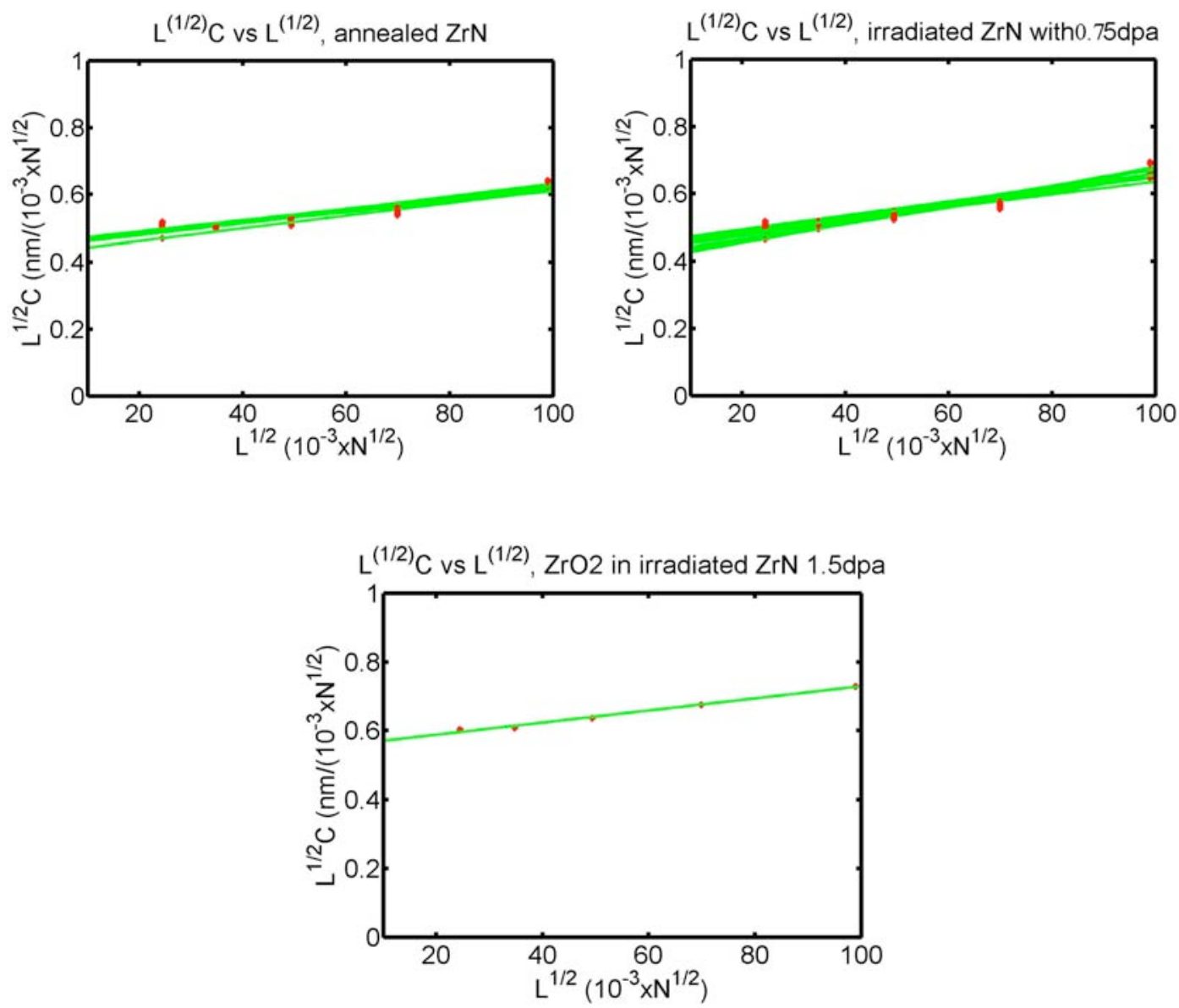

Figure 4.20. Linear regressions of $L^{1 / 2} C$ and $L^{1 / 2}$ for specimens irradiated with different dose levels at $800^{\circ} \mathrm{C}$

The hardness for each indentation was calculated, with the associated load, $L$, and calculated area, $A$, and the effective Young's modulus was determined. Provided that $E_{d}=1141 G P a v_{d}=0.07$ for diamond, and $v_{s}=0.11$ for $\mathrm{ZrN}$, the true Young's modulus for $\mathrm{ZrN}$ can be calculated. Comparison of hardness and the Young's modulus between the annealed and irradiated $\mathrm{ZrN}$ is shown in Figure 4.21. It can be seen that the hardness is almost constant, while the modulus slightly increases for the irradiated sample. However, due to the isotropic properties for different orientations of each grain, EBSD was also attempted to insure that indentations are performed on grains with same orientation. 


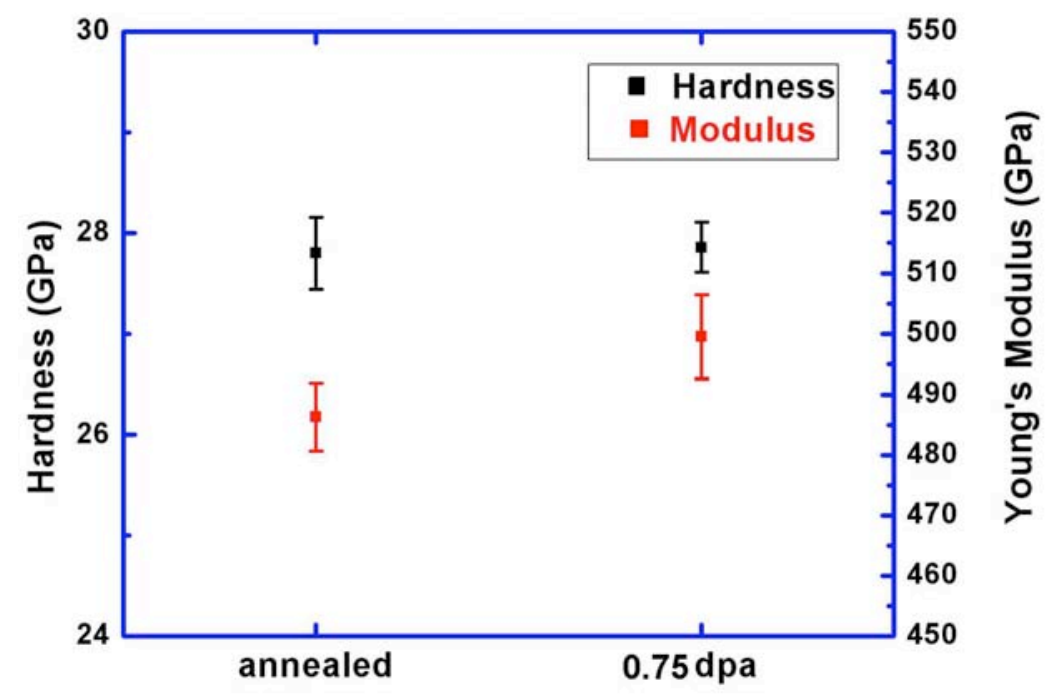

Figure 4.21. Nano-indentation, hardness, and Young's Modulus of annealed and irradiated $\mathrm{ZrN}$

For sintered polycrystalline $\mathrm{ZrN}$, the measured value may depend on the grain orientation, since the nano-impression is normally within one grain. As schematically shown in Figure 4.22, materials with $\mathrm{NaCl}$ structure having a pronounced covalent bonding, e.g., $\mathrm{TiC}, \mathrm{ZrC}$, and $\mathrm{VC}$, slip primarily on the $\{111\}$ planes, while $\{110\}<1 \overline{10}>$ and $\{001\}<110>$ slip systems were observed for $\mathrm{ZrC}_{1-\mathrm{x}}$. For $\mathrm{ZrN}$, $\mathrm{Li}$ has demonstrated that the possible primary slip system is $\{111\}<110>[4.21]$.

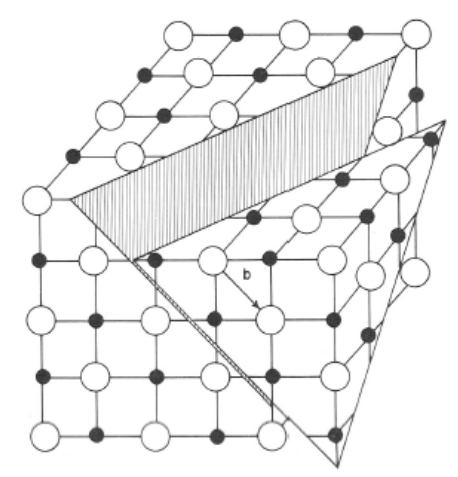

(a) $\{111\}<1 \overline{10}>$ slip

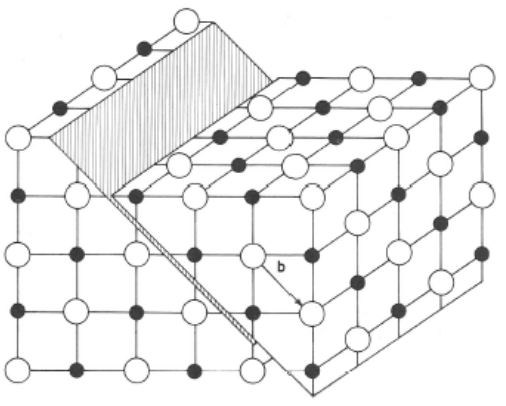

(b) $\{110\}<1 \overline{1} 0>$ slip

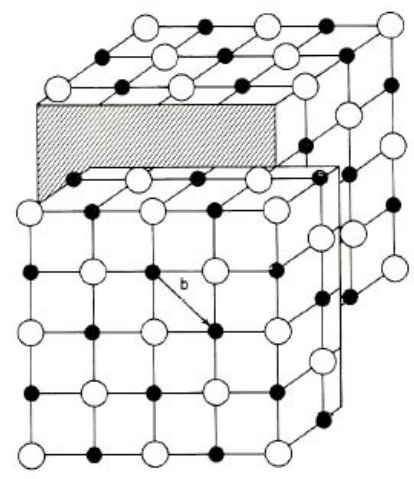

(c) $\{001\}<1 \overline{10}>$ slip

Figure 4.22. Slip system for $\mathrm{NaCl}$, (a) primary slip system; (b) and (c) possible slip system [4.18]

To determine the grain orientation of each indented grain, FIB was used to make a benchmark for nano-indentation and EBSD scanning, as shown in Figure 4.23. During the setup of nanoindentation, the diamond indenter was carefully aligned on the top of the benchmark, which 
makes it much easier to locate the nano-impressions later during SEM. For the $800^{\circ} \mathrm{C}$ irradiation, EBSD scanning was performed on annealed and 0.75 dpa samples around the benchmark; the inverse pole figures in Figure 4.24 show no preferential orientation in either annealed or irradiated samples. A continuous indentation technique was used to measure the hardness and Young's modulus simultaneously. Figure 4.25 displays the atomic force microscopy (AFM) image of the indentation on $\mathrm{ZrN}$ with a FIB-milled benchmark.
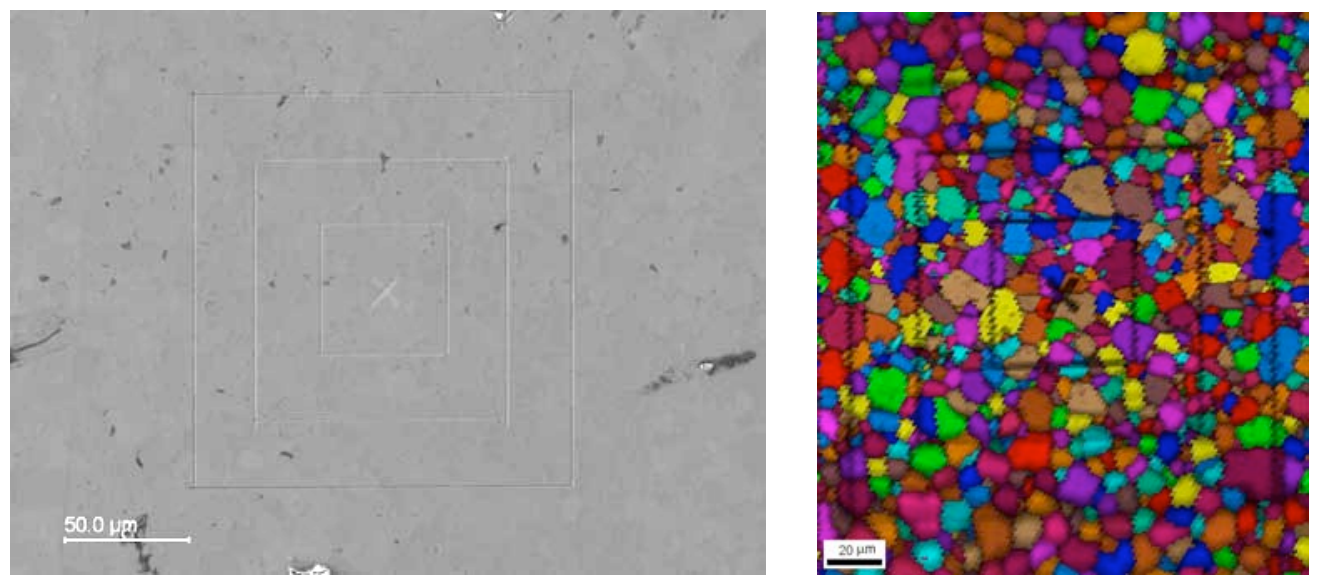

Figure 4.23. Benchmark milled by FIB on $\mathrm{ZrN}$ for nanoindentation

[001]

[001]
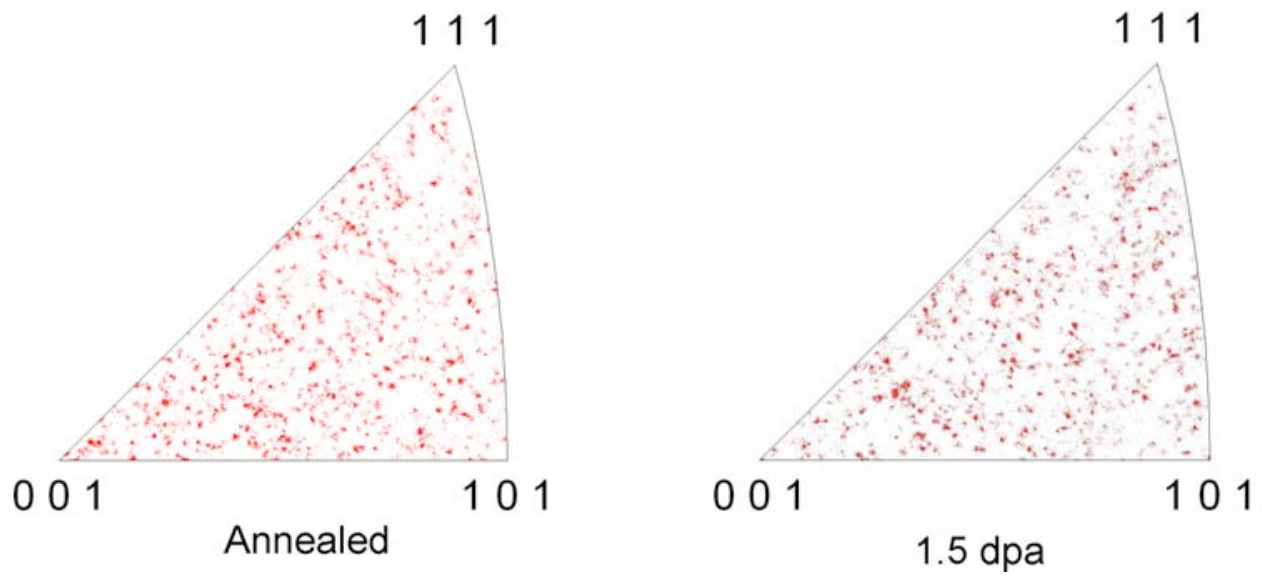

Figure 4.24. Inverse pole figure of annealed and 1.5 dpa irradiated $\mathrm{ZrN}$ 


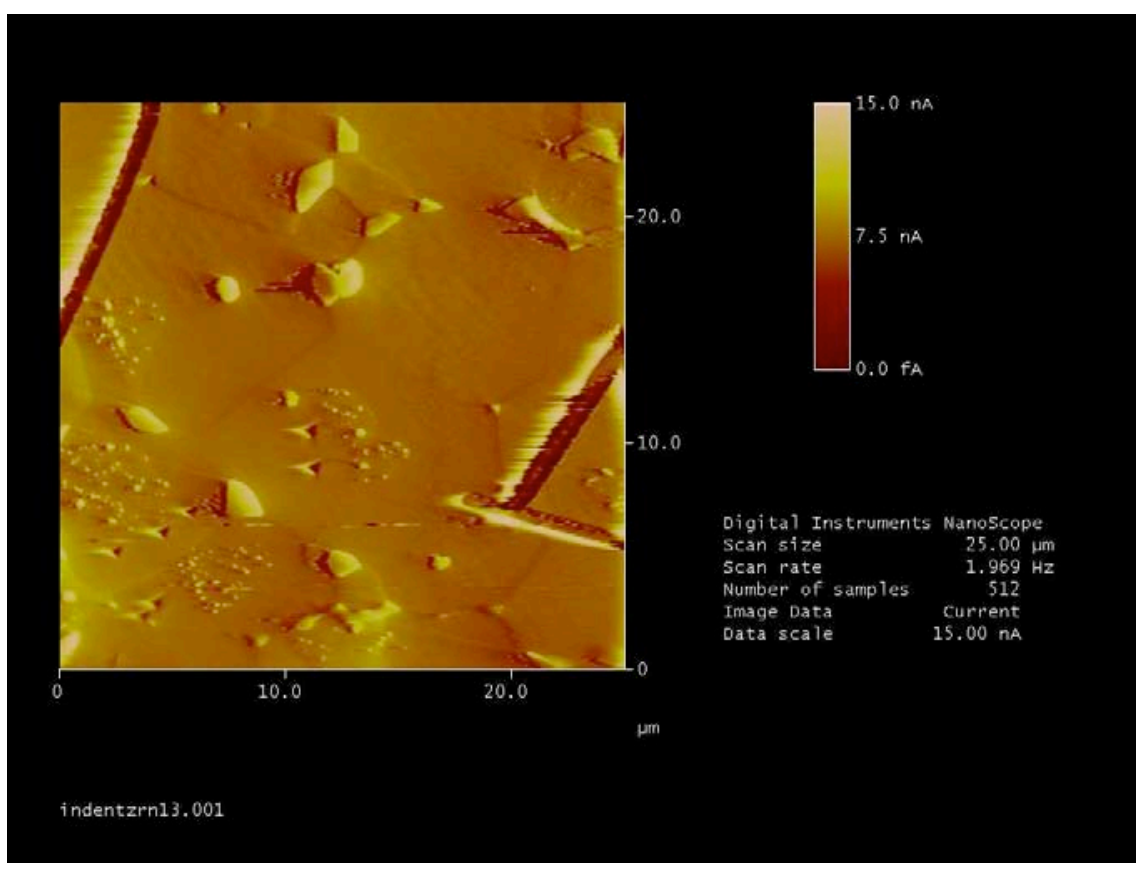

Figure 4.25. AFM image of nano-indentation with FIB-milled benchmark

Impressions from nano-indentation were imaged using SEM, and the area around the impressions was also scanned using EBSD to determine the orientation of each grain. The hk1 orientations are marked on the grains, as shown in Figure 4.26. Unfortunately, no coincident orientation of indented grains was found between these two samples, therefore more indentations will be needed for further studies. In this report, only the data on an annealed sample are analyzed; a total of seven indentations were performed and can be grouped into three grains: three on the grain with orientation $\langle 323\rangle$, three on the grain with orientation $\langle 111\rangle$, and one on grain with orientation $<0101>$. The average hardness of these three grains is displayed in Figure 4.27 , where it can be seen that the value of hardness varies only slightly for different grains, however this conclusion needs to be further confirmed with future study. 

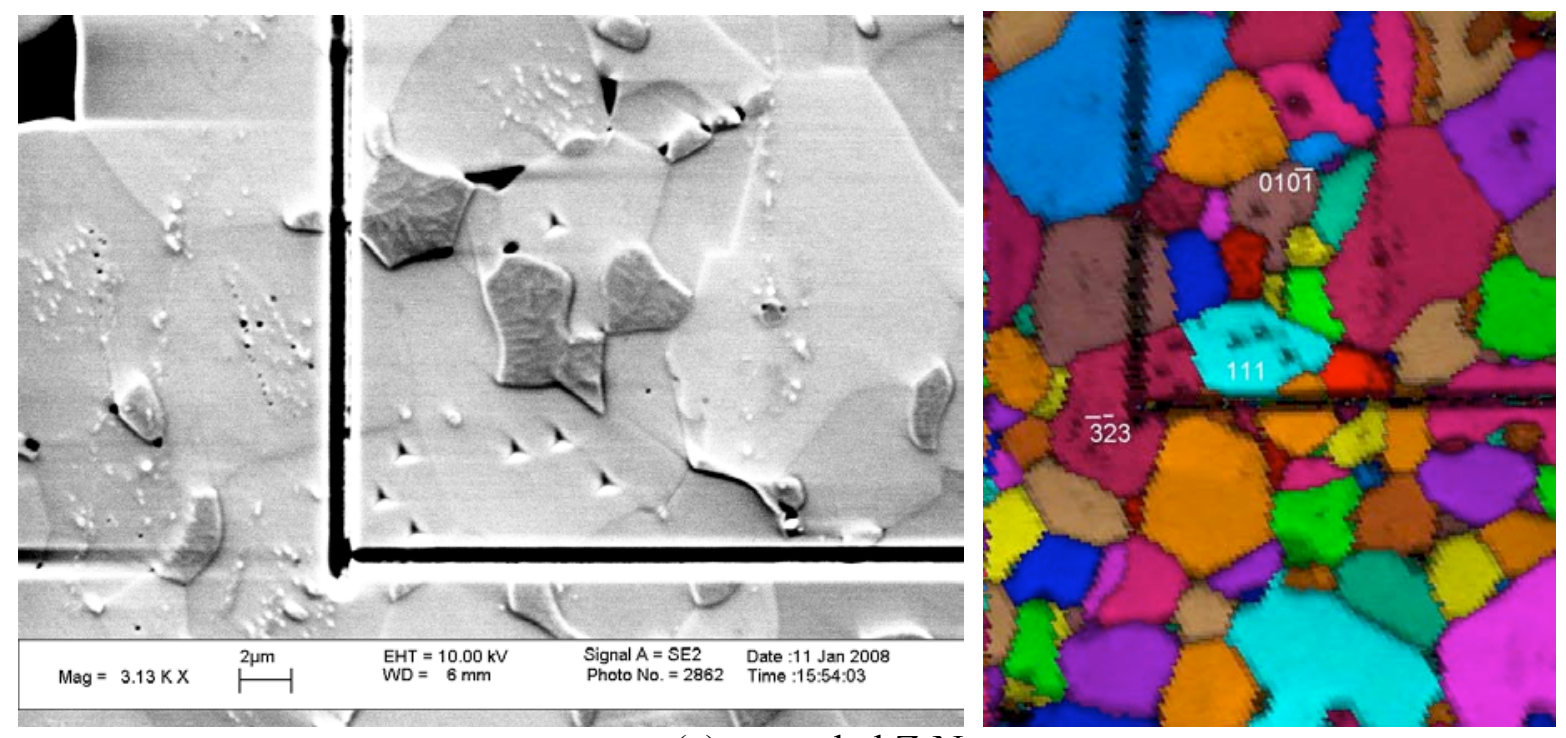

(a) annealed $\mathrm{ZrN}$
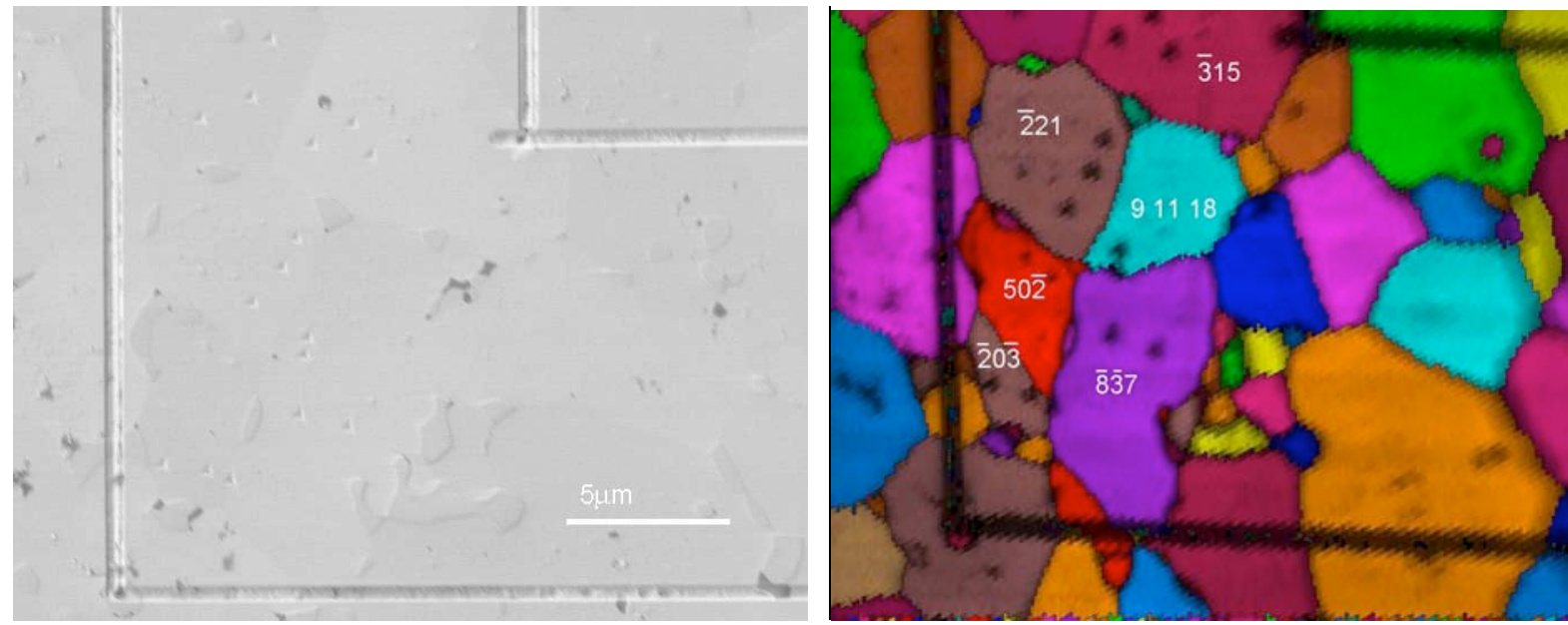

(b) $\mathrm{ZrN}$ irradiated with $1.5 \mathrm{dpa}$

Figure 4.26. SEM image of nano-identation and EBSD for indented grains 


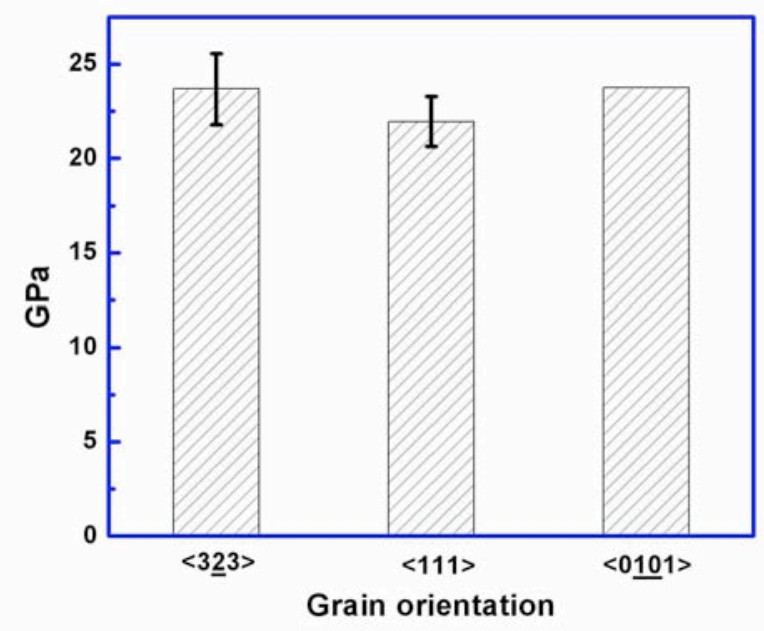

Figure 4.27. Comparison of hardness for different grains in annealed $\mathrm{ZrN}$

\subsection{Conclusions}

Proton irradiation of $\mathrm{ZrN}$ produced no radiation-induced voids or bubbles for doses up to 1.75 dpa. Crack lines and aligned bubbles were observed in the vicinity of the irradiation damage peak, which has a much higher dose level and concentration of stopped hydrogen. No irradiationinduced amorphization or precipitates were detected. The irradiated microstructures are dominated by a high density of dislocation loops and point defects, and lattice resolution TEM images show some of the loops are vacancy-type in nature. The density of dislocation loops increases with dose, while the average size remains nearly constant. Only a slight lattice expansion was observed for the irradiated sample; as the irradiation temperature decreases, the increment of the lattice parameter increases for the same dose.

Radiation hardening was found for specimens irradiated at 800 and $900^{\circ} \mathrm{C}$, and this hardening is postulated to be attributed to the formation of point defects. However, further annealing experiments on the irradiated sample are needed to make a firm conclusion on the mechanism of radiation hardening in $\mathrm{ZrN}$. 


\section{References}

4.1. AFCI Program Plan, 2005

4.2. M. Streit, F. Ingold, J.Eur.Cer. Soc. 25 (2005) 2687

4.3. K. Minato, M. Akabori, M. Takano, Y. Arai, K. Nakajima, A. Itoh, and T. Ogawa, J. Nucl. Mater. 320 (2003) 18

4.4. M. Burghartz, G. Ledergerber, H. Hei, R. R. van der Lann, and R. J. M. Konings, J. Nucl. Mater. 288 (2001) 233

4.5. M. K. Meyer, and N. Chauvin, Proceedings of GLOBAL2003, New Orleans, Louisiana, USA, Nov 16-20, (2003) 1990

4.6. K. Wheeler, P. Peralta, M. Parra, K. McClellan, J. Dunwoody and G. Egeland, J. Nucl. Mater. 366 (2007) 306

4.7. G. W. Egeland, Phd Thesis, 2005

4.8. J. Gan, R. S. Fielding, M. K. Meyer and R. C. Birtcher, FY-2005 Summary Report, INL, 2005

4.9. M. L. Taubin, Soviet Atomic Energy 69(3) (1990) 176

4.10. H. Hochst, R. D. Bringans, R. L. Johnson, Annals of the Israel Physical Soc. 6 (1984) 336

4.11. V. A. Lavrenko, V. A. Shvets, A. D. Panasyuk and L. I. Kuznetsova, Power Met. and Metal Ceramics 42 (2003) 419

4.12. ASTM standard: C 1326-03, Standard Test Method for Knoop Indentation Hardness of Advanced Ceramics

4.13. D. J. Edward, E. P. Simonen, S. M. Bruemmer, J. Nucl. Mater. 317 (2003) 13

4.14. Y. Yang, C. A. Dickson, H. Young, B. Miller and T. R. Allen, J. Nucl. Mater. 378 (2008) 341

4.15. NASA Technical Note $-3533,1966$

4.16. J.C.H.Spence and J.M.Zuo, Electron Microdiffraction, Plenum Press, New York and London, 1992

4.17. Report, INL/EXT-06-11749, September, 2006

4.18. P. Li, and J. M. Howe, Acta Mater., 50 (2002) 4231. 


\section{TiC}

Unirradiated and irradiated microstructures of TiC were studied, and the TEM specimens were prepared using dimpling followed with low angle ion milling for the final finish. Detailed investigation of the microstructure evolution of irradiated $\mathrm{TiC}$ has been conducted with $\mathrm{BF}$, WBDF, and HRTEM. These techniques have provided clear evidence that the most prominent defects present are Frank-type dislocation loops.

\subsection{SEM and EDS characterization of as-received}

SEM analysis of the TiC showed the sample is porous, and some apparent white inclusions were observed in the material, as shown in Figure 5.1. The EDS spectrum shows that the inclusion is $\mathrm{WxCy}$.

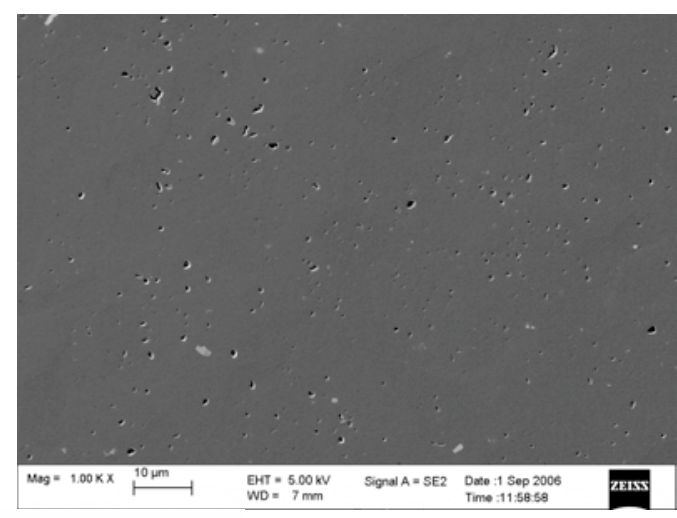

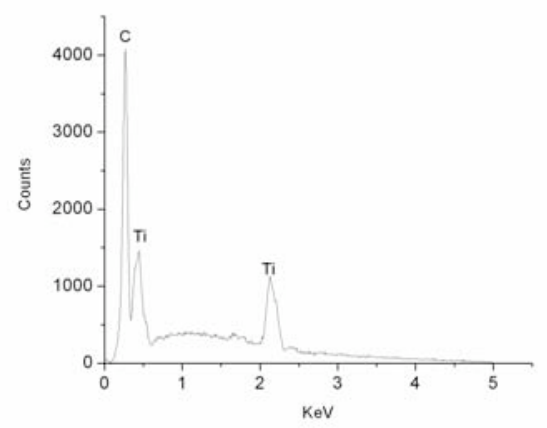

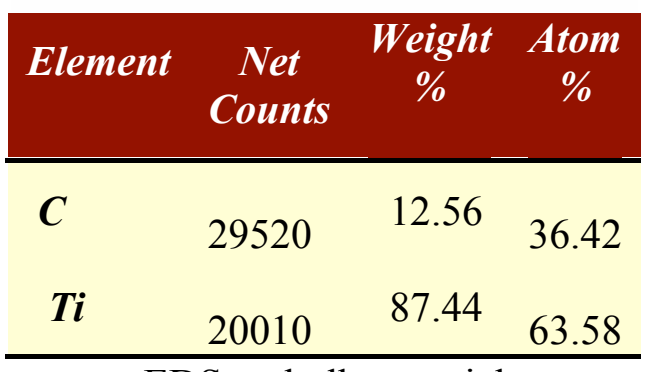

EDS on bulk material
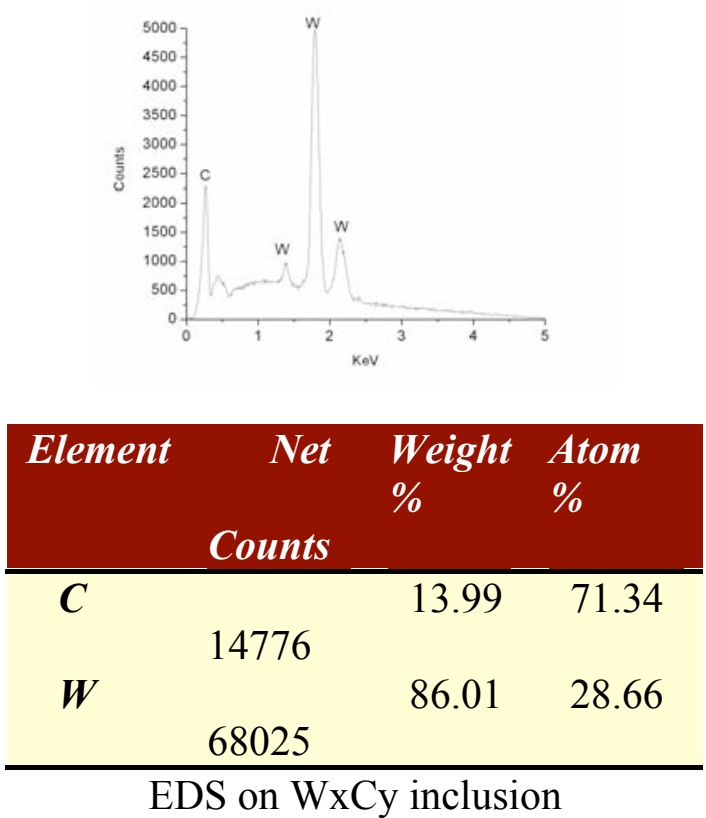

Figure 5.1. SEM and EDS characterization of as-received TiC 


\subsection{TEM characterization}

Only specimens irradiated at $800^{\circ} \mathrm{C}$ were systemically characterized using TEM. In addition, the unirradiated microstructure was studied for comparison. The experiments were mainly conducted using the LEO 912. As shown in Figure 5.2, TEM results at kinematical BF $\left(\mathrm{s}_{\mathrm{g}}>0\right)$ images were taken using a 2-beam condition with $\mathrm{g}=<022>$, and $\mathrm{DF}$ images were taken using the corresponding WBDF, $\mathrm{g}(3 \mathrm{~g})$, condition. Unirradiated TiC displays contrast believed to arise from defect clusters produced by ion milling the TEM samples to electron transparency. While defects in the irradiated material have previously been identified as FLs, no such features have been found in the unirradiated case, although some of the contrast in the unirradiated micrographs is similar to the contrast in the irradiated micrographs for these imaging conditions. The irradiated cases show a high density of black dot contrast in the BF images ascribed to the presence of the dislocation loops.

Continued investigation of the microstructure evolution of irradiated $\mathrm{TiC}$ has been conducted with HRTEM. This technique has provided more evidence that the most prominent defects present are Frank-type dislocation loops. Figure 5.3 shows high-resolution micrographs of TiC irradiated to varying doses at $800^{\circ} \mathrm{C}$. The line contrast seen in the $0.25 \mathrm{dpa}$ and $0.5 \mathrm{dpa}$ images are edge-on dislocation loops, while these features are absent in the unirradiated condition. The Rel-rod image and associated diffraction pattern in Figure 5.4 further shows the existence of the FLs with high density. 

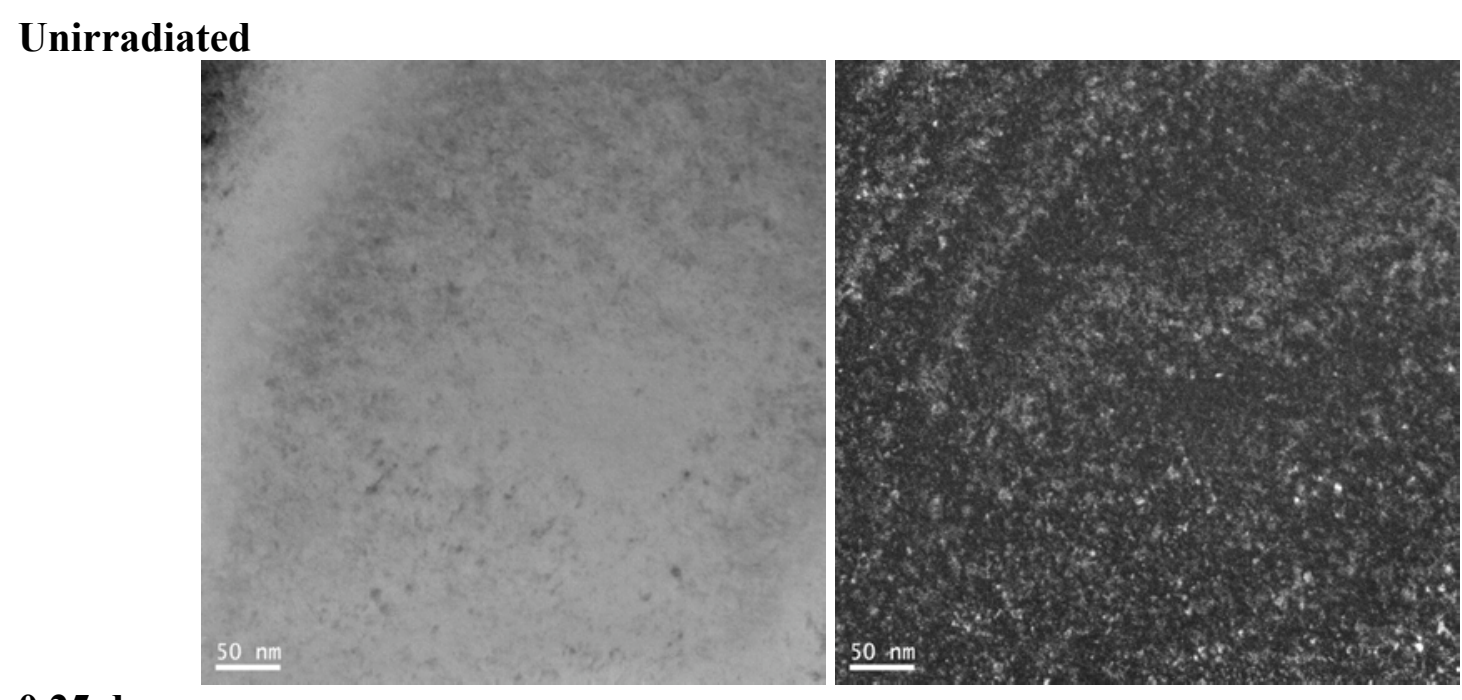

0.25 dpa
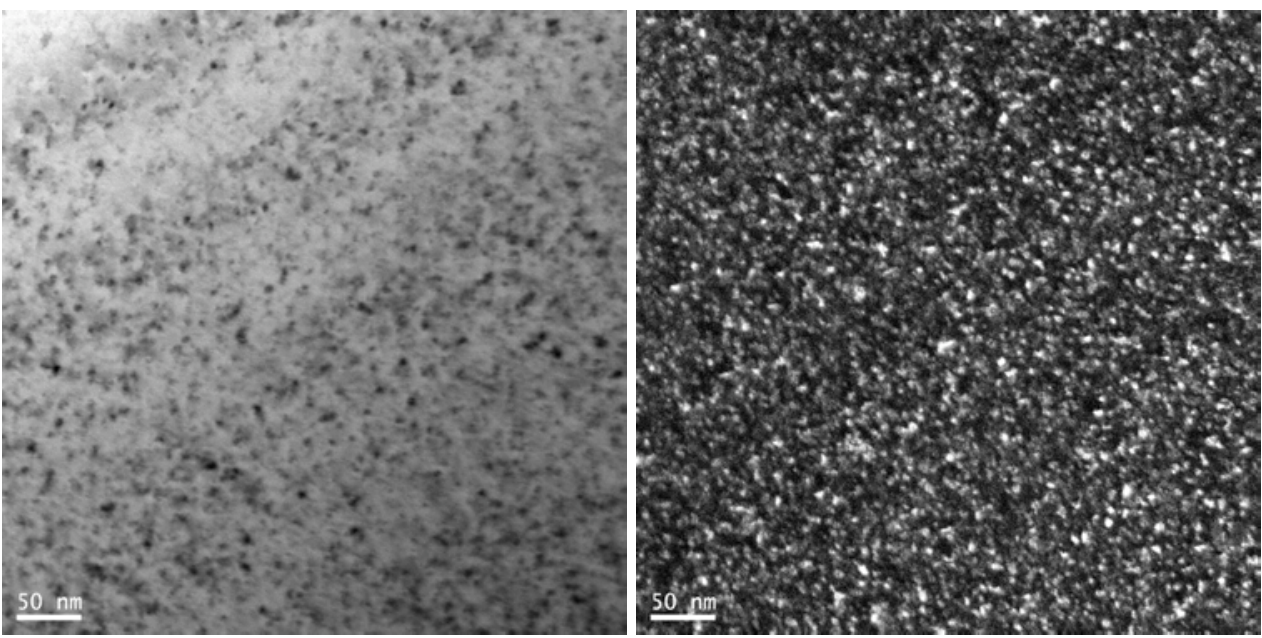

0.5 dpa
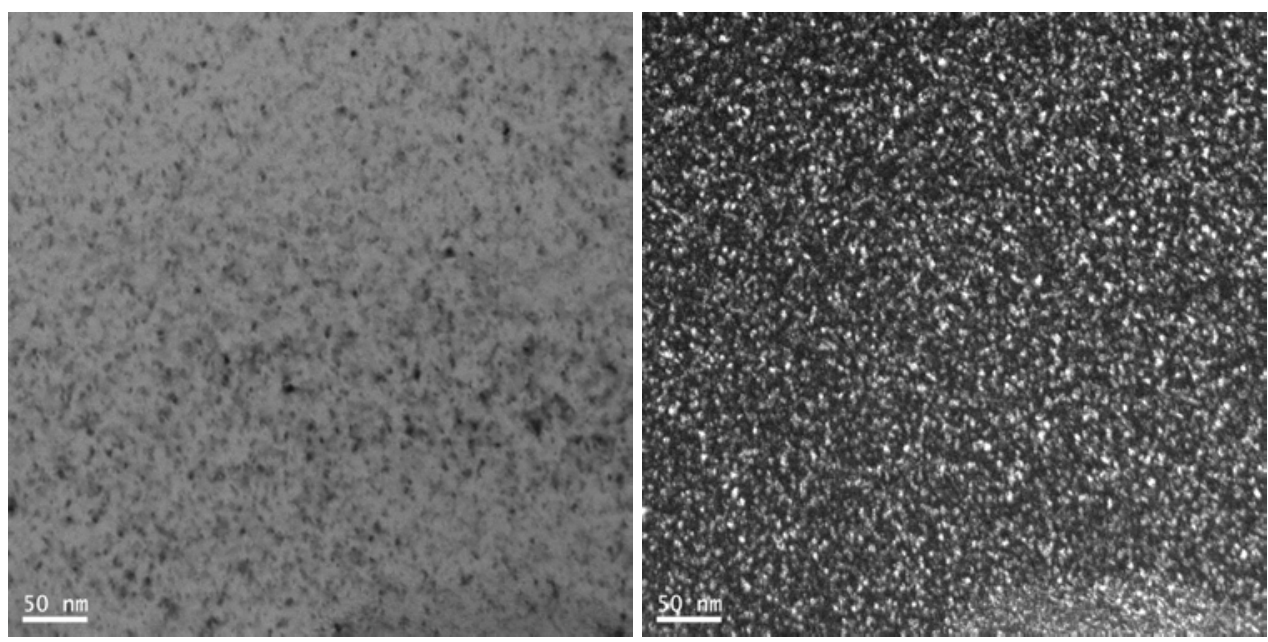

Figure 5.2. Kinematical BF images and WBDF images for unirradiated and irradiated TiC 

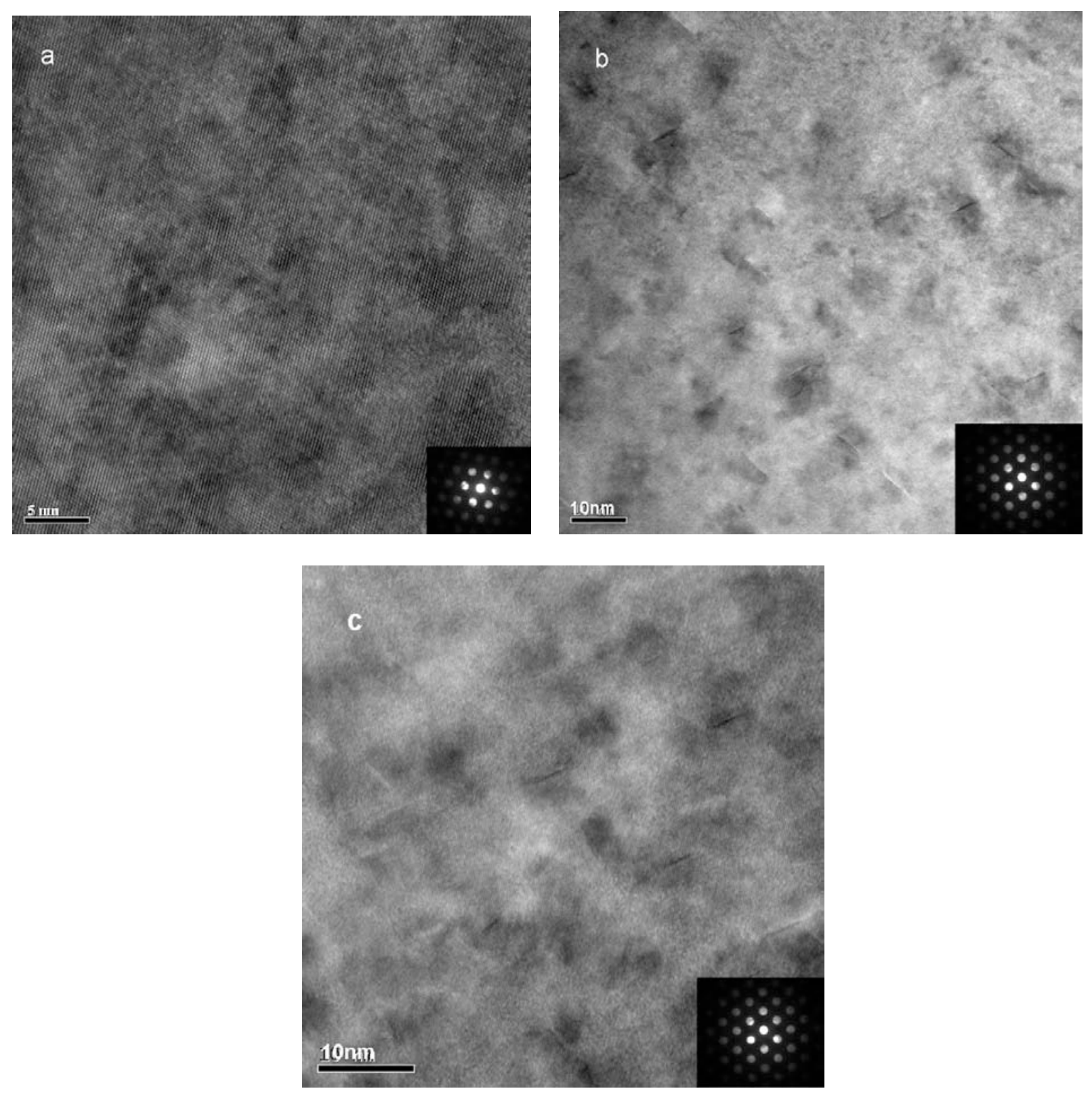

Figure 5.3. (a) Unirradiated TiC, (b) 0.25 dpa TiC, (c) 0.5 dpa TiC 


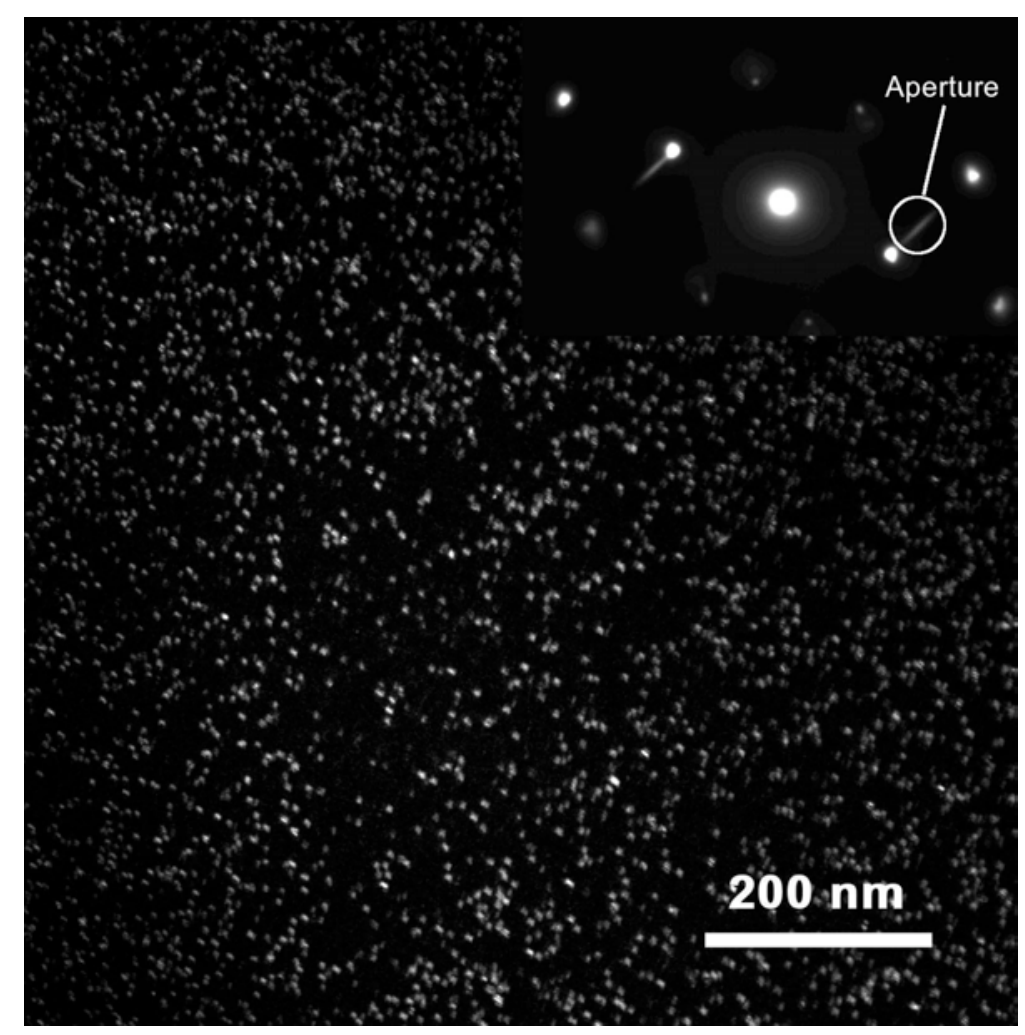

Figure 5.4. Rel-rod DF image of $\mathrm{TiC}$ at $0.5 \mathrm{dpa}$

The densities of the Frank-type dislocation loops that develop in irradiated TiC have been determined from WBDF, g(4.5g) for $\mathrm{g}=200$, images of $0.25 \mathrm{dpa}$ and $0.5 \mathrm{dpa}$ TiC irradiated at $800^{\circ} \mathrm{C}$. Figure 5.5 shows a typical image used to measure the loops, while Table 5.1 reports the densities and average sizes. Figure 5.6 displays the size distribution of the dislocation loops in the irradiated TiC; it can be seen that the higher dose doesn't change the size distribution, while the density apparently increases with irradiation dose. 


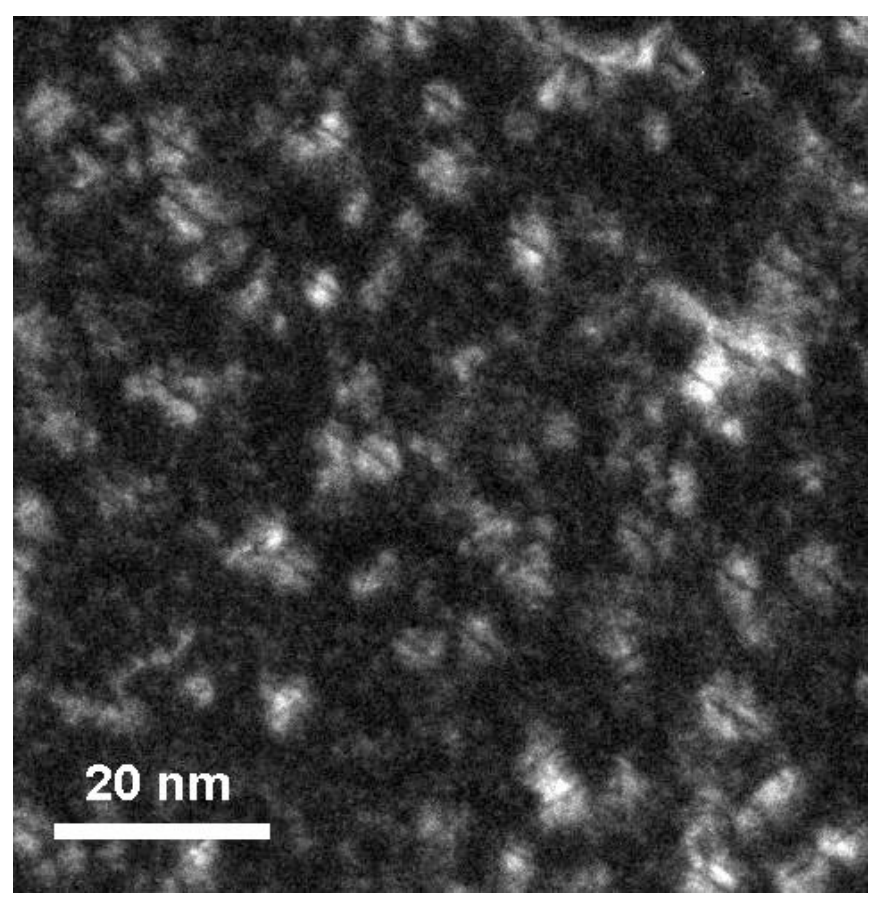

Figure 5.5. WBDF image, $\mathrm{g}(4 \mathrm{~g})$ for $\mathrm{g}=200$, of $0.5 \mathrm{dpa} \mathrm{TiC}$ irradiated at $800^{\circ} \mathrm{C}$

Table 5.1. Mean size and density measurements for $\mathrm{TiC}$ irradiated at $800^{\circ} \mathrm{C}$

\begin{tabular}{ccc}
\hline Dose $(\mathrm{dpa})$ & Mean size $(\mathrm{nm})$ & Density $\left(\mathrm{m}^{-3}\right)$ \\
\hline 0.25 & 3.0 & $7.4 \times 10^{22}$ \\
0.5 & 2.9 & $1.8 \times 10^{23}$ \\
\hline
\end{tabular}




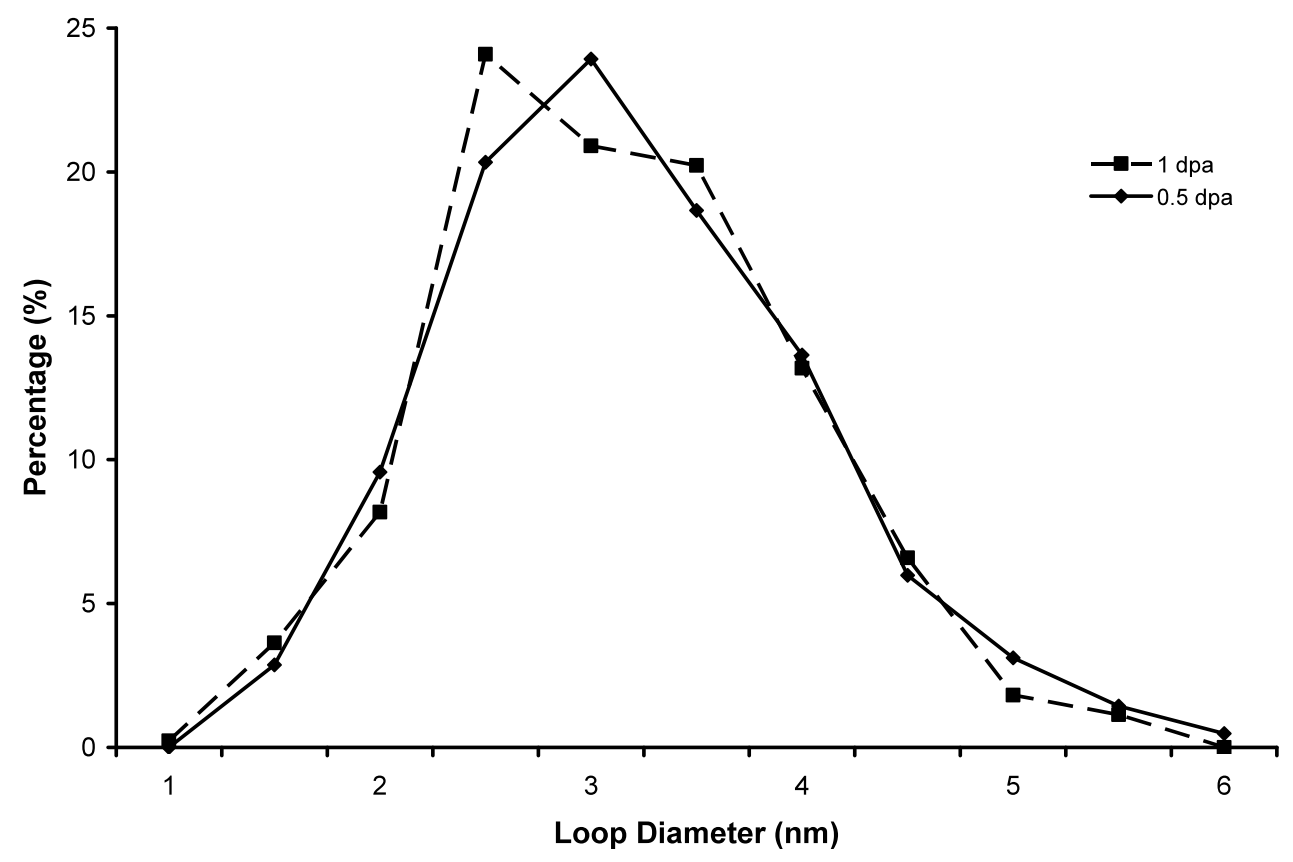

Figure 5.6. Dislocation loop size distributions for $\mathrm{TiC}$ irradiated at $800^{\circ} \mathrm{C}$

Zones of material free of defects near grain boundaries were found in $\mathrm{TiC}$, as displayed in Figure 5.7. The widths of these zones for the two dose conditions are presented in Table 5.2. These denuded zones narrow as the dose increases. A similar trend was found in this project for irradiated $\mathrm{ZrC}$.

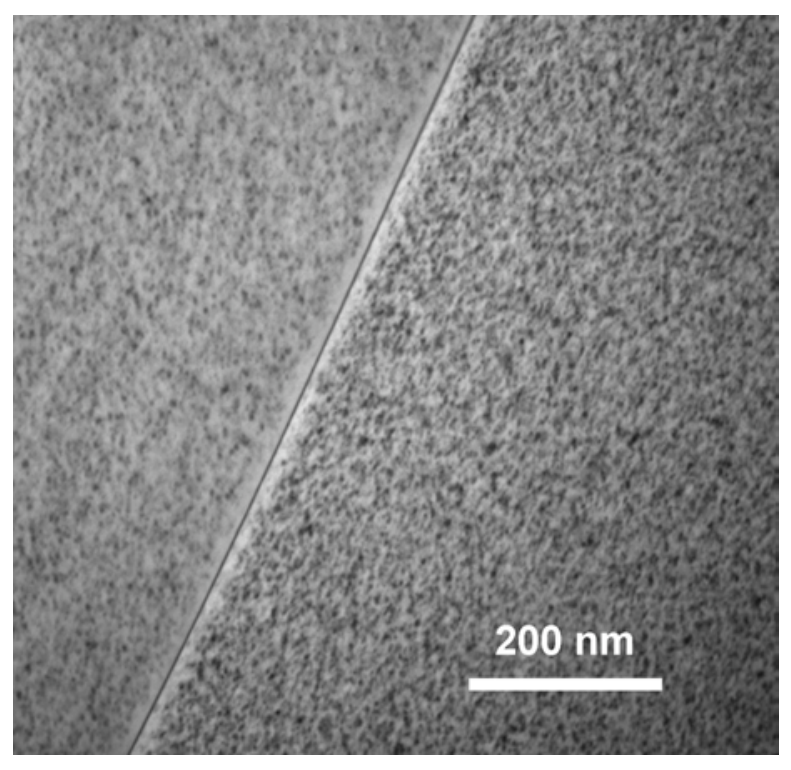

Figure 5.7. Example of the grain boundary denuded zone in $\mathrm{TiC}$ irradiated to $0.5 \mathrm{dpa}$ at $800^{\circ} \mathrm{C}$ 
Table 5.2. Grain boundary denuded zone widths in $\mathrm{TiC}$ irradiated at $800^{\circ} \mathrm{C}$

\begin{tabular}{|c|c|}
\hline Dose (dpa) & Denuded Zone width (nm) \\
\hline 0.5 & 21.8 \\
1.0 & 18.5 \\
\hline
\end{tabular}

\subsection{X-ray diffraction}

For an ideal system, every set of planes in a crystalline material would correspond to a characteristic diffracted peak with infinitesimally small width, and the $2 \theta$ position of every peak could be used to calculate an accurate lattice parameter via the derived plane spacing, $d$, from Bragg's Law. However, for any real system, unavoidable systematic and random errors lead to peak displacements and broadening. Displacements associated with systematic aberrations that arise in the X-ray diffraction process leave the recorded peaks at higher $2 \theta$ values than what would be expected, while displacements due to random errors can cause peak positions to increase or decrease from their true values. Eliminating these errors to accurately calculate the material's lattice parameter can be a useful technique in assessing radiation effects.

In terms of mitigating errors, it is advantageous that $\sin \theta$ and not $\theta$ alone is present in Bragg's Law, $\lambda=2 d \sin \theta$. Understanding the $\sin$ function from $\theta=0^{\circ}-90^{\circ}$, it is apparent that for a fixed error in $\theta$, the error in $\sin \theta$ is minimized as $\theta$ approaches $90^{\circ}$; Figure 5.8 . While practically it is impossible to make measurements at $\theta=90^{\circ}\left(2 \theta=180^{\circ}\right)$, it is possible to extrapolate to this value based on peaks recorded in the achievable $2 \theta$ range [5.1]. For rudimentary lattice parameter determination, a lattice parameter is calculated for each peak based on the centroid of the peak, the plane spacing, and the index of the planes. These lattice parameter values are then extrapolated to $\theta=90^{\circ}$. However, because of the nature of X-ray diffraction, these values should be extrapolated against a trigonometric function of $\theta$ and not $\theta$ itself. The selection of the functional form is very important and should be determined based on the magnitude and types of errors present (i.e. beam divergence, sample misplacement, polarization, etc) [5.2].

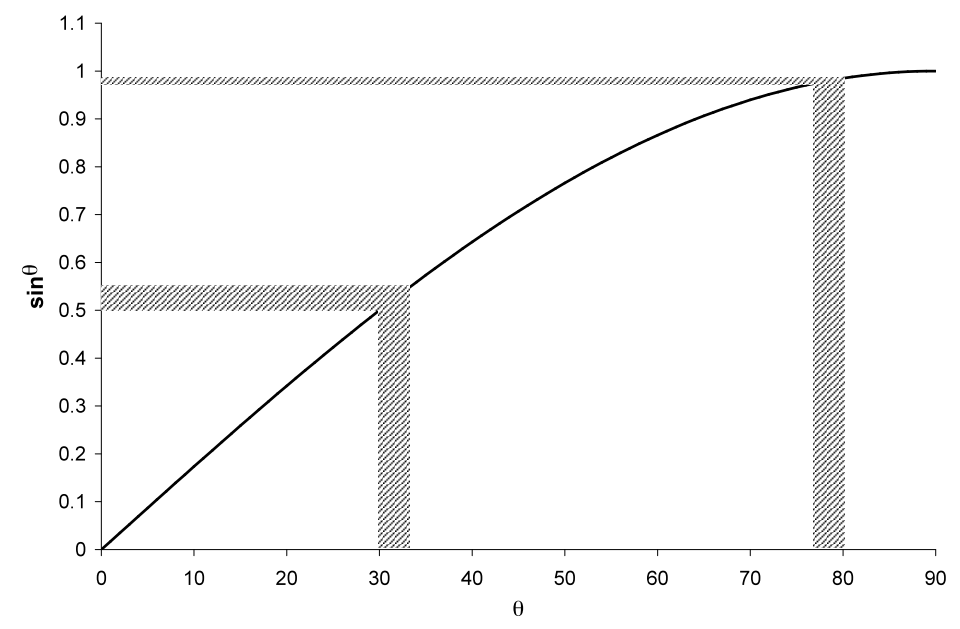

Figure 5.8. The error in $\sin \theta$ approaches zero as $\theta$ approaches $90^{\circ}$ 
Thus far the functional form used corresponds to a customarily predominant error, that of sample positioning error $\left(\cos ^{2} \theta / \sin \theta\right.$, and the lattice parameters determined by extrapolation to $\theta=90^{\circ}$ for various irradiation conditions based on this function. The relation between lattice parameter and dose for $\mathrm{TiC}$ is, for the most part, typical of many other systems. Irradiation by protons creates point defects in the lattice and causes the lattice to strain. Further exposure to energetic protons results in a continued accumulation of point defects and, thus, continued strain up to some saturation level. Also typical is the decrease in the difference in lattice strain for a given dose as the temperature increases. The lattice changes versus different irradiation conditions are summarized in Figure 5.9. There are very clear trends that as the dose increases, the lattice expansion becomes larger, while for a certain dose, the lattice increment decreases with increasing temperature; Figure 5.10 shows this relation more clearly for the dose of 0.25 dpa.

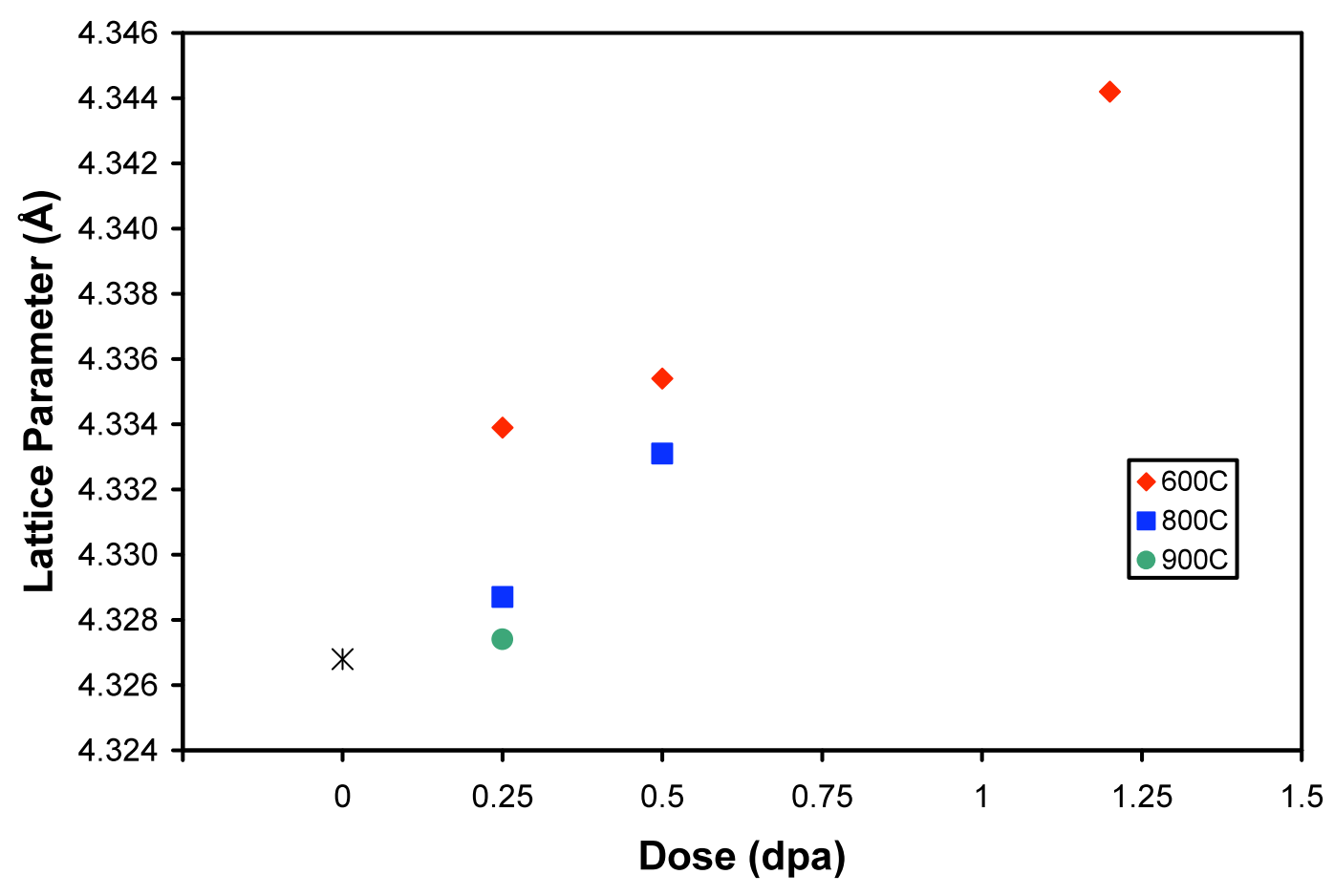

Figure 5.9. Lattice parameters vs. dose for different irradiation temperatures 


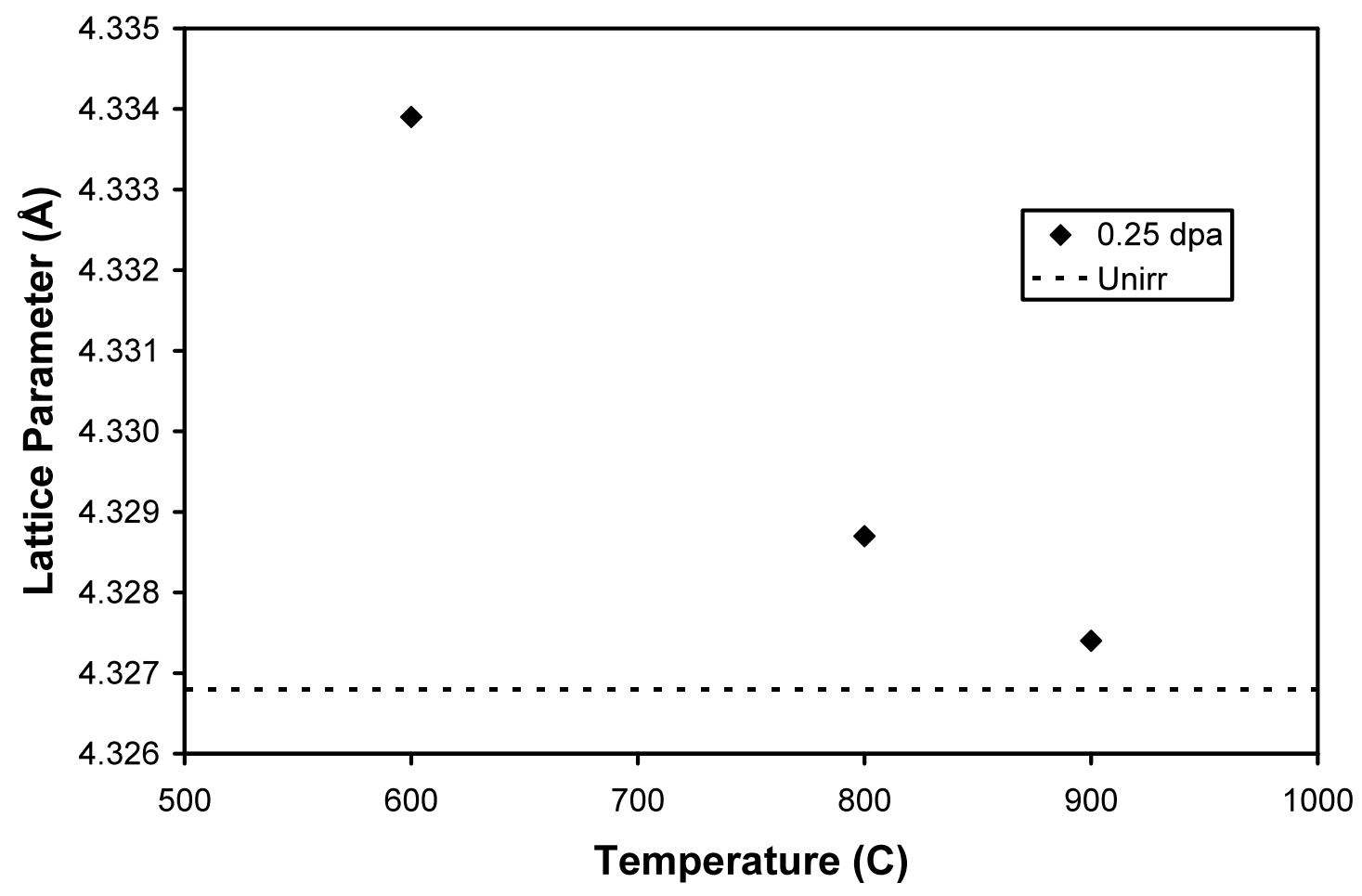

Figure 5.10. Lattice parameters vs. irradiation temperatures for a dose of 0.25 dpa

\subsection{Microhardness}

In an attempt to find a hardness measurement technique resulting in more acceptable indents per indents made, instead of using the Vickers indenter the Knoop indenter was employed with a load of 50gf. An added advantage of this arrangement is that the size of the indent is small enough to be accurately positioned on material free of surface defects, which increases the likelihood of an acceptable result. Figure 5.11 shows a schematic of the Knoop indenter and a DF optical of indentations on the sample surface. Hardness values for TiC at different irradiated conditions, presented in Figure 5.12, show hardening of the material due to development of dislocation loops, and give some indication that the defect microstructures may be similar. 

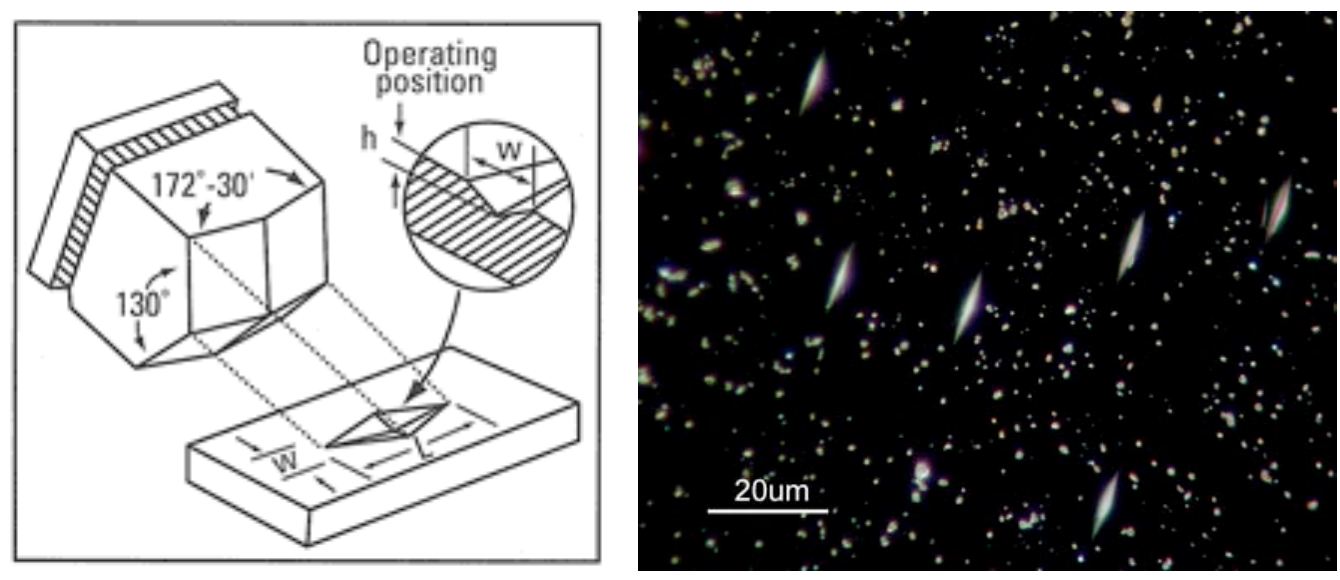

Figure 5.11. Schematic of the Knoop indenter and Knoop indentations on TiC

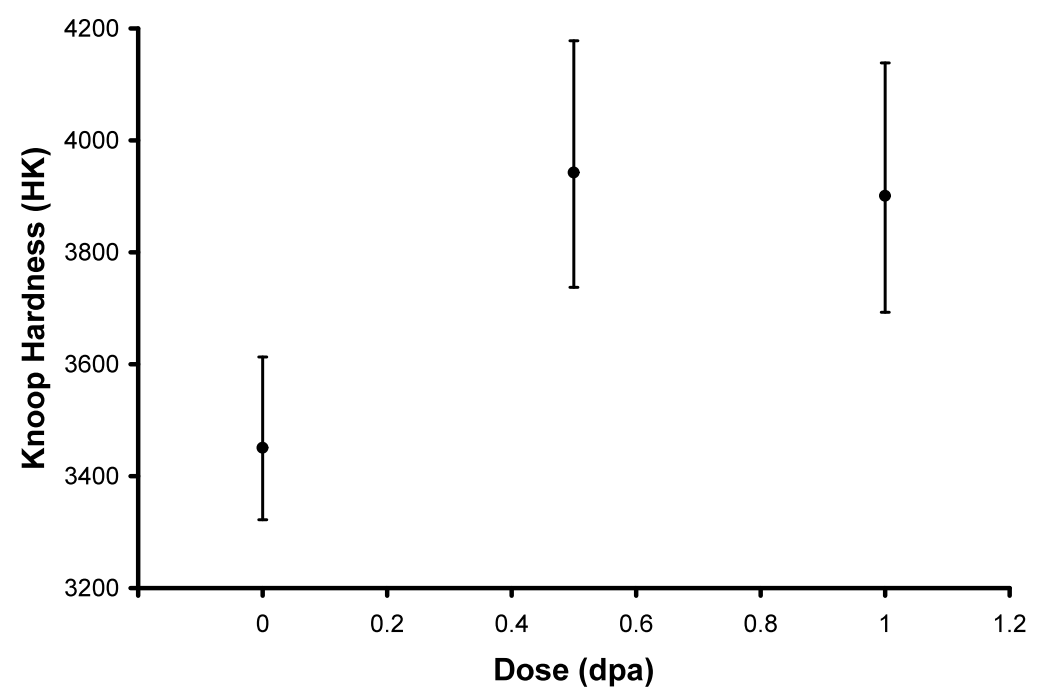

Figure 5.12. Knoop hardness values for $\mathrm{TiC}$ irradiated at $800^{\circ} \mathrm{C}$

\subsection{Fracture toughness}

The ability of a coated fuel particle to resist stresses from thermal expansion and internal fission gas production are vital to its use as a reliable fuel type. Fracture toughness indicates the stress at which failure in a material will occur, given an initial flaw size. Methods for measuring the fracture toughness of pre-notched bulk ceramic specimens with well-defined geometry have been studied and standardized [5.3]. However, the concern of this study is to understand the changes induced by exposure to energetic protons, and since the range of protons in the ceramics of concern is only on the order of $\sim 40 \mu \mathrm{m}$, the need for a method to measure the fracture toughness of small volumes of material is important. Cracks emanating from the corners of Vickers indents have been used in the past, but their applicability to standard $K_{I c}$ fracture toughness measurements has been questioned [5.4]. As a result, a new method of measuring the fracture toughness of thin films is being investigated. This process involves creating micro cantilever 
beams using a FIB on the surface of a material, but with a thin radiation affected area. These cantilever beams are then loaded in a nano-indentation instrument until fracture. For testing purposes, unirradiated $\mathrm{TiC}$ has been the only material studied thus far.

Fabrication of the microbeams follows closely with the procedures described in the literature $[5.5,5.6]$ and is performed with a Zeiss $1500 \mathrm{XB}$ CrossBeam ${ }^{\circledR}$ Workstation using $30 \mathrm{keV} \mathrm{Ga}^{+}$ ions. The first step is to mill two rectangles, $7 \mathrm{~mm}$ deep and $6 \mathrm{~mm}$ apart, with a current of 2000 $\mathrm{pA}$ to provide the basis for the cantilever; Figure 5.13(a). Using a finer milling current, $500 \mathrm{pA}$, which mitigates the amount of affected material adjacent to the feature; two smaller rectangles are used to more accurately define the beam; Figure 5.13(b). At this point the feature is $4 \mathrm{~mm}$ wide by $10 \mathrm{~mm}$ long. One end of the beam is then removed using a 500pA current, which leaves a beam length of roughly $8 \mathrm{~mm}$; Figure 5.13(c). At this point the beam is still completely supported by the underlying material, so to create a cantilever the sample is rotated $45^{\circ}$ about the long axis of the beam so the FIB can remove material directly beneath the beam; Figure 5.13(d). This step is repeated after the sample is spun $180^{\circ}$ about an axis perpendicular to its surface which presents the other vertical face of the beam. The resulting beam cross section is shown in Figure 5.13 (e). The final step is to introduce an initial flaw from which a critical failure will propagate, by defining a fine line feature near the base of the beam; Figure 5.13 (f). A current of $10 \mathrm{pA}$ is used for this final operation and the resulting feature is $0.06 \mathrm{~mm}$ wide by $0.5 \mathrm{~mm}$ deep. As can be seen in the inset of Figure 5.13(f), which shows the cross section of a typical $10 \mathrm{pA}$ fine line feature, the width at the tip is about $10 \mathrm{~nm}$.

The sample is then transferred to a Digital Instruments atomic force microscope fitted with a Hystron nano-indentation transducer. A Berkovich tip is used to image the sample, as well as apply the load. The load is applied $0.5 \mathrm{~mm}$ from the free end of the beam until fracture. A pretested AFM image, as well as a post failure image of the beam, are shown in Figure 5.14, and a typical load versus displacement curve for unirradiated $\mathrm{TiC}$ is reported in Figure 5.15.

The equation used to calculate the plane stress fracture toughness, $K_{I c}$, is

$$
K_{I c}=\sigma_{c} \sqrt{\pi a} F\left(\frac{a}{b}\right)
$$

where $a$ is the initial flaw size, $b$ is the nominally vertical height of the side of the beam, $F=\left(\frac{a}{b}\right)$ is a dimensionless shape factor based on sample geometry and its form was borrowed from Zhao et al., and $s_{c}$ is the critical stress. Assuming that only small deformations occur such that the applied force is nominally perpendicular to the surface of the beam at all times $s_{c}$ can be expressed as

$$
\sigma_{c}=\frac{P L \bar{y}}{I}
$$

where $P$ is the applied load at failure, $L$ is the length from the initial flaw to the point of load application, $\bar{y}$ is the distance from the top surface of the beam to its neutral plane, and $I$ is the second moment of area of the beam's cross section. Both the neutral plane and second moment of area are calculated using the tilt corrected view of the cross section of the beam; Figure 13(e). $K_{I c}$ for unirradiated $\mathrm{TiC}$ was measured to be $4.48 \mathrm{MPa} \sqrt{m}$, which agrees well with the value reported by NIST [5.5] of 3.8MPa $\sqrt{m}$. 
This method has great promise to return reliable fracture toughness data for the irradiated ceramics, which can then be incorporated with other data from the microstructure to develop a full understanding of radiation-induced effects.

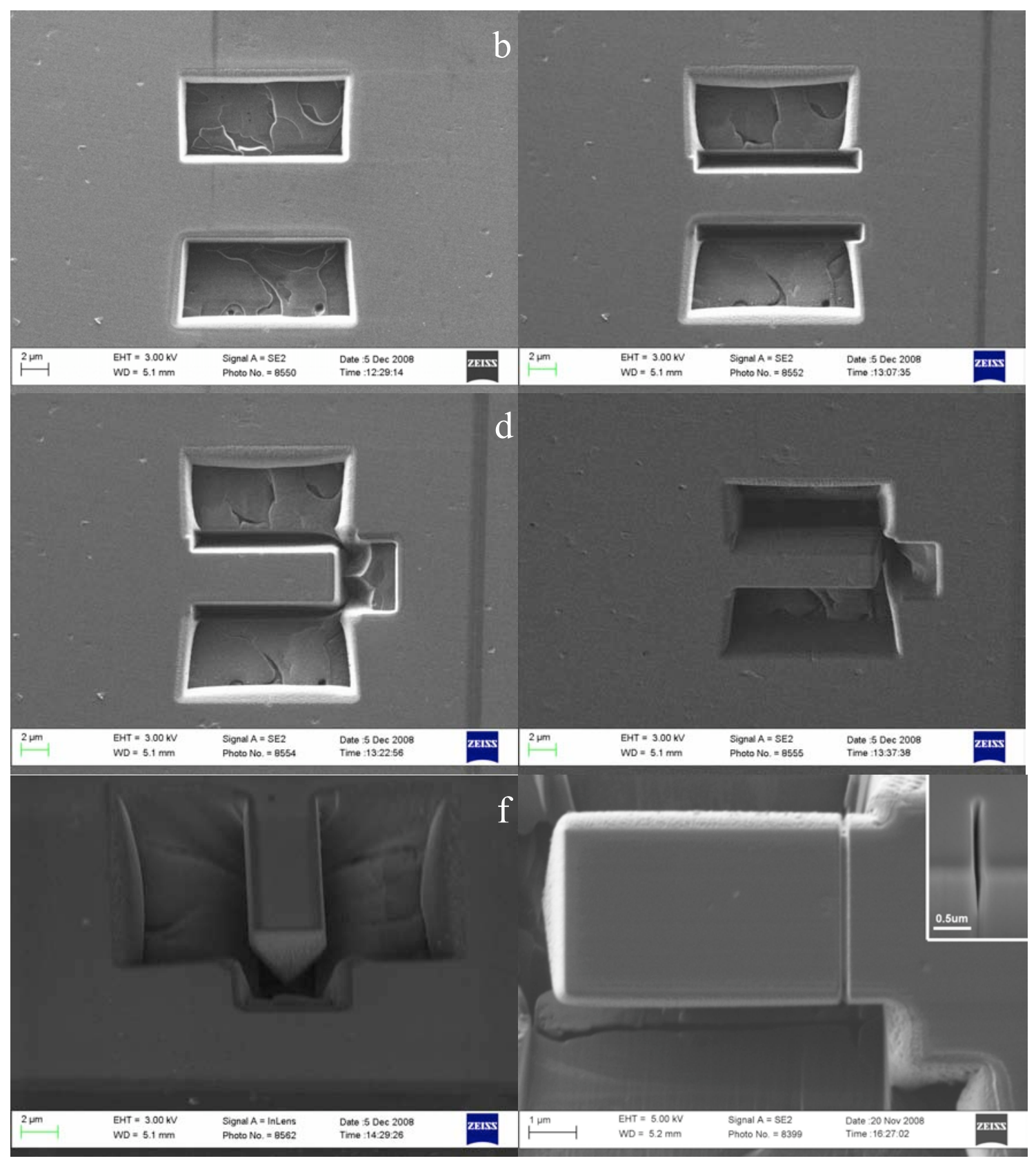

Figure 5.13. a-f: FIB images of the step-by-step process for fabricating a micro cantilever beam. 


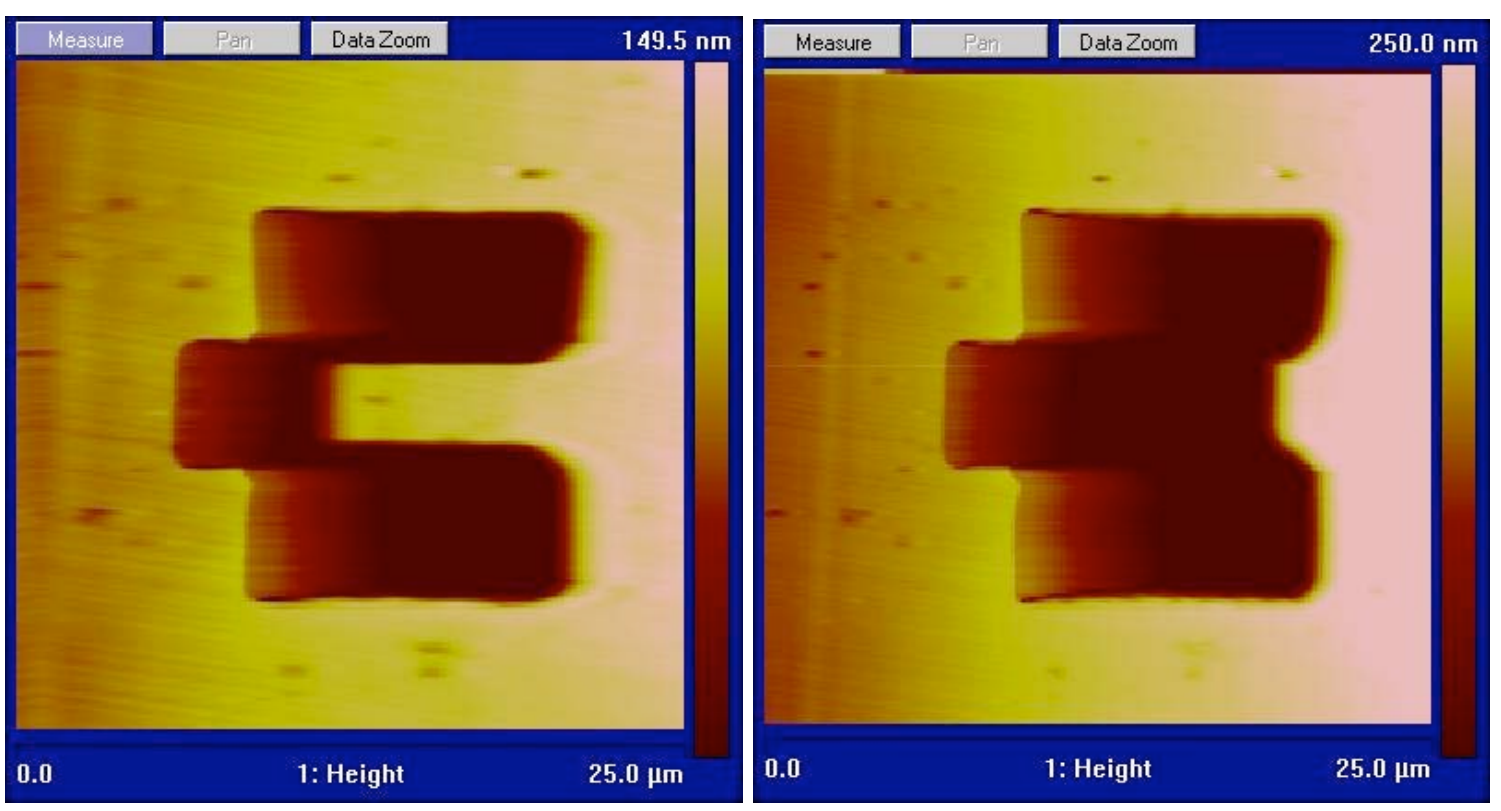

Figure 5.14. AFM images of the micro cantilever beam before and after loading

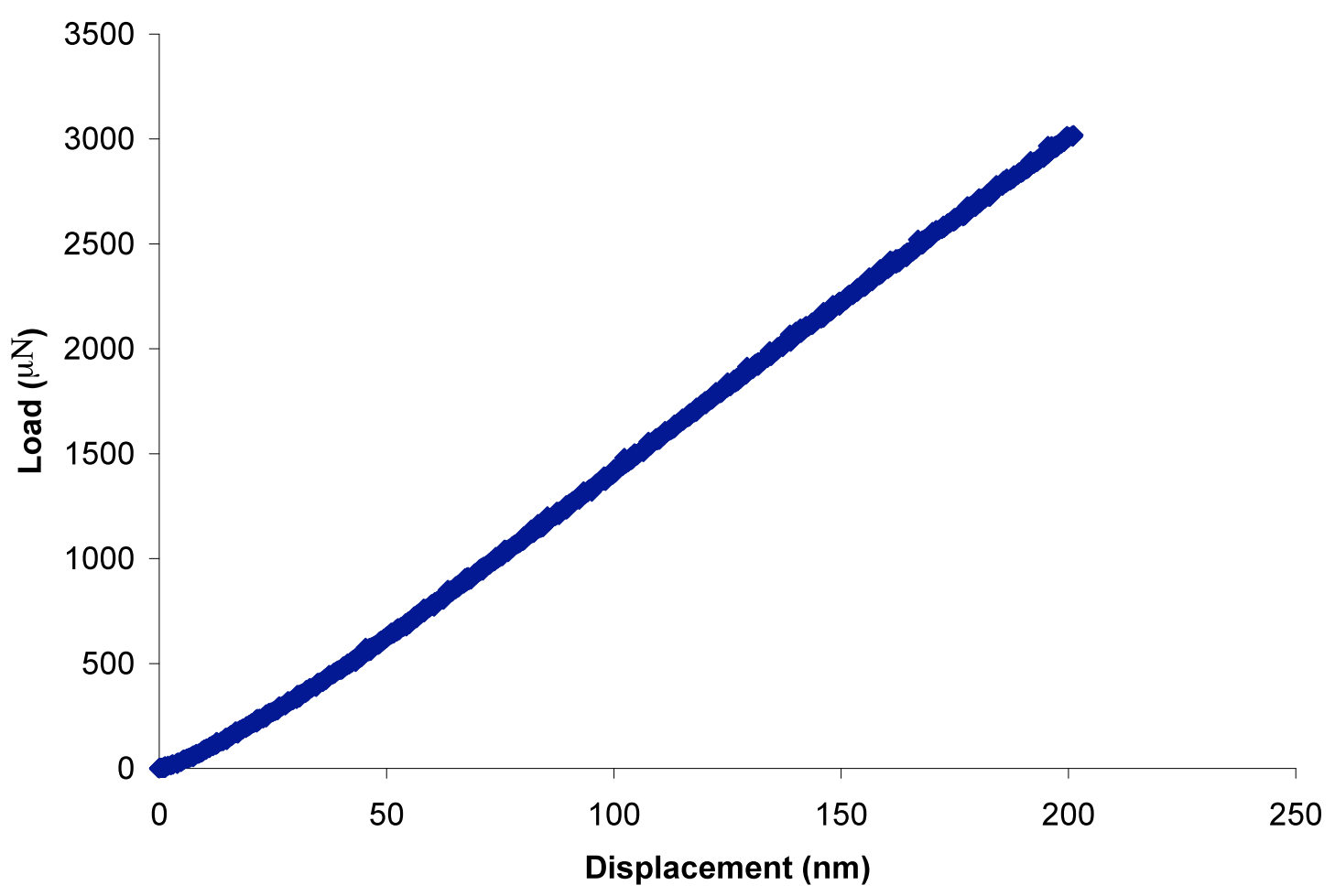

Figure 5.15. The load vs. displacement curve for a micro cantilever loaded to failure 


\section{References}

5.1. Cullity, B.D., Elements of X-ray Diffraction. 2 ed. 1978, Reading, MA: Addison-Wesley. 5.2. Wilson, A.J.C., Mathematical Theory of X-ray Powder Diffraction. 1963, Eindhoven, Netherlands: Philips Gloeilampenfabrieken. 128.

5.3. ASTM C-1421, Standard Test Methods for Determination of Fracture Toughness of Advanced Ceramics at Ambient Temperature, (2007)

5.4. Quinn, G., J. Am. Ceram. Soc., 90 [3] 673-680 (2007)

5.5. Di Maio, D. and S.G. Roberts, J. Mater. Res., 20 [2] (2005)

5.6. Zhao, X. et al., Scripta Materialia 59 39-42 (2008) 


\section{TiN}

\subsection{SEM and EDS characterization}

The SEM image of TiN in Figure 6-1 shows relatively high porosity and no apparent inclusions were observed. The EDS spectrum matches very well with the chemical composition in Table 2.1 .
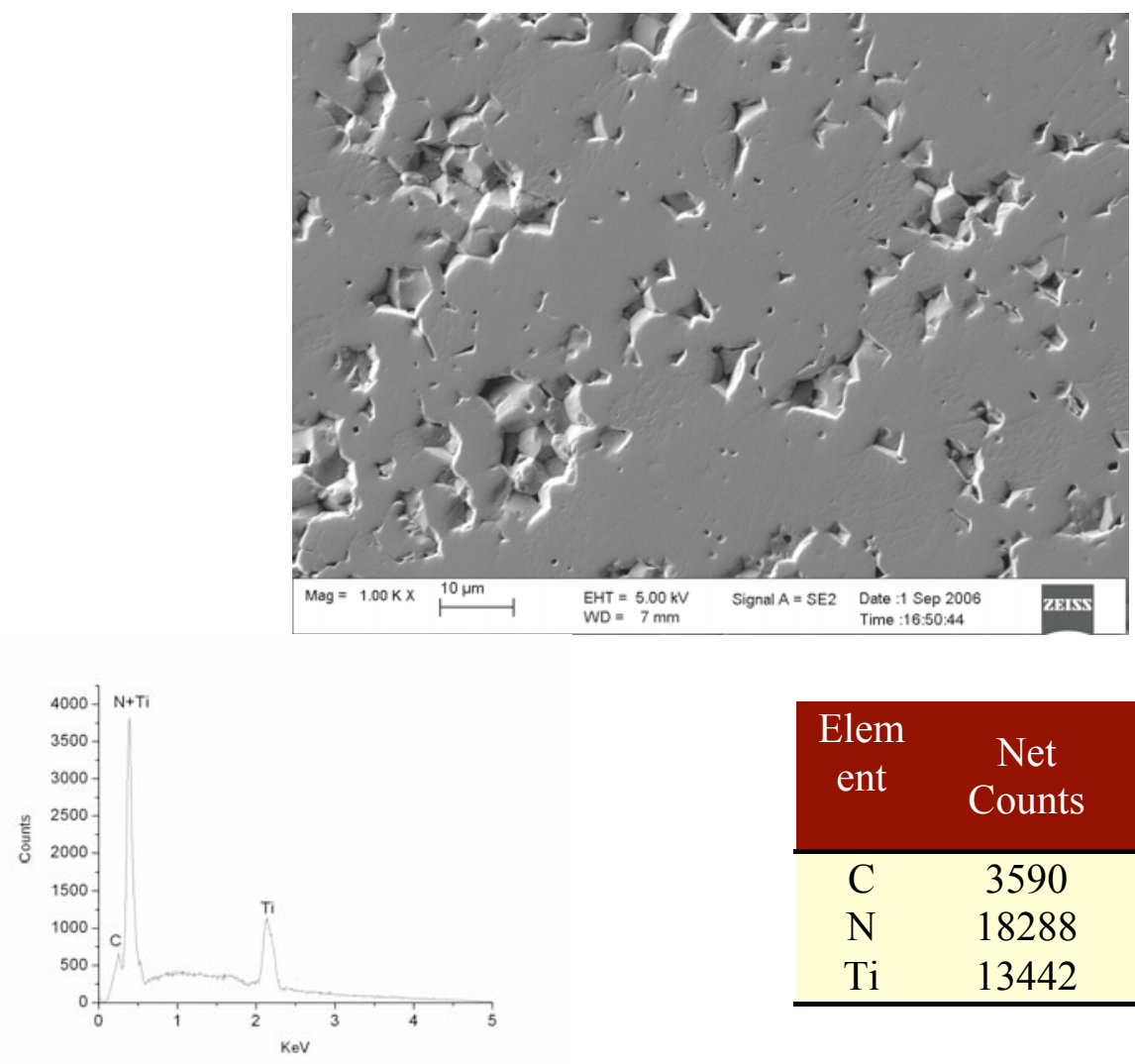

\begin{tabular}{cccc}
$\begin{array}{c}\text { Elem } \\
\text { ent }\end{array}$ & $\begin{array}{c}\text { Net } \\
\text { Counts }\end{array}$ & $\begin{array}{c}\text { Weig } \\
\text { ht } \%\end{array}$ & $\begin{array}{c}\text { Atom } \\
\%\end{array}$ \\
\hline $\mathrm{C}$ & 3590 & 1.74 & 4.60 \\
$\mathrm{~N}$ & 18288 & 18.80 & 42.67 \\
$\mathrm{Ti}$ & 13442 & 79.46 & 52.73 \\
\hline
\end{tabular}

Figure 6.1. SEM and EDS characterization of TiN

As shown in TEM images in Figure 6.2, the unirradiated microstructure of TiN is generally free from pre-existing defects, and no dislocations were observed. 

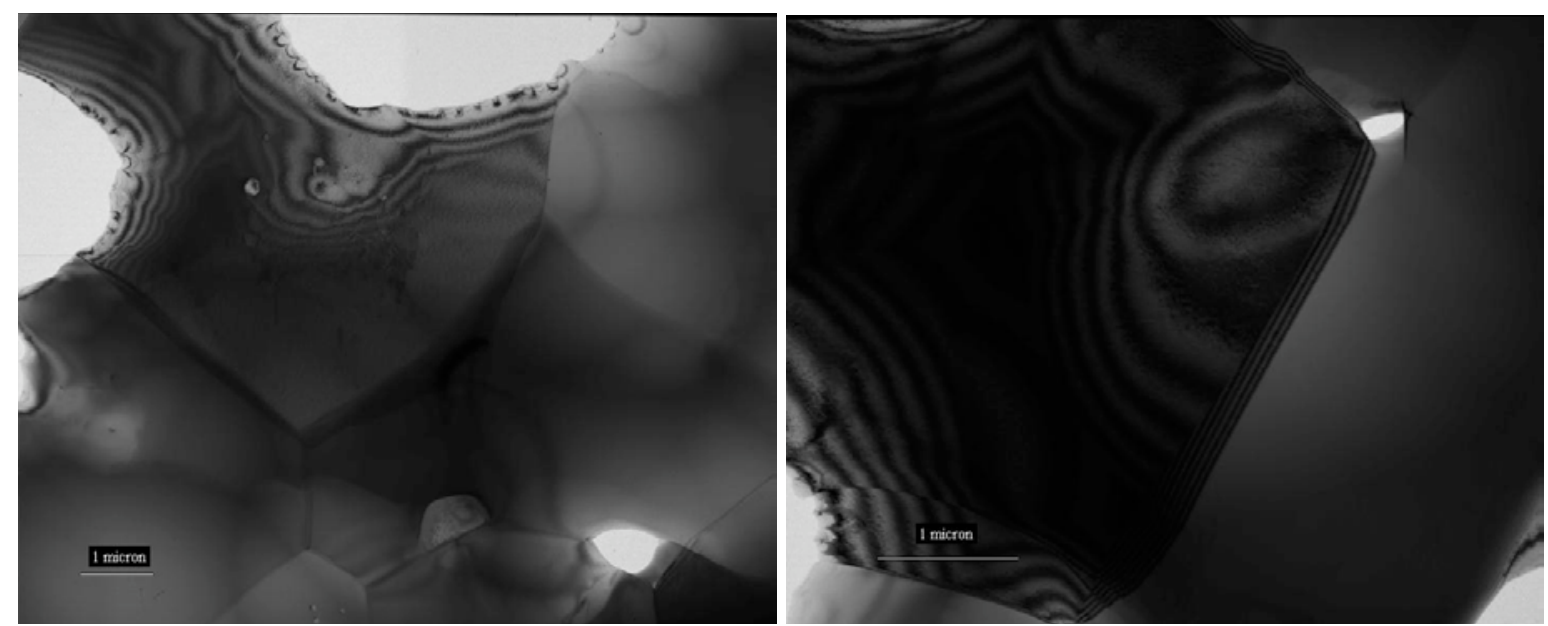

Figure 6.2. TEM images of unirradiated TiN

\subsection{TEM Characterization of irradiated TiN}

\subsubsection{Irradiated at $800^{\circ} \mathrm{C}$}

The presence of stacking fault tetrahedra (SFT) in titanium nitride irradiated at $800^{\circ} \mathrm{C}$ to a dose of 1 dpa was confirmed. Features similar to Frank-type dislocation loops seen in irradiated TiC have been found in TiN; Figure 6.3. These line contrasts with accompanying strain fields have the $\sim 70^{\circ}$ difference in orientation that is characteristic of features lying on $\{111\}$ planes, which have a difference between planes of $70.52^{\circ}$. The SFT occur with a much higher density than do the loops, so size distribution was readily determined for the statistically significant SFT data, while it has been omitted for the loop data. Densities and average sizes were also determined for the measured features; Table 6.1. The edge length was used for SFT, while the diameter was measured for loops. 


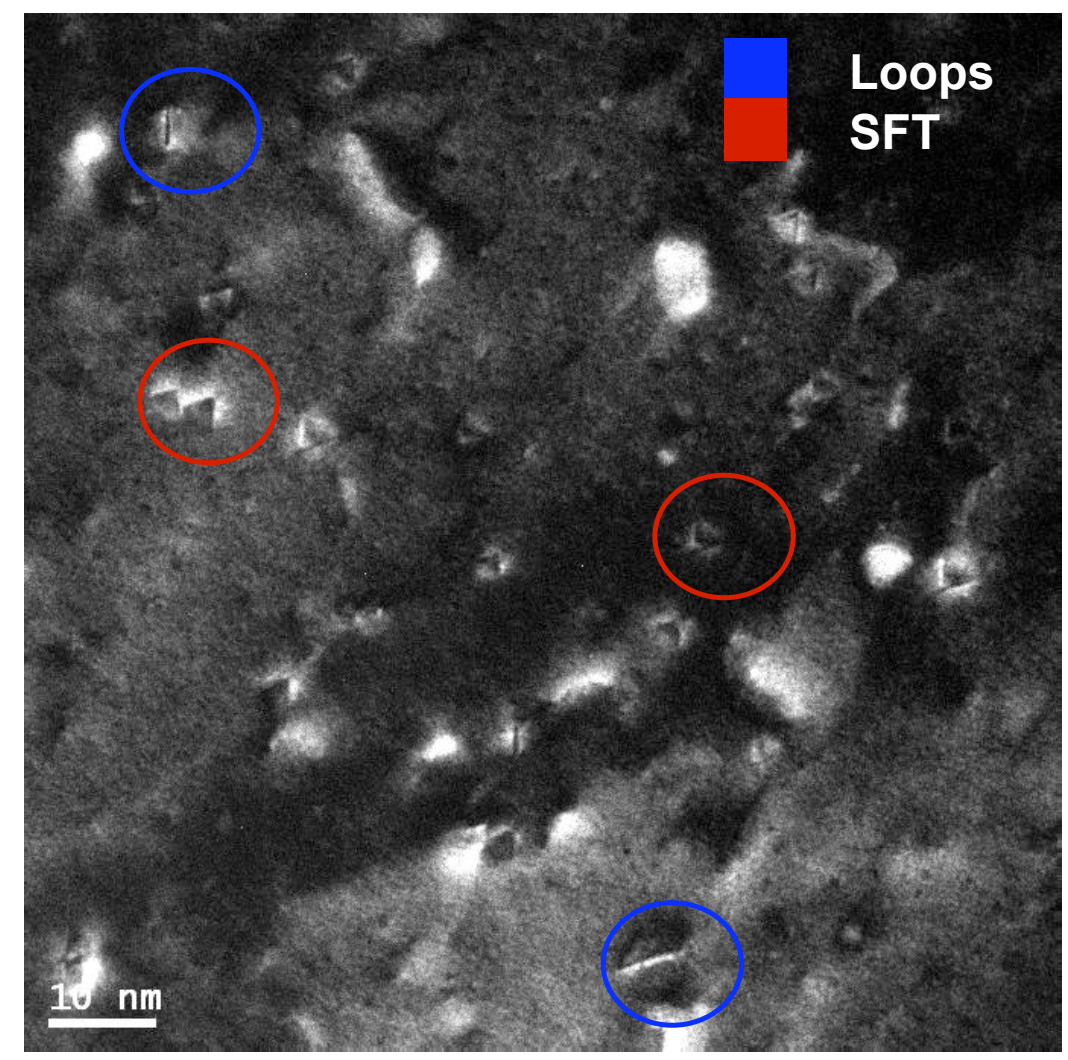

Figure 6.3. WBDF image, $\mathrm{g}(4.5 \mathrm{~g})$ with $\mathrm{g}=200$, of TiN irradiated at $800^{\circ} \mathrm{C}$ to a dose of $0.5 \mathrm{dpa}$ showing both SFT and loops

Table 6.1. Summary of defects in irradiated TiN

\begin{tabular}{|c|c|c|c|}
\hline Dose (dpa) & Defect type & Mean size $(\mathrm{nm})$ & Density $\left(\mathrm{m}^{-3}\right)$ \\
\hline \multirow{2}{*}{0.5} & SFT & 2.9 & $5.2 \times 10^{22}$ \\
\cline { 2 - 4 } & FL $^{*}$ & 3.0 & $6.9 \times 10^{21}$ \\
\hline \multicolumn{3}{|c|}{$*$ Only based on 47 measurements } \\
\hline
\end{tabular}

\section{$\underline{6.2 .3 \text { Irradiated at } 600^{\circ} \mathrm{C}}$}

SFT and Frank-type dislocation loops were present in all dose conditions of the samples irradiated at $600^{\circ} \mathrm{C}$. Figure 6.4 shows characteristic WBDF images for each of the three $600^{\circ} \mathrm{C}$ doses. For each image, a ( $g, 5 \mathrm{~g})$ condition was established for $\mathrm{g}=(200)$. The SFT sizes were determined by measuring the edge length of the defects, while the sizes of the FLs are based on the diameter of the loops. Size distribution data is summarized in Figure 6.5 and compared with data collected for the $800^{\circ} \mathrm{C}, 0.5 \mathrm{dpa}$ irradiated case. The distributions, average sizes, and densities of the $600^{\circ} \mathrm{C}, 1.2 \mathrm{dpa}$ and $800^{\circ} \mathrm{C}, 0.5 \mathrm{dpa}$ conditions are very similar, which may indicate a level of defect saturation, or at least a similar point during the evolution of these defects. The fact that these similarities occur at a much lower dose for the $800^{\circ} \mathrm{C}$ irradiation than for the $600^{\circ} \mathrm{C}$ irradiation is a clear sign of increased mobility of point defects at the elevated temperature. The mean SFT sizes and densities are given in Table 6.2. The densities of SFT for 
each of the conditions are very similar, which indicates these defects are initiated quite early during the irradiation and their presence inhibits the formation of new SFT. While further nucleation of these defects is quite difficult, continued irradiation and creation of point defects serves to grow the existing SFT. 

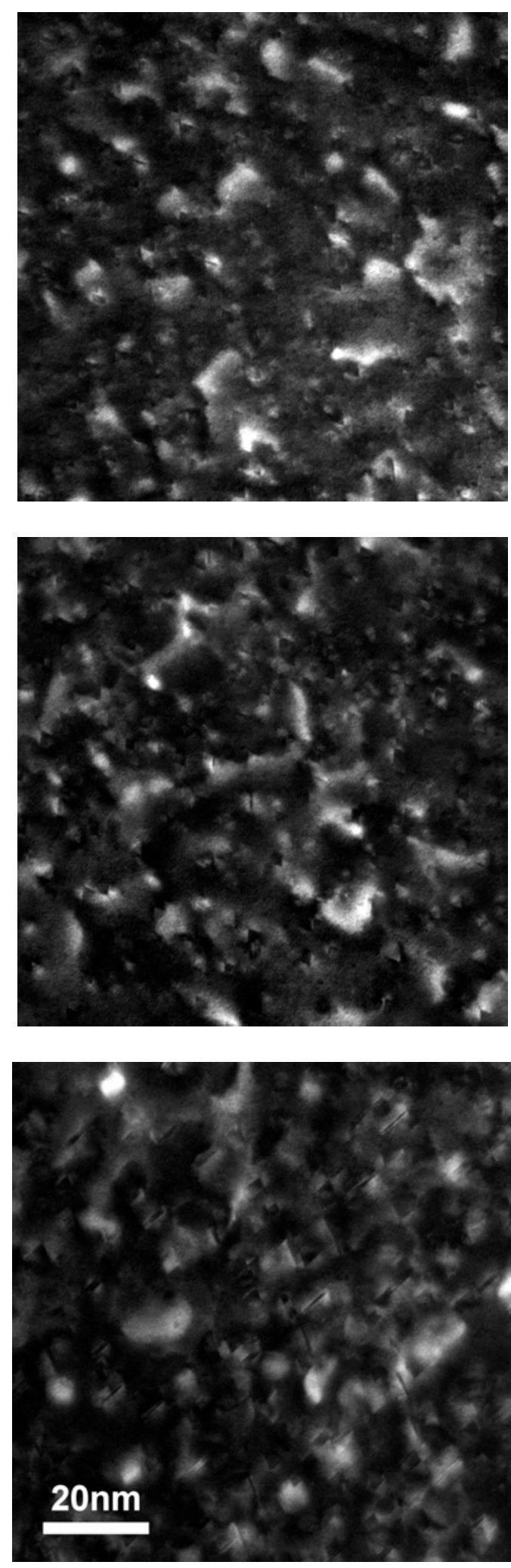

Figure 6.4. WBDF (g5g; $g=\{200\}$ ) images of TiN irradiated at $600^{\circ} \mathrm{C}$ to a) $\left.0.25 \mathrm{dpa}, \mathrm{b}\right)$ $0.5 \mathrm{dpa}$, and c) $1.2 \mathrm{dpa}$ 


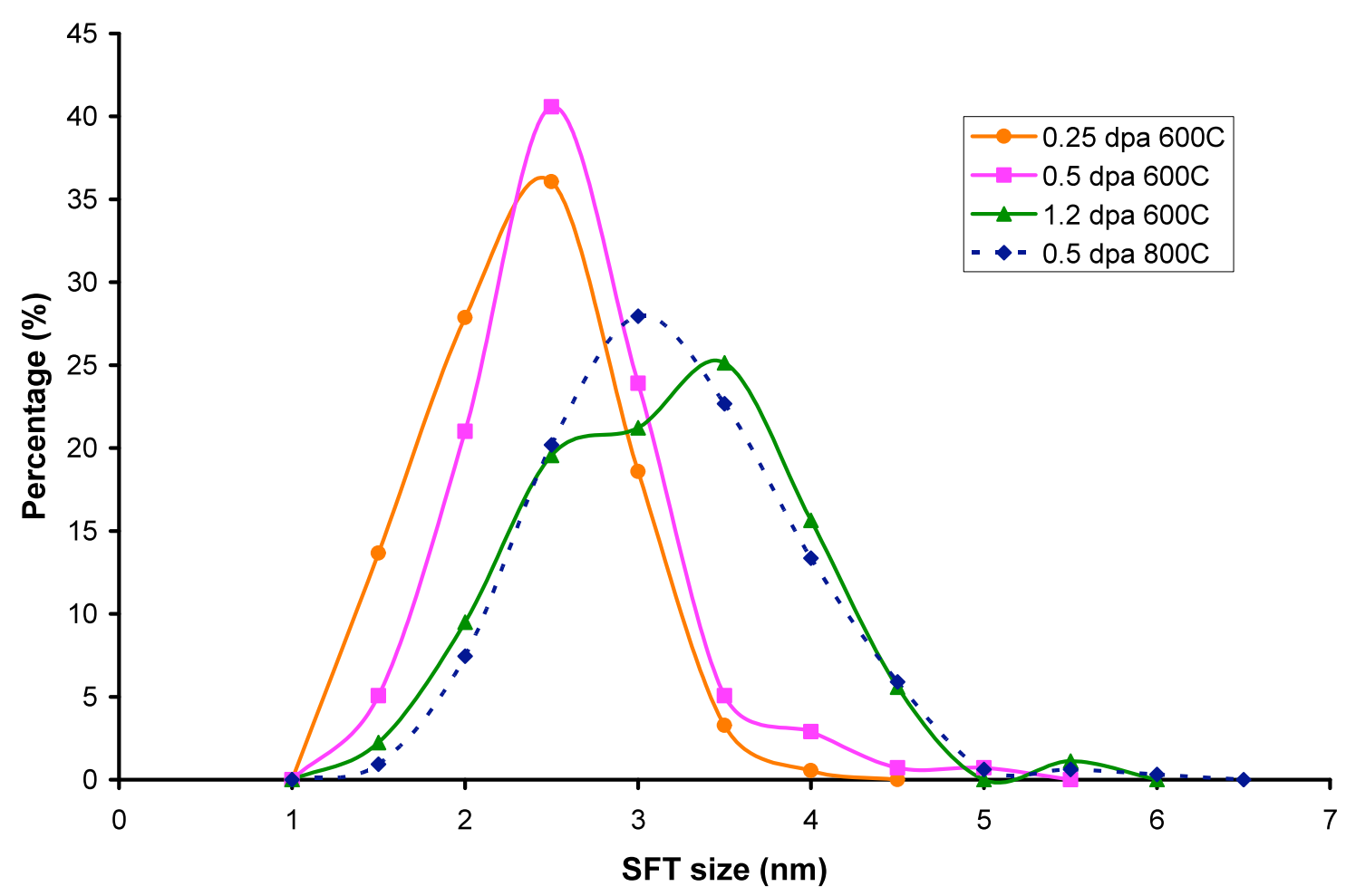

Figure 6.5. Size distributions of SFT for irradiated TiN

Table 6.2. Mean sizes and densities of SFT for irradiated TiN

\begin{tabular}{|c|c|c|c|}
\hline $\begin{array}{c}\text { Dose } \\
(\mathrm{dpa})\end{array}$ & $\begin{array}{c}\text { Temperature } \\
\left({ }^{\circ} \mathrm{C}\right)\end{array}$ & $\begin{array}{c}\text { Average Size } \\
(\mathrm{nm})\end{array}$ & $\begin{array}{c}\text { Density } \\
\left(10^{22} / \mathrm{m}^{3}\right)\end{array}$ \\
\hline 0.25 & 600 & 2.12 & 5.04 \\
\hline 0.5 & 600 & 2.33 & 3.77 \\
\hline 1.2 & 600 & 2.92 & 4.93 \\
\hline 0.5 & 800 & 2.93 & 5.22 \\
\hline
\end{tabular}

SFT have been identified in every previous case to be intrinsic in nature. The defects shown here are too small with respect to the sample thickness to display the characteristic diffraction contrasts used to determine their nature, thus it is assumed these, too, are vacancy-type defects. One mechanism shown to be prominent in the formation of SFT for highly-strained metals is contingent upon the dissociation of large, triangular faulted loops [6.1]. However, since the defects are likely too small to have energetically benefited from the conversion of a faulted loop to a SFT and the strain in the lattice is relatively low $(<0.2 \%)$ according to the XRD data, consideration of this mechanism can be abandoned. A more likely source of the SFT is from the cascade damage itself. Studies have shown SFT to form directly from cascade damage, both with very low temperature irradiations and molecular dynamics simulations [6.2]. 
Information regarding the evolution of the FLs defects observed in irradiated TiN is presented in Figures 6.6 and Table 6.3. The FLs, unlike the SFT, continue to nucleate throughout the irradiation, as indicated by the monotonic increase in FLs density from the low to high dose conditions achieved at $600^{\circ} \mathrm{C}$. At higher temperatures, interstitials are able to migrate faster and are more likely to be emitted from less stable, smaller dislocation loops. For an equivalent dose, these mechanisms are expressed by a smaller average loop size and a higher loop density for a lower temperature; see Table 6.3 for $0.5 \mathrm{dpa}, 600^{\circ} \mathrm{C}$ and $0.5 \mathrm{dpa}, 800^{\circ} \mathrm{C}$.

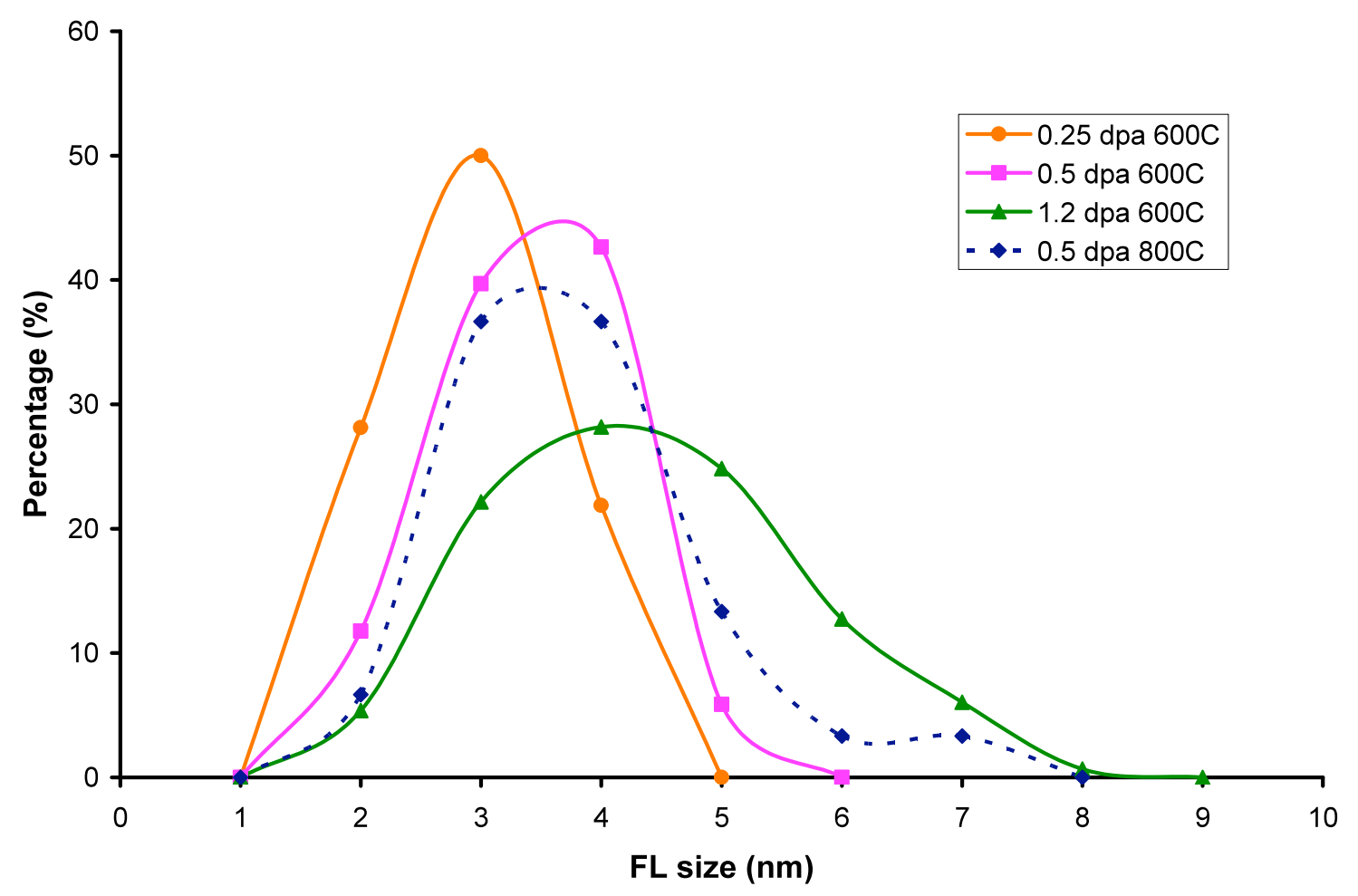

Figure 6.6. Size distributions of FLs for irradiated TiN

Table 6.3. Mean sizes and densities of FL for irradiated TiN

\begin{tabular}{|c|c|c|c|}
\hline $\begin{array}{c}\text { Dose } \\
(\mathrm{dpa})\end{array}$ & $\begin{array}{c}\text { Temperature } \\
\left({ }^{\circ} \mathrm{C}\right)\end{array}$ & $\begin{array}{c}\text { Average Size } \\
(\mathrm{nm})\end{array}$ & $\begin{array}{c}\text { Density } \\
\left(10^{22} / \mathrm{m}^{3}\right)\end{array}$ \\
\hline 0.25 & 600 & 2.52 & 1.76 \\
\hline 0.5 & 600 & 2.90 & 5.00 \\
\hline 1.2 & 600 & 3.90 & 9.48 \\
\hline 0.5 & 800 & 3.31 & 0.79 \\
\hline
\end{tabular}

\subsection{Lattice changes}

Results for TiN are slightly different from those found for the other materials, as shown in Figure 6.7. There is a monotonic increase in lattice parameter with increasing dose between 0 dpa and 
$1.25 \mathrm{dpa}$ for $600^{\circ} \mathrm{C}$, while for $800^{\circ} \mathrm{C}$, lattice expansion was observed for a dose of 0.25 , but lattice contraction was found for a dose of $0.5 \mathrm{dpa}$. A similar trend with TiC can be seen in Figure 6.8; for the low dose of $0.25 \mathrm{dpa}$, as the irradiation temperature increases the increment of lattice parameter decreases.

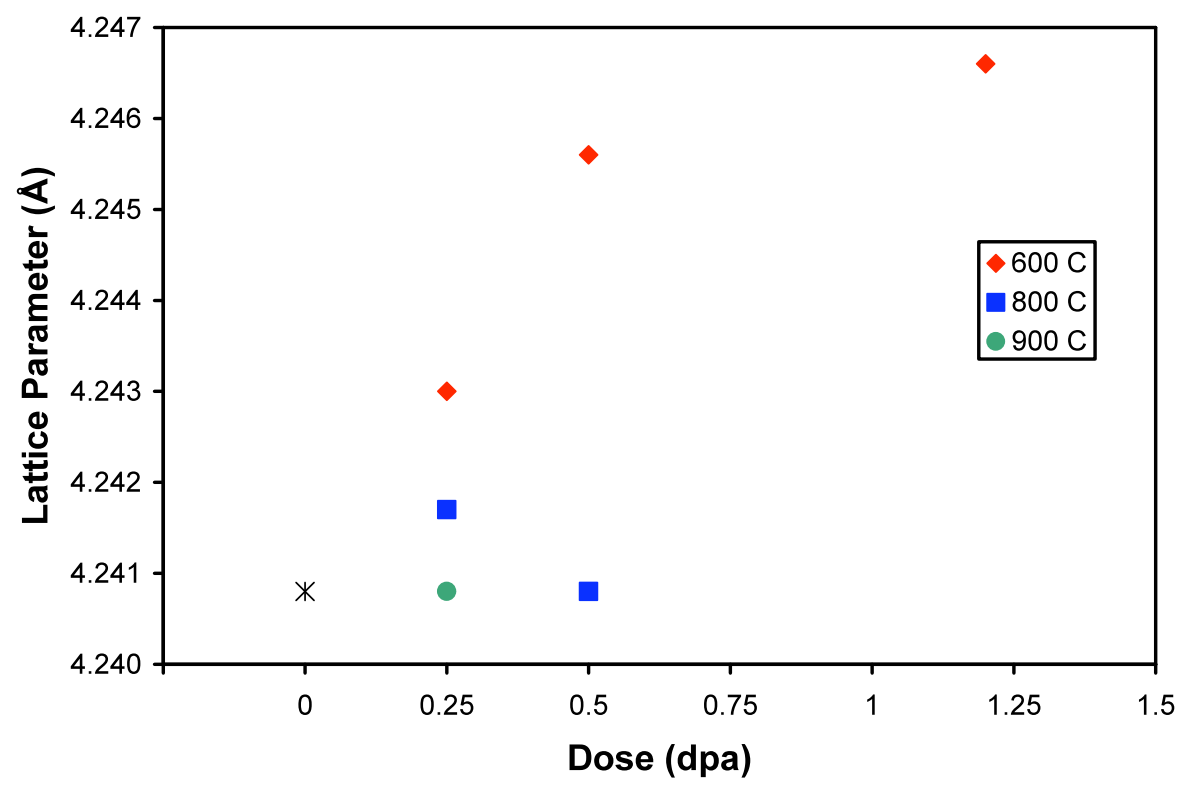

Figure 6.7. Lattice parameters vs. dose for different irradiation temperatures

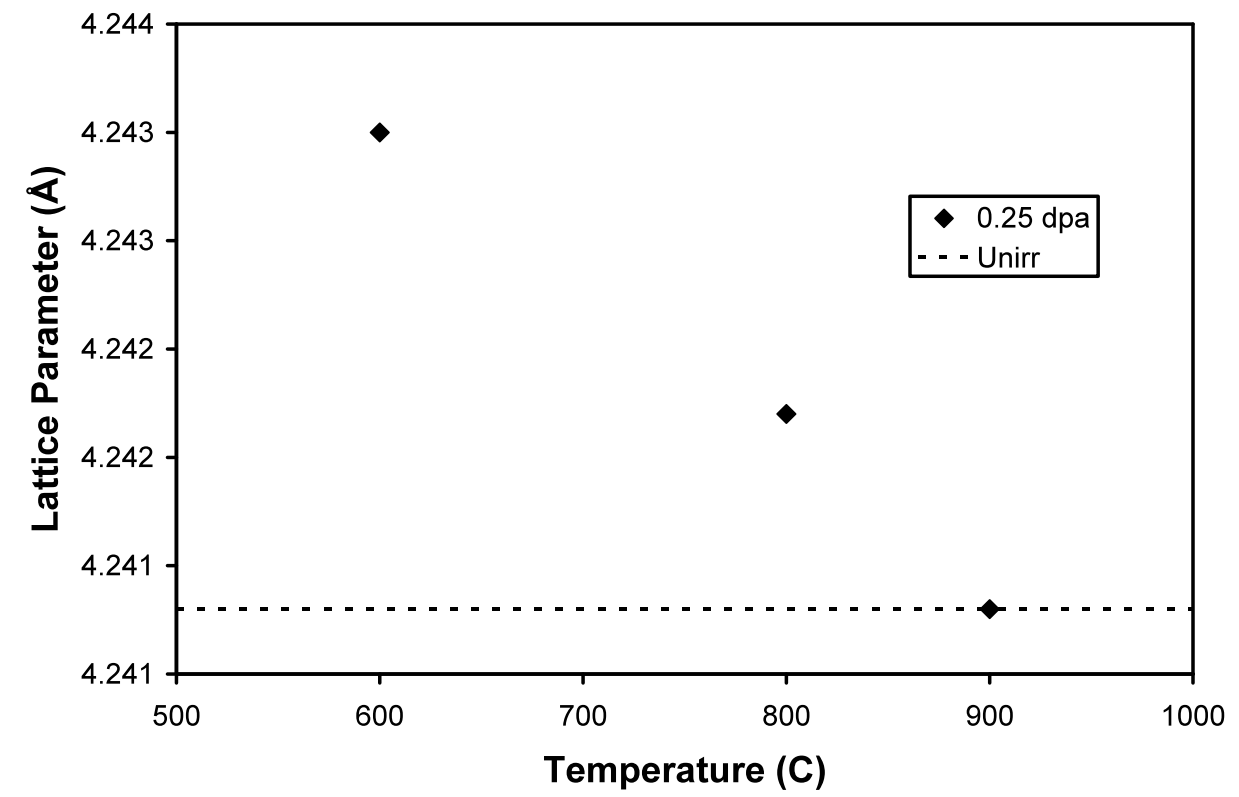

Figure 6.8. Lattice parameters vs. irradiation temperature for a dose of 0.25 dpa 


\section{References}

6.1. J. Silcox and P.B. Hirsch, Philos. Mag. 472 (1959).

6.2. R. Scha“ ublin, M.J. Caturla, M. Wall, et al. J. Nucl. Mater. 307-311, 988 (2002). 


\section{Inert Matrix Fuels (IMF)}

Dual-phase $\mathrm{MgO}-\mathrm{ZrO} 2$ ceramics were investigated as potential candidates for inert matrix fuels. This work stems from the work of Pavel Medvedev at INL. Initially, samples prepared by Pavel Medvedev were used as were samples prepared at the UW. During the course of this project, samples prepared at INL were heat treated and also irradiated at the LANL. Post-irradiation analysis included hardness testing, SEM analysis, XRD analysis, and nano-indentation. Additionally, samples were developed at UW and initial irradiations completed.

\subsection{Characteristics of Dual-Phase MgO-ZrO2 Samples}

The dual-phase $\mathrm{MgO}-\mathrm{ZrO}_{2}$ samples are $40 \mathrm{wt} \% \mathrm{ZrO}_{2}\left(\sim 20 \mathrm{~mol} \% \mathrm{ZrO}_{2}\right)$. Samples are sintered at $1700^{\circ} \mathrm{C}$ in the cubic phase and furnace-cooled to room temperature. The resulting phase structure is cubic $\mathrm{MgO}$, cubic $\mathrm{ZrO}_{2}$, tetragonal $\mathrm{ZrO}_{2}$, and monoclinic $\mathrm{ZrO}_{2}$, as seen in Figure 7.1. The tetragonal to monoclinic phase transformation for $\mathrm{ZrO}_{2}$ is a martensitic phase transformation. It occurs as a result of annealing and mechanical induction. The monoclinic phase results in an increase in volume. Thermally shock resistant $\mathrm{Mg}$, partially stabilized $\mathrm{ZrO}_{2}$ can be created by annealing the sample near $1400^{\circ} \mathrm{C}$ to create more of the tetragonal phase in the material. This phase will readily turn into monoclinic and result in a "toughened" material.

While annealing at or below approximately $1150^{\circ} \mathrm{C}$ should result in rapid phase changes from the cubic to the monoclinic phase, irradiation should cause phase changes from the monoclinic to the tetragonal to the cubic phase. The literature indicates that irradiation of monoclinic zirconia may result in a phase change from monoclinic to cubic zirconia. However, this induced cubic phase is only stable up to approximately $800^{\circ} \mathrm{C}$, where a change from cubic back to monoclinic zirconia will occur [7.1]. This literature also indicates an increase in lattice parameter for zirconia. The ceramic analyzed was cubic zirconia, stabilized with a monoclinic phase of zirconia, and not magnesium stabilized zirconia. This paper also indicates that each succeeding high-temperature structure is more dense than the previous structure (i.e. the cubic phase is more dense than the monoclinic phase).

Dual-phase MgO-ZrO2 (DPMZ) was also studied. Much of the work on DPMZ was carried out at LANL, collaborating with Kurt Sickafus. The DPMZ being used was prepared by Medvedev at INL [7.2]. The composition used was $60 \% \mathrm{MgO}$ and $40 \% \mathrm{ZrO}_{2}$ (60/40 DPMZ). Medvedev performed detailed analysis of these samples, including SEM, EDS, and XRD. A SEM image of 60/40 DPMZ is shown in Figure 7.2 [7.1]. The dark area is the MgO, and the light area is a solid solution magnesia-zirconia phase (SSMZ). EDS analysis by Medvedev revealed the stoichiometry of this phase to be $\mathrm{Mg}_{0.172} \mathrm{Zr}_{0.828} \mathrm{O}_{1.828}$. XRD analysis, seen in Figure 7.3, demonstrates the presence of a cubic zirconia phase, a trace of a monoclinic zirconia phase, and $\mathrm{MgO}$. XRD analysis was repeated at LANL, shown in Figure 7.4, and the results coincide with Medvedev's findings. Additional interesting characteristics are listed in Table 7.1. 


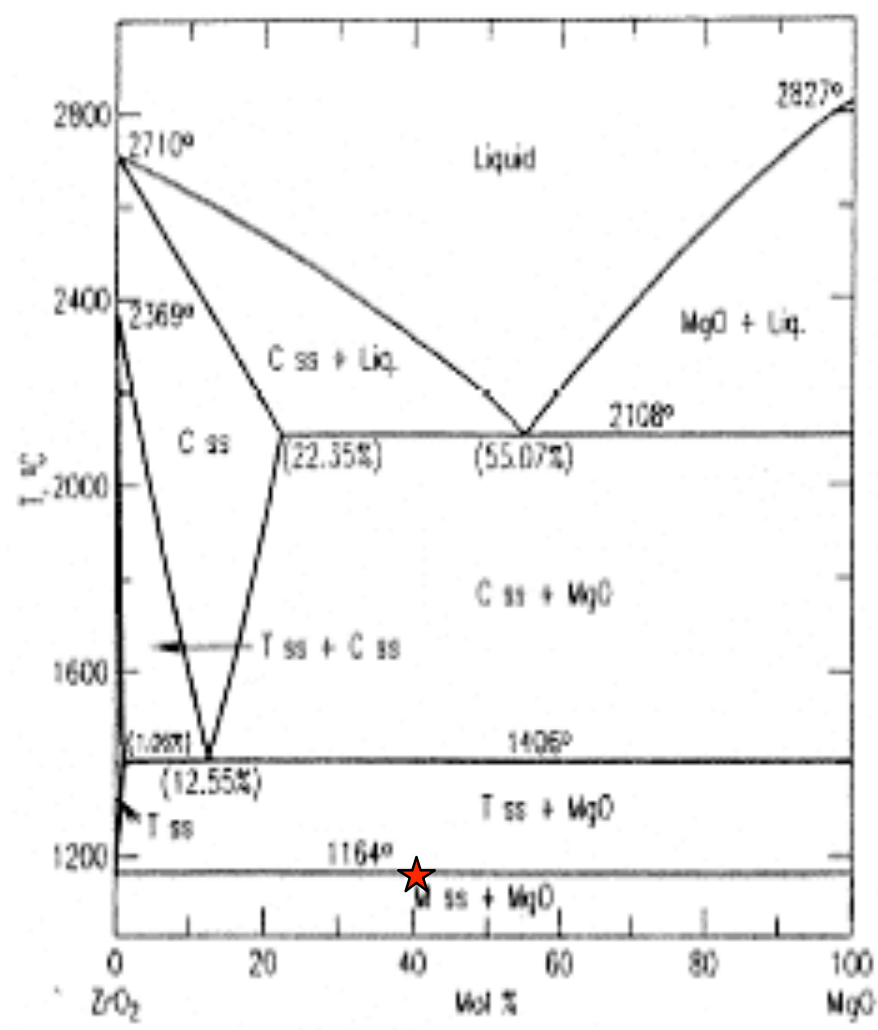

Fig. Zr-073-System $\mathrm{ZrO}_{2}-\mathrm{MgO}$ (oprimized), $\mathrm{C}$ as a solid solution based on cubic $\mathrm{ZrO}_{2} ; \mathrm{T}_{\mathrm{ss}}-$ solid solution based on tetraganal $\mathrm{ZrO}_{2} ; \quad \mathrm{M}$ = monoclinic $\mathrm{ZrO}_{2}$.

Y. Du and Z, P. Jin, CALPHAD Compur, Coupling Phase Diagrams Thermochem., 15 [1] 59-68 (1991)

Figure 7.1. Phase diagram of the $\mathrm{MgO}-\mathrm{ZrO} 2$ system

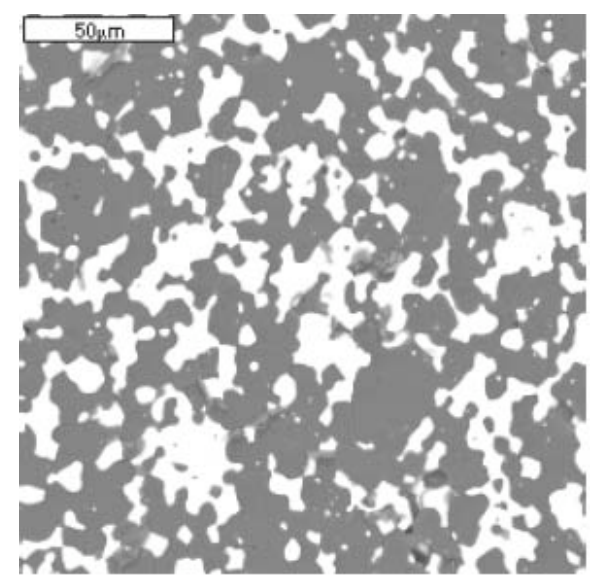

Figure 7.2. SEM image of 60/40 DPMZ [7.2] 


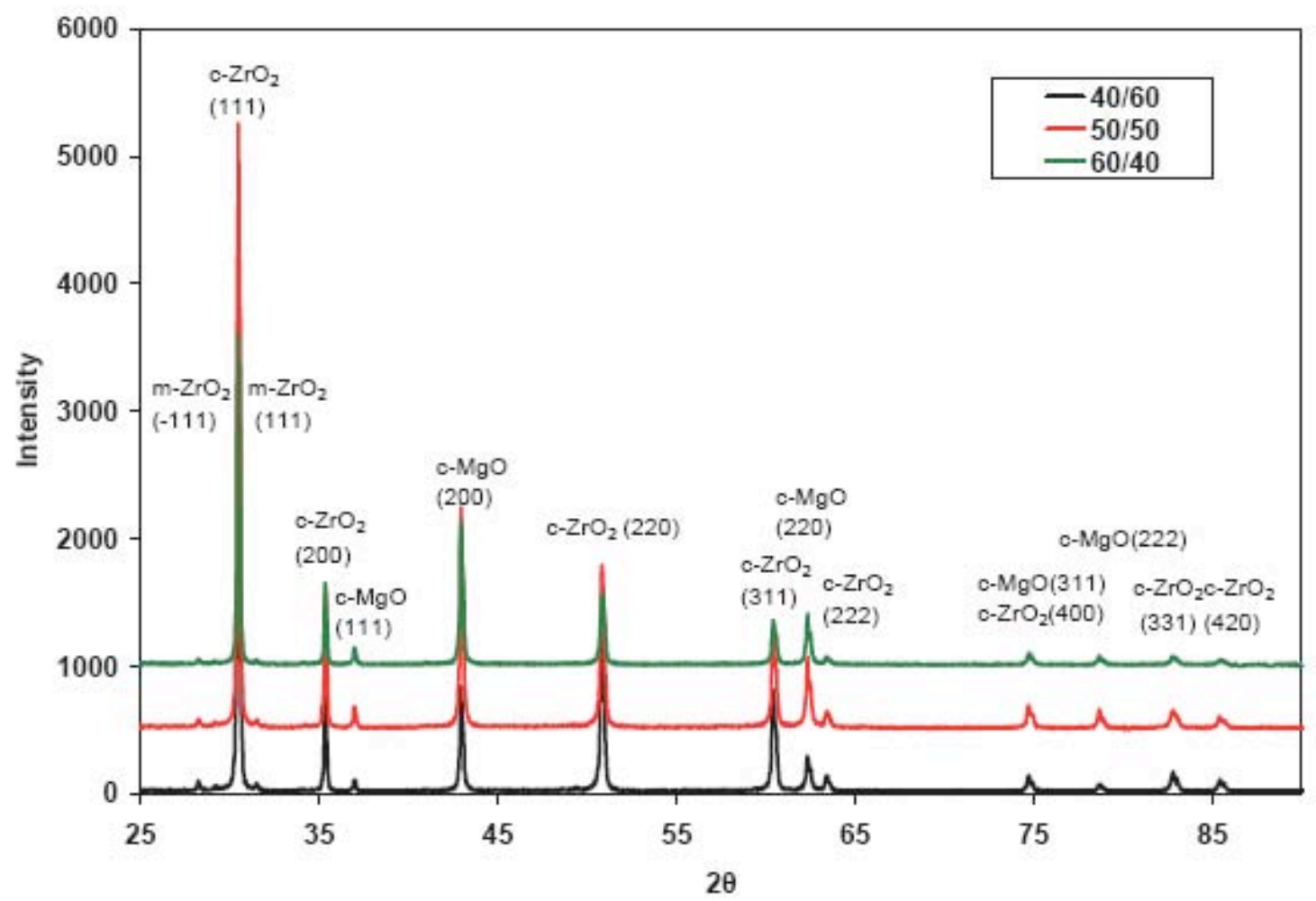

Figure 7.3. XRD analysis of Pristine 60/40 DPMZ [7.2]

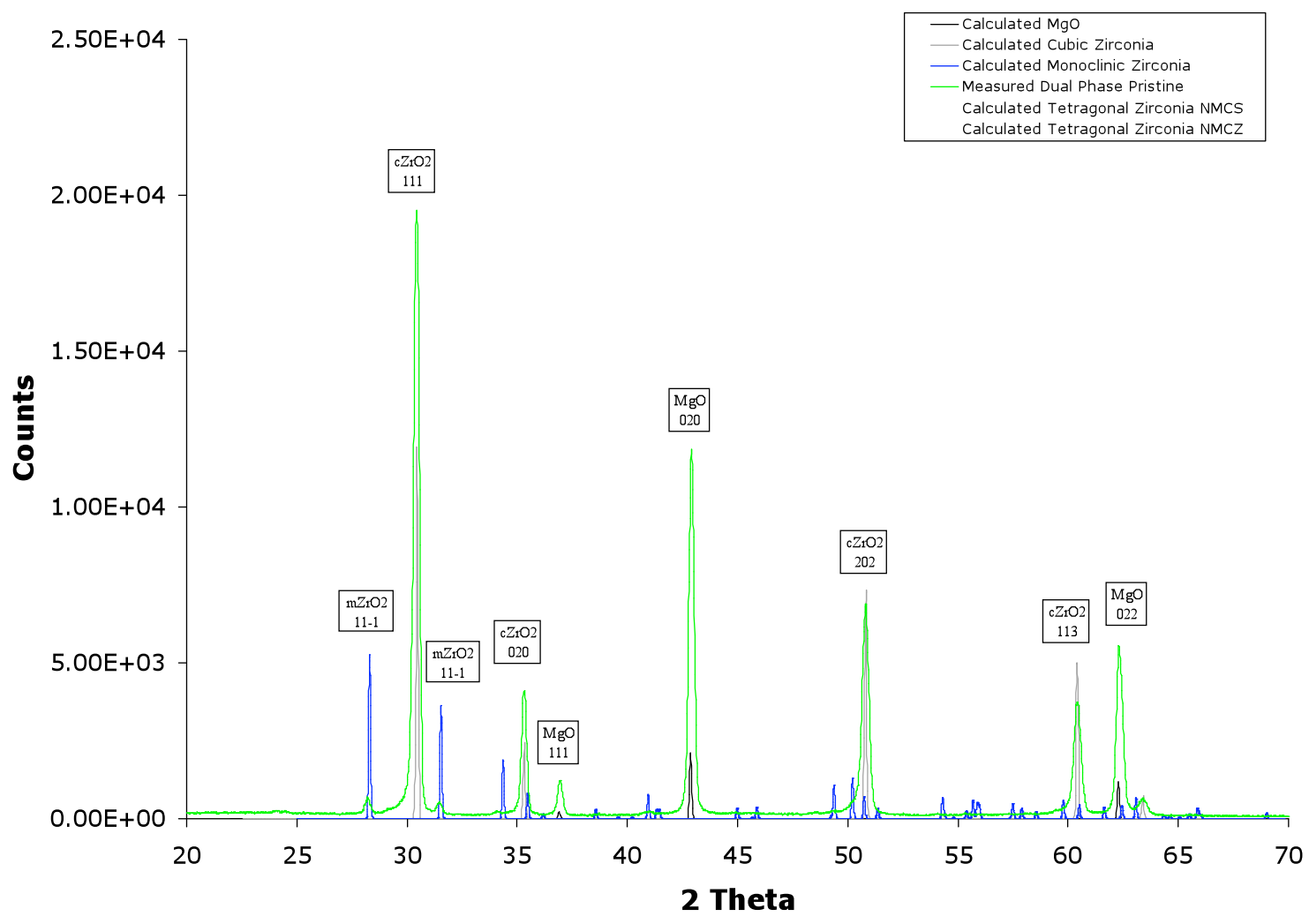

Figure 7.4. XRD analysis of 60/40 DPMZ performed at LANL 
Table 7.1. Characteristics of 60/40 DPMZ [7.2]

\begin{tabular}{|l|l|}
\hline Density $\left(\mathrm{g} / \mathrm{cm}^{3}\right)$ & 4.19 \\
\hline Lattice Parameter $(\AA)$ & $5.0176\left(\right.$ cubic $\left.\mathrm{ZrO}_{2}\right)$ \\
& $4.2106(\mathrm{MgO})$ \\
\hline Stoichoimetry & $\mathrm{Mg}_{0.172} \mathrm{Zr}_{0.828} \mathrm{O}_{1.828}$ \\
\hline
\end{tabular}

More recent irradiations of monoclinic $\mathrm{ZrO}_{2}$ at cryogenic temperatures at LANL also demonstrate a change from a monoclinic to either a tetragonal or cubic phase after irradiation [7.3]. LANL found this transformation to occur between 2 and $20 \mathrm{dpa}$, and it remains up to a dose of $680 \mathrm{dpa}$. Experiments do indicate that the transformation is from monoclinic into tetragonal, rather than monoclinic into cubic. Planned irradiations at the UW will irradiate the dual-phase ceramics at $800^{\circ} \mathrm{C}$.

\subsection{Heat treatments of samples prepared at INL}

Heat treatments of the dual-phase samples were conducted at the $\mathrm{U} W$ at 600 and $1100^{\circ} \mathrm{C}$. XRD analysis of these heat-treated samples showed no change at $600^{\circ} \mathrm{C}$, but definite phase transformations at $1100^{\circ} \mathrm{C}$. This concurs with post-irradiation annealing data in the literature. The quantity of the monoclinic phase present increases with the $1100^{\circ} \mathrm{C}$ heat treatment. Additionally, there may be the presence of the delta phase $\left(\mathrm{Mg}_{2} \mathrm{Zr}_{5} \mathrm{O}_{12}\right)$, which has been seen in Mg-partially-stabilized zirconia used in industry. TEM studies on the irradiated samples will look at the diffraction patterns for phases present and for the delta phase. The results of these heat treatments are in Figure 7.5.
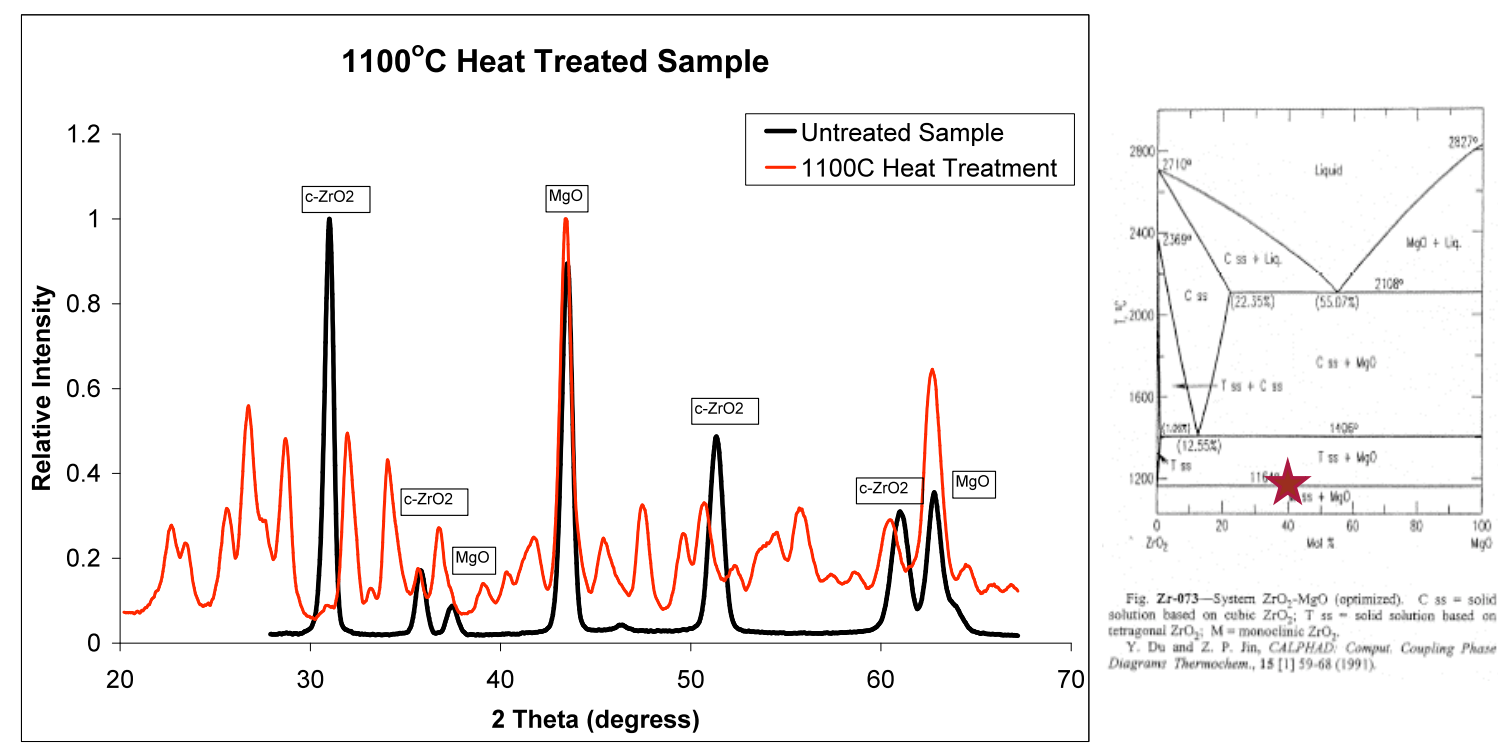

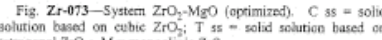

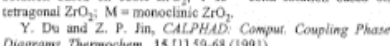

2 Theta (degress)

Figure 7.5. XRD of dual-phase magnesia-zirconia ceramic heat-treated at $1100^{\circ} \mathrm{C}$ 


\subsection{SRIM Calculations}

SRIM-2008 calculations were performed for $\mathrm{MgO}, \mathrm{ZrO}_{2}, \mathrm{Mg}_{0.172} \mathrm{Zr}_{0.828} \mathrm{O}_{1.828}$, and $60 \% \mathrm{MgO}-$ $40 \% \mathrm{ZrO}_{2} . \mathrm{Mg}_{0.172} \mathrm{Zr}_{0.828} \mathrm{O}_{1.828}$ was chosen because it is the measured stoichiometry of the $\mathrm{Mg}$ stabilized $\mathrm{ZrO}_{2}$ phase. $60 \% \mathrm{MgO}-40 \% \mathrm{ZrO}_{2}$ was chosen because it assumes a completely homogenous material. The SRIM-2008 calculations, using the inputs listed in Table 7.1, were used to create a quick-calculated table (Table 7.2) to determine dpa from fluence and visa-versa. The quick-calculate tool is in Figure 7.6, with $1 \mathrm{dpa}$ and $1.0 \times 10^{16} \mathrm{ions} / \mathrm{cm}^{2} / \mathrm{s}$ as example values.

Table 7.1 DPA Calculation Parameters and Results for MgO Irradiated with 2.6 MeV protons at $40 \mu \mathrm{A}$

\begin{tabular}{|l|l|}
\hline Effective Area $\left[\mathrm{mm}^{2}\right]$ & 160 \\
\hline Ion Flux $\left[\right.$ ion $\left./ \mathrm{m}^{2} / \mathrm{s}\right]$ & $1.56 \times 10^{18}$ \\
\hline Molar Mass $[\mathrm{g}]$ & 20 \\
\hline Density $\left[\mathrm{g} / \mathrm{cm}^{3}\right]$ & 3.46 \\
\hline Number Density $\left[\right.$ atoms $\left./ \mathrm{m}^{3}\right]$ & $1.04 \times 10^{29}$ \\
\hline Damage Rate $\left[10^{-5}\right.$ displacements/ion $\left./ \mathrm{m}\right]$ & 300 \\
\hline dpa rate $[$ displacements/atom $/ \mathrm{s}]$ & $4.49 \times 10^{-4}$ \\
\hline
\end{tabular}


Table 7.2. DPA and Fluence Calculations for $\mathrm{MgO}$ and Dual-Phase $\mathrm{MgO}-\mathrm{ZrO}_{2}$

\begin{tabular}{|l|c|c|c|c|}
\hline Material & $\mathrm{MgO}$ & $\mathrm{ZrO} 2$ & $\mathrm{Mg} 0.172 \mathrm{Zr} 0.828 \mathrm{O} 1.828$ & $60 \mathrm{MgO} 40 \mathrm{ZrO} 2$ \\
\hline Density $\left(\mathrm{g} / \mathrm{cm}^{\wedge} 3\right)$ & 3.58 & 6.10 & 5.51 & 4.20 \\
\hline Molar Mass $(\mathrm{g} / \mathrm{mol})$ & 40.30 & 123.22 & 38.53 & 30.61 \\
\hline $\mathrm{N}\left(\right.$ atoms $\left./ \mathrm{cm}^{\wedge} 3\right)$ & $5.35 \mathrm{E}+22$ & $2.98 \mathrm{E}+22$ & $8.61 \mathrm{E}+22$ & $8.26 \mathrm{E}+22$ \\
\hline
\end{tabular}

\begin{tabular}{|l|c|c|c|c|}
\hline \multicolumn{2}{|l|}{ Damage rate (vacancies per ion per cm): } & \\
\hline $150 \mathrm{keV} \mathrm{He}$ & $2.99 \mathrm{E}+06$ & $2.31 \mathrm{E}+06$ & $3.85 \mathrm{E}+06$ & $2.12 \mathrm{E}+06$ \\
\hline $150 \mathrm{keV} \mathrm{Ne}$ & $3.71 \mathrm{E}+07$ & $3.87 \mathrm{E}+07$ & $3.61 \mathrm{E}+07$ & $3.08 \mathrm{E}+07$ \\
\hline $300 \mathrm{keV} \mathrm{Ne}$ & $3.32 \mathrm{E}+07$ & $4.47 \mathrm{E}+07$ & $4.58 \mathrm{E}+07$ & $2.65 \mathrm{E}+07$ \\
\hline $2600 \mathrm{keV}$ protons & $1.50 \mathrm{E}+03$ & $3.23 \mathrm{E}+04$ & $4.08 \mathrm{E}+04$ & $2.92 \mathrm{E}+04$ \\
\hline
\end{tabular}

\begin{tabular}{|l|c|c|c|c|}
\hline \multirow{2}{*}{\multicolumn{1}{c|}{$\begin{array}{c}\text { dpa } \\
1\end{array}$}} & $\mathrm{MgO}$ & $\mathrm{ZrO} 2$ & $\mathrm{Mg} 0.172 \mathrm{Zr} 0.828 \mathrm{O} 1.828$ & $60 \mathrm{MgO} 40 \mathrm{ZrO} 2$ \\
\cline { 2 - 5 } & $1.79 \mathrm{E}+16$ & $1.29 \mathrm{E}+16$ & $2.24 \mathrm{E}+16$ & $3.90 \mathrm{E}+16$ \\
\hline $150 \mathrm{keV} \mathrm{He}$ & $1.44 \mathrm{E}+15$ & $7.70 \mathrm{E}+14$ & $2.39 \mathrm{E}+15$ & $2.68 \mathrm{E}+15$ \\
\hline $150 \mathrm{keV} \mathrm{Ne}$ & $1.61 \mathrm{E}+15$ & $6.67 \mathrm{E}+14$ & $1.88 \mathrm{E}+15$ & $3.12 \mathrm{E}+15$ \\
\hline $300 \mathrm{keV} \mathrm{Ne}$ & $3.57 \mathrm{E}+19$ & $9.23 \mathrm{E}+17$ & $2.11 \mathrm{E}+18$ & $2.83 \mathrm{E}+18$ \\
\hline $2600 \mathrm{keV}$ protons &
\end{tabular}

\begin{tabular}{|l|c|c|c|c|}
\hline \multirow{2}{*}{$\begin{array}{c}\text { Fluence } \\
1.70 \mathrm{E}+16\end{array}$} & \multicolumn{5}{|c|}{} \\
\cline { 2 - 5 } & $\mathrm{MgO}$ & $\mathrm{ZrO} 2$ & $\mathrm{Mg} 0.172 \mathrm{Zr0} 0.828 \mathrm{O} 1.828$ & $60 \mathrm{MgO} 40 \mathrm{ZrO} 2$ \\
\hline $150 \mathrm{keV} \mathrm{He}$ & 0.95 & 1.32 & 0.76 & 0.44 \\
\hline $150 \mathrm{keV} \mathrm{Ne}$ & 11.79 & 22.06 & 7.12 & 6.34 \\
\hline $300 \mathrm{keV} \mathrm{Ne}$ & 10.55 & 25.49 & 9.04 & 5.45 \\
\hline $2600 \mathrm{keV}$ protons & 0.00 & 0.02 & 0.01 & 0.01 \\
\hline
\end{tabular}

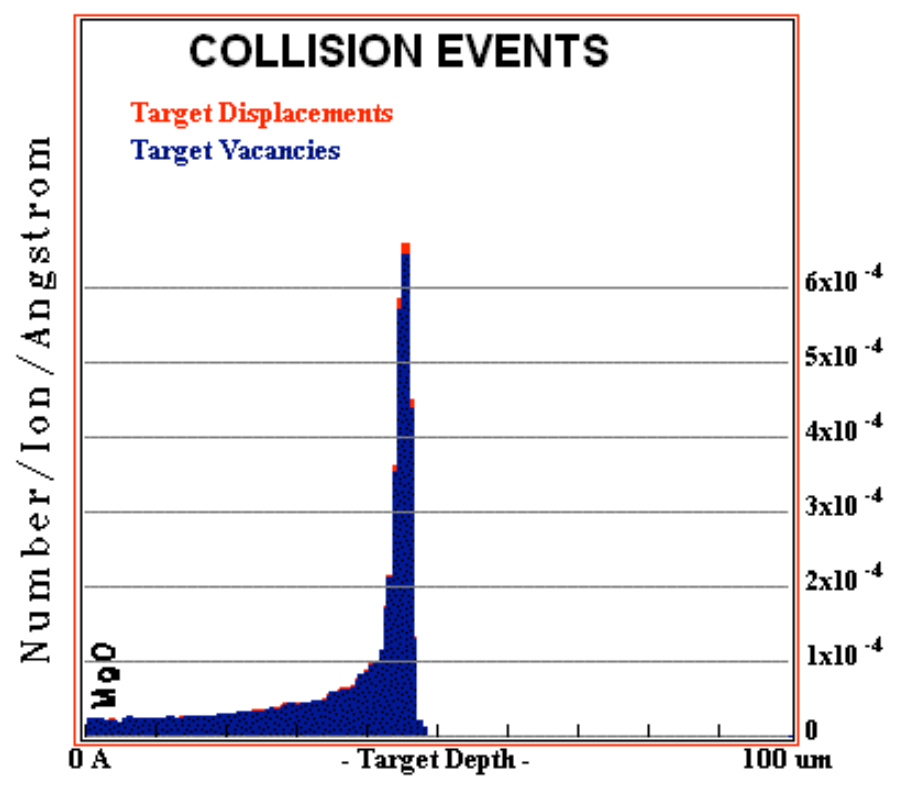

Figure 7.6. Damage Calculation for $\mathrm{MgO}$ 
In addition to the quick-calculate table, comparison of the dpa of various ions with respect to depth in $\mathrm{MgO}$ was completed; Figure 7.7. A fluence of $1.0 \times 10^{16}$ ions $/ \mathrm{cm}^{2} / \mathrm{s}$ was assumed for the dpa calculations. It has been determined that $150 \mathrm{keV} \mathrm{Ne}^{++}$will stay near the surface and have a very high dpa, while $300 \mathrm{keV} \mathrm{Ne}$ and $150 \mathrm{keV}$ He will travel approximately the same distance and produce approximately the same damage. For the LANL irradiations, the $150 \mathrm{keV}$ $\mathrm{Ne}^{++}$causes roughly the same damage as $150 \mathrm{keV} \mathrm{He}$, so we can assume that the He and $\mathrm{Ne}$ in the irradiated samples traveled approximately the same distance and gave approximately the same damage rate. The different dpa calculations for the two experiments is primarily the result of the difference in fluence.

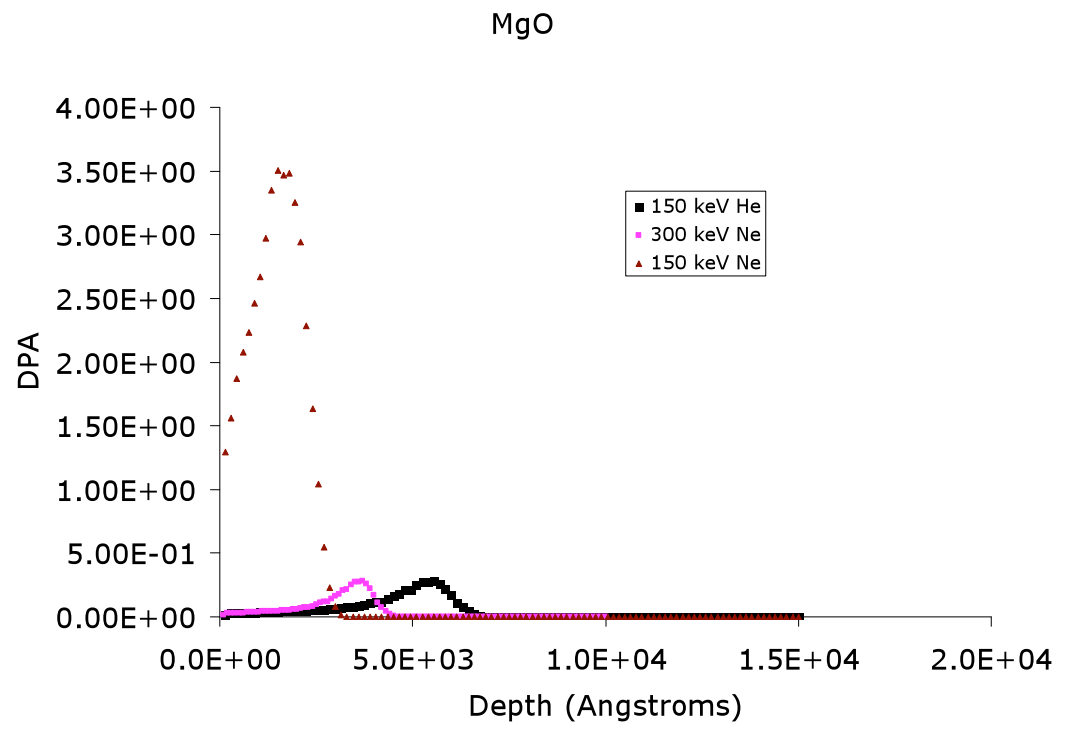

Figure 7.7. dpa vs. depth of $150 \mathrm{keV} \mathrm{He}, 150 \mathrm{keV} \mathrm{Ne}$, and $300 \mathrm{keV} \mathrm{Ne}$ in $\mathrm{MgO}$

In addition to analyzing dpa versus depth for various ions, the relationship can also be compared for the same ion in the four materials chosen. The resulting graphs are shown in Figure 7.8. These comparisons show that the resulting dpa versus depth is approximately the same for all four materials, although the dpa of $\mathrm{ZrO}_{2}$ is slightly higher. Therefore, $\mathrm{MgO}$ is used to approximate dpa. 


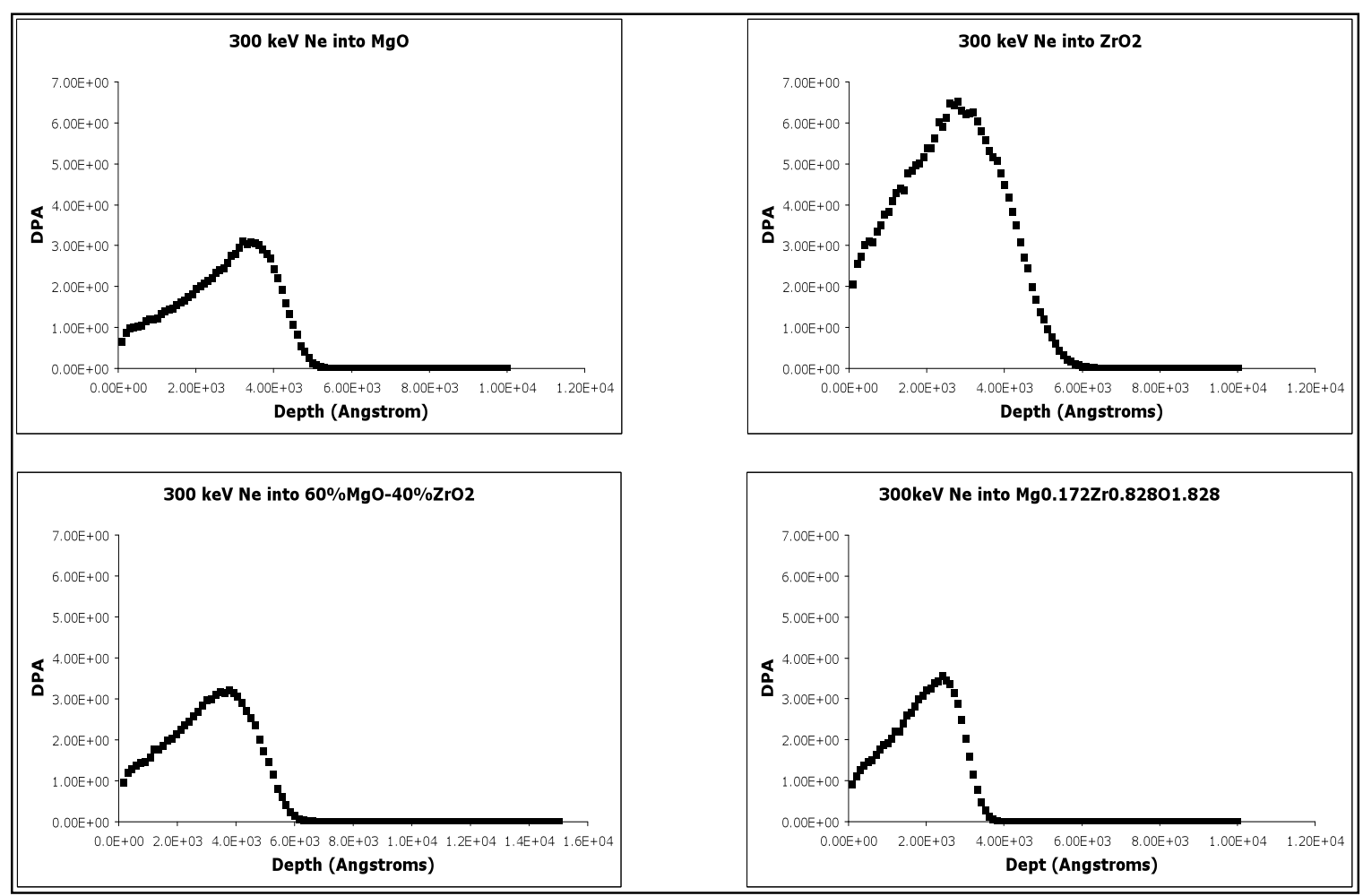

Figure 7.8. dpa vs. depth for $300 \mathrm{keV} \mathrm{Ne}$ into $\mathrm{MgO}, \mathrm{ZrO}_{2}, \mathrm{Mg}_{0.172} \mathrm{Zr}_{0.828} \mathrm{O}_{1.828}$, and $60 \% \mathrm{MgO}-40 \% \mathrm{ZrO}_{2}$

Finally, the effect of the calculated damage rate on irradiation time was calculated assuming a number density and flux. The result is shown in Figure 7.9. 


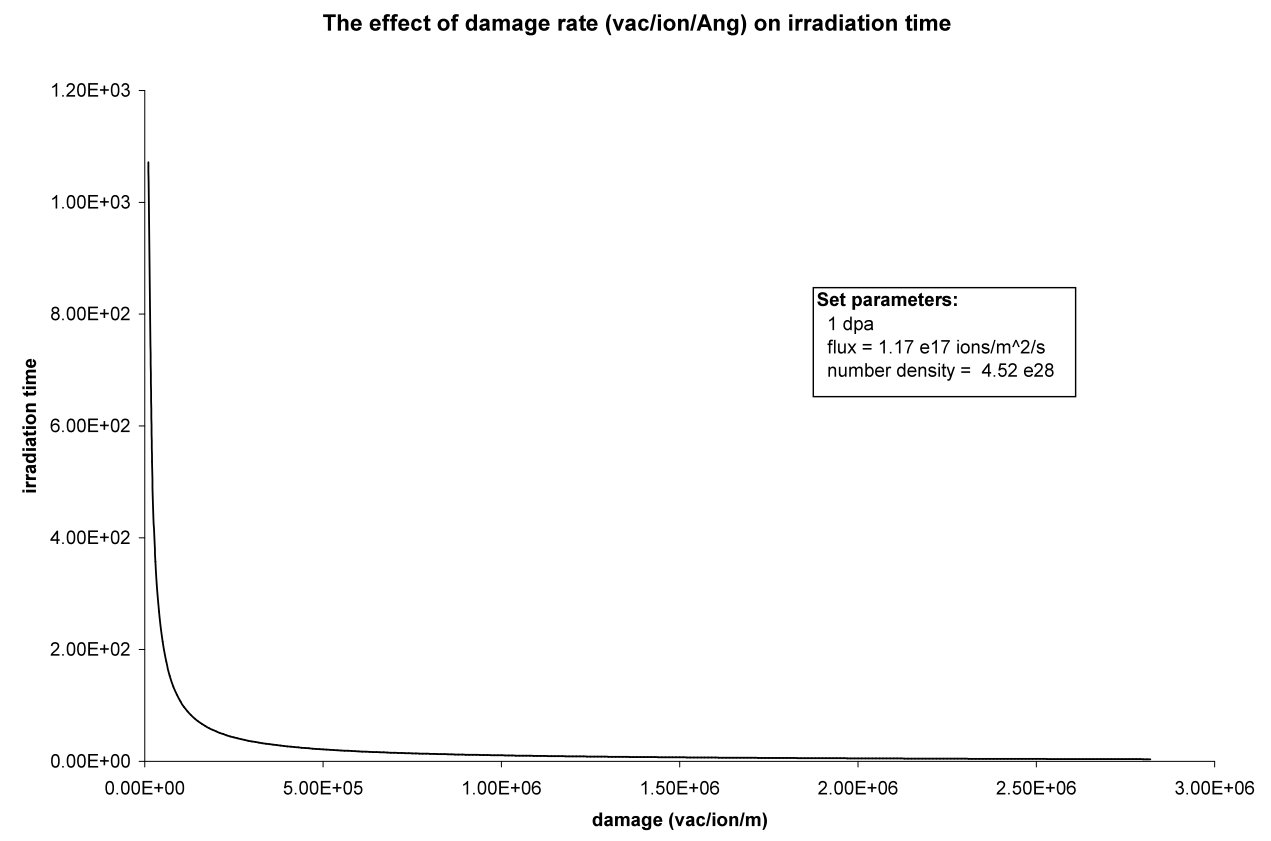

Figure 7.9. Irradiation time vs. damage (vacancies/ion $/ \mathrm{m}$ )

Calculations to determine the approximate beam time needed to achieve the desired dpa at the UW were completed. More accurate values for $\mathrm{ZrO}_{2}$ displacement energies were found in the literature (see Table 7.3). The vacancies per ion per Angstrom calculated by SRIM-2008 for $\mathrm{MgO}$ and $\mathrm{ZrO}_{2}$ using the values in Table 7.3 were very similar, as can be seen in Figure 7.10. These values were used to calculate the beam time needed to achieve the desired dpa in Table 7.4 .

Table 7.3. Threshold Displacement Energies for $\mathrm{MgO}$ and $\mathrm{ZrO}_{2}$

\begin{tabular}{|l|l|l|}
\hline Oxide & Element & Threshold Displacement Energy \\
\hline \multirow{2}{*}{ MgO } & $\mathrm{Mg} 2+$ & $65 \mathrm{eV}-$ experimentally measured \\
\cline { 2 - 3 } & $\mathrm{O} 2-$ & $60 \mathrm{eV}-$ experimentally measured \\
\hline \multirow{3}{*}{ ZrO2 } & $\mathrm{Zr} 4+$ & $\begin{array}{l}80 \mathrm{eV}-\mathrm{MD} \text { calculation based on Y-PSZ } \\
40 \mathrm{eV}-\text { standard value }\end{array}$ \\
\cline { 2 - 3 } & $\mathrm{O} 2-$ & $\begin{array}{l}120 \mathrm{eV}-\mathrm{MD} \text { calculation based on Y-PSZ } \\
40 \mathrm{eV}-\text { standard value }\end{array}$ \\
\hline
\end{tabular}




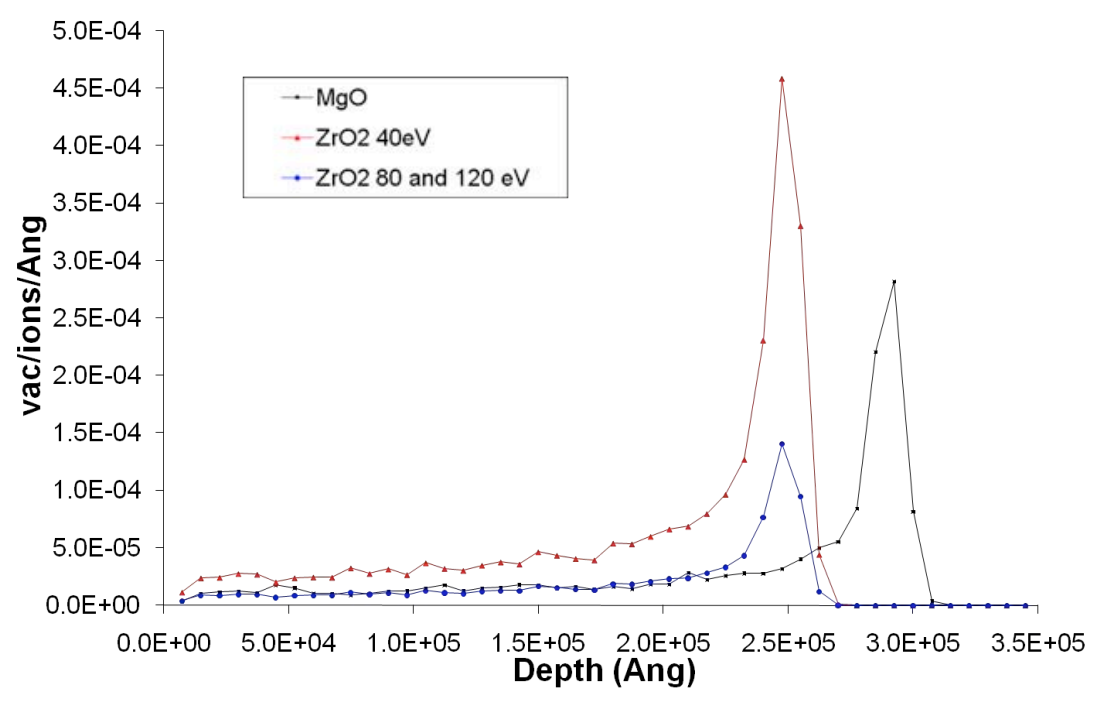

Figure 7.10. Damage profile for $\mathrm{MgO}$ and $\mathrm{ZrO} 2$

Table 7.4. Beam time needed for desired dpa (in hours)

\begin{tabular}{|c|c|c|c|}
\hline dpa & MgO & ZrO2 40 eV & ZrO2 80 and 120 eV \\
\hline $\mathbf{0 . 2 5}$ & 35 & 15 & 29 \\
\hline $\mathbf{0 . 5}$ & 69 & 29 & 58 \\
\hline $\mathbf{0 . 7 5}$ & 103 & 44 & 87 \\
\hline $\mathbf{1}$ & 138 & 58 & 115 \\
\hline
\end{tabular}

\subsection{LANL Irradiations}

Two irradiations were performed on $\mathrm{MgO}$ and $\mathrm{MgO}-40 \mathrm{wt} \% \mathrm{ZrO}_{2}$ developed by Pavel Medvedev at INL [7.2]. First, a 10 dpa heavy-ion irradiation was performed on both $\mathrm{MgO}$ and DPMZ. This experiment used $300 \mathrm{keV} \mathrm{Ne}$ ions to a fluence of $1.0 \times 10^{16}$ ions $/ \mathrm{cm}^{2}$. Second, a $1 \mathrm{dpa}$ heavy-ion irradiation was performed on $\mathrm{MgO}$ and DPMZ. This experiment used $150 \mathrm{keV} \mathrm{He}$ ions to a fluence of $1.7 \times 10^{16}$ ions $/ \mathrm{cm}^{2}$. XRD, SEM, and nano-indentation were performed on the irradiated samples.

\subsubsection{XRD}

The irradiated materials went through a series of post-irradiation tests, beginning with XRD analysis. The XRD results for pristine $\mathrm{MgO}-40 \mathrm{wt} \% \mathrm{ZrO}_{2}$ and irradiated $\mathrm{MgO}$ can be seen in Figures 7.11 and 7.12, respectively. In Figure 7.12, gray indicates the profile calculated with the program Crystal Maker, the black line represents the XRD results for the pristine sample, and the red line the results for the irradiated sample. It is noticeable that the profile for the irradiated sample exhibits peak broadening and slight peak shifting, indicating amorphization of the crystal under irradiation. This effect is well documented and was expected. 


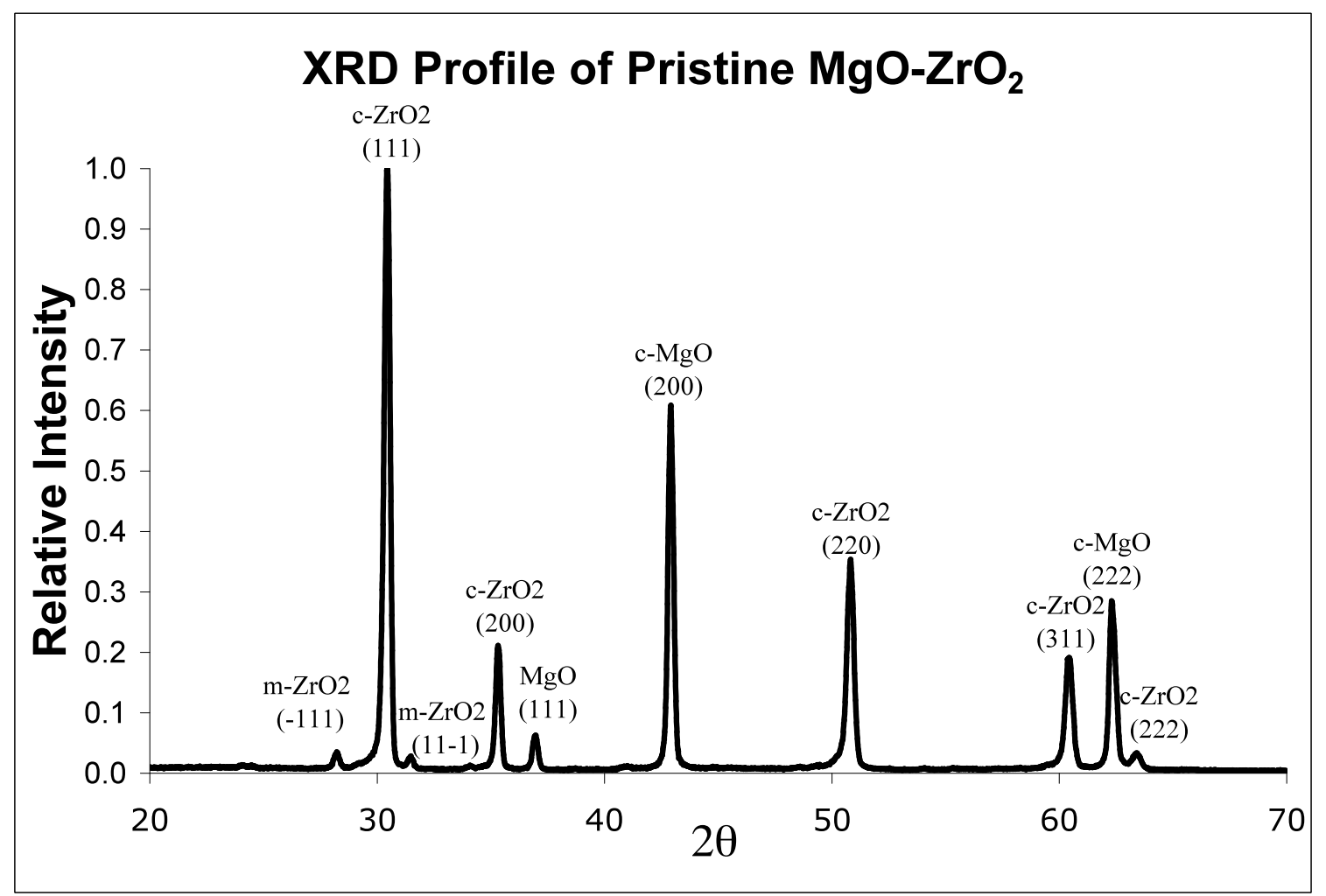

Figure 7.11. $\mathrm{XRD}$ analysis of $\mathrm{MgO}-40 \mathrm{wt} \% \mathrm{ZrO}_{2}$ performed at $\mathrm{LANL}$

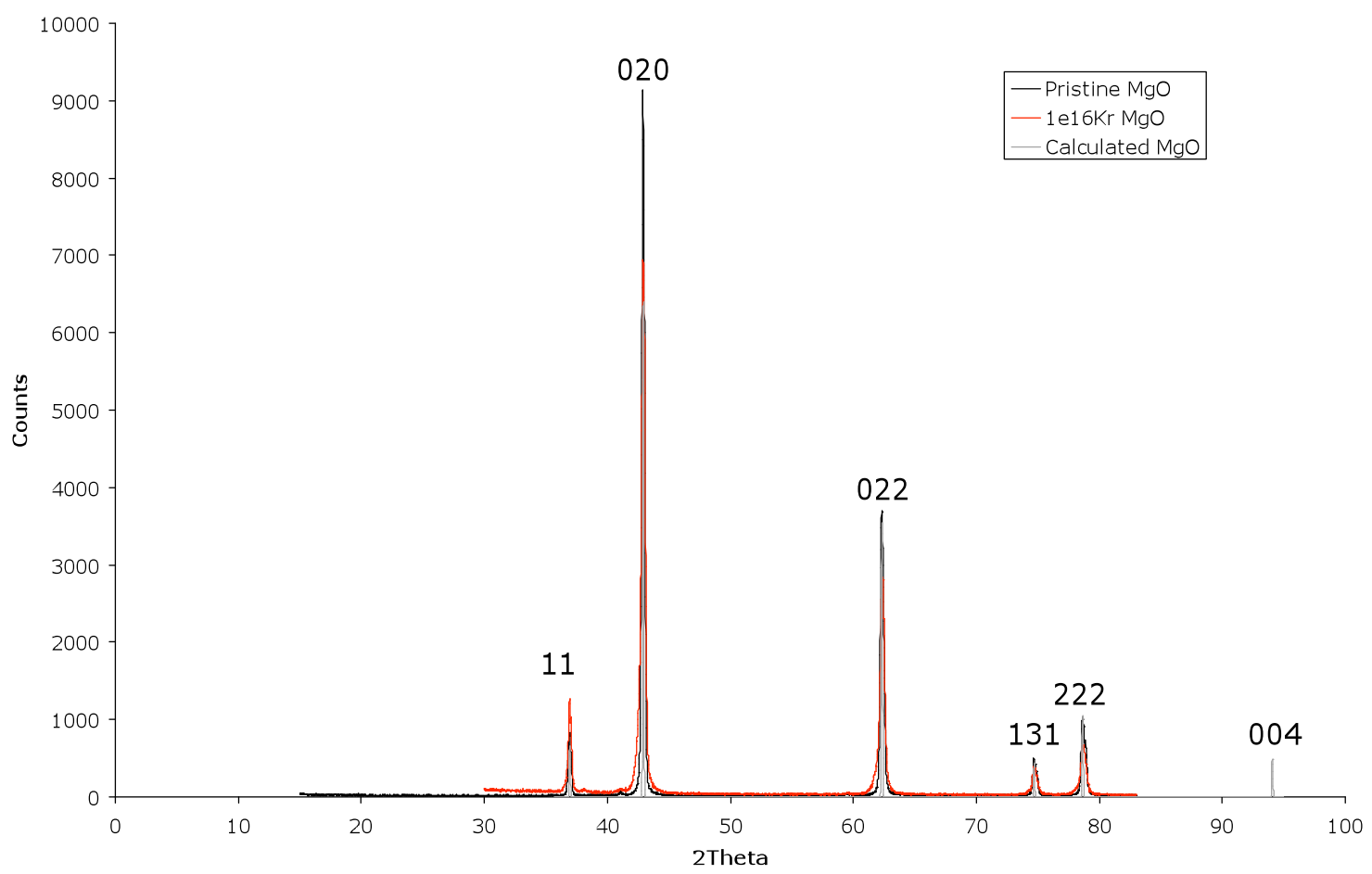

Figure 7.12. Pristine and Irradiated $\mathrm{MgO}$ 
Lattice parameter calculations were completed on untreated samples, samples irradiated to a fluence of $1.0 \times 10^{16} \mathrm{Ne}^{++}$ions $/ \mathrm{cm}^{2} / \mathrm{s}(\sim 10 \mathrm{dpa})$, and samples irradiated to a fluence of $1.7 \times 10^{16}$ $\mathrm{He}^{+}$ions $/ \mathrm{cm}^{2} / \mathrm{s}(\sim 1 \mathrm{dpa})$. XRD measurements of Li-doped $\mathrm{MgO}$ and single crystal $\mathrm{MgO}$ showed them both to be 020 crystals.

The lattice parameter was determined from the XRD profiles, using the angle (2Ө) and the Miller indices of each of the peaks. Using this data it is possible to implement the following equations.

$$
\begin{array}{ll}
a=\frac{d}{\sqrt{h^{2}+k^{2}+l^{2}}} & \text { lattice parameter } \\
\frac{\cos ^{2} \vartheta}{\sin \vartheta} & \text { geometric correction factor }
\end{array}
$$

where $\mathrm{a}$ is the lattice parameter, $\mathrm{d}$ is the displacement between places, $\mathrm{h}, \mathrm{k}$, and $\mathrm{l}$ are the Miller indices, and $\Theta$ is one-half of the measured angle. Both the lattice parameter and the geometric correction were calculated for each peak, which resulted in a linear curve. This curve was extrapolated to zero, which gives the lattice parameter corrected for the geometry. An example of this curve for $\mathrm{MgO}$ is shown in Figure 7.13. The resultant lattice parameters for both $\mathrm{MgO}$ and the $\mathrm{Mg}$-stabilized $\mathrm{ZrO}_{2}$ phases are shown in Tables 7.5 and 7.6. For the pristine $\mathrm{MgO}$ sample, the lattice parameter increases with irradiation, as expected from the literature.

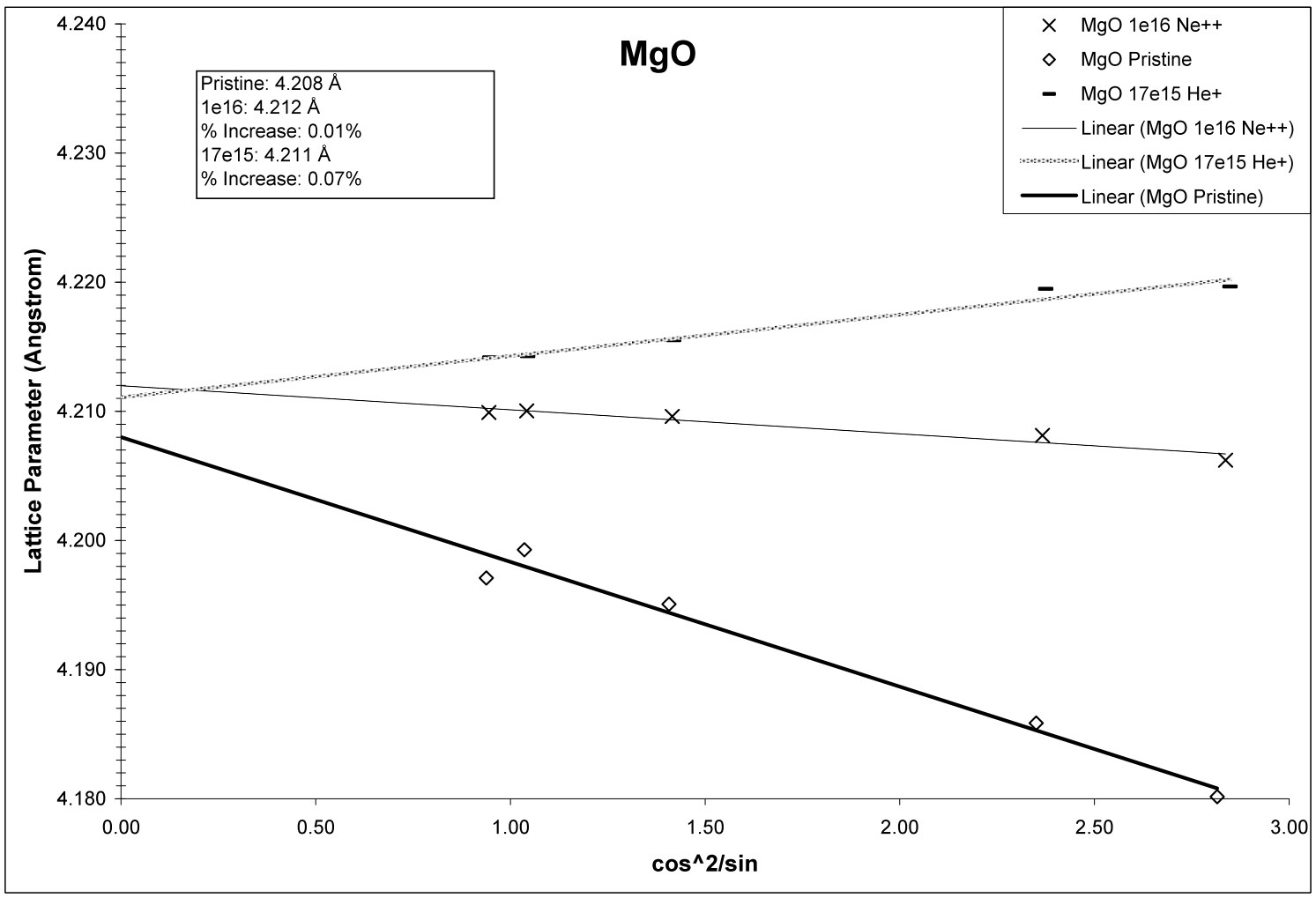

Figure 7.13. Changes in Lattice Parameter Due to Irradiation for $\mathrm{MgO}$ 
Table 7.5. Lattice Parameter of Magnesia

\begin{tabular}{|l|l|l|}
\hline Un-Irradiated $\mathrm{MgO}$ & $1 \mathrm{dpa} \mathrm{MgO}$ & 10 dpa $\mathrm{MgO}$ \\
\hline 4.208 & 4.211 & 4.212 \\
\hline
\end{tabular}

Table 7.6. Lattice Parameter of Dual-Phase Magnesia-Zirconia

\begin{tabular}{|c|c|c|c|}
\hline Phase & $\begin{array}{l}\text { Un-Irradiated } \\
\mathrm{MgO}-\mathrm{ZrO}_{2}\end{array}$ & $\begin{array}{l}1 \mathrm{dpa} \\
\mathrm{MgO}-\mathrm{ZrO}_{2}\end{array}$ & $\begin{array}{l}10 \mathrm{dpa} \\
\mathrm{MgO}-\mathrm{ZrO}_{2}\end{array}$ \\
\hline Cubic & 5.079 & 5.076 & 5.077 \\
\hline Monoclinic & Present & Not present & Present \\
\hline $\mathrm{MgO}$ & 4.2135 & 4.214 & 4.2125 \\
\hline
\end{tabular}

The tetragonal and cubic phases in zirconia are very similar using XRD analysis. Rietveld analysis should be able to distinguish between tetragonal and cubic phases in XRD analysis. The samples irradiated at LANL had too much surface roughness for Rietveld analysis to be successful, but carefully prepared samples should be able to eventually obtain this data. The monoclinic phase in the dual-phase sample disappears at a dose of $1 \mathrm{dpa}$ and reappears at a dose of $10 \mathrm{dpa}$. This phenomenon corresponds to the literature study of monoclinic $\mathrm{ZrO}_{2}$. According to the literature, the monoclinic phase transforms to a tetragonal or cubic phase as a result of irradiation. However, post-irradiation annealing at temperatures at and above $800^{\circ} \mathrm{C}$ showed a transformation of the higher-order phase (cubic or tetragonal) back to monoclinic [7.3 and 7.4].

\subsubsection{SEM line scan}

EDS line scans were performed over the phase boundaries for samples irradiated at LANL. Figures 7.14 and 7.15 show EDS line scans comparing $\mathrm{Mg}$ and $\mathrm{Zr}$ atomic percent in unirradiated samples, and samples irradiated to 1 and $10 \mathrm{dpa}$, respectively. There was no apparent change in the atomic percent of $\mathrm{Mg}$ or $\mathrm{Zr}$ within the limits of this analysis. Some regions were selected to conduct line scans with more data points along the distance, and no change was found in the results. It does not appear that there is any noticeable mixing between the phases as a result of irradiation. 


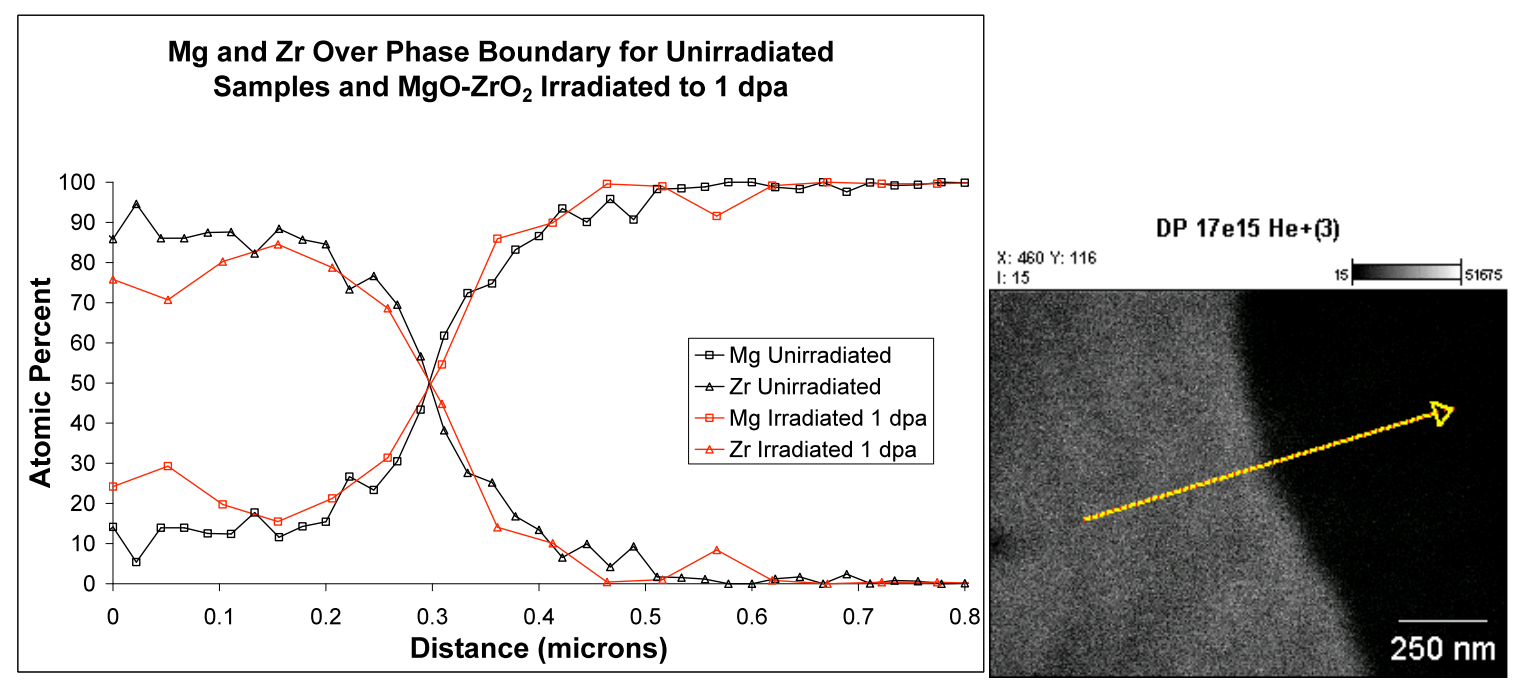

Figure 7.14. Line scans showing atomic percent of $\mathrm{Mg}$ and $\mathrm{Zr}$ over a phase boundary in unirradiated samples and samples irradiated to $1 \mathrm{dpa}$
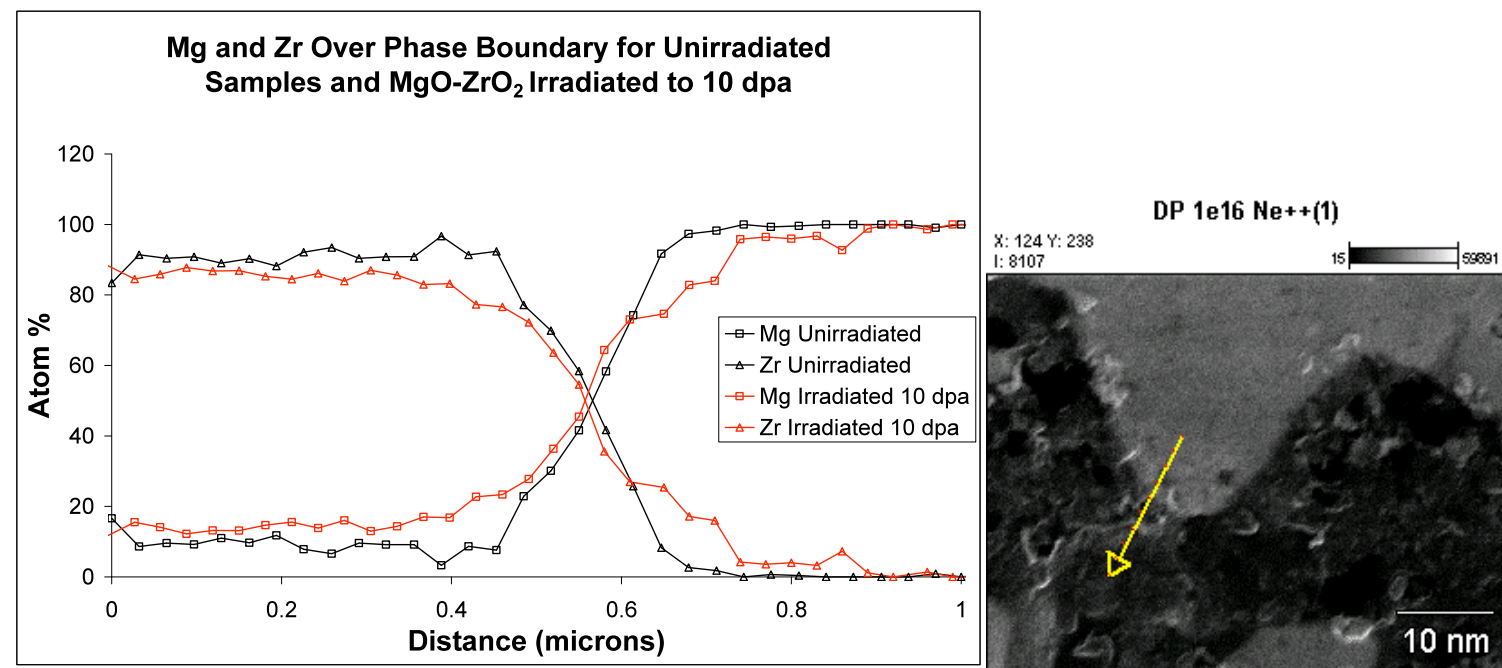

Figure 7.15. Line scans showing atomic percent of $\mathrm{Mg}$ and $\mathrm{Zr}$ over a phase boundary in unirradiated samples and samples irradiated to $10 \mathrm{dpa}$

\subsubsection{Nano-indentation}

Nano-indentation of the dual-phase $\mathrm{MgO}-\mathrm{ZrO}_{2}$ was conducted on untreated samples and samples irradiated to a dose of $10 \mathrm{dpa}$. The nano-indentation produced the force-depth curve seen in Figure 7.16. According to the explanation in Section 3.4.5, the hardness and reduced modulus are calculated accordingly and listed in Table 7.7. 

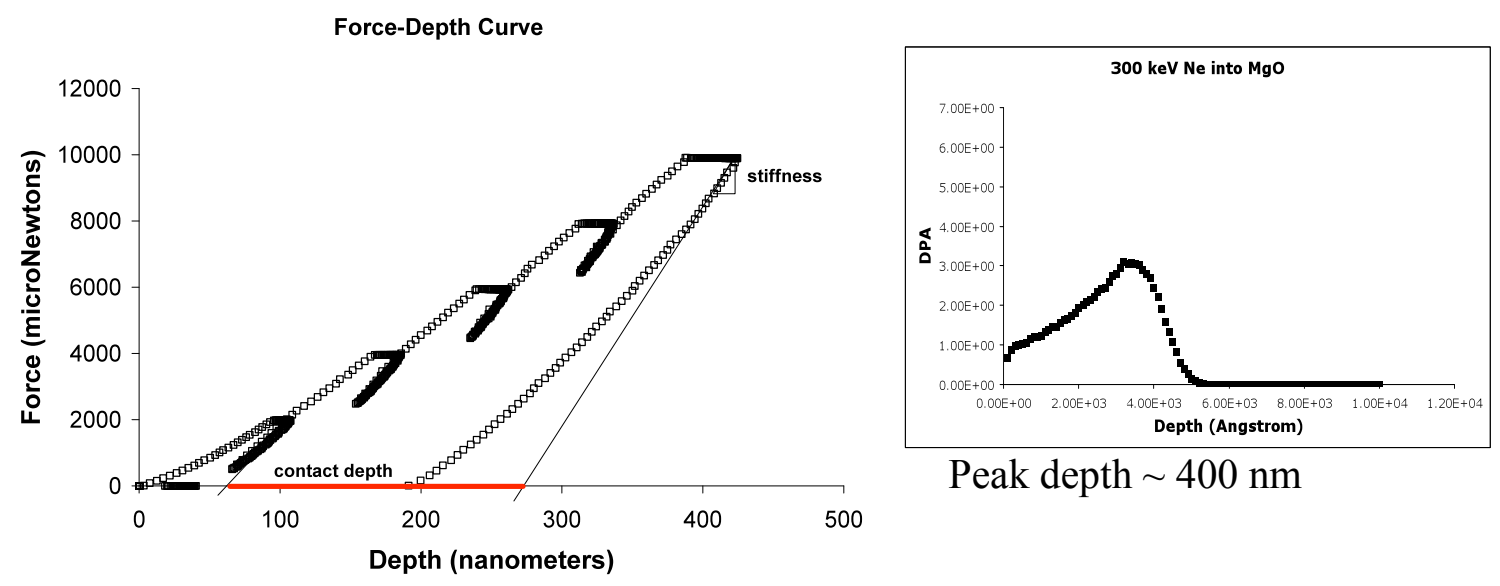

Peak depth $\sim 400 \mathrm{~nm}$

Figure 7.16. Force-depth curve from nano-indentation and approximate dose vs. depth

Table 7.7. Hardness and Reduced Modulus of Dual-Phase ${\mathrm{MgO}-\mathrm{ZrO}_{2}}$

\begin{tabular}{|l|l|l|}
\hline & \multicolumn{1}{|c|}{ Hardness $(\mathrm{GPa})$} & \multicolumn{1}{c|}{ Reduced Modulus $(\mathrm{GPa})$} \\
\hline Un-Irradiated & $9.9 \pm 0.3$ & $112.3 \pm 2.1$ \\
\hline $10 \mathrm{dpa}$ & $20.9 \pm 0.8$ & $209.0 \pm 3.9$ \\
\hline Literature Values $(\mathrm{MgO})$ & -9 & 261 \\
\hline Literature Values $\left(\mathrm{Mg}-\mathrm{ZrO}_{2}\right)$ & -10 & 185 \\
\hline
\end{tabular}

The hardness of the unirradiated sample concurs very closely to the literature values, and the Young's Modulus is fairly low. This may be due to the presence of more $\mathrm{MgO}$ in the test sample than in the samples for the literature values used for comparison. This analysis indicated an increase in both hardness and reduced modulus as a result of irradiation.

\subsubsection{Knoop hardness}

Knoop hardness tests were conducted on $\mathrm{MgO}$ and $\mathrm{MgO}-\mathrm{ZrO}_{2}$ samples prepared at INL. The results are presented in Table 7.8. In the $\mathrm{MgO}$ samples, there was a $10 \%$ reduction in hardness at $1 \mathrm{dpa}$ and a $16 \%$ reduction in hardness at $10 \mathrm{dpa}$. In the $\mathrm{MgO}-\mathrm{ZrO}_{2}$ samples there was no change in hardness within the error of the test.

Table 7.8. Knoop Hardness of MgO-ZrO2 and MgO

\begin{tabular}{|l|l|l|}
\hline \multicolumn{1}{|c|}{ dpa } & \multicolumn{1}{c|}{$\mathrm{MgO}-\mathrm{ZrO}_{2}$} & $\mathrm{MgO}$ \\
\hline 0 & $9.8 \pm 0.32$ & $9.0 \pm 0.32$ \\
\hline 1 & $9.7 \pm 0.51$ & $8.1 \pm 0.44$ \\
\hline 10 & $9.5 \pm 0.20$ & $7.6 \pm 0.23$ \\
\hline
\end{tabular}




\subsection{Synthesis of Materials}

$\mathrm{MgO}-\mathrm{ZrO}_{2}$ samples were synthesized at the UW using a procedure based on the process developed by Pavel Medvedev at INL. $\mathrm{MgO}$ and $\mathrm{MgZrO}_{3}$ powders were mixed in the appropriate proportion to make $40 \mathrm{wt} \% \mathrm{ZrO}_{2}$ samples, then ball-milled for 20 minutes in ultra pure water and dried for greater than 12 hours. The mixed powder was calcined at $1000^{\circ} \mathrm{C}$ for 5 hours, then pressed twice. The first press is at 10,000 pounds, and then the powder was crushed in a mortar and pestle and pressed again at 3,000 pounds. The green powders were then sintered at $1700^{\circ} \mathrm{C}$ for 10 hours.

Since not all of the candidate materials being examined are commercially available, some time spent on in-lab synthesis was necessary. MgO and DPMZ were synthesized at LANL by grinding mixed powders using a ball mill, pressing at room temperature, and then high temperature sintering. Attention was paid to the synthesis techniques developed by Medvedev during his synthesis of DPMZ [7.1]. His materials were used in the first round of testing, but will be available on a limited basis in the future. Therefore, attempts were made to replicate his methods with some success.

Thus far, a SPEX 800M ball mill/mixer has been obtained and is currently being used to grind powders for $\mathrm{MgO}$ and DPMZ. A Carver 4350 manual pellet press has also been obtained and used to press pellets. Sintering was attempted using the Medvedev technique beginning with $\mathrm{MgO} 99.95 \%$ pure and $\mathrm{MgZrO}_{3}$. Pre-weighed amounts of the powders were combined with water in a beaker and stirred for 6 hours with a magnetic stirring rod. The slurry was dried at $80^{\circ} \mathrm{C}$ for 5 hours. The resulting powder was heat-treated at $1000^{\circ} \mathrm{C}$ for 5 hours in an alumina crucible. After cooling, $1 \mathrm{wt} \%$ zinc starate was added with a mortar and pestle. The powder was pressed with $10,000 \mathrm{lbs}$ with a cylindrical die of 0.5 -inch diameter. The pressed pellets were ground into powder with a mortar and pestle. The powder was passed through a sieve with an aperture size of 212 microns. The pellets were pressed again with the same die and a force of $3,000 \mathrm{lbs}$. The pellets were placed in an alumina crucible and sintered in air for 7.5 hours at $1700^{\circ} \mathrm{C}$. Medvedev's heat treatment and sintering temperature profiles are shown in Figure 7.17 [7.2].

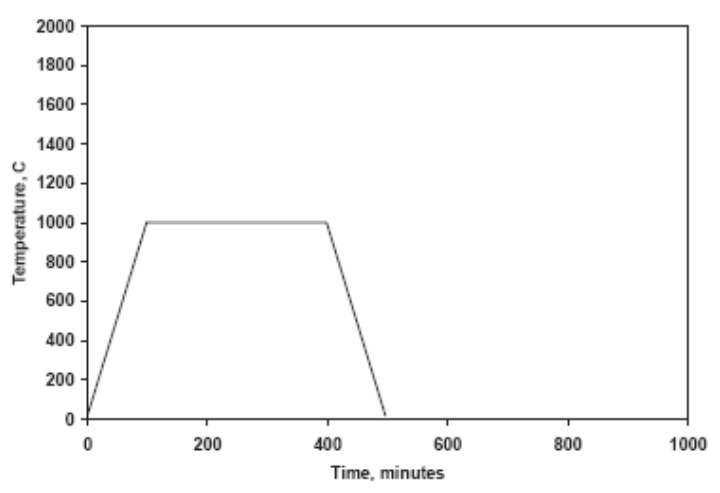

a)

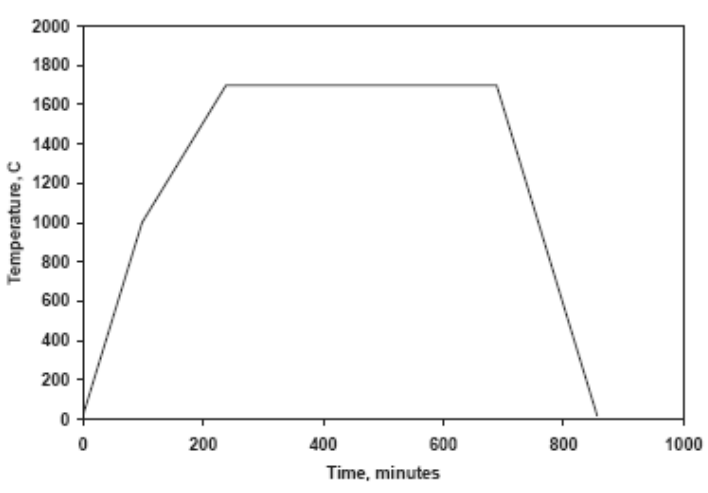

b)

Figure 7.17. Medvedev Temperature profile for a) heat treatment and b) sintering [7.2] 
Our process diverges slightly. Instead of mixing with water, we are using a ball mill. The powder is weighed and measured and mixed with hexane in the ball mill. After mixing, the powder is air dried for 24 hours. Then it is pressed with the pellet press at 3,000 lbs. It was mixed one more time in the ball mill, and then pressed at 10,000 lbs. Finally, it was sintered according to the temperature profile in Figure 7.18. The samples were sintered at $1600^{\circ} \mathrm{C}$ instead of $1700^{\circ} \mathrm{C}$, so they were held for 9 hours instead of 7.5 hours. $\mathrm{MgO}$ pellets have been through the process thus far, but they have not resulted in fully dense pellets. Therefore, the ongoing challenge is to include slight changes to the process to ensure full dense materials.

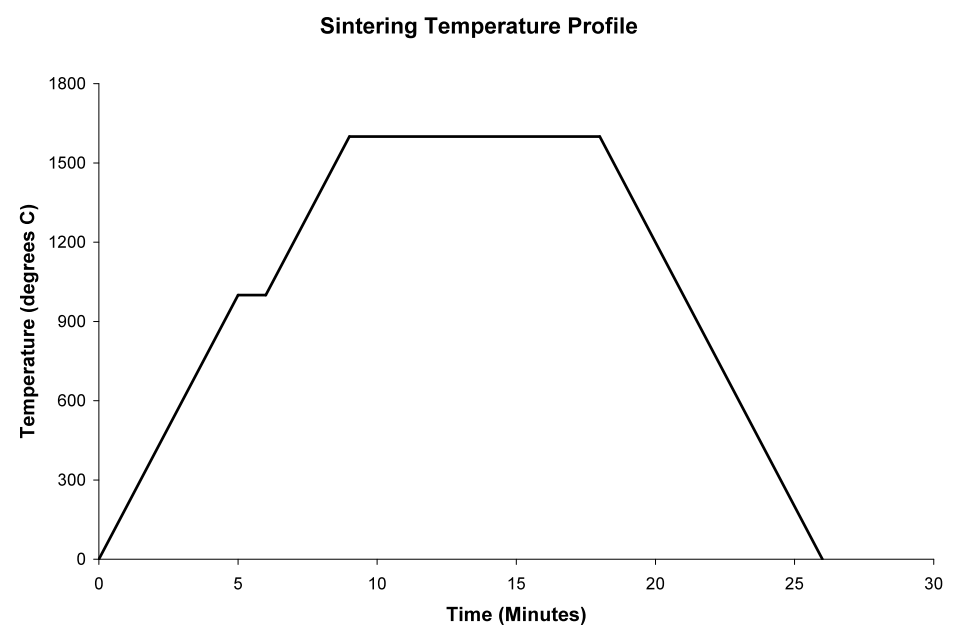

Figure 7.18. UW profile for sintering

\subsection{Failed Irradiation and Explanation of Thermal Cycling}

A 0.25 dpa irradiation of the dual-phase magnesia-zirconia ceramics at $750^{\circ} \mathrm{C}$ was completed. Upon removal from the stage, the samples were very brittle and broke into several pieces. It was determined that the breakdown of the samples occurred due to thermal cycling during the experiment and asymmetric pressure points from the face plate. Post-irradiation counting determined that the irradiation was conducted uniformly along the samples.

Thermal cycling occurred as a result of problems with the source and the switching magnet on the beamline. Since this experiment, both issues have been addressed and fixed. Because dualphase magnesia-zirconia ceramics are temperature sensitive, the heating and cooling of the samples during irradiation has a large effect on the resulting microstructure. When samples are loaded onto the stage, they have been sintered at $1700^{\circ} \mathrm{C}$ and furnace cooled. This results in three phases in the $\mathrm{Mg}-\mathrm{ZrO}_{2}$ region as follows: a cubic- $\mathrm{ZrO}_{2}$ phase, a monoclinic- $\mathrm{ZrO}_{2}$ phase (primarily along grain boundaries), and a tetragonal- $\mathrm{ZrO}_{2}$ phase. The red star and arrow on the phase diagram in Figure 7.19 shows the phase evolution of the sintered samples. At the irradiation temperature, $750^{\circ} \mathrm{C}$, the samples are in the monoclinic- $\mathrm{ZrO}_{2}$ region of the phase diagram, represented by the yellow star in Figure 7.19. The kinetics of the transformation to a monoclinic phase, particularly of the tetragonal- $\mathrm{ZrO}_{2}$ phase, is relatively fast. Therefore, the thermal effects of being heated without radiation interfere with an analysis of the irradiation stability of the samples. 


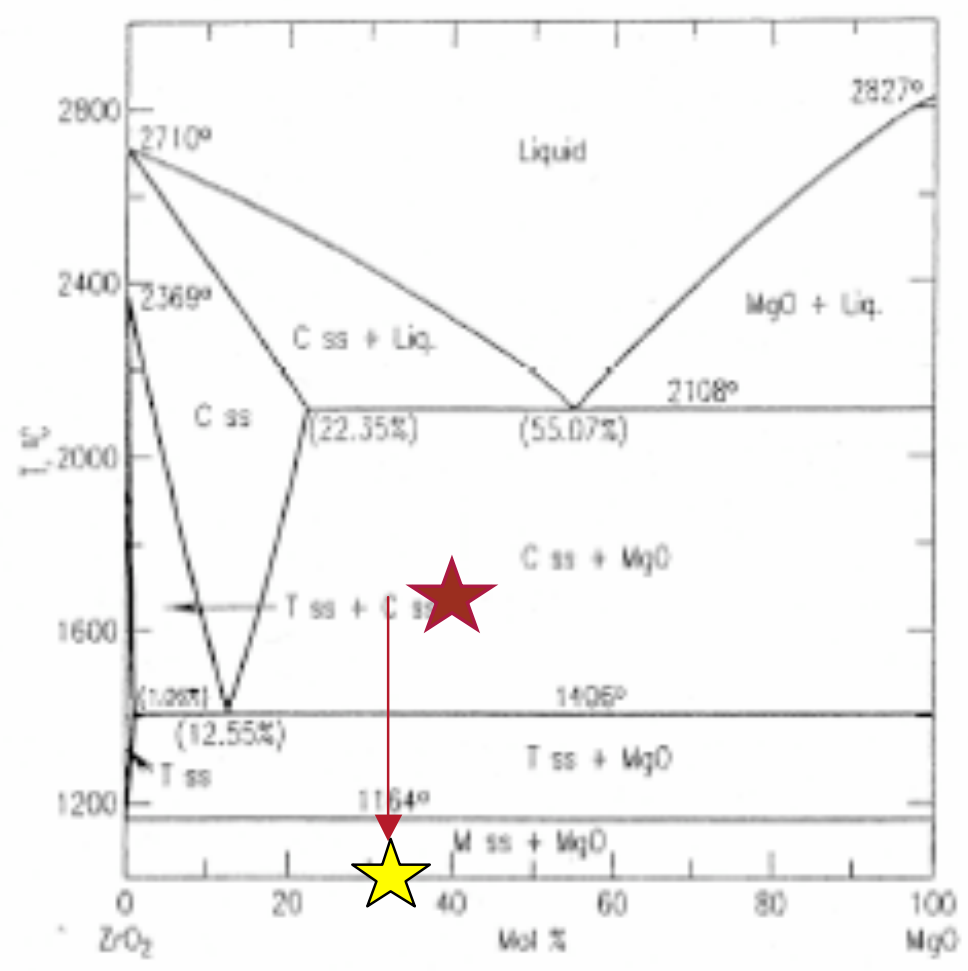

Fig. Zr-073-System $\mathrm{ZrO}_{2}-\mathrm{MgO}$ (optimized), $\mathrm{C}$ ss = solid solution based on cubic $\mathrm{ZrO}_{2}$; $\mathrm{T}$ ss - solid solution based on tetragonal $\mathrm{ZrO}_{2} ; \quad \mathrm{M}=$ monoclinic $\mathrm{ZrO}_{2}$.

Y. Du and Z. P. Jin, CALPHAD Compur, Coupling Phase Diagrams Thermochem., 15 [1] 59-68 (1991)

Figure 7.19. Phase diagram of $\mathrm{ZrO}_{2}-\mathrm{MgO}$ with the unirradiated sample heat-treatment path (red star) and the region of the samples during irradiation (yellow star)

Because of the thermal sensitivity of the samples, two alterations to the experimental schedule have been made. First, thermal tolerance guidelines have been developed for the dual-phase magnesia-zirconia ceramics samples. These guidelines are as follows:

1. According to the literature [7.4], there may be a significant phase change at approximately $200^{\circ} \mathrm{C}$. These compositions were present after 30 minutes at temperature. Therefore, unless irradiation is underway, the sample is not to be held at or above $200^{\circ} \mathrm{C}$.

2. An orthorhombic phase forms at $\sim-90^{\circ} \mathrm{C}$. Therefore, the sample is not to be cooled below $-90^{\circ} \mathrm{C}$. 


\section{References}

7.1 M.C. Wittels and F.A. Sherrill. "Irradiation-Induced Phase Transformations in Zirconia." J. of Applied Physics, v. 27, n. 6, June 1956

7.2 Medvedev, P., Ph.D. Thesis, Nuclear Engineering, Texas A\&M. December 2004

7.3 J.A. Valdez, M. Tang, Z. Chi, M. Peters, K. Sickafus. "Characterization of an ion irradiation induced phase transformation in monoclinic zirconia." NIMB 218 pp103-110: 2004

7.4 C. Howard and E. Kisi. "Neutron Diffraction Studies of Phase Transformations between Tetragonal and Orthorhombic Zirconia in Magnesia-Partially-Stabilized Zirconia.” J. Am. Ceram. Soc. v73, n10, pg 2828-2833 (1990) 


\section{Patents}

None

\section{Publications (accepted, submitted, or in print)}

Yong Yang, Clayton A. Dickerson, and Todd R. Allen, Radiation Stability of Proton Irradiated Zirconium Carbide, Proceedings of ICAPP 09 Tokyo, Japan, May 10-14, 2009 Paper 9314

Yong Yang, Clayton A. Dickerson, Todd R. Allen, Radiation stability of ZrN under 2.6 MeV proton irradiation, J. Nucl. Mat., 92 (2) (2009) 200.

Y. Yang, C.A. Dickerson, H. Swoboda, B. Miller, T. R. Allen, Microstructure and mechanical properties of proton irradiated zirconium carbide, Journal of Nuclear Materials, Vol. 378, 2008, p. 341

C.A. Dickerson, T.R. Allen, and Y. Yang, "Proton Irradiation Induced Effects in Titanium carbide and Titanium Nitride", Transactions of the 2007 ANS Annual Meeting, Boston, MA, Vol. 96, June 2007, p. 697-698

B. D. Miller, C. A. Dickerson, H. J. Yount, and T. R. Allen, "Radiation Resistance of Ceramic Candidates for Generation IV Gas-cooled Reactors," Transactions of the 2006 ANS Annual Meeting, Reno, NV, Vol. 94, June 2006, p. 716.

Yong Yang, Clayton Dickson, Todd R. Allen, Radiation Stability of Proton Irradiated ZrC and ZrN, American Nuclear Society Transactions, Vol. 98, June 2008, p. 1036-37.

Clayton Dickerson, Yong Yang, and Todd Allen, Proton Irradiation Induced Effects in Titanium Carbide and Titanium Nitride, American Nuclear Society Transactions, Vol. 98, June 2008, p. 1051 . 
Budget Data (as of March 2009)

\begin{tabular}{|l|l|l|c|c|}
\hline \multicolumn{2}{|l|}{} & Approved Spending Plan & Actual Spent to Date \\
\hline \multicolumn{2}{|l|}{ Phase / Budget Period } & Total & Total \\
\hline & From & To & & \\
\hline Year 1 & $\begin{array}{l}\text { Mar } \\
2006\end{array}$ & Mar 2007 & $\$ 185,150$ & $\$ 177,205$ \\
\hline Year 2 & $\begin{array}{l}\text { Mar } \\
2007\end{array}$ & Mar 2008 & $\$ 202,457$ & $\$ 200,681$ \\
\hline Year 3 & $\begin{array}{l}\text { Mar } \\
2008\end{array}$ & Mar 2009 & $\$ 210,561$ & $\$ 220,282$ \\
\hline
\end{tabular}

\section{Cost Performance:}

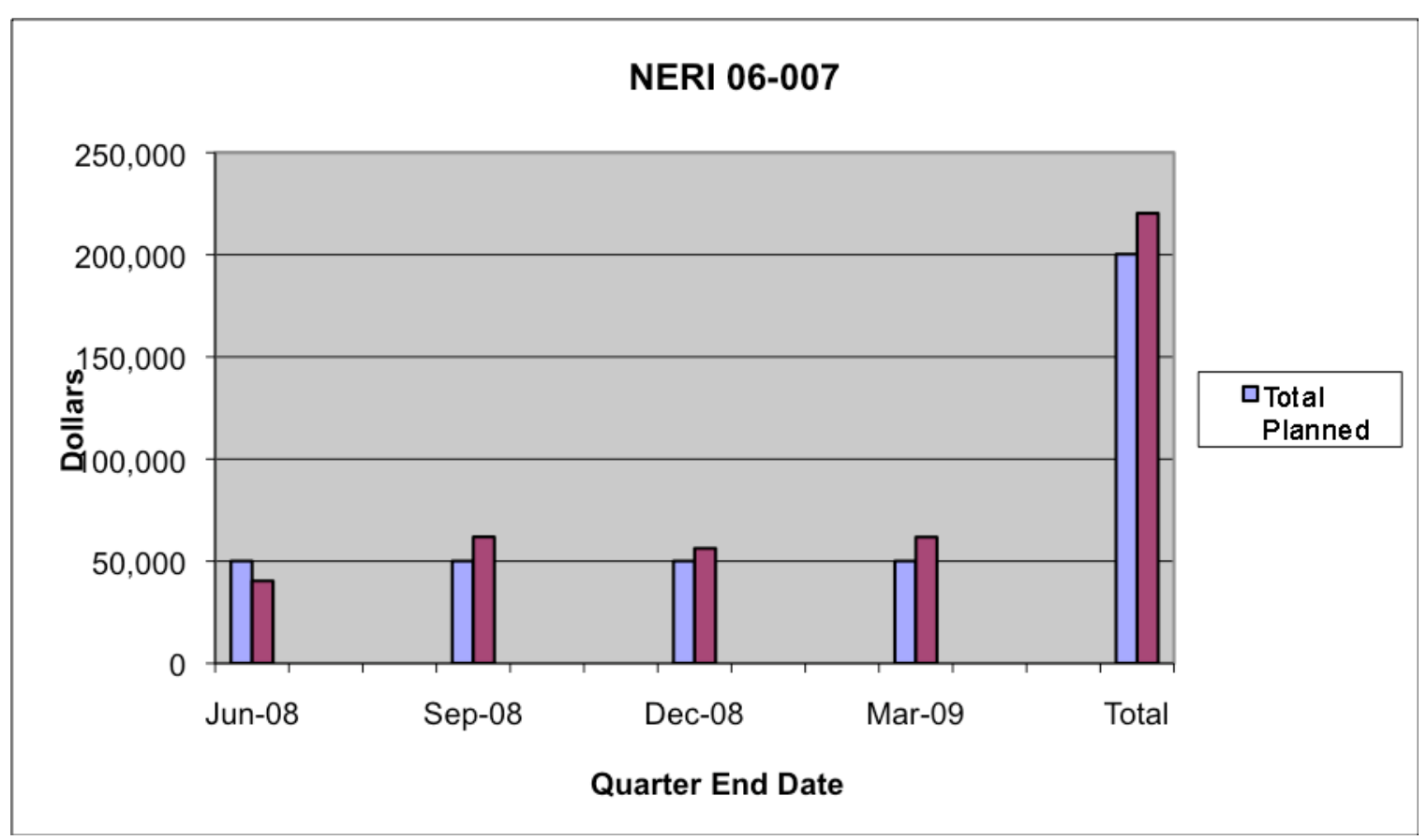

